\title{
- Zellbiologie der Knochenresorption -
}

Osteoklasten und aktivierte Fibroblasten im Resorptionsassay

\author{
Dissertation \\ zur Erlangung des Doktorgrades \\ der Mathematisch-Naturwissenschaftlichen Fakultäten \\ der Georg-August-Universität zu Göttingen
}

vorgelegt von

Anja Claus

aus Hannover

Göttingen 2002 
D 7

Referent: Prof. Dr. R. Hardeland

Korreferent: Prof. Dr. U. Grossbach

Tag der mündlichen Prüfung: 29.10.2002 
für Jörg 


\section{$\underline{\text { Inhaltsverzeichnis }}$}

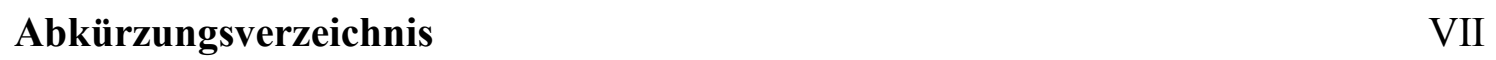

$1 \quad$ Einleitung

2.1 Herkunft der Gewebe, Flüssigkeiten und Zellen

Nährmedien

2.2.2 Medium für Fibroblasten

2.3.1 Bestimmung der Zellzahl und Zellvitalität

2.3.2 Kontrolle der Zelldifferenzierung und des Zellwachstums

2.3.3 Isolierung der Lymphozyten/Monozyten-Fraktion aus peripherem Blut

2.3.4.1 Plastikadhäsion 14

2.3.4.2 Magnetische Partikel (Dynabeads ${ }^{\circledR}$ ) 14

2.3.5 Differenzierung und Kultivierung von Osteoklasten 16

2.3.6 Anreicherung und Weiterverarbeitung von Osteoklasten 16

2.3.7 Isolierung von Fibroblasten aus synovialem Gewebe 17

$\begin{array}{lll}\text { 2.3.8 Isolierung von Fibroblasten aus synovialer Flüssigkeit } & 17\end{array}$

$\begin{array}{lll}2.3 .9 & \text { Kultivierung von Fibroblasten } & 17\end{array}$

2.3.10 Kultivierung von Zellen auf Calciumphosphat-Plättchen 18

2.3.11 Kultivierung von Zellen auf Dentin 19

$\begin{array}{lll}\text { 2.3.11.1 Vorbereitung des Dentins } & 19\end{array}$

2.3.11.2 Inkubation von Zellen auf Dentin 20

2.3.12 F-Actin Färbung 21 
2.5.1 Anfertigung von Zytospinpräparaten

2.5.2 Subkultivierung von Zellen auf Objektträgern mit

$$
\text { Kulturkammern }
$$

2.5.3.1 Lösungen für TRAP-Färbung 23

2.5.3.2 Durchführung der TRAP-Färbung 24

2.5.4 Immunzytochemische Techniken 24

2.5.4.1 Lösungen und Puffer der Immunzytochemie 25

2.5.4.2 Antikörper 25

2.5.4.3 Immunzytochemischer Nachweis des Vitronektin-Rezeptors (modifiziert nach Horton et al.) 26

2.5.4.4 Immunzytochemischer Nachweis von Kathepsin K 26

2.5.4.5 Immunzytochemischer Nachweis von RANK 27

2.6 Charakterisierung von Zellen mittels Durchflußzytometrie

2.7.1 Allgemeine Arbeitsbedingungen

2.7.2 Isolierung von RNA aus Zelllysaten (Chomczynski et Sacchi, 1993)

2.7.3 Konzentrationsbestimmung von Nukleinsäuren 30

2.7.4 RNA-(Reverse Transkription-) Polymerase-Kettenreaktion 30

2.7.4.1 cDNA Synthese 30

2.7.4.2 Amplifikation von cDNA mittels PCR 31

2.7.5 Isolierung und Reinigung von Nukleinsäuren 32

2.7.6 Auftrennung von DNA-Fragmenten 33 
2.7.6.1 Agarosegelelektrophorese

2.7.6.2 Größenbestimmung von Nukleinsäuren

2.12 Western Blot und immunologischer Nachweis von Proteinen

2.12.1 Übertragung von Proteinen auf Polyvenylidinfluorid-

(PVDF)-Membranen

2.12.2 Immunologischer Nachweis von Proteinen und

Detektionsverfahren

Proteinfärbung von Polyacrylamidgelen und

Blot-Membranen

2.13.1 Unspezifische Proteinfärbung mit Coomassie

(WEBER u. OSBORN, 1969, mod.)

2.13.2 Unspezifische Proteinfärbung mit Ponceau S Rot

2.14 Bestimmung der Molekularmassen von Proteinen

2.15 Behandlung der Dentinpräparate für die

Rasterelektronen-mikroskopie (REM)

2.16 Bezugsquellen

3.1 Differenzierung von Osteoklasten, die zur Resorption 
3.1.1 Isolierung von Osteoklastenvorläuferzellen aus peripherem Blut 46

$\begin{array}{lll}3.1 .2 & \text { Osteoklastendifferenzierung } & 47\end{array}$

3.2 Charakterisierung der Osteoklasten 51

3.2.1 TRAP-Färbung 53

3.2.1.1 Vergleich verschiedener SpenderInnen mittels TRAP-Färbung 53

3.2.1.2 Untersuchung verschiedener Differenzierungsstadien mittels

TRAP-Färbung 54

3.2.2 Charakterisierung der Zellen mittels

immunzytologisches Nachweisverfahren $\quad 56$

3.2.2.1 Nachweis des RANK auf Osteoklasten 56

3.2.2.2 Nachweis des Vitronectin Rezeptors 57

3.2.2.3 Nachweis des Kathepsin K 59

3.2.3 Nachweis von Osteoklastenmarkern mitttels RT-PCR 61

3.2.4 Analyse der Sequenzdaten 64

$\begin{array}{lll}\text { 3.2.5 Bildung von F-Actin-Ringen } & 64\end{array}$

3.3 Rasterelektronenmikroskopische Darstellung von

Osteoklasten auf Dentin 66

3.3.1 Etablierung des Resorptionsassays 66

3.3.1.1 Auswahl des Knochenersatzmaterials für den Resorptionsassay 66

3.3.1.2 Osteoklastenkulturen im Resorptionsassay 69

3.3.2 Oberflächenmorphologie der Osteoklasten 70

3.3.3 Darstellung der Ausbreitung von Osteoklasten auf einer Oberfläche $\quad 71$

3.3.4 Oberflächenmorphologie der Resorptionslakunen 74

3.3.5 Darstellung früher Stadien der Osteoklastenresorption 76

3.3.6 Untersuchung spenderabhängiger Unterschiede bei

$\begin{array}{ll}\text { Osteoklasten auf Pottwaldentin } & 78\end{array}$

3.3.7 Darstellung der Substratseite des Osteoklasten 81

3.4 Osteoklasten auf Calciumphosphat- (CP-)Plättchen 85 
3.5
Untersuchungen zur Beteiligung von aktivierten

Fibroblasten an Knochen-Resorptionsprozessen

Auswahl des Zellmaterials

Synoviale Fibroblasten von Patienten mit rheumatoider Arthritis

Humane Fibroblasten aus einer Membran im Bereich

einer Prothesenlockerung

Prothesenlockerungs-Fibroblasten aus einem

ICSS Wistar Rattenmodell

Charakterisierung RA synovialer Fibroblasten

FACS-Analyse

Nachweis von Kathepsin K im Western Blot

Fibroblasten auf Dentin

Oberflächenmorphologie der Fibroblastenkulturen

aktivierte Fibroblasten

Hemmung synovialer RA Fibroblasten im Resorptionsassay

Stimulierung synovialer RA Fibroblasten im Resorptionsassay

100 
4.3.2.3 Osteoklasten in der matrixdegradierenden Phase

4.3.3 Rasterelektronenmikroskopische Darstellung der Substratseite der Osteoklasten

4.4 Spenderabhängige Unterschiede in Ausmaß der

Knochenresorption

4.5

Untersuchung von RA synovialen Fibroblasten und PL Fibroblasten im Dentin-Resorptionsassay

4.5.1 Charakterisierung der Fibroblastenkulturen

4.5.2 Oberflächenmorphologie der Fibroblasten auf Dentin

4.5.3 Bildung resorptiver Veränderungen durch aktivierte

Fibroblasten im Dentin-Resorptionsassay 


\section{Abkürzungsverzeichnis}

\begin{tabular}{|c|c|}
\hline Abb. & Abbildung \\
\hline AMP & Adenosinmonophosphat \\
\hline APS & Ammoniumpersulfat \\
\hline bidest & zweifach destilliert \\
\hline $\mathrm{bp}$ & Basenpaar \\
\hline BSA & Rinderserumalbumin \\
\hline bzw. & beziehungsweise \\
\hline${ }^{\circ} \mathrm{C}$ & Grad Celsius \\
\hline ca. & circa \\
\hline cDNA & komplementäre DNA \\
\hline $\mathrm{CO}_{2}$ & Kohlendioxid \\
\hline $\mathrm{d}$ & Dichte \\
\hline d.h. & das heißt \\
\hline $\mathrm{Da}$ & Dalton \\
\hline DEPC & Diethylpyrocarbonat \\
\hline DMSO & Dimethylsulfoxid \\
\hline DNA & Desoxyribonukleinsäure \\
\hline dNTP & Desoxyribonukleotid-5'-triphosphat \\
\hline DTT & Dithiothreitol \\
\hline E-Cup & Eppendorf-Reaktionsgefäß \\
\hline EDTA & Ethylendiaminotetraacetat \\
\hline EGTA & Ethylenglycolbitetraacetat \\
\hline Etbr & Ethidiumbromid \\
\hline et al. & et alii (und andere) \\
\hline $\mathrm{EtOH}$ & Ethanol \\
\hline Fa. & Firma \\
\hline \multirow[t]{2}{*}{ FACS } & fluorescence activiated cell sorter \\
\hline & (Durchflußzytometer) \\
\hline FCS & fetales Kälberserum \\
\hline FITC & Fluorescein-Isothiocyanat \\
\hline FSC & forward scatter \\
\hline $\mathrm{g}$ & Gramm \\
\hline
\end{tabular}




\begin{tabular}{|c|c|}
\hline x g & -fache Erdbeschleunigung \\
\hline $\mathrm{h}$ & Stunde \\
\hline HBSS & Hank's balanced salt solution \\
\hline $\mathrm{H}_{2} \mathrm{O}_{\text {bidest }}$ & zweifach destilliertes Wasser \\
\hline $\mathrm{IL}$ & Interleukin \\
\hline $\mathrm{k}$ & Kilo \\
\hline $\mathrm{kDa}$ & Kilodalton \\
\hline 1 & Liter \\
\hline M & molar \\
\hline $\mathrm{mA}$ & Milliampere \\
\hline $\mathrm{mm}$ & Milli $\left(10^{-3}\right)$ Meter \\
\hline mRNA & messanger RNA \\
\hline$\mu-$ & Mikro- $\left(10^{-6}\right)$ \\
\hline $\min$ & Minute \\
\hline MW & Molekulargewicht \\
\hline nano- & Nano- $\left(10^{-9}\right)$ \\
\hline OD & Optische Dichte \\
\hline PAGE & Polyacrylamidgelelektrophorese \\
\hline PBS & phosphate buffered saline \\
\hline \multirow[t]{2}{*}{ PCR } & Polymerase chain reaction (Polymerase- \\
\hline & kettenreaktion) \\
\hline PE & Phycoerythrin \\
\hline \multirow[t]{2}{*}{$\mathrm{pH}$} & negativer dekadischer Logarithmus der \\
\hline & Protonenkonzentration \\
\hline PVDF & Polyvenylidinfluorid \\
\hline REM & Rasterelektronenmikroskopie \\
\hline Rf & elektrophoretische Mobilität \\
\hline RNA & Ribonukleinsäure \\
\hline RT & Raumtemperatur \\
\hline RT-PCR & reverse Transkription-PCR \\
\hline s & Sekunde \\
\hline s. & siehe \\
\hline SDS & Natriumdodecylsulfat \\
\hline s.o. & siehe oben \\
\hline
\end{tabular}




$\begin{array}{ll}\text { SSC } & \text { sideward scatter } \\ \text { s.u. } & \text { siehe unten } \\ \mathrm{T}_{\mathrm{m}} & \text { Schmelzpunkt } \\ \text { TAE } & \text { Tris-Acetat-EDTA } \\ \text { TE } & \text { Tris-EDTA } \\ \text { TEMED } & \text { N,N,N,N'-Tetramethylethylendiamin } \\ \text { TRIS } & \text { Tris-(Hydroxymethyl)-aminoethan } \\ \text { U } & \text { Unit } \\ \text { u.a. } & \text { unter anderem } \\ \text { UE } & \text { Untereinheit } \\ \text { UMP } & \text { Uridinmonophosphat } \\ \text { Upm } & \text { Umdrehungen pro Minute } \\ \text { UV } & \text { ultraviolettes Licht } \\ \text { V } & \text { Volumen, Volt } \\ \text { v/v } & \text { Volumen pro Volumen } \\ \text { w/v } & \text { Masse pro Volumen } \\ \text { z.B. } & \text { zum Beispiel }\end{array}$




\section{Einleitung}

Der Knochenapparat ist aufgrund seiner Funktion als Stützgerüst des Körpers und Bestandteil des Bewegungsapparates sowie als Stoffwechseldepot für den menschlichen Organismus von grundlegender Bedeutung. Das Knochengewebe besteht aus einem zellulären Anteil (15\%), einer organischen Grundsubstanz (40 \%) und einer mineralischen Phase (45 \%). Da im Mineralstoffanteil des Skeletts $99 \%$ des Calciums und $75 \%$ des Phosphates des gesamten Körpers enthalten sind, dient der Knochen als wichtiger Speicher in der Phosphat- und Calciumhomöostase.

Die ständigen Auf- und Abbauvorgänge des Knochens sind im Rahmen von Wachstumsvorgängen, Anpassungsprozessen an wechselnde mechanische Belastung sowie der direkten und indirekten Wirkung von Hormonen physiologisch. Während Parathormon und Kortisol auf den Knochenabbau und damit die Freisetzung von Calcium aus dem Knochengewebe stimulierend wirken, wird der Knochenaufbau durch das D-Hormon und die Geschlechtshormone gefördert. Calcitonin hingegen wirkt über Hemmung knochenresorbierender Zellen inhibierend auf den Knochenabbau.

Die hohe Stoffwechselaktivität wird durch die hohe Durchblutung des Knochens ermöglicht. Von der Knochenhaut, dem Periost, dringen größere Gefäße durch die Foramina nutritia und kleine Gefäße an vielen Stellen senkrecht zur Knochenoberfläche in das Organ ein. Die Gefäße setzen sich in den Haversschen Gefäßen der Osteone fort, über die eine Verbindung zum Knochenmark hergestellt und eine Versorgung des Knochens ermöglicht wird.

Die organische Knochengrundsubstanz, Osteoid genannt, wird von Osteoblasten abgeschieden und besteht aus Proteoglykan-Komponenten (z.B. Chondroitinsulfat), Glykoproteinen (u.a. Osteopontin und Osteonectin), Elektrolyten und Wasser. In diese Matrix sind kollagene Fasern (Kollagen I) eingelagert. Der mineralisierte Anteil besteht aus Calciumphosphat, das in Form von Hydroxylapatit $\left(\mathrm{Ca}_{10}\left(\mathrm{PO}_{4}\right)_{6}(\mathrm{OH})_{2}\right)$ unter Einfluss von Osteoblasten abgelagert wird. Die Hydroxylapatitkristalle sind parallel zu den Kollagenfasern angeordnet und stellen schlanke Prismen mit hexagonaler Grundfläche dar. Durch Verunreinigungen der Kristalle mit Magnesium, Natrium, Strontium, Chlor und weiteren Elementen (WIRZ, 1999) ist die chemische Stabilität des Hydroxylapatits im Knochen geringer als die des natürlichen Minerals und kann daher leichter von Osteoklasten abgebaut werden. 
Der stetige Knochenumbau stellt unter physiologischen Bedingungen eine konzertierte Aktion von Osteoklasten, die Matrix abtragen, und Osteoblasten, die sie aufbauen, dar. Ein integraler Bestandteil dieser Knochenumbauvorgänge ist die Knochenresorption.

Der Knochenabbau erfolgt durch Osteoklasten, die als vielkernige Riesenzellen, mit einem Durchmesser von 30 bis über $100 \mu \mathrm{m}$, in den von ihnen gebildeten Einbuchtungen im Knochen, den so genannten Howship'schen Lakunen (nach J. HOWSHIP, 1781 - 1841, Chirug aus London) $\mathrm{zu}$ finden sind. Osteoklasten sind hochspezialisierte Zellen, die von myeloischen Vorläuferzellen abstammen. Mittels formveränderlicher Pseudopodien sind sie amöboid beweglich (CHAMBERS et al., 1984) und durch den hohen Ribosomengehalt stark basophil. Eine wichtige Rolle bei der Knochenresorption spielt eine F-Actin-reiche Ringstruktur, die von Osteoklasten durch Zytoskelettveränderungen gebildet wird. Es ist bisher nicht geklärt, ob diese auch als „sealing zone“ bezeichnete Struktur zur Bildung eines isolierten Kompartiments führt, in dem die Knochenmatrix abgebaut wird oder über dort exprimierten Integrine der Erkennung der Matrix dient. Innerhalb dieser Kontaktzone ist die Membran zur Vergrößerung der Oberfläche tief gefaltet und verzweigt. Dieser Membranbereich ist transelektronenmikroskopisch als Bürstensaum oder „ruffled border“ beschrieben. An der ruffled border finden die Resorptionsprozesse statt, die in zwei Schritten erfolgen. Zunächst werden in einem extrazellulären Bereich in der Kontaktzone zum Knochen Protonen abgegeben und in dem sauren Milieu das Calciumphosphat des Knochens in Lösung gebracht. Hierzu verfügen Osteoklasten über Zellmembran-gebundene ATPaseabhängige Protonen-Pumpen. In einem zweiten Schritt wird die demineralisierte Knochensubstanz von extrazellulär sezernierten Proteasen vorverdaut und im Weiteren intrazellulär von lysosomal gelegenen Proteasen weiter abgebaut. Die Knochenresorption umfasst dementsprechend Vorgänge der Demineralisierung und der enzymatischen Matrixdegradation.

$\mathrm{Zu}$ diesen Matrix-degradierenden Proteasen zählen die MMP's (Matrix Metalloproteinases) wie z.B. Kollagenasen und Gelatinasen. Die Expression der MMP's wird auf der Ebene der Transkription durch Wachstumsfaktoren, Zytokine sowie Hormone reguliert. Ihre Sekretion erfolgt als Proenzym, das durch proteolytische Spaltung aktiviert wird. Durch endogene Inhibitoren, D-Makroglobuline und spezifischen inhibitorischen Faktoren, den TIMP's (Tissue Inhibitors of Metalloproteinases), wird die proteolytische Aktivität in vivo kontrolliert. Die Spezifität 
der MMP's ist unterschiedlich: Kollagenasen bauen natives triplehelikales Kollagen I, II, III, VII und X ab, Gelatinasen degradieren denaturiertes Kollagen. Das pH Optimum der MMP's liegt im neutralen Bereich, während die lysosomal gelegenen Zysteinproteinasen, z. B. Kathepsine, ihre proteolytische Aktivität bei sauren $\mathrm{pH}$ Bedingungen entfalten. Eine der wichtigsten Zysteinproteinasen für den Abbau von Kollagen I ist Kathepsin K, welches innerhalb der Kathepsine als einziges auch als Exoprotease arbeitet und proteolytische Aktivität sowohl bei saueren als auch neutralen Bedingungen zeigt. In Osteoklasten wird Kathepsin K vermehrt exprimiert.

Die Resorptionskapazität der Osteoklasten beträgt bis zu $100 \mu \mathrm{m}^{2}$ pro Tag. Ihre Wirkung während des Abbauprozesses ist beachtlich: die Abbauleistung eines Osteoklasten entspricht der Aufbauleistung von 100 Osteoblasten (ALBREKTSSON et al., 1985).

Nach BURKHARDT, 1992, wird die Koordination der Auf- und Abbauvorgänge vor allem durch Osteoblasten gesteuert. Die Mechanismen der molekularen Kommunikation dieser Zellen sind sehr komplex und noch nicht vollständig geklärt. Sowohl lokale und als systemische Mechanismen regulieren die Kopplung der Knochenneubildung mit der Knochenresorption, auch „,coupling“ genannt. Systemische Faktoren wie Parathormon, D-Hormon und Calcitonin sowie zirkulierende mineralische Knochenbestandteile wie Calcium und Phosphat, aber auch lokal freigesetzte Zytokine beeinflussen den Knochenmetabolismus. Calcitonin, beispielsweise, hemmt die Aktivität der Osteoklasten über die Bindung an Rezeptoren an der Zelloberfläche. Die Interleukine IL-1 (JIMI et al., 1999), IL-6 und IL-11 (ROODMAN, 1999) sowie TNF-D (Tumornekrosefaktor-D), aber auch das Parathormon führen hingegen $\mathrm{zu}$ einer Stimulation der resorptiven Aktivität (SUDA et al., 1992). Die durch osteoklastäre Knochenresorption aus der Knochenmatrix freigesetzten Wachstumsfaktoren wie beispielsweise das BMP (Bone Morphogenetic Protein) und TGF-E (Transforming Growth Factor-E) stimulieren die reifen Osteoblasten sowie ihre Vorläuferzellen und fördern so den Aufbau der Knochenmatrix. Dagegen führt die Expression von RANKL (Receptor Activator of Nuclear Factor Nb (NF-kB) Ligand) durch Osteoblasten, unter der stimulierenden Wirkung von IL-1 und TNF-D, wiederum zu einer Aktivierung der Osteoklasten und zum Abbau des Knochens.

Die resorptive Aktivität von Osteoklasten kann in vitro in einem Zellkultursystem anhand der Bildung von Lakunen in Knochen oder knochenähnlicher Matrix untersucht 
werden. In einem sogenannten Dentin-Resorptionsassay werden Osteoklasten, die aus Knochenmark gewonnen oder aus myeloischen Zellen herandifferenziert wurden, auf der Matrix inkubiert. Die Bildung von Aushöhlungen in der Matrixoberfläche ist Ausdruck der resorptiven Aktivität der Osteoklasten und kann sowohl lichtmikroskopisch als auch im Rasterelektronenmikroskop dargestellt werden.

Knochen oder knochenähnliche Substanzen wie humanes Dentin oder Pottwaldentin werden in dem in vitro System allgemein als Substrat verwendet. Nach BOYDE et al., 1984, eignet sich Dentin aufgrund der homogenen Struktur besonders gut für den Resorptionsassay. Außerdem wird die Substratanalyse bei der Verwendung von Dentin nicht durch bereits resorbierte Oberflächen oder Gefäßkanäle gestört (BOYDE et al., 1967). Die Härte des Dentin ist höher als die des Knochens, in der Zusammensetzung sind sich die beiden Gewebe jedoch ähnlich. Unterschiede liegen in den relativen Anteilen von Wasser, organischer und anorganischer Substanz: Knochen besteht zu 50 $\%$ aus anorganischer Substanz, $25 \%$ organische Substanz und $25 \%$ Wasser. Dentin enthält $70 \%$ anorganischer Substanz, $17 \%$ organischer Substanz und $13 \%$ Wasser.

Eine pathologisch gesteigerte Knochenresorption steht im Mittelpunkt bestimmter Krankheitszustände und ist auf eine vermehrte Osteoklastendifferenzierung aus Vorläuferzellen oder auf eine erhöhte Aktivität bereits differenzierter Osteoklasten zurückzuführen.

Progessive Knochenresorption ist ein charakteristisches Merkmal der rheumatoiden Arthritis, eine der häufigsten, rheumatischen Erkrankungen. Die rheumatoide Arthritis wird als eine chronisch-entzündliche Systemerkrankung aufgefasst, die vorwiegend den Bewegungsapparat angreift und über Jahre bis zur völligen Gelenkdestruktion führen kann. Bei der Entstehung der Erkrankung spielen genetische Disposition und Autoimmunmechanismen eine Rolle. In der initialen Phase kommt es zu einer Antigenpräsentation durch das HLA-(Humane Leukozyten-Antigen) Molekül der Klasse II von Antigen-präsentierenden Zellen (Makrophagen und dendritische Zellen) an T-Lymphozyten, die den HLA-Antigen-Komplex mit ihrem T-Zellrezeptor sowie dem CD4-Rezeptor erkennen und binden. Die Immunreaktion führt in der 2. Phase zu einem Entzündungsprozess der Gelenkinnenhaut, die durch exsudative und proliferative Veränderungen gekennzeichnet ist. Das Synovium wird durch Entzündungszellen infiltriert, die Lymphozyten, Monozyten und Granulozyten beinhalten können. Aus dem Synovium wird ein aggressiv wachsendes Gewebe, das von proliferierenden 
Fibroblasten gebildet wird. Dieser sogenannte Pannus destruiert tumorähnlich, invasiv wachsend den Knorpel sowie den Knochen des Gelenks und kann bis zur völligen Zerstörung der Gelenkstruktur führen. Durch Gelenkluxationen und Vernarbungsvorgänge kommt es schließlich klinisch zu Gelenkfehlstellungen und einer Einschränkung der Gelenkbeweglichkeit.

Zahlreiche Untersuchungen haben sich mit den Mechanismen der rheumatoiden Knorpeldestruktion befasst. Danach wird aktivierten, synovialen Fibroblasten von Patienten mit rheumatoider Arthritis (RA Patienten) eine Schlüsselrolle bei der Zerstörung des Knorpels zugeschrieben. Die Bindung und Adhäsion der RA synovialen Fibroblasten an den Knorpel wird nach MÜLLER-LADNER et al, 1996, durch Adhäsionsmoleküle wie das Vascular Cell Adhesion Molecule (VCAM)-1 erleichtert, die von den aktivierten Fibroblasten in der äußeren Schicht des RA Synoviums exprimiert werden (WILKIMSON et al., 1993, und KRIEGSMANN et al., 1995). VCAM-1 gehört zur Immunglobulin Superfamilie und wurde bisher als Oberflächenmolekül von Endothelzellen beschrieben, dass Lymphozyten als Wegweiser zu den entzündeten Bereichen des RA Synoviums dient ( sogenanntes „,cell traficking“). Die Morphologie der RA synovialen Fibroblasten stellt sich verändert dar: sie haben ein transformiert erscheinendes Aussehen mit einem großen glasigen Zellkern (FASSBENDER et al., 1983).

Aktivierte Fibroblasten sind durch Veränderungen in der Expression von Signalmolekülen und -kaskaden gekennzeichnet, wie sie in ähnlicher Weise bei Tumoren gefunden wurde. Als Ausdruck der zellulären Aktivierung ist die Expression von Protoonkogenen wie c-myc, fos und ras hochreguliert (GAY et al., 1993, TRABANDT et al., 1992, KEYSZER et al., 1994). ras ist direkt in die Produktion von Gewebe-abbauenden Molekülen und Wachstumsfaktoren involviert. c-myc und fos kodieren für Proteine, die Zelldifferenzierung und Proliferation regulieren.

Durch die im entzündeten Synovium freigesetzten Zytokine werden die RA synovialen Fibroblasten zusätzlich stimuliert. Dabei stellen IL-1 und TNF-D Schlüsselmoleküle dar, die u.a. in RA synovialen Fibroblasten eine gesteigerte Produktion von Matrixabbauenden Proteasen wie MMP's und Zysteinproteasen induzieren. In einem SCID (,severe combined immunodeficiency“) Maus Modellsystem gelang der Nachweis, dass RA synoviale Fibroblasten in Abwesentheit von anderen Zellen in der Lage sind, Knorpel zu zerstören (MÜLLER-LADNER et al., 1996). 
Knochenresorption findet sich bei der rheumatoiden Arthritis zum einen subchondral als sogenannte juxta-artikuläre Osteoporose. Zum anderen kommt es typischerweise zu Knochenerosionen im Umschlagbereich des Synoviums in den artikulären Rezessus und an den Stellen, an den die Knorpeldestruktion bis an die Knochengrenze fortgeschritten ist.

Die juxta-artikuläre Osteoporose wird auf einen durch lokale Faktoren gesteigerten Knochenabbau durch Osteoklasten zurückgeführt. Zentrale Faktoren in der Pathophysiologie der rheumatoiden Arthritis sind die proinflammatorischen Zytokine IL-1 und TNFD, die von aktivierten synovialen Makrophagen und Fibroblasten freigesetzt werden und die Knochenresorption über Interaktion mit Osteoklasten (GRAVALLESE et al., 2000) stimulieren. Diese Effekte scheinen aber nicht auf der direkten Beeinflussung der Osteoklasten zu beruhen.

Der wichtigste Faktor bei der Differenzierung und Aktivierung von Osteoklasten ist nach neuen Studien der RANKL (LACEY et al., 1998, YASUDA et al., 1998), der von Osteoblasten, synovialen Fibroblasten von Patienten mit rheumatoider Arthritis (RA Fibroblasten) (SHIGEYAMA et al., 2000) und aktivierten Lymphozyten (KONG et al., 1999) exprimiert wird. RANKL bindet an seinen Rezeptor RANK (receptor activator of nuclear factor NB (NF-kB)) auf Osteoklasten und deren Vorläuferzellen, wodurch Differenzierungs- und Aktivierungsprozesse in Gang gesetzt werden. Der natürliche Gegenspieler ist Osteoprotegrin (OPG), der durch Bindung an RANKL die Interaktion mit dem RANK verhindert. IL-1 und TNFD induzieren die Expression von RANKL in Osteoblasten, RA synovialen Fibroblasten und T-Zellen und fördern somit die Knochenresorption. Studien mit Tiermodellen geben Hinweise darauf, dass durch Gabe von OPG oder Hemmung des RANKL der gesteigerte Knochenabbau bei der rheumatoiden Arthritis möglicherweise verhindert werden kann (KONG et al., 1999).

Darüber hinaus entstehen Knochenerosionen bei der rheumatoiden Arthritis in dem artikulären Rezessus durch Invasion und Destruktion des Pannusgewebes. Wenig ist bisher über die Mechanismen bekannt, die zur Knochenerosion durch den Pannus führen. Es wird angenommen, dass bei dieser Form der Knochenresorption, ähnlich wie bei der Osteoporose, Osteoklasten oder zumindest Osteoklasten-ähnliche Zellen beteiligt sind (GRAVALLESE et al., 1998).

Bislang galten Osteoklasten, neben Odontoklasten, als die einzigen Zellen, die unter physiologischen Bedingungen zur Resorption von Knochen befähigt sind. 
Untersuchungen zur gesteigerten Knochenresorption haben sich daher bislang hauptsächlich auf die Entwicklung von Medikamenten konzentriert, die den Abbau der Knochenmatrix durch verminderte Bildung oder Aktivierung von Osteoklasten verhindern sollen.

Bisphosphonate sind die bisher effektivsten Inhibitoren der Knochenresorption. Sie reichern sich selektiv im Knochen an, werden dann bei der Knochenresorption von den Osteoklasten aufgenommen, wodurch die Aktivität der Zellen gehemmt und sogar die Apoptose induziert wird. Probleme der Bisphosphonattherapie sind Nebenwirkungen wie gastrointestinale Beschwerden und die Beschränkung des Therapieerfolges auf einen Höhepunkt in den ersten zwei Jahren (SCHARLA, 2001).

Der therapeutische Einsatz von Antikörpern gegen TNF-D, führt zur Hemmung proinflammatorischer Effekte dieses Zytokins. Dazu gehört die Einschränkung der Migration von Leukozyten in das Gelenk und die Unterdrückung der Freisetzung weiterer proinflammatorischer Zytokine wie IL-1 und IL-6, was wiederum hemmend auf die Knorpel- und Knochendestruktion wirkt. Jedoch wird eine erhöhte Tumorinzidenz durch die TNF-D-Therapie diskutiert.

Ein neueres therapeutisches Ziel für die Osteoklastenhemmung ist das RANKL RANK - OPG System. Untersuchungen haben jedoch ergeben, dass OPG, als Inhibitor der Interaktion zwischen RANKL und RANK, möglicherweise Immunantworten auslöst und auch mit anderen Organen als den Knochen agiert (RODAN et al, 2000). Problematisch ist auch die Beeinflussung von RANKL und RANK, da diese Faktoren in die Regulation von Interaktionen zwischen T-Zellen und dendritischen Zellen involviert sind (Dougall et al., 1999). Kathepsin K Inhibitoren oder auch die Blockierung der $\mathrm{H}^{+}$ATPase zur Hemmung der Osteoklastenfunktion sind weitere derzeit aktuelle Forschungsschwerpunkte bei Erkrankungen mit gesteigerter Knochenresorption.

Klinische Studien mit Patienten, die an rheumatoider Arthritis erkrankt sind und bei denen die resorptive Aktivität von Osteoklasten mit Bisphosphonaten und Calcitonin gehemmt wurde, lassen vermuten, dass neben Osteoklasten noch andere Zellen an der Bildung von Knochenerosionen beteiligt sind (SILEGHEM et al., 1992, EGGELMEIJER et al., 1996). Nach HUMMEL et al., 1998, gibt es Hinweise auf eine Beteiligung von aktivierten Fibroblasten an der gesteigerten Knochenresorption. In histologischen Studien zur rheumatoiden Arthritis wurden in Bereichen von aktiver Knochenresorption Fibroblasten gefunden, die Kathepsin K mRNA exprimierten. HOU et al., 2000, zeigte, dass Kathepsin $\mathrm{K}$ auch auf Proteinebene in RA synovialen 
Fibroblasten produziert wird. Außerdem wurde in RA synovialen Fibroblasten eine Osteoklasten-ähnliche vakuoläre $\mathrm{H}^{+}$-ATPase nachgewiesen. (OTSU et al., 2000).

Die Problematik einer gesteigerten Knochenresorption tritt auch bei der aseptischen Prothesenlockerung auf, einer der häufigsten Komplikationen in der Gelenkendoprothetik. Als Ursachen der Lockerungsvorgänge werden u.a. der Einfluss des Prothesenmaterials sowie der Abriebpartikel, die an der artikulierenden Reibfläche von Prothesenkopf und Pfanne freigesetzt werden, diskutiert. Auch die Implantationstechniken, bei denen die suboptimale Positionierung der Prothese zu Mikrobewegungen im Implantatlager führen, werden als Gründe für die Prothesenlockerung angeführt.

Die Prothesenlockerung ist ein aktiver Prozess, der mit der Bildung einer bindegewebigen Grenzmembran verbunden ist. Nach einer Prothesenimplantation finden eine Reihe von histologischen Veränderungen im Grenzbereich zwischen Knochen und Prothese statt. In den ersten Wochen bilden sich dünne Zonen aus nekrotischem Gewebe und Fibrin. Im Laufe der Zeit wandern Fibroblasten in den Grenzbereich ein, der außerdem von kleinen Gefäßen durchwachsen wird. Im weiteren kommt es zur Bildung einer 0,1 bis 1,0 mm dicken Membran zwischen dem Knochen und der Prothese (HEILMANN et al., 1975, FORNASIER et al., 1976). Diese Grenzmembran, die hauptsächlich aus Makrophagen, Fibroblasten und Endothelzellen besteht, produzuiert große Mengen an Prostaglandin $\mathrm{E}_{2}$ und Kollagenasen (GOLDRING et al., 1983). In zahlreichen Studien wurde in der Grenzmembran außerdem eine erhöhte Expression von Zytokinen wie TNF-D nachgewiesen, die die Produktion von Matrixdegradierenden Enzymen in Fibroblasten stimulieren können (XU et al., 1996). Der an die Prothese angrenzende Knochen wird offenbar aktiv durch die Grenzmembran abgebaut, was letztlich nach Jahren zur Prothesenlockerung führt.

Neben den Fibroblasten aus der Grenzmembran, den sogenannten Prothesenlockerungs(PL-) Fibroblasten, wurden bisher vornehmlich die Makrophagen im Prozess der Prothesenlockerung betrachtet. PANDEY et al., 1996, zeigten, dass Makrophagen aus dem Bereich einer Arthroplastik zu multinukleären Zellen herandifferenziert werden konnten, die alle Charakteristika von Osteoklasten aufwiesen, einschließlich der Fähigkeit zur Knochenresorption. Nach XU et al., 1997, wird diese Differenzierung scheinbar durch humorale Faktoren wie den M-CSF stimuliert

Die Grenzmembran zwischen Prothese und Knochenoberfläche weist Ähnlichkeiten mit dem rheumatoiden Synovium auf (GOLDRING et al., 1983). PL-Fibroblasten, die aus 
der Grenzmembran isoliert wurden, zeigen wie die RA synovialen Fibroblasten eine unabhängige Proliferation (LAFYATIS et al., 1989), eine Aktivierung von Protoonkogenen (XUE et al., 1997) und Änderungen im Apoptoseverhalten (FRANZ et al., 2000). Gemeinsame Merkmale der PL Fibroblasten und der RA synovialen Fibroblasten sind weiterhin die Produktion von Matrix-abbauenden Enzymen wie Kathepsine und Matrixmetalloproteinasen (PAP et al., 1999) sowie die Abgabe von Faktoren, die die Knochenresorption durch Osteoklasten erhöhen (BERTOLINI et al., 1986, XU et al., 1997). Außerdem wurde die Expression einer v-ATPase in den PLFibroblasten nachgewiesen (OTSU et al., 2000).

Es wird kontrovers diskutiert, ob neben Osteoklasten auch andere Zellen wie z.B. Fibroblasten als Zellen mesenchymalen Ursprungs die Fähigkeit entwickeln könnten, direkt Knochen zu resorbieren (GRAVALLESE et al., 2000). Das Ziel dieser Arbeit war es, Untersuchungen zur direkten Beteiligung von aktivierten Fibroblasten an der Knochenresorption durchzuführen. Dazu sollte ein in vitro System etabliert werden, in dem die Fähigkeit zur Resorption von Knochen-ähnlicher Matrix anhand der Bildung von Aushöhlungen in dem Substrat demonstriert wird. Mit dem Einsatz von Osteoklasten als Knochen-resorbierende Zellen in dem in vitro System sollten die verschiedenen Stadien der Resorption dargestellt und eine Grundlage zum Vergleich resorptiver Fähigkeiten von Osteoklasten und aktivierter Fibroblasten geschaffen werden.

Zunächst wurden Osteoklasten aus myeloischen Zellen herandifferenziert und charakterisiert. Bei Vorversuchen zur Differenzierung der Osteoklasten traten unerwartet und wiederholt morphologische und funktionelle Unterschiede zwischen Osteoklasten verschiedener SpenderInnen auf, die in dieser Arbeit aufgezeigt und deren Auswirkungen auf die Resorptionsvorgänge analysiert wurden. Im Weiteren wurde der Prozess der Knochenresorption durch Osteoklasten in verschiedenen Phasen definiert. Die Anfangsstadien des osteoklastären Resorptionsprozesses wurden analysiert und die Morphologie der resorbierenden Membran dieser Zellen dargestellt.

Nach Etablierung des in vitro Systems durch Osteoklasten wurden sowohl RA synoviale Fibroblasten als auch PL-Fibroblasten in dem Resorptionsassay eingesetzt, um die Beteiligung dieser Zellen an Prozessen pathologisch gesteigerter Knochenresorption zu untersuchen. Die aktivierten Fibroblasten wurden unter hemmenden als auch stimulierenden Bedingungen in dem Resorptionsassay betrachtet. Veränderungen im 
Substrat wurden den osteoklastären Resorptionsstadien gegenübergestellt. Weiterhin wurde die Substratseite der Fibroblasten im Vergleich zur resorbierenden Membran der Osteklasten dargestellt. 


\section{Material und Methoden}

\subsection{Herkunft der Gewebe, Flüssigkeiten und Zellen}

Die im Rahmen dieser Arbeit kultivierten Zellen sowie deren Ausgangsmaterial und Herkunft sind in Tabelle 1 aufgelistet.

Tabelle 1: Herkunft von Zellen, Geweben und Flüssigkeiten

\begin{tabular}{|c|c|}
\hline Zellen/Bezeichnung & Ausgangsmaterial/Herkunft \\
\hline Osteoklasten & humanes peripheres Blut, gesunde Spender, \\
Sp1 - 4 & Universitätsklinikum Göttingen \\
\hline Osteoklasten & humanes peripheres Blut aus Buffy Coat, gesunde Spender, \\
BC1 - 15 & Universitätsklinikum Göttingen \\
\hline Fibroblasten & synoviale Flüssigkeiten, Patienten mit rheumatoider Arthritis, \\
Rh630, SZ44 & Universitätsklinikum Göttingen \\
\hline Fibroblasten & Universitätsklinikum Göttingen \\
Rh540, 542 & University Hospital Zurich, Switzerland \\
\hline Fibroblasten & synoviale Gewebe, Patienten mit rheumatoider Arthritis, \\
SHK85, 87 & Otto-von-Guericke-Universität, Magdeburg \\
\hline Fibroblasten & humanes Membrangewebe um eine gelockerte Gelenkprothese, \\
PL13,36, 38, 42 & Membrangewebe um eine gelockerte Gelenkprothese einer \\
\hline Fibroblasten & männlichen Wistar-Ratte, Otto-von-Guericke-Universität, \\
PL104 & Magdeburg \\
\hline
\end{tabular}

\section{$\underline{\text { 2.2 Nährmedien }}$}

Alle verwendeten Medien wurden bei $4{ }^{\circ} \mathrm{C}$ gelagert. Seren wurden vor der Zugabe zu den Medien 30 min bei $58{ }^{\circ} \mathrm{C}$ inaktiviert. Über einen Sterilfilter (Filtropur S 0.2, Porengröße 0,2 $\mu \mathrm{m}$, Fa. Sarstedt, Nümbrecht) wurden den Medien die Seren und Antibiotikalösungen zugesetzt. 


\section{$\underline{\text { 2.2.1 Medium für Osteoklasten }}$}

Für die Differenzierung und Kultivierung der Osteoklasten wurde Minimum Essential Medium (MEM Alpha Medium (1x) flüssig mit L-Glutamin, Ribonukleotiden, Desoxyribonukleotiden, Life Technologies, Inc.) mit $10 \%$ fetalem Kälberserum (FCS, Gemini Biological Products, Calabasas, CA) und $2 \%$ Penicillin/Streptomycin-Lösung (GibcoBRL, Eggenstein) verwendet.

\section{$\underline{\text { 2.2.2 Medium für Fibroblasten }}$}

Fibroblasten wurden in Dulbecco`s modified Eagle`s medium (DMEM (1x) flüssig mit L-Glutamin, $4500 \mathrm{mg} / \mathrm{l}$ D-Glucose, ohne Natriumpyruvat, Life Technologies, Inc.) mit $10 \%$ FCS und $2 \%$ Penicillin/Streptomycin-Lösung kultiviert.

\section{$\underline{2.3 \text { Zellkulturverfahren }}$}

Die Kultivierung der Zellen erfolgte bei $37{ }^{\circ} \mathrm{C}$ in $5 \% \mathrm{CO}_{2}$ und $95 \%$ wasserdampfgesättigter Atmosphäre in einem Zellkulturschrank (Fa. Sanyo). Alle Zellkulturarbeiten wurden unter einer sterilen Werkbank (Fa. Clean Air, Hilden) mit sterilen Lösungen durchgeführt.

\section{$\underline{\text { 2.3.1 Bestimmung der Zellzahl und Zellvitalität }}$}

Zur Überprüfung der Zellvitalität wurde der Trypanblau-Test angewandt. Die Zellsuspensionen wurden 1:1 mit Trypanblau versetzt. Der Farbstoff Trypanblau kann nur durch die Zellmembran toter oder stark beschädigter Zellen diffundieren und sie anfärben. Da der Farbstoff nach längerer Einwirkungsdauer zytotoxisch wirkt, erfolgte die Auswertung sofort. Die Lebendzellzahl wurde durch Auszählen der nicht angefärbten Zellen in einer „Neubauer Improved“ Zählkammer ermittelt. 


\section{$\underline{\text { 2.3.2 Kontrolle der Zelldifferenzierung und des Zellwachstums }}$}

Alle Kulturen wurden in regelmäßigen Abständen mit dem Kulturmikroskop (DIAVERT, Fa. Leitz, Wetzlar) betrachtet, um morphologische Veränderungen und Zellteilungsvorgänge zu kontrollieren.

\subsubsection{Isolierung der Lymphozyten/Monozyten-Fraktion aus peripherem Blut}

Das periphere Vollblut $(50 \mathrm{ml})$ wurde gesunden, erwachsenen SpenderInnen aus der Armvene entnommen. Buffy coats wurden von SpenderInnen der Blutbank des Universitätsklinikums Göttingen bezogen.

Das heparinisierte Vollblut wurde im Verhältnis 1:3 mit Hank`s Balanced Salt Solution (HBSS, BIOxWHITTAKER EUROPE) verdünnt. Dem Blut aus den Buffy coats wurde im Verhältnis 1:1 phos. buffered saline, $\mathrm{pH}$ 7,4 (PBS, Life Technologies, Inc.) dazugegeben.

Die Zellisolierung durch Dichtezentrifugation beruht auf dem unterschiedlichen Sedimentationsverhalten der Zellen, bedingt vor allem durch ihre Dichteunterschiede. Nach Zentrifugation des auf Trennmedium geschichteten, verdünnten Blutes, verbleiben die Monozyten und Lymphozyten auf der Interphase zwischen Blutserum und Medium, während Granulozyten und Erythrozyten durch das Trennmedium zum Boden sedimentieren.

In sterile $50 \mathrm{ml}$ Zentrifugenröhrchen wurden $15 \mathrm{ml}$ Trennmedium (Biocoll Separating Solution, $\mathrm{d}=1,077 \mathrm{~g} / \mathrm{ml}$, Biochrom KG, Berlin) gegeben. Darauf wurden vorsichtig 25 ml verdünntes Blut geschichtet. Nach Zentrifugation (800 x g, 20 min, ohne Bremse, RT) wurde die Bande über der Interphase mit der Pipette abgenommen und die Lymphozyten/Monozyten-Fraktion in ein neues Zentrifugenröhrchen überführt. Die Zellsuspension wurde auf $50 \mathrm{ml}$ mit eiskaltem PBS aufgefüllt und zentrifugiert (2000 x g, 10min, $4{ }^{\circ} \mathrm{C}$ ). Der Überstand wurde abgenommen und das Pellet in $30 \mathrm{ml}$ in $4{ }^{\circ} \mathrm{C}$ kalten PBS resuspendiert. Es wurde erneut zentrifugiert $\left(1200 \times \mathrm{g}, 5 \mathrm{~min}, 4{ }^{\circ} \mathrm{C}\right)$. Der letzte Waschschritt wurde dreimal wiederholt, da das Trennmedium zytotoxisch ist und möglichst vollständig entfernt werden sollte. Die Konzentration vitaler Zellen wurde in der Neubauer Zählkammer bestimmt. Für die unterschiedlichen Experimente wurden die Lymphozyten/Monozyten durch Verdünnung auf unterschiedliche Konzentrationen eingestellt. 


\subsubsection{Monozytenanreicherung}

\subsubsection{Plastikadhäsion}

Zur weiteren Abtrennung der Lymphozyten aus der Lymphozyten/Monozyten-Fraktion und Separation der Monozyten mittels Plastikadhäsion wurde das Pellet nach dem letzten Waschschritt in MEM Nährmedium aufgenommen, resuspendiert und in einer Zellkonzentration von ungefähr $5 \times 10^{7} \mathrm{Zellen} / \mathrm{ml}$ in eine große Petriderm-Schale gegeben. Die Zellen wurden für $1 \mathrm{~h}$ bei $37{ }^{\circ} \mathrm{C}$ und $5 \% \mathrm{CO}_{2}$ inkubiert. Während dieser Inkubationsphase adhärieren die Monozyten am Plastikboden der Schale, so dass die in Lösung bleibenden Lymphozyten später abgetrennt werden können. Zum Entfernen der Lymphozyten wurde die Petriderm-Schale dreimal mit $37{ }^{\circ} \mathrm{C}$ warmen PBS gespült. Dann wurde auf die verbleibenden Zellen $4{ }^{\circ} \mathrm{C}$ kaltes PBS gegeben und die Schalen ca. 30 min unter regelmäßiger Kontrolle auf Eis inkubiert. Hierdurch sollen die Monozyten wieder vom Plastikboden gelöst werden. Nach Ablauf der Inkubationszeit wurde das Ablösen der Zellen durch kräftiges Spülen unterstützt. Die zellhaltige Spülflüssigkeit wurde in ein Zentrifugenröhrchen gegeben und zentrifugiert ( $\left.2000 \mathrm{x} \mathrm{g}, 10 \mathrm{~min}, 4{ }^{\circ} \mathrm{C}\right)$. Das Pellet wurde in $10 \mathrm{ml}$ PBS aufgenommen. Die Zahl vitaler Zellen wurde in der Neubauer Zählkammer ermittelt. Die so gewonnenen Monozyten haben eine Reinheit von mindestens $85 \%$.

\subsubsection{Magnetische Partikel (Dynabeads ${ }^{\circledR}$ )}

Als alternative Methode zur Monozytenanreicherung mittels Plastikadhäsion wurde eine negative Isolierung von humanen Monozyten mit Hilfe von magnetischen Kügelchen aus Polystyren, auch Dynabeads ${ }^{\circledR}$ genannt, vorgenommen (Monocyte Negative Isolation Kit, Fa. DYNAL, Hamburg). Bei diesem indirekten Verfahren werden die Lymphozyten in einem ersten Schritt mit monoklonalen Maus-Antikörpern markiert, an die magnetische Kügelchen gekoppelt werden, die mit einem Fc spezifischen, humanen IgG4 Antikörper gegen Maus IgG beschichtet sind. Mit einem Magneten können die so markierten Lymphozyten von den Monozyten abgetrennt werden.

Die Monozyten/Lymphozyten-Fraktion wurden nach 2.3.3 aus peripherem Blut isoliert und abschließend auf eine Konzentration von 1 x 10 $0^{7}$ Zellen pro 100-200 $\mu 1$ PBS / 0,1 \% BSA eingestellt. 
Da Dynabeads ${ }^{\circledR}\left(4,5 \mu \mathrm{m}\right.$ Durchmesser, Dichte: $\left.1,5 \mathrm{~g} / \mathrm{cm}^{3}\right)$ in einer zellschädigenden Konservierungslösung aufbewahrt werden, ist es notwendig, die Partikel vor Gebrauch gründlich zu waschen. Hierzu wurden $100 \mu$ Dynabeads $^{\circledR}$ (oder mehr, je nach Anzahl der zu isolierenden Zellen) in entsprechendes Röhrchen überführt und für 1 min in einen „Magnetic Particle Concentrator“ (Dynal MPC ${ }^{\circledR}$ ) gestellt. Die Dynabeads ${ }^{\circledR}$ wurden in dieser magnetischen Vorrichtung über einen Magneten fixiert und die Lösung wurde klar. Mit einer Pipette wurde die Lösung vorsichtig entfernt und die magnetischen Kügelchen, nach Entfernen des Röhrchen aus der MPC-Vorrichtung, in $1-2$ ml PBS / $0,1 \%$ BSA gewaschen. Wiederum wurde das Röhrchen für $1 \mathrm{~min}$ in die MPCVorrichtung gestellt, anschließend der Puffer entfernt und die Partikel in das Ausgangsvolumen von $100 \mu \mathrm{PBS} / 0,1 \%$ BSA aufgenommen.

Bei den anschließenden Inkubations- und Separationsschritten zur Abtrennung der Monozyten von den übrigen Zellen wurden die Puffer und Zellsuspensionen auf $2-8$ ${ }^{\circ} \mathrm{C}$ gekühlt. Nach dem Protokoll der Hersteller wurden folgende Schritte durchgeführt:

1. Resuspendieren von $1 \times 10^{7}$ Zellen in $100-200 \mu 1$ PBS / 0,1\% BSA

2. Zugabe von $20 \mu 1$ Blocking Reagenz

3. Zugabe von $20 \mu$ l Antibody Mix

4. 10 min Inkubation bei $2-8^{\circ} \mathrm{C}$

5. waschen durch Zugabe von $1 \mathrm{ml}$ PBS / 0,1\% BSA und 8 min zentrifugieren bei 500 $\mathrm{x} \mathrm{g}$

6. Resuspendieren der Zellen in 0,9 $\mathrm{ml} \mathrm{PBS} \mathrm{/} \mathrm{0,1} \mathrm{\%} \mathrm{BSA}$

7. Zugabe von $100 \mu 1$ Dynabeads ${ }^{\circledR}$

8. 15 min Inkubation bei $2-8{ }^{\circ} \mathrm{C}$ und vorsichtigem Schwenken

9. 5 - 6 x vorsichtig pipettieren, um Rosettenbildung aufzulösen

10. 2 min Inkubation des Röhrchen in der magnetischen MPC-Vorrichtung

11. Entnahme des Überstandes, in dem sich die negativ isolierten Monozyten befinden

Mit dieser Isolationsmethode wird nach Angaben des Herstellers eine Reinheit der Monozyten von $90 \%$ erreicht. Die isolierten Zellen sind frei von oberflächengebundenen Antikörpern und magnetischen Partikeln. 
Lösungen:

Dynabeads: $4 \times 10^{8}$ Dynabeads ${ }^{\circledR}$ pro ml PBS mit $0,1 \%$ BSA u. $0,02 \% \mathrm{NaN}_{3}$ Antibody Mix: $\quad$ Mixtur von monoklonalen Maus-Antikörpern gegen CD2, CD7, CD16, CD19 und CD56 in PBS mit 0,02\% $\mathrm{NaN}_{3}$

Blocking Reagenz: $10 \mathrm{mg} / \mathrm{ml}$ Gammaglobulin in $0,9 \%$ NaCl-Lösung mit $0,02 \% \mathrm{NaN}_{3}$

\section{$\underline{\text { 2.3.5 Differenzierung und Kultivierung von Osteoklasten }}$}

Die nach 2.3.4 isolierten Monozyten wurden in einer Dichte von 1 x $10^{6} / \mathrm{ml}$ in Osteoklasten-Nährmedium aufgenommen. Die Lymphozyten/Monozyten-Fraktion (2.3.3) wurde in Osteoklasten-Nährmedium auf eine Konzentration von $2 \times 10^{6} / \mathrm{ml}$ eingestellt.

Die Zellen wurden in 24-well plates oder 6-well plates mit den Differenzierungsfaktoren RANKL $(50 \mathrm{ng} / \mathrm{ml})$ und M-CSF $(25 \mathrm{ng} / \mathrm{ml})$ bei $37{ }^{\circ} \mathrm{C}$ und $5 \% \mathrm{CO}_{2}$ über 2 bis 6 Wochen kultiviert. Die Konzentration der Differenzierungsfaktoren als auch die Faktoren selbst (alternativ wurde $10^{-7} \mathrm{M}$ Vitamin $\mathrm{D}$ und $2 \mathrm{ng} / \mathrm{ml}$ M-CSF in DMEM-Medium eingesetzt) wurden während der zellbiologischen Experimente variiert, um die bestmögliche Kombination zu ermitteln.

Alle 3 Tage wurde die Hälfte des Mediums abgenommen, durch frisches, auf $37{ }^{\circ} \mathrm{C}$ vorgewärmtes Nährmedium und erneute Zugabe der Differenzierungsfaktoren ersetzt.

\section{$\underline{\text { 2.3.6 Anreicherung und Weiterverarbeitung von Osteoklasten }}$}

Um eine möglichst hohe Anzahl von Osteoklasten aus den Differenzierungskulturen für weitere Experimente zu erhalten, wurde das Kulturmedium abgenommen und die Zellen für 5 min bei RT in PBS mit 0,001 \% Pronase E und 0,02\% EDTA inkubiert. Danach wurden die gelösten Zellen mit PBS dreimal abgewaschen. Die verbliebenen Zellen wurden für 2 h in Osteoklasten-Nährmedium kultiviert und dann für Western-Blot, RTPCR oder Cytospinpräparate weiter verwendet.

Hierzu wurden die Zellen nach Anreicherung zum Ablösen vom Kulturschalenboden $10 \mathrm{~min}$ in einer Trypsin-EDTA-Lösung bei $37{ }^{\circ} \mathrm{C}$ und $5 \% \mathrm{CO}_{2}$ inkubiert. Da Osteoklasten sehr fest am Plastikboden adhärieren und sich durch alleinige Trypsinierung nicht lösen, wurden sie nach Inkubation mit einem Zellschaber 
(Fa. Sarstedt, Nümbrecht) vom Boden abgelöst. Nach Zentrifugation bei 1200 Upm für 10 min, wurde das Zellpellet vorsichtig in PBS resuspendiert und die Zellzahl in einer Neubauer Zählkammer bestimmt.

\section{$\underline{\text { 2.3.7 Isolierung von Fibroblasten aus synovialem Gewebe }}$}

Synovialgewebe zur Zellpräparation wurden von Patienten mit rheumatoider Arthritis im Rahmen von gelenkchirurgischen Eingriffen aus der Destruktionszone entnommen. Um Fibroblasten aus dem Zellverband zu lösen, wurde das synoviale Gewebe in eine sterile Glasflasche mit Rührfisch überführt und $1 \mathrm{~h}$ bei RT in $50 \mathrm{ml}$ PBS mit 0,075 g Dispase II (neutral protease, Boehringer Mannheim) inkubiert. Anschließend wurde für 10 min kräftig gerührt. Der Überstand mit gelösten Zellen wurde abgenommen und für $10 \mathrm{~min}$ bei $1200 \mathrm{Upm}$ zentrifugiert. Das Zellsediment wurde vorsichtig in Fibroblasten-Medium resuspendiert und über ein Zellsieb (Maschenweite $100 \mu \mathrm{m}$, Nylon, Falcon) filtriert. Nach einem weiteren Zentrifugationsschritt wurde die Zellzahl festgestellt und die Zellvitalität (2.3.1) kontrolliert.

\section{$\underline{\text { 2.3.8 Isolierung von Fibroblasten aus synovialer Flüssigkeit }}$}

Fibroblasten wurden aus synovialer Flüssigkeit isoliert, die im Rahmen von diagnostischen oder therapeutischen Gelenkpunktionen gewonnen wurde.

Nach Überführung von $10-20 \mathrm{ml}$ der synovialen Flüssigkeit in sterile Zentrifugenröhrchen $(50 \mathrm{ml})$, wurde für $20 \mathrm{~min}$ bei $2000 \mathrm{Upm}$ zentrifugiert. Das Zellsediment wurde anschließend vorsichtig in $10 \mathrm{ml}$ PBS gewaschen und für $10 \mathrm{~min}$ bei 1200 Upm zentrifugiert. Anschließend wurde die Zellzahl bestimmt sowie die Vitalität der Zellen (2.3.1) überprüft.

\section{$\underline{\text { 2.3.9 Kultivierung von Fibroblasten }}$}

Die nach 2.3.7 und 2.3.8 isolierten Zellen wurden in Fibroblasten-Medium auf eine Dichte von $10^{6}$ Zellen/ml eingestellt und in kleinen Zellkulturflaschen $\left(25 \mathrm{~cm}^{2}\right.$ Wachstumsfläche, mit Belüftung, Fa. Sarstedt, Nümbrecht) bei $37^{\circ} \mathrm{C}$ und $5 \% \mathrm{CO}_{2}$ kultiviert. Nach 3 Tagen wurde die Hälfte des Medium entfernt und durch frisches, auf $37{ }^{\circ} \mathrm{C}$ vorgewärmtes Nährmedium ersetzt. 
Im Laufe der weiteren Kultivierung erfolgte ein vollständiger Mediumwechsel alle 3 Tage, so dass die nicht adhärenten Zellen entfernt wurden.

Bei einer Konfluenz von 90 bis 100 \% wurden die Zellen von der Zellkulturflasche abgelöst und vereinzelt, indem die Zellen einmal in PBS gewaschen und dann 5 min in einer Trypsin-EDTA-Lösung (1 $\mathrm{ml}$ kleine Zellkulturflasche bzw. $3 \mathrm{ml}$ große Zellkulturflasche) bei $37{ }^{\circ} \mathrm{C}$ im Zellkulturschrank inkubiert wurden. Durch Zugabe von 4 bzw. 7 ml Kultivierungsmedium wurde die Trypsinierung gestoppt und die Zellen auf neue und evtl. größere Zellkulturflaschen $\left(75 \mathrm{~cm}^{2}\right.$ Wachstumsfläche, mit Belüftung, Sarstedt) in einer Verdünnung von 1:2 bis 1:5 (je nach Zelldichte und Zellkultur) verteilt. Für den Einsatz der Zellen in weiteren Experimenten erfolgte eine mindestens vierfache Passagierung der Zellen.

\section{$\underline{\text { 2.3.10 Kultivierung von Zellen auf Calciumphosphat-Plättchen }}$}

„Osteologic Discs“ des BioCoat Osteologic Bone Cell Culture Systems (Fa. Becton Dickinson, Bedford, MA) sind Glasplättchen, die mit einem dünnen, synthetischen Calciumphosphatfilm beschichtet sind. Nach Angaben des Herstellers sind diese Calciumphosphat (CP)-Plättchen zur Bestimmung der Aktivität von Osteoklasten und Osteoblasten in vitro geeignet: die durch Resorption entstandenen Lakunen können lichtmikroskopisch visualisiert werden und sind im Vergleich zu anderen biologischen Hartgewebestücken größer, ansonsten aber morphologisch gleich.

Zur Untersuchung der Calciumphosphatresorption wurden sowohl Osteoklasten als auch Fibroblasten auf den CP-Plättchen in 24 well-plates kultiviert. Zum einen wurden Osteoklasten auf den CP-Plättchen herandifferenziert, indem die unter 2.3.3 isolierten und teils auch nach 2.3.4 angereicherten Monozyten gleich auf die CP-Plättchen gesetzt wurden. Die Inkubationsdauer betrug mindestens 28 Tage. Zum anderen wurden Osteoklasten erst über 2 Wochen, wie unter 2.3.5 beschrieben, herandifferenziert, nach 2.3.6 angereichert und anschließend auf den CP-Plättchen für 7 bis 14 Tage kultiviert.

Die Inkubationsdauer der nach 2.3.9 kultivierten Fibroblasten auf den CP-Plättchen betrug mindestens 4 bis 6 Wochen. Die Kultivierung erfolgte in dem, den Zellen entsprechenden Nährmedium (s. 2.2) bei $37{ }^{\circ} \mathrm{C}$ und $5 \% \mathrm{CO}_{2}$. Nach Ablauf der Inkubationsdauer wurden die Zellen von den CP-Plättchen abgelöst, um die darunter liegenden Resorptionslakunen $\mathrm{zu}$ erkennen. Hierzu wurde, nach Angaben des Herstellers, eine NAHO/NaCl-Lösung in die Kulturschalen $(0,5 \mathrm{ml} \mathrm{NAHO} / \mathrm{NaCl}-$ 
Lösung pro well einer 24-well plate) gegeben, ohne vorher das Medium zu entfernen. Nach 5-minütiger Inkubation wurde der Überstand verworfen, die CP-Plättchen mehrfach in $\mathrm{H}_{2} \mathrm{O}_{\text {bidest }}$ gewaschen und anschließend getrocknet. Die Auswertung erfolgte lichtmikroskopisch nach einem stereometrischen Verfahren (Axioskop, Fa. Zeiss, Computerprogramm Flex Scan F77S).

\section{$\underline{\text { 2.3.11 Kultivierung von Zellen auf Dentin }}$}

Zur Überprüfung resorptiver Fähigkeiten von Osteoklasten als auch von aktivierten Fibroblasten wurden Zellen auf Knochenersatzmaterialien gesetzt und über verschiedene Zeiträume inkubiert. Als Knochenersatzmaterialien wurden Wildschweinstoßzähne, humane Weisheitszähne und das Dentin eines Pottwals eingesetzt. Die humanen Weisheitszähne stammten von Patienten des Universitätsklinikums Göttingen. Ein Pottwalzahn wurde freundlicherweise vom Institut für Zoologie und Anthropologie und dem Zoologischem Museum, Prof. Dr. R. Willmann, Universität Göttingen, zur Verfügung gestellt.

\subsubsection{Vorbereitung des Dentins}

Die Wildschweinstoßzähne wurden in kleine Stücke $(0,5 \times 05 \mathrm{~cm})$ gebrochen, für $3 \mathrm{~h}$ in $70 \%$ Ethanol (v/v) gelegt und über Nacht in einer hochkonzentrierten Antibiotika/Fungizidlösung (Penicillin/Amphotericin B) inkubiert. Die auf diese Weise vorbehandelten Zahnsplitter wurden dann in Zellkulturen eingesetzt. Vorversuche zeigten, dass außerdem eine Sterilisierung im Ultraschallbad notwendig ist, um kleinste Partikel von der Oberfläche zu entfernen. Dazu wurden die Zahnsplitter vor Versuchsbeginn für 30 min in $\mathrm{H}_{2} \mathrm{O}_{\text {bidest }}$ in einem Ultraschallbad gereinigt.

Um das Dentin der Weisheitszähne und des Pottwals in der Zellkultur verwenden zu können, mussten handhabbare Stücke hergestellt und das Dentin für die Zellen offengelegt werden.

Sowohl die Weisheitszähne als auch der Pottwalzahn wurden mit einer diamantierten Säge in der Abt. Kieferchirurgie des Zentrums für Zahn-, Mund- und Kieferheilkunde, Universitätsklinikum Göttingen, in $300-400 \mu \mathrm{m}$ dicke Scheiben geschnitten. Im Falle des Pottwallzahns wurde die Querschnitte von 6 x 3,7 cm noch in kleine Stücke 
gebrochen $(0,5 \times 0,5 \mathrm{~cm}$ für 24-well plates, $0,2 \times 0,2 \mathrm{~cm}$ für $96-w e l l$ plates $)$, wobei die Randbereiche der Scheiben nicht verwendet wurden.

Die Zahnscheiben wurden wie die Stoßzahnsplitter einer Alkoholbehandlung und einer Inkubation über Nacht in der Antibiotika-/Fungizidlösung unterzogen. Es folgte eine Reinigung für $30 \mathrm{~min}$ im Ultraschallbad, um vorhandene Sägespanrückstände zu entfernen. Im Laufe der Experimente zeigte sich, dass die Vorbehandlung des Dentins in Alkohol und Antibiotika-/Fungizidlösung die Aktivität der Zellen beeinflusste und es wurde dazu übergegangen, das Dentin allein durch Inkubation im Ultraschallbad zu sterilisieren. Außerdem wurde nach einigen Vorversuchen dazu übergangen, das Pottwaldentin nach dem Schneiden zu polieren, um die durch das Sägen entstandenen Furchen zu entfernen und eine möglichst glatte Oberfläche zu erhalten. Hierzu wurde eine Schleifpaste, bestehend aus Diamantpulver in Öl (Fa. Winter, Hamburg), auf die Zahnscheiben aufgebracht und mit einem Hochgeschwindigkeitspoliergerät (Fa. Dremel, Leinefelden-Echterdingen) mit weichem Filzaufsatz für 5 min poliert. Anschließend wurden die Dentinstücke im Ultraschallbad sterilisiert und in den Zellkulturen eingesetzt

\subsubsection{Inkubation von Zellen auf Dentin}

Die nach 2.3.11.1 präparierten Dentinstückchen wurden in 96-well plates vorgelegt und $2 \times 10^{4}$ Osteoklasten oder Fibroblasten bzw. 4 x $10^{5}$ Monozyten/Lymphozyten in jeweils $200 \mu 1$ Nährmedium dazugegeben. Osteoklasten und Monozyten/Lymphozyten wurden in Osteoklasten-Medium (s. 2.2.1) mit $50 \mathrm{ng} / \mathrm{ml}$ RANKL und $25 \mathrm{ng} / \mathrm{ml}$ M-CSF inkubiert. Die Wachstumsfaktoren wurden den Kulturen alle 3 Tage zugegeben. Für die Fibroblastenkulturen wurde das Fibroblasten-Medium eingesetzt (s. 2.2.2). Zur Hemmung der Resorption wurden Fibroblastenkulturen mit $10^{-6}$ bis $10^{-8} \mathrm{M}$ Bafilomycin $\mathrm{A}_{1}$ (Fa. Sigma, Deisenhofen) inkubiert. Dieser v-ATPase Blocker wurde alle 3 Tage erneut zugesetzt.

Die Zellen wurden für verschiedene Zeiträume auf dem Dentin inkubiert. Die Inkubationsdauer für Monozyten/Lymphozyten-Kulteren sowie für FibroblastenKulturen betrug 4 bis 6 Wochen. Osteoklasten wurden für 3, 6, 9 und 14 Tagen mit dem Dentin kultiviert. 


\subsubsection{F-Actin Färbung}

Fluoreszierende Phalloidine binden kompetitiv an F-Actin und können über die Markierung der F-Actinfilamente das Zytoskelett in Zellen darstellen und so auch zum Nachweis der F-Actinringbildung in Osteoklasten herangezogen werden. Die Affinität der Phalloidine ist zu großen und kleinen F-Actinfilamenten gleich hoch und sie binden mit einer stöchiometrischen Ratio von 1 Phalloidinmolekül : 1 Actinuntereinheit.

Über 4 Wochen herandifferenzierte Osteoklasten (s. 2.3.5) sowie Fibroblasten der 5. Passage (s. 2.3.9) wurden nach Entfernung des Nährmediums zweimal in $37^{\circ} \mathrm{C}$ warmen PBS gewaschen. Anschließend wurden die Zellen für $30 \mathrm{~min}$ in einer 0,3 $\mathrm{mM}$ Rhodamine-konjugierten Phalloidin/PBS-Lösung (Fa. Mo Bi Tec, Göttingen) bei $37{ }^{\circ} \mathrm{C}$ inkubiert. Die Verteilung der F-Actinfilamente wurde unter dem Fluoreszenzmikroskop (Fa. Zeiss) anhand der roten Fluoreszenz detektiert.

\section{$\underline{\text { 2.4 Histologische Techniken }}$}

\section{$\underline{\text { 2.4.1 Aufarbeitung des Gewebes }}$}

Synovialgewebe wurden von Patienten mit rheumatoider Arthritis im Rahmen von gelenkchirurgischen Eingriffen aus der Destruktionszone entnommen. Die Gewebeproben wurden für $48 \mathrm{~h}$ in $4 \%$ igem Paraformaldehyd fixiert und anschließend in einer 0,5 M EDTA-Lösung dekalzifiziert. Die Einbettung des Gewebes erfolgte im Rahmen der routinemäßigen Gewebeaufarbeitung der Pathologieabteilung des Universitätsklinikums Göttingen (Prozessor: Tissue-Tek ${ }^{\circledR}$ VIP, Fa. Miles Scientific). Die Schnitte wurden an dem Rotationsmikrotom (Mikrotom 2040, Fa. Reichert-Jung) mit einer Schnittdicke von $2 \mu \mathrm{m}$ hergestellt und auf. beschichtete Objektträger (Fa. Perkin Elmer) aufgebracht.

\subsubsection{Zytochemische Färbung histologischer Gewebeschnitte}

Für die zytochemische Färbung wurden die Gewebeschnitte für 20 min in Xylol und in einer absteigenden Alkoholreihe (100\%, $90 \%, 70 \%$ EtOH jeweils $3 \mathrm{~min}$ ) entparaffiniert. Nach 4maligen Waschen für $3 \mathrm{~min}$ in $\mathrm{H}_{2} \mathrm{O}_{\text {bidest }}$ wurden die Schnitte für 5 
min in PBS inkubiert. Die sich anschließende zytochemische Färbung mit dem Sigma Diagnostics Acid Phosphatase Kit zum Nachweis der Tartrat-resistenten Sauren Phosphatase (TRAP) in Osteoklasten wurde analog der unter 2.5.3.1 und 2.5.3.2 beschriebenen Anweisung durchgeführt.

\subsection{Zytochemische und Immunzytochemische Techniken}

\subsubsection{Anfertigung von Zytospinpräparaten}

Für die enzymchemischen und immunzytochemischen Nachweise wurden Zellen mit Hilfe einer Zytospinzentrifuge (Cytospin 2, Fa. Shandon) auf Glas-Objektträger (geschnitten, Mattrand, Fa. Menzel-Gläser) aufgetragen. Hierzu wurden die Zellen in Nährmedium auf eine Konzentration von 1 x $10^{5}$ Zellen/ml verdünnt.

Die Glas-Objektträger wurden vorab in 99 \%igem Ethanol gelegt und kräftig mit einem Leinentuch trocken gerieben. Dann wurden die Objektträger in die Halterung der Zytospinzentrifuge eingespannt und pro Objektträger $100 \mu \mathrm{l}$ der vorbereiteten Zellsuspension eingesetzt. Die Zentrifugation erfolgte bei RT und $600 \mathrm{Upm}$ für $10 \mathrm{~min}$. Anschließend wurden die Präparate (ca. 1 x 10 $0^{4}$ Zellen/Objektträger) bei RT für 10 min in Aceton fixiert, über Nacht getrocknet und anschließend bei $-20{ }^{\circ} \mathrm{C}$ gelagert.

\subsubsection{Subkultivierung von Zellen auf Objektträgern mit Kulturkammern}

Zur immunzytochemischen Untersuchung der Fibroblasten wurden Objektträger mit Kulturkammern, sogenannten Chamber slides (Fa. Nunc), verwendet. In einer Dichte von $2 \times 10^{4}$ Zellen/ml Nährmedium wurden die Zellen in die Kulturkammern der Objektträger gegeben und für $24 \mathrm{~h}$ bei $37{ }^{\circ} \mathrm{C}$ und $5 \% \mathrm{CO}_{2}$ inkubiert. Während dieser Zeit adhärierten die Zellen auf dem Objektträger. Nach Entfernen der Kulturkammern wurden die Zellen auf dem Objektträger für $10 \mathrm{~min}$ in Aceton bei RT fixiert. Anschließend wurden die Präparate über Nacht bei RT getrocknet und zur Lagerung bei $-20^{\circ} \mathrm{C}$ eingefroren. 


\subsubsection{Zytochemische Färbung}

Mittels zytochemischer Färbung mit dem Sigma Diagnostics Acid Phosphatase Kit wurde in Osteoklasten die Tartrat-resistente Saure Phosphatase (TRAP) nachgewiesen. Das Prinzip des Tests beruht auf der Nutzung von substituierten Naphthol AS Phosphaten in Verbindung mit Diazoniumsalzen zur Detektion der sauren Phosphatase. Zellpräparate werden in einer Lösung aus Naphthol AS-BI Phosphorsäure und frisch diazotisiertem Fast-Garnet GBC inkubiert. Das nach enzymatischer Hydrolyse freigesetzte Naphthol AS-BI bindet sofort Fast-Garnet GBC unter Bildung eines unlöslichen kastanienbraunen Farbniederschlages. Wird der Lösung Tartratpuffer zugegeben, zeigen nur Zellen mit einer tartrat-resistenten sauren Phosphatase hydrolytische Aktivität und somit eine Farbreaktion. Zellen mit einer tartratempfindlichen sauren Phosphatase werden nur angefärbt, wenn kein Tartratpuffer verwendet wird.

\subsubsection{Lösungen für TRAP-Färbung}

Fixierlösung: $\quad 25 \mathrm{ml}$ Citratlösung

$65 \mathrm{ml}$ Aceton

$8 \mathrm{ml}$ Formaldehyd (37\%)

Die Lösung wurde vor Gebrauch auf RT erwärmt.

\begin{tabular}{|c|c|}
\hline \multirow[t]{8}{*}{ SLP-Lösung: } & 0,5 ml Fast-Garnet GBC Lösung \\
\hline & 0,5 ml Natriumnitrit-Lösung \\
\hline & 30 s kräftig geschüttelt, dann 2 min stehengelassen. \\
\hline & $45 \mathrm{ml} \mathrm{H} \mathrm{O}_{\text {bidest }}\left(37^{\circ} \mathrm{C}\right)$ \\
\hline & 0,5 ml Naphthol AS-BI Phosphorsäurelösung \\
\hline & $2 \mathrm{ml}$ Acetatlösung \\
\hline & $1 \mathrm{ml}$ Tartratlösung \\
\hline & Die Lösung wurde gut gemischt. \\
\hline
\end{tabular}

Die Fxierlösung wurde bei $4{ }^{\circ} \mathrm{C}$ aufbewahrt und wurde mehrmals verwendet. Die SLPLösung wurde für jede Färbung neu angesetzt und danach verworfen. 


\subsubsection{Durchführung der TRAP-Färbung}

Nach dem Auftauen wurden die Cytospinpräparate (s. 2.5.1) getrocknet und für $30 \mathrm{~s}$ in eine mit Fixierlösung gefüllte Küvette gegeben. Anschließend wurden die Objektträger gut mit $\mathrm{H}_{2} \mathrm{O}_{\text {bidest }}$ gespült und für $1 \mathrm{~h}$ lichtgeschützt bei $37{ }^{\circ} \mathrm{C}$ in der SLP-Lösung inkubiert. Nach einem weiterem Waschschritt in $\mathrm{H}_{2} \mathrm{O}_{\text {bidest }}$ wurden die Präparate für 1 min mit Hämatoxylin gegengefärbt. Die Küvette mit den Ojektträgern wurde für 5 min mit fließendem Leitungswasser gespült und abschließend kurz in $\mathrm{H}_{2} \mathrm{O}_{\text {bidest }}$ getaucht. Die Objektträger wurden mit wasserlöslichem Medium (Aqua mount, Fa. Paesel + Lorei, Hanau) eingedeckt (Deckgläser, Fa. Menzel-Gläser).

\subsubsection{Immunzytochemische Techniken}

Bei der hier angewandten indirekten, immunzytochemischen Methode bindet ein unkonjugierter Antikörper an das Antigen (primärer Antikörper). Diese Bindung wird durch einen konjugierten, sekundären Antikörper, der gegen den Primärantikörper gerichtet ist, sichtbar gemacht. Als sekundäre, enzymgekoppelte Antikörper wurden hier u.a. die Envision mouse Peroxidase bzw. die Envision mouse/rabbit Alkaline Phosphatase eingesetzt. Als Substrat der Peroxidase wurde im folgenden 3,3'Diaminobenzidin (DAB) verwendet, das nach Oxidation ein braunes Reaktionsprodukt ergibt. Die Vorinkubation der fixierten Zellen in einem Peroxidaseblock hemmt die endogene Peroxidase und verhindert so ungewünschte Farbreaktionen. Bei Verwendung der Alkalischen Phosphatase als Markerenzym wird das Chromogen Fuchsin umgesetzt, das eine rote Farbreaktion zeigt. Als Inhibitor der endogenen Alkalinen Phosphatase wurde Levamisole eingesetzt.

Beim immunzytochemischen Nachweis von Kathepsin K ist der Einsatz eines BrückenAntikörpers notwendig. Der primäre Antikörper wurde in der Ziege hergestellt. Der Brückenantikörper (Maus, anti-Ziege) ist spezifisch gegen den Ziegenantikörper gerichtet und stellt die Verbindung zum enzymgekoppelten Antikörper (Envision mouse/rabbit Alkaline Phosphatase) her, der an Maus- (bzw. Kaninchen-) Antikörper binden kann. 


\subsubsection{Lösungen und Puffer der Immunzytochemie}

Lösungen:

Peroxidase-Block

(Fa. DAKO, Hamburg)

Levamisole

(Fa. DAKO, Hamburg)

Schweineserum

(Fa. DAKO, Hamburg)

Envision mouse Peroxidase

(Fa. DAKO, Hamburg)

Envision mouse/rabbit Alkaline Phosphatase

(Fa. DAKO, Hamburg)

Fuchsin ${ }_{+}$Substrat-Chromogen-System

(Fa. DAKO, Hamburg)

DAB Kit

(Fa. DAKO, Hamburg)

Hämatoxylin

(Fa. Sigma, Deisenhofen)

Puffer:

PBS

(Fa. Life Technologies, Inc.)

PBS-FCS PBS mit $5 \%$ FCS

(Fa. Gemini Biological

Products, Calabasas, CA)

\subsubsection{Antikörper}

Folgende Primärantikörper standen zur Charakterisierung der Zellen zur Verfügung:

Tabelle 2: Angewandte Primärantikörper für die immunzytochemische Analyse

\begin{tabular}{|c|c|c|c|}
\hline Antikörper & Herkunft & Hersteller & Antigen \\
\hline VNR & Maus & Prof. Horton, London & Vitronectinrezeptor \\
\hline Kathepsin K & Ziege & Santa Cruz & Kathepsin K \\
\hline RANK & Kaninchen & Santa Cruz & Receptor Activator of NFNB \\
\hline
\end{tabular}




\subsubsection{Immunzytochemischer Nachweis des Vitronectinrezeptors (modifiziert nach Horton et al., 1985)}

Nach dem Auftauen wurden die Aceton-fixierten Objektträger für 10 min in PBS-FCS dehydriert und anschließend zur Hemmung der endogenen Peroxidase für weitere 10 min in Peroxidase-Blockierungslösung vorinkubiert. Nach Waschen in $\mathrm{H}_{2} \mathrm{O}_{\text {bidest }}$ und PBS-FCS wurden die Präparate für $1 \mathrm{~h}$ bei RT mit dem Primärantikörper VNR inkubiert. In allen Färbungen wurden Kontrollpräparate mitgeführt, auf die, anstelle des Primärantikörpers, nur PBS-FCS gegeben wurde. Die Objektträger wurden gut in PBS-FCS gewaschen und es folgte eine 30 minütige Inkubation in Envision mouse Peroxidase. Nach einem weiteren Waschschritt in PBS-FCS wurde die Farbreaktion mit DAB Kit entsprechend dem Protokoll des Herstellers entwickelt. Die Kerngegenfärbung wurde mit Hämatoxylin (1 min) durchgeführt. Nach 5 minütigem Spülen in fließendem Leitungswasser und kurzem Waschen in $\mathrm{H}_{2} \mathrm{O}_{\text {bidest, }}$ wurden die Präparate mit wasserlöslichem Medium eingedeckt.

\subsubsection{Immunzytochemischer Nachweis von Kathepsin K}

Die aufgetauten Objektträger (Aceton fixiert) wurden für 10 min in PBS dehydriert und zur Blockierung unspezifischer Bindungsstellen für $1 \mathrm{~h}$ in PBS mit $5 \%$ Schweineserum inkubiert. Nach Entfernung der Blockierungslösung folgte die einstündige Inkubation bei RT mit dem Primärantikörper gegen Kathepsin K (Ziege), der in einer Verdünnung von 1:50 in PBS eingesetzt wurde. In allen Färbungen wurde Kontrollpräparate mitgeführt, die anstelle des Primärantikörpers nur in PBS inkubiert wurden. Nach Waschen in PBS wurden die Präparate mit einem Maus anti-Ziege Brückenantikörper in einer Verdünnung von 1:200 in PBS für 30 min behandelt. Wiederum wurde in PBS gewaschen und anschließend für $30 \mathrm{~min}$ mit der Envision mouse/rabbit Alkaline Phosphatase inkubiert. Nach Waschen in PBS folgte die Farbentwicklung (2 min) mit dem Fuchsin ${ }_{+}$Substrat-Chromogen-System entsprechend dem Protokoll des Herstellers. Der Substratlösung wurde Levamisole in einer Endkonzentration von 0,2 mM zugesetzt (1 Tropfen Levamisole/ml Substratlösung). Die Präparate wurden dann in $\mathrm{H}_{2} \mathrm{O}_{\text {bidest }}$ gewaschen und eine Kerngegenfärbung mit Hämatoxylin für $1 \mathrm{~min}$ durchgeführt. Die Präparate wurden für $5 \mathrm{~min}$ mit fließendem Leitungswasser gespült. Abschließend wurden die Präparate in $\mathrm{H}_{2} \mathrm{O}_{\text {bidest }}$ getaucht und in wasserlöslichem Medium eingedeckt. 


\subsubsection{Immunzytochemischer Nachweis von RANK}

Nach dem Auftauen wurden die Objektträger für 10 min in PBS dehydriert und anschließend für weitere $10 \mathrm{~min}$ in Peroxidase-Blockierungslösung vorinkubiert. Nach dem Waschen in $\mathrm{H}_{2} \mathrm{O}_{\text {bidest }}$ und PBS wurden die Präparate für $1 \mathrm{~h}$ in PBS mit $5 \%$ Schweineserum inkubiert, um die unspezifischen Bindungsstellen zu blockieren. Dem Entfernen der Blockierungslösung folgte eine einstündige Inkubation bei RT mit dem Primärantikörper RANK (Kaninchen) in einer Verdünnung von 1:50. Es wurden Kontrollpräparate mitgeführt, die anstelle des Primärantikörper nur in PBS inkubiert wurden. Nach Spülen in PBS wurde der enzymgekoppelte Sekundärantikörper (labbeled Polymer, Kaninchen, DAB-Kit) aufgetragen. Nach 30-minütiger Inkubation wurden die Präparate in PBS gewaschen und als Chromogen wurde DAB appliziert. Die Inkubation erfolgte für 5 min bei RT. Dann wurde in $\mathrm{H}_{2} \mathrm{O}_{\text {bidest }}$ gewaschen, für 1 min in Hämatoxylin gegengefärbt und für $5 \mathrm{~min}$ mit fließendem Leitungswasser gespült. Schließlich wurden die Präparate in wasserlöslichem Medium eingedeckt.

\section{$\underline{\text { 2.6 Charakterisierung von Zellen mittels Durchflußzytometrie }}$}

In der Durchflußzytometrie im Fluoreszenz-aktivierten Zellsorter (FACS) ist die Analyse von Zellen getrennt nach verschiedenen Parametern wie Größe, Granularität und Fluoreszenzen (Grün- und Rotfluoreszenz) möglich. Die Zellen werden für die Messung in einen Flüssigkeitsstrom durch einen Laserstrahl geleitet, wobei jede einzelne Zelle vom Strahl getroffen wird. Die dabei entstehenden Signale werden elektronisch verstärkt und der zeitlichen Reihenfolge nach gespeichert. Als Maß für die Größe dient die Lichtstreuung nach vorne, also in $180^{\circ}$ (forward scatter (FSC)). Die Streuung im $90^{\circ}$ Winkel (sideward scatter (SSC)) ist ein Maß für die Granularität. Werden bestimmte Antigene auf der Oberfläche der Zellen mit einem monoklonalen, Fluoreszenz-gekoppelten Antikörper markiert, können die Fluoreszenzen mit dem Laser angeregt werden. Die dabei abgestrahlten Signale im grünen (FL1) und/oder roten (FL2) Lichtbereich, je nach Markierung, können ebenfalls gespeichert werden. Mit diesem Verfahren besteht daher die Möglichkeit, in einer inhomogenen Zellpopulation diejenigen Zellen herauszusuchen, die für eine bestimmte Fragestellung interessant sind und sie statistisch gegen die Gesamtpopulation abzugrenzen. 


\section{$\underline{\text { 2.6.1 Charakterisierung von Fibroblasten mittels FACS-Analyse }}$}

Die in den zellbiologischen Experimenten eingesetzten Fibroblastenkulturen (s. 2.3.7 bis 2.3.9) wurden mittels Durchflußzytometrie auf mögliche Verunreinigungen mit Leukozyten kontrolliert. Hierzu wurde ein unmarkierter Antikörper (Klon D-7FIB, DPC Biermann, Bad Nauheim) verwendet, der spezifisch gegen ein 112 kDa Molekül gerichtet ist, das auf der Zelloberfläche von humanen Fibroblasten expremiert wird. Periphere Blutzellen expremieren dieses Antigen nicht. Durch anschließende Kopplung des Fibroblasten-Antikörpers D-7FIB an einen Flourochrom-markierten Antikörper, wurde die Fibroblastenpopulation markiert. Als floureszierendes Molekül diente Phycoerythrin (PE). Als Negativkontrolle für Verunreinigungen der Kulturen mit Leukozyten wurde der monoklonale, Fluoreszein-isothiozyanat I (FITC) markierte Antikörper gegen CD45 (pan-Leukozyten) verwendet. Außerdem wurde eine Isotypenkontrolle mitgeführt.

Für die Analyse wurde eine mit Zellen vollständig bewachsene Zellkulturflasche (75 $\mathrm{cm}^{2}$ Wachstumsfläche (ca. 1 Millionen Zellen) benötigt. Mit einem Zellscharber wurden die adhärenten Zellen vom Plastikboden abgescharbt, für 10 min bei $800 \mathrm{x} g$ zentrifugiert und in PBS gewaschen. Nach einem weiteren Zentrifugationsschritt wurde das Pellet in $500 \mu$ PBS resuspendiert. Die Antikörperlösungen anti-CD45 (Klon J.33, Coulter/Immunotech, Krefeld), $5 \mu 1 /$ Röhrchen, und D-7FIB, $10 \mu 1 /$ Röhrchen, wurden in fünf FACS-Röhrchen (5 ml, 75 x 12 mm Durchmesser, Fa. Sarstedt, Nümbrecht) vorgelegt und mit jeweils $100 \mu \mathrm{l}$ Zellsuspension (ca. 200.000 Zellen/Röhrchen) für 30 min bei RT im Dunkeln inkubiert. Danach wurde in die Röhrchen mit dem Fibroblasten-Antikörper D-7FIB zusätzlich $50 \mu 1$ der 1:100 verdünnten PE-markierten Antikörperlösung (Becton Dickinson, San Jose, CA, USA) gegeben und für weitere 10 min im Dunkeln bei RT stehen gelassen. Anschließend wurde in jedes Röhrchen $2 \mathrm{ml}$ PBS pipettiert, zentrifugiert (800 x g, 10min) und der Überstand verworfen. Die Resuspension des Pellets erfolgte in $400 \mu \mathrm{l}$ PBS pro Röhrchen. Es wurden 10000 Zellen pro Probe mit dem FACS Calibur (Becton Dickinson, San Jose, CA, USA) gemessen.

Die weitere Auswertung erfolgte über das Computerprogramm Cellquest (Becton Dickinson, San Jose, CA, USA). 


\subsection{Molekularbiologische Analyse der Genexpression charakteristischer Enzyme}

\subsubsection{Allgemeine Arbeitsbedingungen}

Der Umgang mit Nukleinsäuren erfordert aufgrund der Empfindlichkeit gegenüber Nukleasen, die die Nukleinsäuren hydrolytisch spalten, besondere Vorsichtsmaßnahmen. Alle hitzestabilen Geräte und Lösungen wurden 20 min bei $120^{\circ} \mathrm{C}$ und 1,4 bar autoklaviert, um Nukleasen zu inaktivieren. Alle Lösungen für das Arbeiten mit RNA wurden mit 0,1\% (v/v) Diethylpyrocarbonat (DEPC) - behandelten Wasser, angesetzt und, wenn möglich, autoklaviert. Hitzeempfindliche Lösungen wurden sterilfiltriert (Filtropur S 0.2, Porengröße 0,2 $\mu \mathrm{m}$, Fa. Sarstedt, Nümbrecht). Soweit es die Versuchsbedingungen zuließen, wurde unter der Sterilbank gearbeitet. Durch das Tragen von Einweghandschuhen wurde einer Kontamination durch Nukleasen vorgebeugt.

\subsubsection{Isolierung von RNA aus Zelllysaten (Chomczynski et Sacchi, 1993)}

Bei dieser Methode wird zur Zelllyse eine monophasische Lösung aus Phenol und Guanidin isothiocyanat (Trizol, Life Technologies, Inc.) verwendet. Zugabe von Chloroform mit anschließender Zentrifugation, trennt die Lösung in eine wässrige und eine organische Phase. Die RNA befindet sich nur in der wässrigen Phase.

Zur Isolierung von RNA wurden die in 6 oder 24 well-plates kultivierten Zellen nach Entfernung des Nährmedium für $5 \mathrm{~min}$ in Trizol (Life Technologies, Inc.) bei RT inkubiert. Bei den 6 well-plates wurden $750 \mu$ Trizol/well verwendet, bei den 24-well plates $375 \mu 1 /$ well, wobei hier nach Ablauf der Inkubationszeit die Zelllysate zweier wells in einer Probe vereinigt wurden. Das lysierte Material wurde in E-Cups überführt und mehrfach pipettiert, um eine weitere Homogenisierung $\mathrm{zu}$ bewirken. Dann wurde pro E-Cup $200 \mu$ l Chloroform dazugegeben, gemixt, 5 min inkubiert und bei $12.000 \mathrm{x}$ g für $15 \mathrm{~min}$ zentrifugiert. Anschließend wurde vorsichtig die obere, wässrige Phase, in der sich die RNA befindet, abgenommen, in neue E-Cups überführt und durch Zugabe von $500 \mu 1$ Isopropanol präzipitiert. Nach 10minütiger Inkubation bei RT und anschließender Zentrifugation bei 12.000 x g für 20 min, wurde der Überstand verworfen. Das Pellet wurde durch Zugabe von $1 \mathrm{ml} 70 \%$ (v/v) Ethanol und 
Zentrifugation (12.000 x g, $5 \mathrm{~min}$ ) gewaschen, getrocknet und in $50 \mu \mathrm{l}$ DEPC-Wasser aufgenommen. Die Qualität der RNA wurde auf einem Agarosegel überprüft (s. 2.7.6.1). Die Lagerung der RNA erfolgte bei $-80^{\circ} \mathrm{C}$.

\subsubsection{Konzentrationsbestimmung von Nukleinsäuren}

Die Konzentration von RNA- oder DNA-Lösungen wurde photometrisch durch Messung der Absorption bei $260 \mathrm{~nm}$ in Quarzküvetten bestimmt. Die Wellenlänge von $260 \mathrm{~nm}$ entspricht dem Absorptionsmaximum der Nukleotide AMP und UMP. Für RNA und einzelsträngige DNA entspricht $40 \mu \mathrm{g} / \mathrm{ml}$ einer optischen Dichte von 1 . Zur quantitiativen Erfassung der Nukleinsäuren wurden die Proben 1:100 in DEPCbehandeltem Wasser verdünnt. Bei allen Proben wurde zusätzlich die Extinktion bei einer Wellenlänge von $280 \mathrm{~nm}$ gemessen, dem Absorptionsspektrum der Aminosäure Tryptophan. Über das Verhältnis von $\mathrm{OD}_{260}: \mathrm{OD}_{280}$ konnte der Reinheitsgrad der Nukleinsäurelösung in Bezug auf den Proteingehalt bestimmt werden. Der Reinheitsgrad sollte zwischen 1,8 und 2,0 liegen (Maniatis et al., 1989).

\subsubsection{RNA-(Reverse Transkription-) Polymerase-Kettenreaktion}

Die RNA-(Reverse Transkription-) Polymerase-Kettenreaktion (RT-PCR) ist eine hochsensible Methode zur Untersuchung der Genexpression auf der Stufe der RNA. Mit dem Enzym Reverse Transkriptase wird von der mRNA-Matrize ein komplementäre DNA (cDNA)-Strang hergestellt. Anschließend wird die cDNA mit bestimmten Oligonukleotiden (Primern) mittels PCR amplifiziert. Die Amplifikate lassen Rückschlüsse auf die Expression bestimmter Gene zu, die für Enzyme kodieren, welche für einen Zelltyp charakteristisch sind.

\subsubsection{1 cDNA Synthese}

Zur reversen Transkription mit dem First Strand cDNA Kit (MBI Fermentas, St Leon Rot, Germany) wurden $0,1-5 \mu \mathrm{g}$ RNA in einem Volumen von $14 \mu 1$ mit $1 \mu$ l Oligo $(\mathrm{dT})_{18}$ Primern $(0,5 \mu \mathrm{g} / \mu \mathrm{l})$ gemischt und kurz zentrifugiert $(12.000 \mathrm{x}$ g, $20 \mathrm{sec})$. Die Denaturierung erfolgte bei $70{ }^{\circ} \mathrm{C}$ für $5 \mathrm{~min}$. Danach wurde der Ansatz für 1 min auf Eis abgekühlt. In einem zweiten Gefäß wurden für jede Reaktion $5 \mu$ RT-Puffer, 2,5 $\mu 110$ 
mM dNTP-Mix und 1,25 $\mu 1$ Ribonuklease-Inhibitor $(20 \mathrm{U} / \mu \mathrm{l})$ gemischt. Diese Mixtur wurde 5 min bei $37{ }^{\circ} \mathrm{C}$ inkubiert, anschließend $1 \mu$ l Revert Aid ${ }^{\mathrm{TM}}$-MLV Reverse Transkriptase $(200 \mathrm{U} / \mu \mathrm{l})$ dazu pipettiert und dem auf Eis inkubierten Ansatz hinzugefügt. Die Reaktion erfolgte bei $42{ }^{\circ} \mathrm{C}$ für $1 \mathrm{~h}$. Zur Inaktivierung der Reversen Transkriptase wurde der Ansatz schließlich noch für 10 min bei $72{ }^{\circ} \mathrm{C}$ inkubiert. Die cDNA wurde bei $-20^{\circ} \mathrm{C}$ aufbewahrt.

\subsubsection{Amplifikation von cDNA mittels PCR}

In der Polymerase-Kettenreaktion lassen sich aus geringen Mengen einer cDNAMatrize mit Hilfe einer thermostabilen DNA-Polymerase und zweier zur „Ziel-DNA“ passender Oligonukleotide spezifische DNA-Fragmente amplifizieren (SAIKI et al., 1988). Die eingesetzten Primer waren in der Regel 19 - 25 Basen lang. Eine optimale Amplifikation war gewährleistet, wenn beide Oligonukleotide den gleichen Schmelzpunkt hatten und in gleicher Konzentration vorlagen. Die Berechnung des Schmelzpunktes erfolgte nach CHESTER \& MARSHAK (1993):

$$
\begin{aligned}
\mathrm{T}_{\mathrm{m}}=69,3+0,41(\% \mathrm{G}+\mathrm{C}-\text { Gehalt })-650 / \mathrm{L} \\
\% \mathrm{G}+\mathrm{C}-\mathrm{Gehalt}= \\
\mathrm{L} \quad=\text { prozentualer } \mathrm{G}+\mathrm{C}-\text { Gehalt des Primers } \\
=\text { Länge des Primers }
\end{aligned}
$$

Die Standard-PCR-Reaktionen wurden in $25 \mu 1$ Ansätzen (PCR-Reaktionsgefäß) durchgeführt und enthielt folgende Komponenten:

$\begin{array}{lcl}\text { cDNA (Matrize) } & 0,5-1,0 & \mu \mathrm{g} \\ \text { Oligonukleotid 1 } & 20 & \mathrm{pmol} \\ \text { Oligonukleotid 2 } & 20 & \mathrm{pmol} \\ \mathrm{dNTP}-G e m i s c h & 200 & \mu \mathrm{mol} \\ \mathrm{MgCl}_{2}(25 \mathrm{mM}) & 2 & \mathrm{mM} \\ \text { Reaktionspuffer }(10 \mathrm{x}) & 2,5 & \mu \mathrm{l} \\ \text { Taq-Polymerase }(. . \mathrm{U} / \mu \mathrm{l}) & 0,25 & \mu \mathrm{l} \\ \mathrm{H}_{2} \mathrm{O}_{\text {bidest }} & \mathrm{ad} \mathrm{19,0} & \mu \mathrm{l}\end{array}$


Die Taq-Polymerase wurde zusammen mit dem Reaktionspuffer von der Fa. MBI Fermentas (St Leon Rot, Germany) bezogen. Die Komponenten wurden auf Eis zusammenpipettiert, gemischt und kurz zentrifugiert (12.000 x g, $20 \mathrm{~s})$. Anschließend wurde der Ansatz im PCR-Thermocycler (Gene Amp ${ }^{\circledR}$ PCR System 9700, Fa. PE Applied Biosystems) für 2 min bei $95{ }^{\circ} \mathrm{C}$ inkubiert, um eine vollständige Denaturierung der DNA zu gewährleisten. Zur Amplifizierung schlossen sich folgende Temperaturzyklen in 25- bzw. 35-facher Wiederholung an:

$\begin{array}{lrr}\text { Denaturierung } & 95{ }^{\circ} \mathrm{C} & 20 \mathrm{~s} \\ \text { Anlagerung } & \mathrm{x}{ }^{\circ} \mathrm{C} & 45 \mathrm{~s} \\ \text { Polymerisierung } & 68^{\circ} \mathrm{C} & \mathrm{y} \mathrm{s}\end{array}$

Die Anlagerungstemperatur war abhängig von der Schmelztemperatur der Primer und lag idealer Weise $5{ }^{\circ} \mathrm{C}$ tiefer. Die Dauer y der Polymerisierung betrug $1 \mathrm{~min}$ pro $\mathrm{kb}$ zu amplifizierender DNA. Zur Optimierung der PCR konnten einzelne Parameter variiert werden wie z.B. die Anlagerungstemperatur und die Anzahl der Zyklen oder auch die Konzentrationen der eingesetzten Oligonukleotide sowie der Matrizen-cDNA. Ferner konnte die Spezifität durch Verringerung der $\mathrm{MgCl}_{2}$-Konzentration gesteigert werden. Nach Abschluss der Amplifikation wurde ein Aliquot im Agarosegel überprüft. In einigen Fällen wurden Ansätze mit dem QIAquick-Kit (Fa. Qiagen, Hilden) gereinigt, um die amplifizierte DNA sequenzieren zu lassen. Die Sequenzierung wurde von der Fa. SeqLab, Göttingen durchgeführt.

\section{$\underline{\text { 2.7.5 Isolierung und Reinigung von Nukleinsäuren }}$}

Zur Isolierung von DNA-Fragmenten aus Agarosegelen sowie zur Reinigung wurde der kommerziell erhältliche QIAquick-Kit der Fa. Qiagen (Agarose Gel Extraction Protocol) eingesetzt.

Das zu isolierende DNA-Fragment wurde mit einem Skalpell aus dem Agarosegel ausgeschnitten, mit Puffer QG (3 Volumeneinheiten Puffer QG zu 1 Volumeneinheit des Gelfragments) versetzt und 10 min bei $50{ }^{\circ} \mathrm{C}$ inkubiert. Während der Inkubation wurde die Probe alle 2-3 min gemischt. Nach vollständiger Auflösung des Gelfragmentes wurde die Farbe der Mixtur überprüft, die wie der QG Puffer gelb sein sollte. Bei Abweichung der Farbe zum orange oder violett wurden $10 \mu \mathrm{l}$ einer 
3 M Natriumacetat-Lösung zugegeben. Die Mixtur nimmt damit wieder eine gelbe Farbe an. Der Puffer QG enthält einen pH-Indikator, der mittels der Farbänderung einen Hinweis auf einen $\mathrm{zu}$ hohen $\mathrm{pH}-$ Wert gibt. Die Adsorption der DNA an die QIAquick Membran ist nur bei einem $\mathrm{pH}$ von 7,5 effizient.

Die Probe wurde mit 1 Gelvolumeneinheit Isopropanol versetzt und gemischt. Zur Bindung der DNA an die Säulenmembran, wurde der Ansatz auf die QIAquick Säule überführt und für $1 \mathrm{~min}$ bei $12.000 \mathrm{x} \mathrm{g}$ zentrifugiert. Zum Entfernen sämtlicher Agarosebestandteile wurden 0,5 ml Puffer QG auf die Säule gegeben und wiederum zentrifugiert (12.000 x g, $1 \mathrm{~min}$ ). Anschließend wurde die Säule mit 0,75 ml PE Puffer gewaschen und zweimal zentrifugiert (12.000 x g, $1 \mathrm{~min}$ ). Zur Elution der DNA wurden $30 \mu \mathrm{H}_{2} \mathrm{O}_{\text {bidest }}$ auf die Säule pipettiert, für $1 \mathrm{~min}$ bei RT inkubiert und anschließend für 1 min mit maximaler Geschwindigkeit (13.500 x g) zentrifugiert. Die Lagerung der DNA erfolgte bei $-20^{\circ} \mathrm{C}$.

\subsubsection{Auftrennung von DNA-Fragmenten}

\subsubsection{Agarosegelelektrophorese}

Für die analytische und präparative Auftrennung von DNA sowie für die Qualitätsprüfung von RNA wurden horizontale Gelelektrophoresen in Agarosegelen durchgeführt. In der Gelelektrophorese werden geladene Moleküle einem elektrischen Feld ausgesetzt, in dem sie entsprechend ihrer Größe und Ladung aufgetrennt werden. Die Wanderungsgeschwindigkeit von Nukleinsäure-Fragmenten in Agarosegelen hängt neben dem Molekulargewicht und der Konfiguration der Nukleinsäuren auch von der Konzentration der Agarosegele, der angelegten Spannung und der Temperatur ab. Der Zusatz von Ethidiumbromid zur gelösten Agarose ermöglicht durch Interkalation einen stabilen Komplex mit der aufgetrennten Nukleinsäure, der unter UV-Licht fluoresziert.

Die Gelelektrophorese-Kammern (Horizon ${ }^{\circledR}$, Fa. Life Technologies, Inc.) hatten eine Größe von 5 x $8 \mathrm{~cm}$ (kleine Gele) und 11 x $14 \mathrm{~cm}$ (große Gele). Die Agarose wurde in 1,5 \%ig (w/v) in TAE-Puffer angesetzt, welcher gleichzeitig auch als Elektrophoresepuffer diente. 
$\underline{50 \times \text { TAE-Puffer (SAMBROCK et al., 1989) }}$

Tris

$\operatorname{EDTA}(0,5 \mathrm{M} ; \mathrm{pH} 8,5)$

Essigsäure (konz.)

$\mathrm{H}_{2} \mathrm{O}_{\text {bidest }}$
$242 \mathrm{~g}$

$100 \mathrm{ml}$

$57 \mathrm{ml}$

ad $1000 \mathrm{ml}$

Vor dem Auftragen der Proben in die Geltaschen wurden diese mit 6 x Beschwererlösung (Fa. MBI Fermentas) versetzt. Dadurch konnte während der Gelelektrophorese die Lauffront verfolgt werden, und eventuell vorhandene Proteine wurden denaturiert. Neben den zu untersuchenden Proben wurde noch der DNALängenstandard (2.7.6.2) aufgetragen. Die Elektrophorese erfolgte bei ca. $80 \mathrm{~V}$, bis die Lauffront die Mitte des Gels nach ca. 60 - 90 min erreicht hatte.

\subsubsection{Größenbestimmung von Nukleinsäuren}

Um die Größe von DNA-Fragmenten, die in Agarosegelen aufgetrennt worden waren, bestimmen zu können, wurde als Längenstandard der 100 bp-Marker der Fa. MBI Fermentas verwendet. Der Marker wurde 1:10 mit $\mathrm{H}_{2} 0_{\text {bidest }}$ verdünnt, mit Beschwererlösung versetzt und parallel auf das Gel aufgetragen. Nach dem Lauf konnte die Größe der erhaltenen Fragmente berechnet werden, indem man die Laufstrecke mit der des Längenstandards verglich.

\section{$\underline{\text { 2.8 Proteingewinnung aus Zellkulturmaterial }}$}

Zur Proteingewinnung aus Osteoklasten und synovialen Fibroblasten für Western BlotAnalysen wurden 6 well-plates eingesetzt, die vollständig mit Zellen bewachsen waren. Um die Zellen zu lysieren, wurde das Medium aus den Kulturschalen entfernt und pro well $500 \mu$ Lysepuffer mit $10 \mu 1100$ mM PMSF auf die Zellen gegeben. Nach 15minütiger Inkubation auf Eis wurden die Zellen mechanisch mit einem Zellschaber abgelöst und zum weiteren Aufschluss mit einer feinen Glaspipette pipettiert. Nach Abzentrifugieren der Zellkerne bei RT für $5 \mathrm{~min}$ und bei $800 \mathrm{x} \mathrm{g}$, wurden die Überstande mit den Proteinen in neue Reaktionsgefässe überführt. Nach Bestimmung der Proteinkonzentration (s. 2.9) wurden die Überstände so verteilt, dass auf jedes ECup $150 \mu \mathrm{g}$ Protein entfielen. Zur denaturierenden Fällung wurden die Proben dann mit 
4 Teilen Aceton vermischt und für $10 \mathrm{~min}$ auf Eis inkubiert. Die so ausgefällten Proteine wurden bei 1200 x g für 20 min abzentrifugiert und für $1 \mathrm{~h}$ bei $37{ }^{\circ} \mathrm{C}$ getrocknet. Abschließend wurden die Proteine in 0,1 ml SDS-Puffer pro E-Cup resuspendiert und bei $-20{ }^{\circ} \mathrm{C}$ gelagert.

Die Lösungen setzen sich wie folgt zusammen:

Lysepuffer

Natriumdeoxycholat

Tergitol (NP-40)

EGTA

1 M Tris-HCl-Lösung, $\mathrm{pH} 7,4$

$\mathrm{H}_{2} \mathrm{O}_{\text {bidest }}$

$0,4 \mathrm{~g}$
$1 \mathrm{ml}$
$1,9 \mathrm{~g}$
$1 \mathrm{ml}$
ad $100 \mathrm{ml}$

\section{$1 \%$ ige SDS-Lösung}

SDS

$1 \mathrm{~g}$

$\mathrm{H}_{2} \mathrm{O}_{\text {bidest }} \quad$ ad $100 \mathrm{ml}$

$\underline{\text { SDS-Puffer }}$

$1 \%$ ige SDS-Lösung

$1 \mathrm{ml}$

$100 \mathrm{mM}$ PMSF

$20 \mu 1$

0,5 M EDTA $20 \mu 1$

$100 \mathrm{mM}$ NEM

\subsection{Bestimmung der Proteinkonzentration}

Die Konzentrationsbestimmung von Proteinlösungen erfolgte nach BRADFORD (1976, mod.). Die Methode beruht auf der Bindung des Farbstoffes „CoomassieBrilliant-Blue“ an Proteine. $10 \mu \mathrm{l}$ Probe (unverdünnt sowie in 1:10 Verdünnung) wurden mit $300 \mu 1$ Bradford-Reagenz (Fa. Sigma, Deisenhofen) vermischt und 5 min bei RT inkubiert. Die Messung der Extinktion erfolgte in einem Spektralphotometer bei $595 \mathrm{~nm}$ gegen $\mathrm{H}_{2} \mathrm{O}_{\text {bidest }}$ als Leerwert. Die Eichgerade wurde mit Rinderserumalbumin im Bereich von $0-6 \mu \mathrm{g}$ Protein erstellt.

\section{$\underline{\text { 2.10 Herstellung von Proteinkonzentraten }}$}

Zentrifugenfiltereinheiten (Ultrafree-0.5, Biomax-10, Fa. Millipore) eignen sich besonders zum schnellen Aufkonzentrieren geringvolumiger Proteinlösungen eingesetzt. $100 \mu \mathrm{l}$ Proteinprobe (s. 2.8) wurden in die Filtriereinheit mit der Ausschlußgrenze von $10 \mathrm{kDa}$ eingefüllt, verschlossen und in das Filtratgefäß eingesetzt. Mittels Zentrifugation bei 12.000 x g für $10 \mathrm{~min}$ bei RT wurde die Probe 10 fach 
eingeengt. Die Proteinkonzentrierung erfolgte jeweils zu Beginn der Auftrennung von Proteinen mit Hilfe der Gelelektrophorese (s.2.11). Sowohl Konzentrat als auch Filtrat wurden in weiteren Experimenten eingesetzt.

\subsection{Polyacrylamidgelelektrophorese (PAGE) von Proteinen}

Zum Nachweis charakteristischer Proteine sowie zu deren Molekulargewichtsbestimmung diente die Elektrophorese in einem Polyacrylamidgel unter denaturierenden Bedingungen (SDS-PAGE, nach LAEMMLI, 1970, mod.). Das anionische Detergenz Natriumdodecyl-Sulfat (SDS) zerstört die Quartärstruktur von Proteinen und lagert sich an die hydrophoben Regionen des Proteins an. Dadurch wird die Eigenladung des Proteins überdeckt, und es findet nur noch eine Auftrennung nach der Masse und nicht nach der Ladung statt. Zur besseren Trennungsleistung arbeit man zusätzlich mit diskontinuierlichen Gelen (Sammel- und Trenngel). Die Elektrophorese wurde in einer vertikalen Minigelkammer (Mini-PROTEAN ${ }^{\circledR} 3$ Cell, Fa. Biorad, München) durchgeführt mit 10 x $10 \mathrm{~cm}$ Glasplatten und $1 \mathrm{~mm}$ Spacer durchgeführt.

Die Lösungen setzten sich folgendermaßen zusammen:

Gelgrundlösung

$\begin{array}{lr}\text { Tris- } \mathrm{HCl}(1,5 \mathrm{M}) & 181,7 \mathrm{~g} \\ \text { EDTA }(8 \mathrm{mM}) & 2,98 \mathrm{~g} \\ 0,4 \% \mathrm{SDS} & 4,0 \mathrm{~g} \\ \mathrm{H}_{2} \mathrm{O}_{\text {bidest }} & \text { ad } 1000 \mathrm{ml} \\ \mathrm{pH} 8,8 & \end{array}$

$12 \%$ ige Trenngel-Lösung

Polyacrylamid $(40 \%)$

$15 \mathrm{ml}$

Gelgrundlösung

$\mathrm{H}_{2} \mathrm{O}_{\text {bidest }}$

$22 \mathrm{ml}$

$4 \%$ ige Trenngel-Lösung

Polyacrylamid (40\%)

$5 \mathrm{ml}$

Gelgrundlösung $13 \mathrm{ml}$

$\mathrm{H}_{2} \mathrm{O}_{\text {bidest }}$ $32 \mathrm{ml}$ 
4 \%ige Sammelgel-Lösung Polyacrylamid (40 \%)

$$
\begin{array}{r}
10,0 \mathrm{ml} \\
1,2 \mathrm{~g} \\
0,07 \mathrm{~g} \\
0,1 \mathrm{~g} \\
\text { ad } 100 \mathrm{ml}
\end{array}
$$

Tris- $\mathrm{HCl}$

\begin{tabular}{|c|c|c|}
\hline \multirow[t]{2}{*}{ Lösung } & APS & $0,1 \mathrm{~g}$ \\
\hline & $\mathrm{H}_{2} \mathrm{O}_{\text {bidest }}$ & $940 \mu 1$ \\
\hline \multirow[t]{6}{*}{ Laufpuffer (10x) } & Tris-HCl & $15,0 \mathrm{~g}$ \\
\hline & Glycin & $72,0 \mathrm{~g}$ \\
\hline & SDS & $5,0 \mathrm{~g}$ \\
\hline & $\mathrm{H}_{2} \mathrm{O}_{\text {bidest }}$ & ad $500 \mathrm{ml}$ \\
\hline & $\mathrm{pH} 8,3$ & \\
\hline & $\begin{array}{l}\text { Der Laufpuffer wurde vor } \\
\text { verdünnt. }\end{array}$ & $\mathrm{H}_{2} \mathrm{O}_{\text {bidest }}$ \\
\hline \multirow[t]{6}{*}{$6 \times$ Probenauftragspuffer } & 4 x Tris-HCl/SDS, pH 6,8 & $7 \mathrm{ml}$ \\
\hline & Glycerol & $3,8 \mathrm{~g}$ \\
\hline & SDS & $1 \mathrm{~g}$ \\
\hline & DTT & $0,93 \mathrm{~g}$ \\
\hline & Bromphenolblau & $1 \mathrm{mg}$ \\
\hline & $\mathrm{H}_{2} \mathrm{O}_{\text {bidest }}$ & ad $10 \mathrm{ml}$ \\
\hline
\end{tabular}

EDTA

SDS

$\mathrm{H}_{2} \mathrm{O}_{\text {bidest }}$

$\underline{\text { Ammoniumpersulfat- }}$

Lagerung in $0,5 \mathrm{ml}$ Aliquots bei $-70{ }^{\circ} \mathrm{C}$. 
Für eine $10 \%$ Polyacrylamidkonzentration des Trenngels wurden die Lösungen folgendermaßen zusammengegeben:

Tabelle 3: Zusammensetzung von $10 \%$ igem Trenngel u. 4 \%igem Sammelgel

\begin{tabular}{lll}
\hline Lösung & Trenngel & Sammelgel \\
& $10 \%$ & $4 \%$ \\
\hline 4\%ige Trenngel-Lösung & $2 \mathrm{ml}$ & - \\
12\%ige Trenngel-Lösung & $6 \mathrm{ml}$ & - \\
Sammelgel-Lösung & - & $4 \mathrm{ml}$ \\
TEMED & $5 \mu 1$ & $5 \mu 1$ \\
APS & $50 \mu 1$ & $50 \mu 1$ \\
\hline
\end{tabular}

Die einzelnen Komponenten des Trenngels wurden gemischt, zwischen die mit $\mathrm{H}_{2} \mathrm{O}_{\text {bidest }}$ und Ethanol (70 \% (v/v)) gesäuberten Glasplatten gegossen und mit $\mathrm{H}_{2} \mathrm{O}_{\text {bidest }}$ abgesättigtem Isopropanol überschichtet, damit eine ebene Geloberfläche entstand. Nach dem Polymerisieren wurde das Isopropanol mit einer Glaskapillare entfernt, die frisch angesetzte Sammelgellösung über das Trenngel geschichtet und der Kamm zur Taschenformung luftblasenfrei eingesetzt. Vor dem Auftragen der Proben wurde das Gel in die mit Laufpuffer gefüllte Kammer gespannt und der Kamm entfernt.

$20 \mu 1$ Probe (Proteingehalt $10 \mu \mathrm{g}$ ), Probenkonzentrat oder -filtrat wurden 1:6 mit dem Probenauftragspuffer vermischt und für 5 min bei $95{ }^{\circ} \mathrm{C}$ inkubiert. Nach kurzer Zentrifugation (12.000 x g, $20 \mathrm{~s}$ ) wurden die Proben in die Taschen des Gels eingefüllt. Die Auftrennung der Proteine erfolgte bei RT und konstanter Stromstärke von $25 \mathrm{~mA}$ und war beendet, wenn die blaue Lauffront das Gelende erreicht hatte (ca. $45 \mathrm{~min}$ ).

\section{$\underline{\text { 2.12 Western Blot und immunologischer Nachweis von Proteinen }}$}

\subsection{1 Übertragung von Proteinen auf Polyvenylidinfluorid (PVDF)-Membranen}

Für den spezifischen immunochemischen Nachweis charakteristischer matrixdegradierender Proteasen wurden Proteine von SDS-Polyacrylamidgelen auf Poly Screen ${ }^{\circledR}$ PVDF Transfer Membranen (Fa. NEN ${ }^{\circledR}$ Life Science Products, Inc., 
Boston, MA) übertragen. Der Proteintransfer erfolgte in der „Mini Trans-Blot ${ }^{\circledR}$ “ Elektrophoresekammer (Fa. Bio-Rad, München). Der Transferpuffer bestand aus folgenden Komponenten:

$\begin{array}{lrr}\text { Transferpuffer } & & \\ \text { Tris-HCl } & 25 & \mathrm{mM} \\ \text { Glycin } & 192 & \mathrm{mM} \\ \mathrm{H}_{2} \mathrm{O}_{\text {bidest }} & \text { ad } 1000 & \mathrm{ml} \\ \mathrm{pH} 8,3 & & \end{array}$

Nach Beendigung der SDS-PAGE wurde das Gel für etwa 10 min in Transferpuffer gelegt. Während dessen wurde die PVDF-Membran auf die Gelgröße zugeschnitten und auf der Vorderseite markiert, $15 \mathrm{~s}$ in Methanol äquilibriert, 2 min in $\mathrm{H}_{2} \mathrm{O}_{\text {bidest }}$ gewaschen und mindestens $5 \mathrm{~min}$ in Transferpuffer vorinkubiert. Anschließend wurden auf der Kathodenseite (-) der Blotkassette folgende Komponenten luftblasenfrei übereinandergeschichtet:
1. Faserpolster der Blotapparatur
2. Filterpapier
3. äquilibrierte SDS-Gel
4. äquilibrierte PVDF-Membran
5. Filterpapier
6. Faserpolster der Blotapparatur

Die Blotkassette wurde unter leichtem Druck geschlossen und in die mit Transferpuffer gefüllte Blotkammer eingesetzt. Durch einen mit Eis gefüllten Vorratsbehälter in der Kammer wurde der Transferpuffer während des Blotvorganges gekühlt. Der Transfer der Proteine erfolgte bei $80 \mathrm{~V}$ über 1 h. Der Erfolg des Transfers wurde durch Färbung des SDS-PAGE-Gels mit Coomassie (s. 2.13.1) überprüft. Um die Bindung der Proteine an die PVDF-Membran zusätzlich zu festigen, wurde die Membran nach dem Blotvorgang für $10 \mathrm{~s}$ in Methanol getränkt und abschließend für 10 min luftgetrocknet. 


\section{$\underline{\text { 2.12.2 Immunologischer Nachweis von Proteinen und Detektionsverfahren }}$}

Zur Markierung des Proteinstandards wurde die äquilibrierte Blot-Membran zunächst mit Ponceau S Rot gefärbt und anschließend, nach Markierung der Standardproteinbanden, wieder entfärbt (s. 2.13.2). Für den spezifischen, sensitiven Proteinnachweis wurde die PVDF-Membran dann zur Absättigung freier Bindungsstellen für $1 \mathrm{~h}$ in einer Roti-Blocklösung geschwenkt. Nach gründlichem Abtropfen wurde die Membran $1 \mathrm{~h}$ mit dem Primärantikörper gegen Kathepsin $\mathrm{K}$ (Fa. Santa Cruz; mit Roti-Blocklösung 1:1000 verdünnt) unter ständiger Bewegung inkubiert. Es folgte ein 15-minütiger Waschschritt in TBS/Tween-Puffer und eine einstündige Inkubation mit dem zweiten Antikörper, einem Horseradish Peroxidase (HRP)-konjugierten Maus-Anti-Ziege-Antikörper (Fa. Dianova; mit Roti-Blocklösung 1:2000 verdünnt). Die Blot-Membran wurde anschließend einmal $15 \mathrm{~min}$ und viermal 5 min in TBS/Tween-Puffer gründlich gewaschen.

In der Dunkelkammer wurde die Blot-Membran für $1 \mathrm{~min}$ in einem ChemilumineszenzReagenz (Western Blot Chemiluminescence Reagent, Fa. Perkin Elmer Life Sciences, Inc., Boston, MA) geschwenkt. Das Chemilumineszenz-Reagenz wurde direkt vor dem Gebrauch 1:1 aus zwei Komponenten zusammengemischt: dem Luminol-Reagenz und dem Oxidationsreagenz. Das Enzym HRP katalysiert durch die Oxidation von Luminol eine Lichtemission bei einer Wellenlänge von $428 \mathrm{~nm}$, die auf einem Röntgenfilm eingefangen wird.

Nach Abtropfen des Reagenz wurde die Membran in eine durchsichtige Plastikfolie gelegt. Anschließend erfolgte die Exposition auf dem Röntgenfilm (Kodak BioMax MR, Fa. Kodak, Stuttgart) in einer Expositionskassette mit Verstärkerfolie für 5 min, 20min und $24 \mathrm{~h}$. Der Film wurde in einem Vollautomaten (Curix 60, Fa. AGFA) entwickelt, gewässert sowie fixiert und anschließend bei RT getrocknet. Bereiche, an den der Primärantikörper gebunden hat, erscheinen als schwarze Signale.

$\underline{\text { Roti-Blocklösung }}$

Roti-Block (Fa. Roth, Karlruhe)

$1: 10$ in $\mathrm{H}_{2} \mathrm{O}_{\text {bidest verdünnt }}$
TBS-Puffer (10x)

$\begin{array}{lr}\mathrm{NaCl} & 1,5 \mathrm{M} \\ \text { Tris-HCl, pH 7,4 } & 0,5 \mathrm{M} \\ \mathrm{H}_{2} \mathrm{O}_{\text {bidest }} \text { ad } 1000 \mathrm{ml}\end{array}$


$\underline{\text { TBS/Tween-Puffer }}$

TBS-Puffer (10x) $100 \mathrm{ml}$

Tween ${ }^{\circledR} 20$

$\mathrm{H}_{2} \mathrm{O}_{\text {bidest }}$ ad $1000 \mathrm{ml}$
Chemilumineszenz-Reagenz

Luminol-Reagenz $\quad 2,5 \mathrm{ml}$

Oxidationsreagenz $\quad 2,5 \mathrm{ml}$

\section{$\underline{\text { 2.13 Proteinfärbung von Polyacrylamidgelen und Blot-Membranen }}$}

\subsubsection{Unspezifische Proteinfärbung mit Coomassie (WEBER u. OSBORN, 1969,} $\underline{\bmod .)}$

Die Färbung von Polyacrylamid-Gelen erfolgte in Coomassie-Lösung bei RT unter permanentem Schütteln auf einer Gelwippe. Dabei wurden die Gele ca. 30 min der Färbelösung ausgesetzt und anschließend unter kontinuierlicher Bewegung in der Entfärbelösung inkubiert, bis der Hintergrund transparent wurde. Während des Entfärbens wurde die Entfärbelösung mehrfach gewechselt.

\section{Färbelösung}

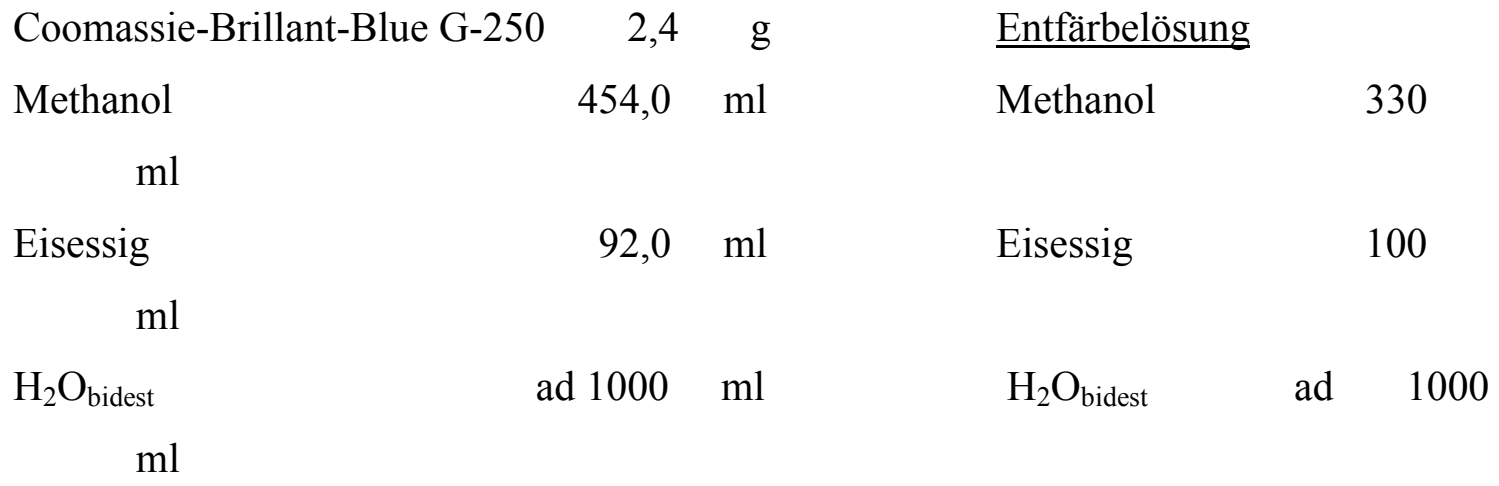

\subsubsection{Unspezifische Proteinfärbung mit Ponceau S Rot}

Die Detektion der Proteinbanden auf den Blot-Membranen wurde mit einer Ponceau S Rot-Färbung vorgenommen. Hierzu wurde die Membran vorab für $15 \mathrm{~s}$ in Methanol äquilibriert und anschließend für 2 min in $\mathrm{H}_{2} \mathrm{O}_{\text {bidest }}$ gewaschen. Die Färbung erfolgte für $1 \mathrm{~min}$ in Ponceau $\mathrm{S}$ Rot (Fa. Sigma). Durch Waschen in $\mathrm{H}_{2} \mathrm{O}_{\text {bidest }}$ wurde soweit entfärbt, dass die Proteinbanden gut sichtbar wurden und Standardbanden mit einem Fettstift auf der Membran markiert werden konnten. Die vollständige Entfärbung wurde in einer $0,1 \mathrm{~N} \mathrm{NaOH}$-Lösung vorgenommen. 


\section{$\underline{\text { 2.14 Bestimmung der Molekularmassen von Proteinen }}$}

Zur Bestimmung des Molekulargewichtes von Proteinen in SDS-Gelen wurden gleichzeitig entsprechende Standardproteine mit aufgetrennt. Die Zusammensetzung und die molekularen Massen der Markerproteine sind in Tabelle 4 aufgeführt.

\section{Tabelle 4: Molekulare Massen der Standardproteine für die SDS-PAGE}

\begin{tabular}{lc}
\hline $\begin{array}{l}\text { Standardproteine } \\
\text { (broad range)* }\end{array}$ & Molekulargewicht $*$ Da@ \\
\hline Myosin & 200,00 \\
E-Galaktosidase & 116,25 \\
Phosphorylase b & 97,40 \\
Rinderserumalbumin & 66,20 \\
Ovalbumin & 45,00 \\
Carboanhydrase & 31,00 \\
Trypsin-Inhibitor & 21,50 \\
Lysozym & 14,40 \\
Aprotinin & 6,5 \\
* Fa. Bio-Rad, München &
\end{tabular}

Nach Anfärbung der Gele oder nach Abschluss des Detektionsverfahrens von BlotMembranen konnten die Molekularmassen von Proteinen berechnet werden, indem die Wanderungsstrecken im Gel bzw. auf der Membran mit der von Standardproteinen verglichen wurden. Die Auftragung des Logarithmus der Molekularmassen der Standardproteine gegen deren Rf-Wert ergab eine Eichgerade, aus der die Molekularmassen der unbekannten Proteine abgelesen werden konnten.

$$
\begin{array}{cc}
\text { Wanderungsstrecke des Proteins } \\
\text { Rf-Wert }=\quad \begin{array}{c}
\text { G } \\
\text { Wanderungsstrecke des Farbstoffmarkers }
\end{array}
\end{array}
$$




\subsection{Behandlung der Dentinpräparate für die Rasterelektronen- mikroskopie (REM)}

Für die REM Untersuchungen wurden die Dentinstücke (s. 2.3.11) direkt aus den Kulturschalen entnommen und in 2,5\%-igem Glutaraldehyd in 0,1 molarem Cacodylatpuffer für mindestens $4 \mathrm{~h}$ fixiert. Anschließend erfolgte die Entwässerung der Präparate in einer aufsteigenden Alkoholreihe (70\% - $100 \%$-iges Ethanol). Die Präparate wurden dann in einer Kritisch-Punkt-Trocknungsanlage (Fa. Polaron E 3100, VG Microtech, Uckfield, UK) getrocknet. Nach Befestigung der Dentinstücke auf den Präparatehaltern, wurden diese in einem Cool-Sputter-Coater (SC 510, Fisons Instant, UK) mit Gold-Palladium bedampft. Die Betrachtung und das Fotografieren der Präparate erfolgte mit einem Digital Scanning Microscop (DSM-960) der Fa. Zeiss Oberkochem.

Zur Untersuchung der Substratseite der Zellen sowie zur Betrachtung der Dentinoberfläche wurden die darauf adhärierten Zellen nach einer Tape-Methode entfernt. Hierzu wurden die Zellen von den bereits für das Rasterelektronenmikroskop behandelten und betrachteten Präparaten (s.o.) durch vorsichtiges Aufbringen und Abheben eines Tesafilmstückes entfernt. Die Dentinstücke sowie die Tesafilmstücke mit den anhaftenden Zellen (mit der Substratseite nach oben) wurden nochmals mit Gold-Palladium bedampft und anschließend im Rasterelektronenmikroskop untersucht und fotografiert.

\section{$\underline{2.16 \text { Bezugsquellen }}$}

Standardchemikalien mit dem Reinheitsgrad „pro analysis“ oder „reinst“ wurden von der Fa. Sigma Chemie GmbH (Deisenhofen) bezogen. Die Bezugsquellen weiterer Chemikalien, Enzyme, Verbrauchsmaterialien und Kits sind nachfolgend aufgeführt:

Becton Dickinson, Heidelberg: „Osteologic Discs“, PE-markierte Antikörperlösung Biochrom KG, Berlin: Biocoll Seperationg Solution BIOxWHITTAKER Europe, Apen: HBSS

Boehringer Mannheim GmBH, Mannheim: Dispase II Coulter/Immunotech, Krefeld: anti-CD45 (Klon J.33) 
DAKO, Hamburg: Peroxidase-Block, Levamisole, Schweineserum, Envision mouse Peroxidase, Envision mouse/rabbit Alkaline Phosphatase, Fuchsin Substrat-ChromogenSystem, DAB Kit

Dianova, Hamburg: HRP-konjugierter Maus-anti-Ziege-Antikörper

DPC Biermann, Bad Nauheim: Fibroblasten-Antikörper D-7FIB

DYNAL, Hamburg: Monocyte Negative Isolation Kit

GibcoBRL, Eggenstein: Penecillin/Streptomycin-Lösung, Trypanblau, Trypsin-EDTALösung

Kodak, Stuttgart: Kodak BioMax MR-Röntgenfilm

Life Technologies, Inc.: MEM Alpha Medium, DMEM Medium, PBS, Trizol

MBI Fermentas GmbH (St. Leon Rot): First Strand cDNA Kit, Taq-Polymerase, Beschwererlösung, DNA-Längenstandard

Menzel-Gläser, Braunschweig: Glas-Objektträger, Deckgläser

Millipore, Schwalbach: Ultrafree-0.5, Biomax-10-Zentrifugenfiltereinheiten

MoBiTec, Göttingen: Rhodamine-konjugiertes Phalloidin

Nunc, Wiesbaden: Chamber slides

Paesel + Lorei, Hanau: Eindeckmedium

Perkin Elmer Life Sciences, Inc., Boston, MA: Poly Screen PVDF Transfermembran, Western Blot Chemilumineszenz-Reagenz

Qiagen GmbH, Hilden: QIAquick-Kit

R \& D Systems, Stuttgart: M-CSF

Roth, Karlsruhe: Roti-Block

Santa Cruz, Wien: Antikörper (Kathepsin K, RANK)

Serotec, Düsseldorf: rekombinantes RANKL

Sarstedt, Nümbrecht: Sterilfilter, Zellschaber, Zellkulturflaschen, 6-, 24-, 96-well plates, FACS-Röhrchen

Winter, Hamburg: Schleifpaste 


\section{Experimente und Ergebnisse}

Das Ziel dieser Arbeit war es, ein in vitro System zur Analyse von Matrixdegradierenden Prozessen zu etablieren. Mit diesem System wird die Fähigkeit von Zellen zur Resorption einer knochenähnlichen Matrix (Dentin; Calciumphosphatbeschichtete Plättchen) anhand der Bildung von Aushöhlungen im Substrat demonstriert und licht- bzw. rasterelektronenmikroskopisch sichtbar gemacht. Zur Etablierung des Resorptionsassays wurden humane Osteoklasten in dem in vitro System eingesetzt und in verschiedenen Phasen des Abbauvorganges morphologisch und funktionell definiert. Anschließend wurden vergleichende Untersuchungen mit RA synovialen Fibroblasten und PL Fibroblasten durchgeführt, für die indirekte Hinweise bestehen, dass sie an der pathologisch gesteigerten Knochenresorption beteiligt sind.

Unter physiologischen Bedingungen werden Knochenumbauprozesse durch die Aktivität von Osteoklasten, die Knochen resorbieren und den knochenaufbauenden Osteoblasten gesteuert. Von besonderem Interesse sind Osteoklasten oder Osteoklastenähnliche Zellen bei der rheumatoiden Arthritis, wenn das Gleichgewicht zwischen Knochenauf- und abbau gestört ist und Knochenresorption überwiegt. In dieser Arbeit wurden Osteoklasten aus peripheren Blutzellen herandifferenziert und charakterisiert, in vitro morphologisch bei dem Resorptionsprozess untersucht sowie die daraus resultierenden Veränderungen des Substrats dargestellt. Es wurden durch Osteoklasten hervorgerufene Anfangsstadien der Resorption sowie späte Veränderungen im Substrat erfasst. Da bei der Durchführung der Experimente wiederholt spenderabhängige Unterschiede bei den Osteoklastenkulturen festgestellt wurden, erfolgte am Rande der eigentlichen Untersuchungen eine Darstellung der Auswirkungen unterschiedlicher Herkunft der Osteoklasten-Vorläuferzellen auf die Morphologie und Funktionalität der reifen Zellen.

Als weiterer Schwerpunkt dieser Arbeit wurde die Rolle aktivierter Fibroblasten an Resorptionsprozessen mit dem in vitro System analysiert. An der Zerstörung des Gelenkknorpels bei rheumatoider Arthritis sind maßgeblich aktivierte, synoviale Fibroblasten (= synoviale RA Fibroblasten) mit einem hohen proteolytischen Potential beteiligt. Die Zellen stammen aus dem sogenannten Pannus, der durch Invasion und Destruktion im Verlauf auch Knochenerosionen hervorruft. Bisher wurde angenommen, 
dass bei dieser Form der Knochenresorption eher Osteoklasten oder osteoklastenähnliche Zellen beteiligt sind. Untersuchungen haben jedoch indirekte Hinweise darauf gegeben, dass auch synoviale RA Fibroblasten an der Knochendestruktion beteiligt sind (HUMMEL et al., 1998). Ähnlichkeiten mit diesen Zellen zeigen aktivierte Fibroblasten aus einer Grenzmembran, die sich bei der aseptischen Prothesenlockerung zwischen der Knochenoberfläche und der Prothese gebildet hatte (PAP et al., 1999).

Diese sogenannten Prothesenlockerungs- (PL) Fibroblasten sowie die synovialen RA Fibroblasten wurden in dem in vitro System bezüglich ihrer Fähigkeit zur Resorption von knochenähnlicher Matrix im Vergleich zu den Osteoklasten untersucht. Weitere Erläuterungen zur Auswahl dieser Zellen sind unter 3.5.1 dargelegt.

\subsection{Differenzierung von Osteoklasten, die zur Resorption von knochenähnlicher Matrix befähigt sind}

\subsubsection{Isolierung von Osteoklastenvorläuferzellen aus peripherem Blut}

Osteoklasten wurden aus myeloischen Zellen gewonnen, da in den Zellbanken (ATCC) bislang keine humanen Osteoklastenzellinien erhältlich sind. Als Quelle für myeloische Zellen können nach Literaturbeschreibungen Knochenmarkzellen sowie monozytäre Zellen dienen, die aus peripherem Blut, synovialer Flüssigkeit oder aus dem Verdau von synovialem Gewebe gewonnen werden. Unter geeigneten Bedingungen können nach MATSUZAKI et al., 1998, auch aus peripheren Blutmonozyten Zellen gebildet werden, die die phänotypischen Charakteristika von Osteoklasten aufweisen und resorptive Fähigkeiten zeigen. Die Wahl der Ausgangsmaterialien zur Isolation der Vorläuferzellen fiel nach einigen Vorversuchen auf peripheres Blut, aus dem die größte Anzahl an mononuklären Zellen pro Ansatz gewonnen wurde. Außerdem stand über die Blutbank des Universitätsklinikums Göttingen jederzeit ausreichend peripheres Blut als Buffy Coat von gesunden erwachsenen SpenderInnen zur Verfügung. Knochenmark, synoviale Flüssigkeit oder synoviales Gewebe sind nur sehr unregelmäßig bei entsprechenden Entnahmen aus dem Knochen bzw. Gelenken zu erhalten und liefern häufig nicht genügend Zellen für weitere Experimente. Ein weiteres Argument für die Verwendung von peripheren Blutzellen war, dass das Blut von den SpenderInnen negativ auf $\mathrm{HIV} / \mathrm{HBV} / \mathrm{HCV}$ getestet war und nicht durch Medikamenteneinnahme beeinflusst wurde. 
Im Laufe der Etablierung einer schnellen und effizienten Methodik wurde dazu übergegangen, peripheres Vollblut bestimmter SpenderInnen zur Isolierung von Vorläuferzellen zu verwenden, da sich spenderabhängige Unterschiede bezüglich der Anzahl der ausdifferenzierten Zellen sowie der Matrix-degradierender Fähigkeiten zeigten.

Zur Ermittlung der bestmöglichen Anreicherungsmethode wurden vergleichende Vorversuche durchgeführt. Nach der 1. Variante wurde die Monozyten/LymphozytenFraktion, die mittels Ficoll-Separation aus dem peripherem Blut gewonnen wurde (s. 2.3.3), direkt für anschließende Differenzierung der Osteoklasten eingesetzt. Bei der 2 . Variante wurde, nach Isolierung der Monozyten/Lymphozyten-Fraktion mittels FicollDichtezentrifugation, ein großer Anteil der Lymphozyten über Plastikadhäsion von den übrigen Zellen abgetrennt (s. 2.3.4.1). Bei der alternativen Variante 3 diente der Einsatz magnetischer Partikel (s. 2.3.4.2) der weiteren Anreicherung der Monozyten nach Ficoll-Separation. In den Vorversuchen wurden die drei Varianten jeweils dreimal parallel durchgeführt. Bei erheblich höherem Aufwand zeigte die Monozytenanreicherung durch magnetische Partikel oder Plastikadhäsion in allen drei Vorversuchen keine erkennbar höhere Osteoklastenausbeute. In den folgenden Experimenten wurden daher die nach 2.3.3 isolierten Monozyten/Lymphozyten ohne weitere Anreicherung zur Differenzierung der Osteoklasten eingesetzt.

\subsubsection{Osteoklastendifferenzierung}

Myeloische Zellen werden nach gängigen Methoden zusammen mit Osteoblasten unter Zugabe von M-CSF (Monocyte-Colony-Stimulating-Factor) und 1,25-Dihydroxyvitamin $\mathrm{D}_{3}$ inkubiert. In einer Beschreibung von TAKAYANAGI et al. (1997) wurden an Stelle von Osteoblasten aus RA-Synovium gewonnene Fibroblasten verwendet. Diese Zellen wurden durch Gewebeverdau aus entsprechenden Operationspräparaten isoliert und kultiviert (MÜLLER-LADNER, 1997). Die synovialen Fibroblasten - als auch Osteoblasten - produzieren ein membrangebundenes Protein, das RANKL oder auch ODF (Osteoklasten-differenzierender Faktor), TRANCE (tumor necrosis factorrelated activation-induced cytokine) oder OPGL (Osteoprotegerin Ligand) genannt wird (QUINN et al., 2000). RANKL bindet an den RANK Rezeptor der OsteoklastenVorläuferzellen und induziert so die weitere Osteoklastogenese (TSUKII et al., 1998). 
Wie bei der Isolierung bzw. Anreicherung von Monozyten wurden auch bei der Differenzierung mehrere Vorversuche durchgeführt, um die bestmögliche Methode für eine hohe Osteoklastenausbeute zu ermitteln.

Entsprechend den Studien von TAKAYANAGI et al.,1997, wurde nach der 1. Methode die Osteoklastenbildung durch Koinkubation der Monozyten/Lymphozyten-Fraktion im Verhältnis 200:1 mit synovialen Fibroblasten und unter Einfluss von $10^{-7} \mathrm{M}$ 1,25-Dihydroxyvitamin $\mathrm{D}_{3}$ und $2 \mathrm{ng} / \mathrm{ml}$ M-CSF in DMEM-Medium in den Vorläuferzellkulturen angeregt (s. 2.3.5). 1,25-Dihydroxyvitamin $\mathrm{D}_{3}$ (Calciferol) ist einer der aktivsten Metabolite des Vitamin $\mathrm{D}_{3}$ und fördert die Fusion von OsteoklastenVorläuferzellen (KURIHARA et al., 1990). Auch ausdifferenzierte Osteoklasten exprimieren einen Vitamin $D_{3}$ Rezeptor (MENAA et al., 1997). M-CSF ist nicht nur essentiell in der frühen Entwicklungsphase der Osteoklasten, sondern wird außerdem bei ausdifferenzierten Osteoklasten zur Erhöhung der Motilität und zum Schutz vor Apoptose (FULLER et al., 1993) benötigt. Nach drei bis vier Wochen Inkubationsdauer unter den o.g. Bedingungen, waren lichtmikroskopisch vielkernige Riesenzellen in den Kulturen zu erkennen (Abbildung 1), die Charakteristika von Osteoklasten aufwiesen (s.u.).

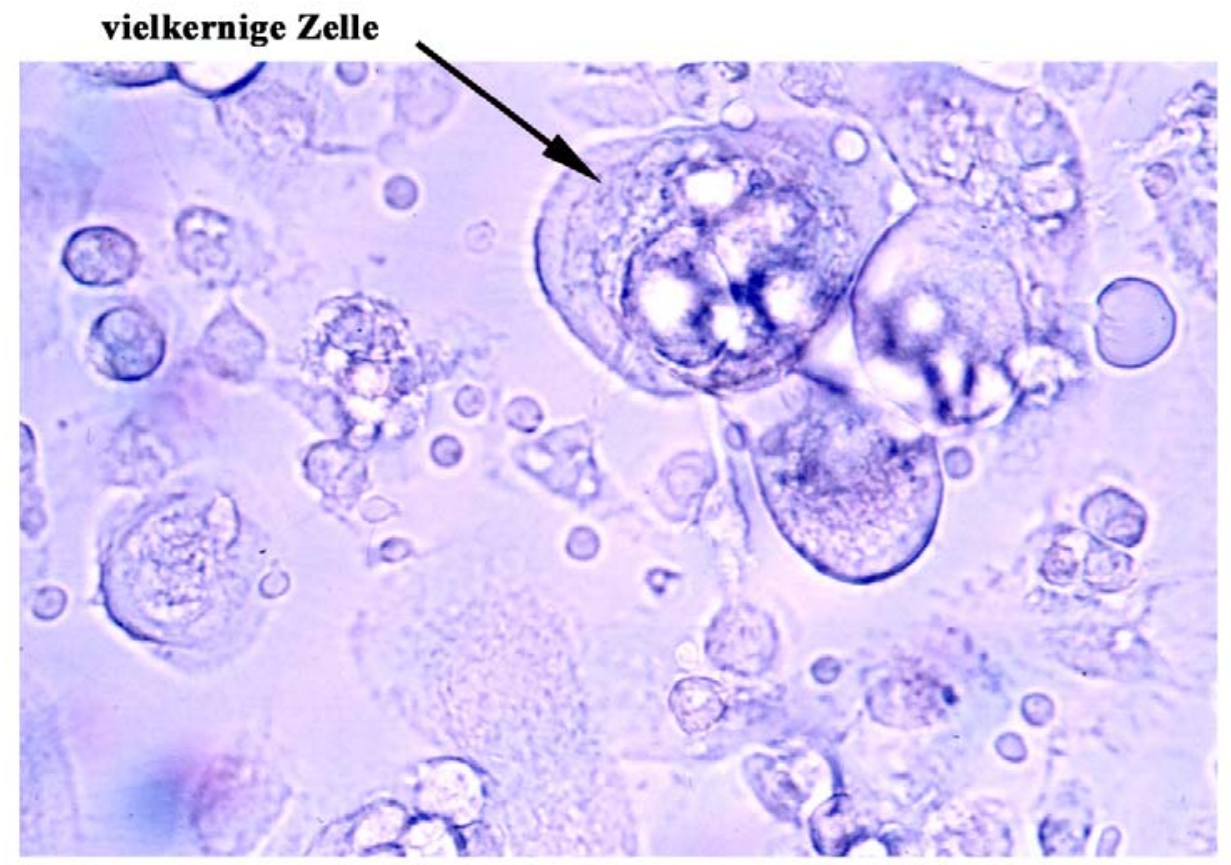

Abbildung 1: Lichtmikroskopische Aufnahme einer vielkernigen Zelle in einer Cokultur von Monozyten/Lymphozyten und synovialen RA Fibroblasten (x 400) 
Problematisch bei der Koinkubation von synovialen Fibroblasten und Monozyten war die hohe Proliferationsrate der Fibroblasten. Während der mehrwöchigen Dauer der Osteoklastendifferenzierung kam es zu einer unerwünscht starken Zunahme des Fibroblastenanteils in der Kokultur, so dass die Anzahl der sich entwickelnden Osteoklasten für die weiteren Experimente sehr gering war. Ein Ausweg bot schließlich der Einsatz des Differenzierungsfaktors RANKL, der erst nach Versuchsbeginn als rekombinantes Protein erhältlich war.

Bei der Durchführung der Vorversuche nach der 2. Methode wurde RANKL anfangs in einer Konzentration von $5 \mathrm{ng} / \mathrm{ml}$ zusammen mit $10^{-7} \mathrm{M}$ 1,25-Dihydroxyvitamin $\mathrm{D}_{3}$, $2 \mathrm{ng} / \mathrm{ml} \mathrm{M-CSF}$ und $10 \mathrm{ng} / \mathrm{ml}$ Interleukin 1 beta ((IL-1 E) eingesetzt. IL-1 E trägt nach MATAYOSHI et al., 1996, zu einer beschleunigten Osteoklastenbildung bei. Die Anzahl der Osteoklasten nach Ablauf von 4 Wochen war aber auch bei Anwendung dieser Methode noch nicht zufriedenstellend.

Ein sehr gutes Ergebnis hinsichtlich der Anzahl der ausdifferenzierten Zellen und der Differenzierungsdauer wurde, nach der 3. Methode, unter Einfluss von $50 \mathrm{ng} / \mathrm{ml}$ RANKL und 25 ng/ml M-CSF in MEM Alpha Medium (LADER et al., 2001) mit der Monozyten/Lymphozyten-Fraktion aus peripherem Vollblut erzielt (s. 2.3.5). Die multinukleären Zellen mit z. T. mehr als 10 Zellkernen wiesen weitere phänotypische Merkmale von Osteoklasten auf (s.u.).

RANKL bindet an seinen Rezeptor RANK (s. auch Ausführungen unter 3.2.2.1), der von Osteoklasten und deren Vorläuferzellen exprimiert wird, und induziert Differenzierungs-, Aktivierungs- und Überlebenssignale in Osteoklasten. In vivo wird der membranständige RANKL von Osteoblasten und stromalen Zellen unter Einfluss von 1,25-Dihydroxyvitamin $\mathrm{D}_{3}$, IL-11 und Parathormon sowie von T-Lymphozyten produziert. JIMI et al., 1999a, zeigten, dass die Zugabe einer löslichen Form des RANKL in Zellkulturen Osteoklastenvorläufer zur Fusion anregt, das Überleben von Osteoklasten fördert und die Zellen resorptiv aktiv werden läßt. Der Gegenspieler des RANKL ist das OPG (Osteoprotegerin), ein extrazelluläres TNF-Rezeptor verwandtes Protein, das sowohl in vivo als auch in vitro die Osteoklastendifferenzierung durch Bindung des RANKL blockiert (Yasuda et al., 1998). Abbildung 2 stellt diese Zusammenhänge in einer Erläuterungsgraphik schematisch dar. 


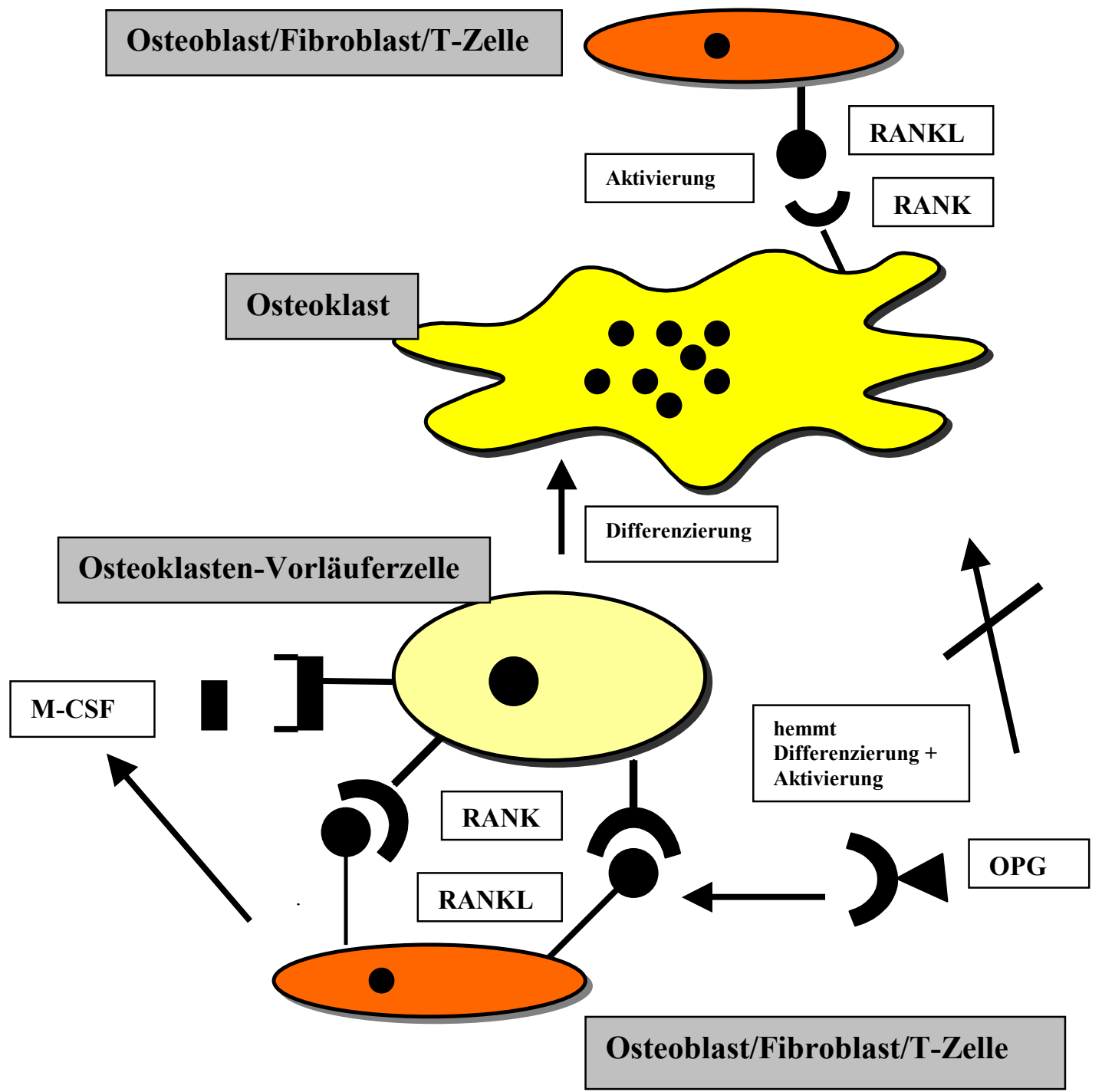

Abbildung 2: Erläuterungsgraphik zum Einfluss des RANKL - RANK - OPG Systems und des M-CSF auf Osteoklasten und deren Vorläuferzellen

Während der Vorversuche wurde jede der drei Methoden zur Osteoklastendifferenzierung fünfmal durchgeführt. Nach Ablauf der Inkubationszeit, Anreicherung der Zellen durch Inkubation in einer Pronase E/EDTA-Lösung (s. 2.3.6) und Bestimmung der Zellzahl wurden die drei Methoden miteinander verglichen. Die quantitativ besten Ergebnisse bei kürzester Inkubation wurden nach der 3. Methode erhalten. 
Unter Anwendung der RANKL induzierten Differenzierung ermöglichte die 3. Methode eine Osteoklastenbildung innerhalb von 2 Wochen, während bei den anderen beiden Methoden mindestens 3 Wochen benötigt wurden. Die Anzahl der ausdifferenzierten Zellen lag hierbei nach Anreicherung (s. 2.3.6) bei 5 bis $8 \times 10^{4}$ Zellen $/ \mathrm{ml}$. Mit der 1. Methode konnte gerade die Hälfte dieser Größenordnung erreicht werden. Auch bei Anwendung der 2. Methode war die Osteoklastenausbeute bei allen Vorversuchen geringer als bei der 3. Methode. Die Durchführung aller weiteren Experimente erfolgte daher mit Zellen, die nach 3. Methode zu Osteoklasten herandifferenziert und kultiviert wurden.

\subsection{Charakterisierung der Osteoklasten}

Da es keinen spezifischen Osteoklastenmarker gibt, ist zur Identifizierung der herandifferenzierten Zellen als Osteoklasten der Nachweis mehrerer Faktoren notwendig. Ein charakteristisches Merkmal der reifen Osteoklasten ist nach BARON et al., 1986, die Vielkernigkeit. Nach neuen Studien von CONNOR et al., 1995, wurden aber auch mononukleäre Osteoklasten gefunden, die Knochenmatrix resorbieren. Die in den Versuchen eingesetzten Zellen wurden regelmäßig sowohl lichtmikroskopisch als auch mit einer Hämatoxylin-Färbung bezüglich des Vorhandenseins mehrkerniger Zellen überprüft. Die Abbildung 3 zeigt ein Zytospinpräparat mit einer multinukleären Zelle.

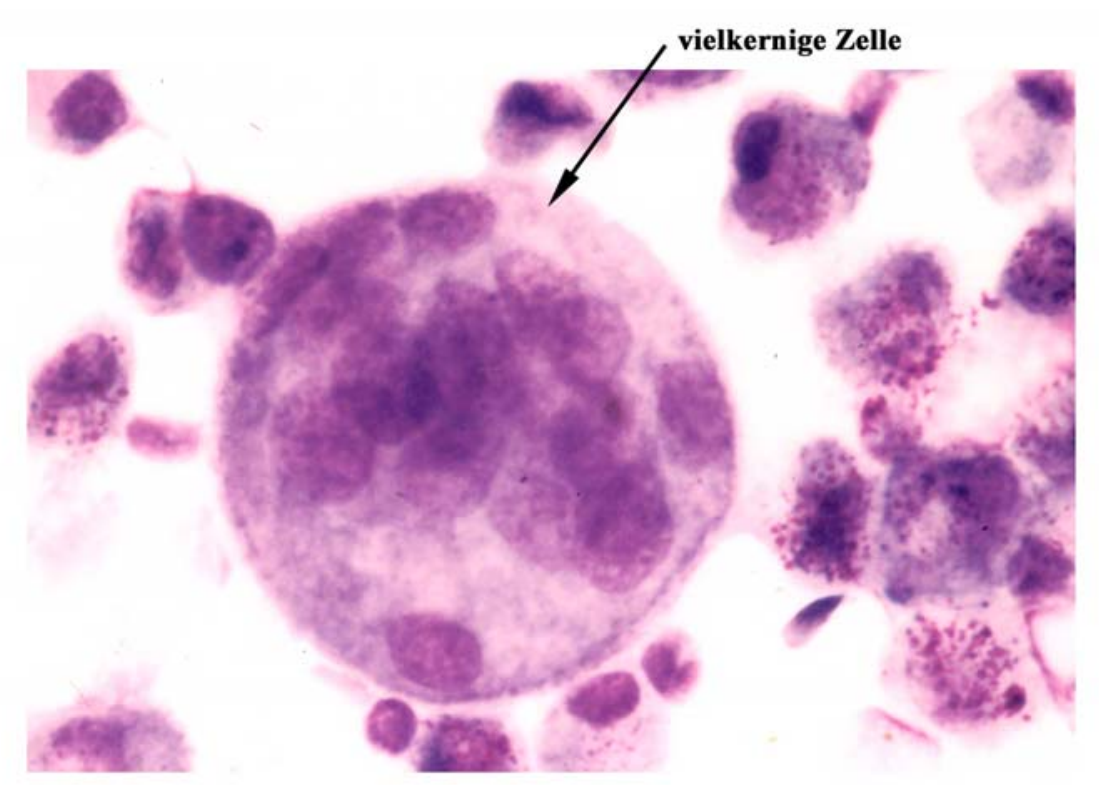

Abbildung 3: Lichtmikroskopische Aufnahme eines Zytospinpräparates mit einer vielkernigen Zelle, Hämatoxylin-Färbung (x 600) 
Nach ATHANASOU et al., 1996, wird weiterhin eine positive TRAP-Färbung (Tartratresistente saure Phosphatase), die Darstellung des Calcitoninrezeptors (CTR) und der Nachweis von Kathepsin K gefordert. Neuerdings ist außerdem der Rezeptor für den RANKL, der RANK, nachzuweisen (ROODMAN et al., 1999). Ein weiteres phänotypisches Merkmal ist die Expression des Vitronectinrezeptors (VNR) (HORTON et al, 1985).

Zum Nachweis der Osteoklastenmarker wurden in dieser Arbeit zytochemische Methoden für TRAP bzw. immunzytochemische Methoden für Kathepsin K, VNR und RANK angewandt. Hierzu wurden viermal während des Differenzierungszeitraums von 30 Tagen Zytospinpräparate von Zellen angefertigt (s. 2.5.1). Auf diese Weise konnte die Expression der TRAP, des Kathepsin K, des VNR und des RANK auf den herandifferenzierenden Zellen zeitlich verfolgt werden.

Die unter 3.1.1 dargelegten spenderabhängigen Unterschiede bei der Gewinnung von Osteoklasten wurden anhand einer TRAP-Färbung an Zellen von 4 verschiedenen SpenderInnen untersucht.

Für den CTR und zusätzlich für die anderen o.g. Osteoklastenmarker wurde der Nachweis über RT-PCR geführt. 


\subsubsection{TRAP-Färbung}

Humane saure Phoshatasen stellen eine Gruppe von 6 Isoenzymen (LAM et al., 1978) dar, wobei Isoenzym Typ 5 sich durch Resistenz gegenüber L(+)-Tartrat (LAU et al., 1992) von den anderen unterscheidet. Die TRAP ist ein Mannose-haltiges MetalloGlykoprotein (SAUNDERS et al., 1985), das als Zellmembrankomponente oder an intrazellulären Organellen von Osteoklasten, Leukozyten, alveolären und von Monozyten-abstammenden Makrophagen, Plazentazellen sowie Erythrozyten gefunden wurde. BULL et al., 1999, konnten außerdem TRAP-Aktivität in humanen embryonalen Lungenfibroblasten nachweisen. Die Freisetzung der TRAP unterliegt bei Osteoklasten hormoneller Steuerung und steht im Zusammenhang mit dem physiologischen Knochenumbauprozessen und dem Calciumhaushalt. Die TRAP stellt einen Marker für Osteoklasten-abhängige Knochenresorption dar, da bei pathologischen Prozessen, wie beispielsweise der Osteoporose, abnormal hohe TRAP-Serumkonzentrationen zu beobachten sind. Als alleiniger spezifischer Osteoklastenmarker kann die TRAP allerdings nicht angesehen werden.

Die TRAP wurde mittels zytochemischer Färbung mit einem kommerziellen Testsystem an Zytospinpräparaten nachgewiesen (s. 2.5.1 und 2.5.3). Die Gegenfärbung der Zellkerne wurde mit Hämatoxylin durchgeführt. Die TRAP konnte an mehrkernigen Riesenzellen aber auch an zahlreichen mononukleären Zellen anhand des kastanienbraunen Farbniederschlags gezeigt werden (Abbildungen 4 a - d).

\subsubsection{Vergleich verschiedener SpenderInnen mittels TRAP-Färbung}

Die spenderabhängigen Unterschiede (s. auch 3.1.1) wurden durch Vergleich von Osteoklasten, die aus peripherem Blut von vier SpenderInnen gebildet worden waren, untersucht (Abbildung 4 a - d). Die TRAP-Färbung wurde nach 4 Wochen Inkubationszeit durchgeführt. Die Unterschiede bezüglich der Anzahl und Intensiät der TRAP-positiven Zellen waren besonders deutlich beim Vergleich der SpenderInnen Sp3 und Sp4. Bei der Spenderin Sp3 waren 70 \% der Zellen TRAP-positiv und zeigten einen intensiven Farbniederschlag. Hingegen waren bei Spenderin Sp4 nur 10 \% der Zellen 
TRAP-positiv und weniger stark gefärbt. Bei Spender Sp1 waren deutlich mehr Zellen TRAP-positiv als bei Spender Sp2.
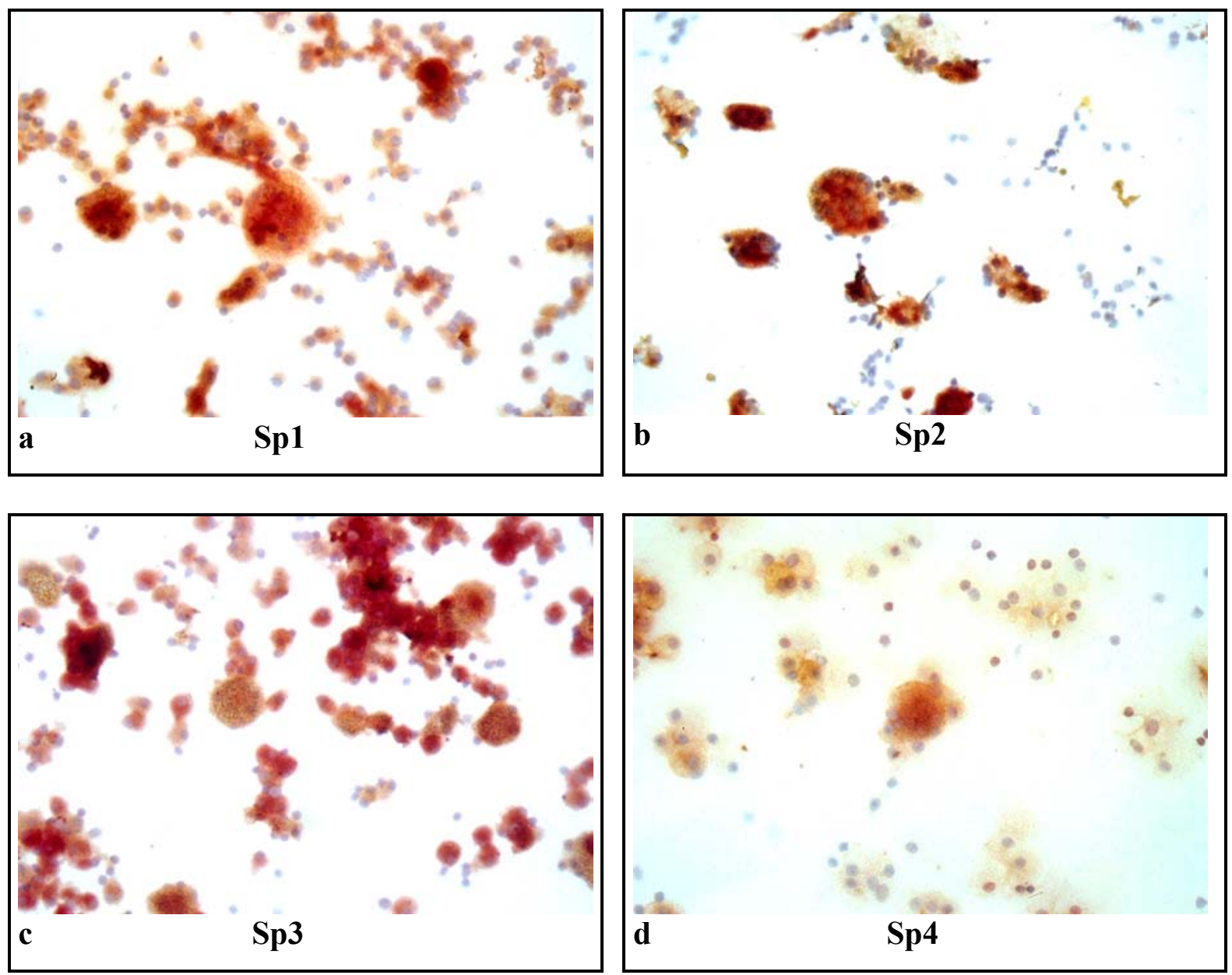

Abbildungen 4 a - d: Lichtmikroskopische Aufnahmen von Zytospinpräparaten mit TRAP-positiv gefärbten Zellen verschiedener SpenderInnen Sp1 bis Sp4 (x 100)

\subsubsection{Untersuchung verschiedener Differenzierungsstadien mittels TRAP-} Färbung

Die Zellen wurden am 3., 6., 9. und 30. Tag der Osteoklastendifferenzierung bezüglich der Expression der TRAP getestet (Abbildung $5 \mathrm{a}-\mathrm{d}$ ). Bereits nach 3 Tagen Inkubationszeit waren $30 \%$ der Zellen TRAP positiv. Die Anteil der positiven Zellen stieg bis zum 9. Tag auf $50 \%$. Am 30. Tag zeigten $70 \%$ der Zellen einen positiven, 
kastanienbraunen Farbniederschlag und viele dieser Zellen waren multinukleär. In allen Stadien der Differenzierung gab es einen Anteil kleiner, mononukleärer Zellen, die bezüglich der TRAP-Färbung negativ waren.
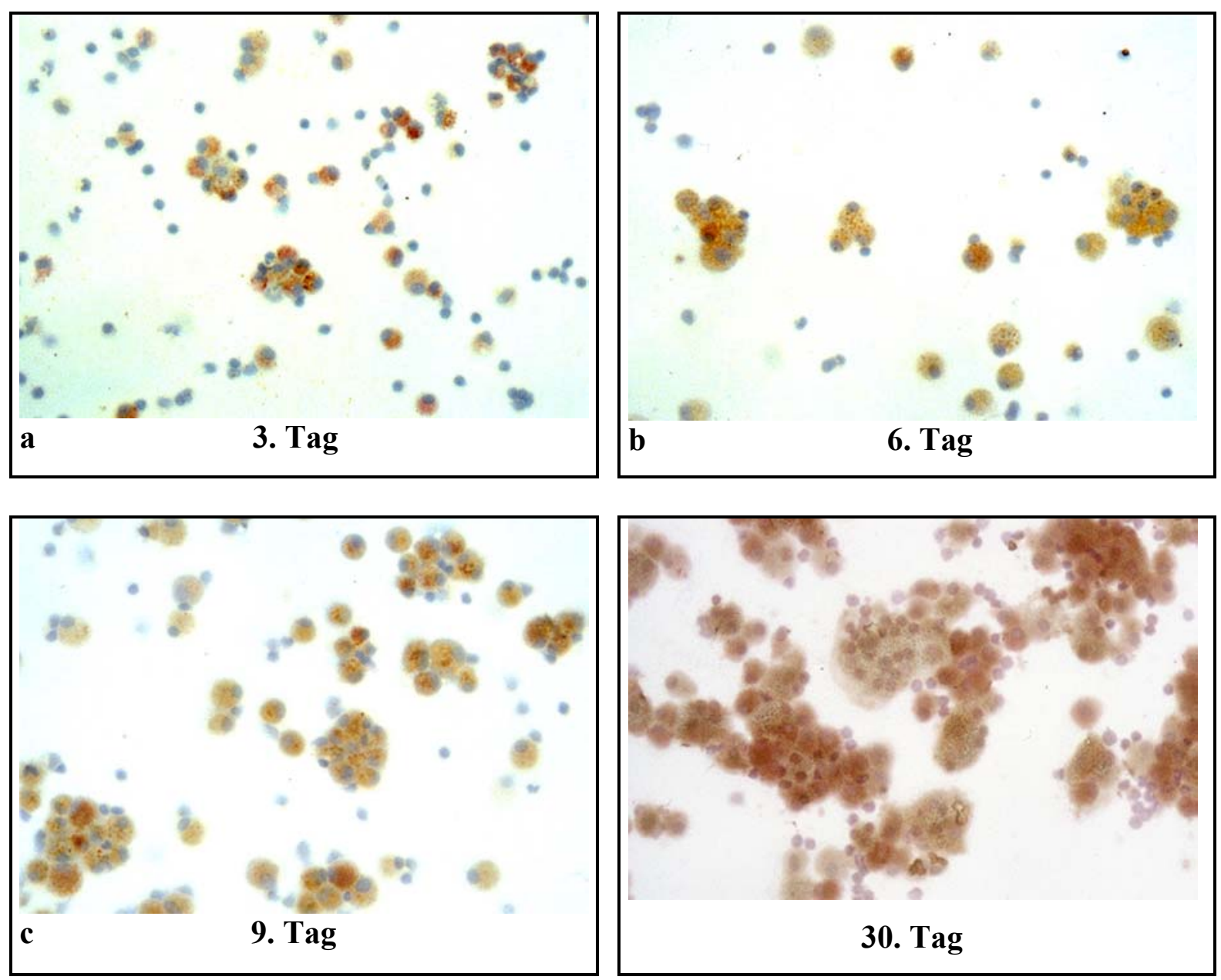

Abbildungen 5 a - d: Lichtmikroskopische Aufnahmen von Zytospinpräparaten mit TRAP-positiv gefärbten Zellen am 3., 6., 9. und 30. Tag der Osteoklastendifferenzierung (x 100) 


\subsubsection{Charakterisierung der Zellen mittels immunzytochemischer} Nachweisverfahren

\subsubsection{Nachweis des RANK auf Osteoklasten}

RANK ist ein membranständiger Rezeptor und gehört zur TNF-Rezeptor-Familie. Über diesen Rezeptor wird die Differenzierung von Vorläuferzellen zu Osteoklasten induziert. Die grundlegende Rolle des Rezeptors zeigte sich bei RANK-Knockout Mäusen, die aufgrund fehlender Osteoklasten eine schwere Osteopetrose entwickeln (LI et al., 2000).

Durch Bindung des RANKL an die extrazelluläre Domäne des RANK wird eine Signaltransduktion gestartet. Das zytoplasmatische Ende des Rezeptors interagiert mit den TNF-Rezeptor assoziierten Faktoren Typ 1 bis 6 (TRAF1 - 6). Diese Signalkaskade scheint über Aktivierung des Transkriptionsfaktors NFNB (DARNAY et al., 1998) an der Differenzierung von Osteoklasten beteiligt zu sein. Dabei überführen die von TRAF6-induzierte Signale die Zellen anscheinend in eine aktive Form, da Osteoklasten von TRAF6-Knockoutmäusen keine ,ruffled border“ ausgebilden und die Tiere ebenfalls eine Osteopetrose entwickeln (LOMEGA et al., 1999).

RANK ist nach Untersuchungen von LI et al., 2000, der einzige Osteoklasten-Rezeptor für RANKL. Seine Interaktionen kontrollieren die Osteoklastenbildung und damit indirekt die Knochenumbauprozesse und den Calciumhaushalt. Die Expression des RANK ist neben Osteoklasten auch für dendritische Zellen und mononukläre Phagozyten nachgewiesen (Anderson et al., 1997).

Der immunzytochemische Nachweis wurde mit einem polyklonalen Antikörper (s. 2.5.4.5) geführt und demonstrierte die Expression des RANK auf Osteoklasten und Osteoklasten-Vorläuferzellen. Die Gegenfärbung der Zellkerne erfolgte mit Hämatoxylin. Am 3. Tag der Differenzierung waren $35 \%$ der Zellen RANK-positiv. Der Anteil der Zellen, die den RANK exprimierten, stieg bis zum 6. Tag auf $45 \%$. Am 30. Tag waren $70 \%$ der Zellen RANK-positiv. 

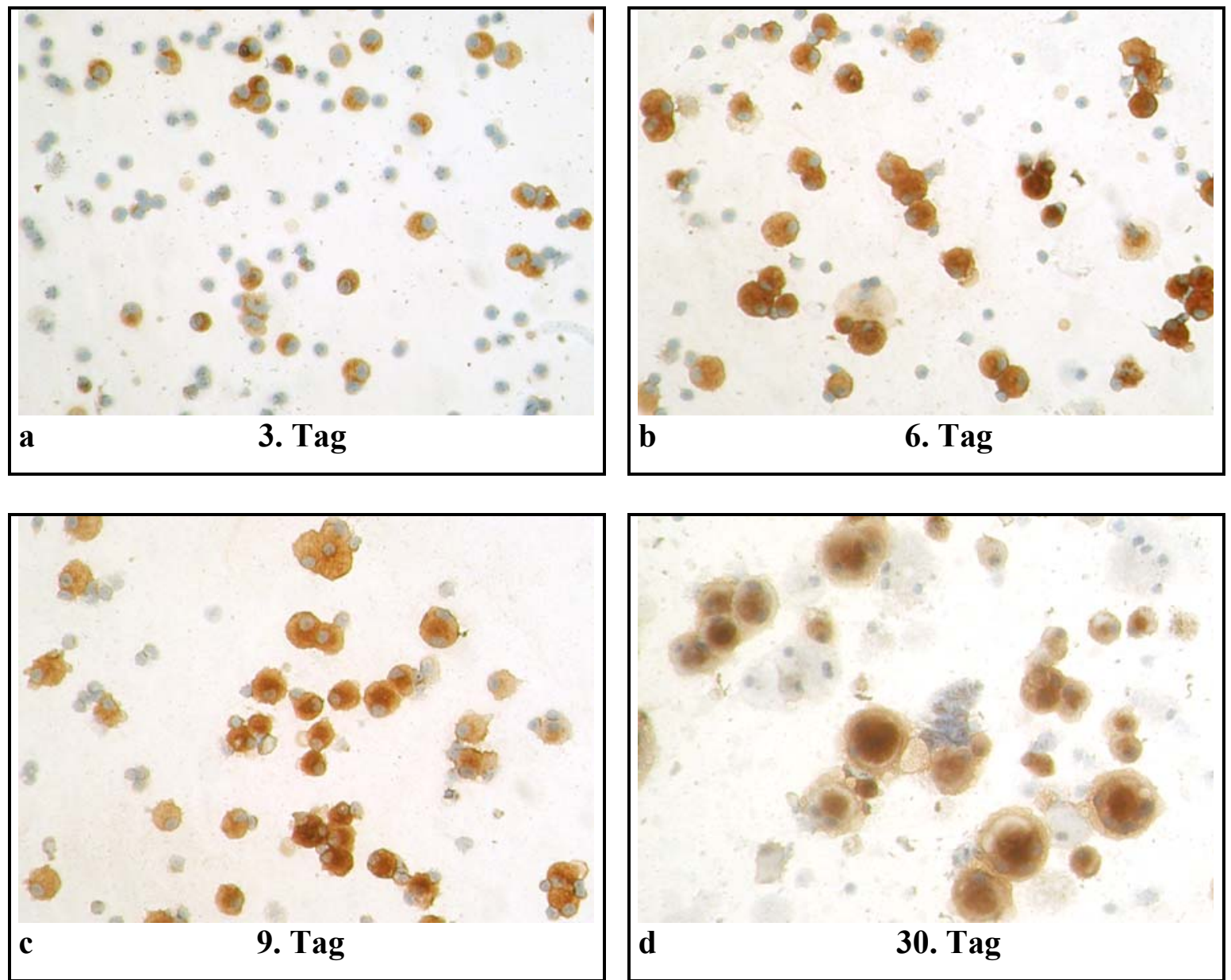

Abbildungen 6 a - d: Lichtmikroskopische Aufnahmen von Zytospinpräparaten mit RANK-positiv gefärbten Zellen am 3., 6., 9. und 30. Tag der Osteoklastendifferenzierung (x100)

\subsubsection{Nachweis des Vitronectinrezeptors}

Der Vitronectinrezeptor alpha $\mathrm{v}$ beta 3 (VNR) wird nur von wenigen Zelltypen exprimiert. $\mathrm{Zu}$ ihnen gehören Osteoklasten, die in vivo die höchste Expression dieses Rezeptors zeigen (DUONG et al., 1998). Niedrigere Level des VNR wurden in Megakaryozyten sowie in Zellen aus dem Endothel, dem Nierengewebe und der Plazenta gefunden. SINGER et al., 1988, lokalisierten den VNR, zusammen mit dem Fibronectinrezeptor, an der dem Substrat zugewandten Membran von GingivaFibroblasten und Melanomzellen. Wie der RANK spielt auch der VNR bei der Regulation der Knochenresorption eine wichtige Rolle. Durch Bindung von Proteinen 
mit einer Argenin-Glycin-Asparagin Aminosäuresequenz wie Vitronectin, Osteopontin oder das Bone Sialoprotein an den Rezeptor wird die Knochenresorption in vivo und in vitro inhibiert.

Der VNR gehört zur Rezeptor-Familie der Integrine. Diese Proteinkomplexe sind heterodimere, membranständige Glykoproteine. Integrine vermitteln und kontrollieren Wechselwirkungen der Zellen untereinander und mit ihrer Umgebung. Auch Adhäsionseigenschaften der Zellen werden den Integrinen zugeordnet. Einige Studien zeigten, dass über den VNR auch initiale Adhäsionsprozesse von Osteoklasten, wie Ausbreitung der Zelle und Umstrukturierung des Actins, gesteuert werden (NAKAMURA et al., 1996). Außerdem wird angenommen, das der VNR an der zur Fusion notwendigen Wanderung von Vorläuferzellen während der Differenzierung beteiligt ist (DUONG et al., 1998).

Die Expression des VNR auf den Osteoklasten und den Vorläuferzellen wurde immunzytochemisch mit dem Antikörper 23C5 (HORTON, M.A., 1990) nachgewiesen. Die Zellkerne wurden mit Hämatoxylin gegengefärbt. Abbildungen $7 \mathrm{a}-\mathrm{d}$ zeigen die VNR-Expression während verschiedener Differenzierungsstadien. Nach 3 Tagen Inkubationszeit waren $5 \%$ der Zellen VNR-positiv. Am 6. Tag waren bereits $20 \%$ der Zellen positiv. Während der Differenzierungsdauer stieg die Anteil der VNR-positiven Zellen weiter und betrug nach 30 Tagen 70 \%. Sowohl mehrkernige Riesenzellen als auch mononukleäre Zellen wurden positiv gefärbt. Bei allen Differenzierungsstadien gab es einige kleine, mononukleäre Zellen, die VNR-negativ waren. 

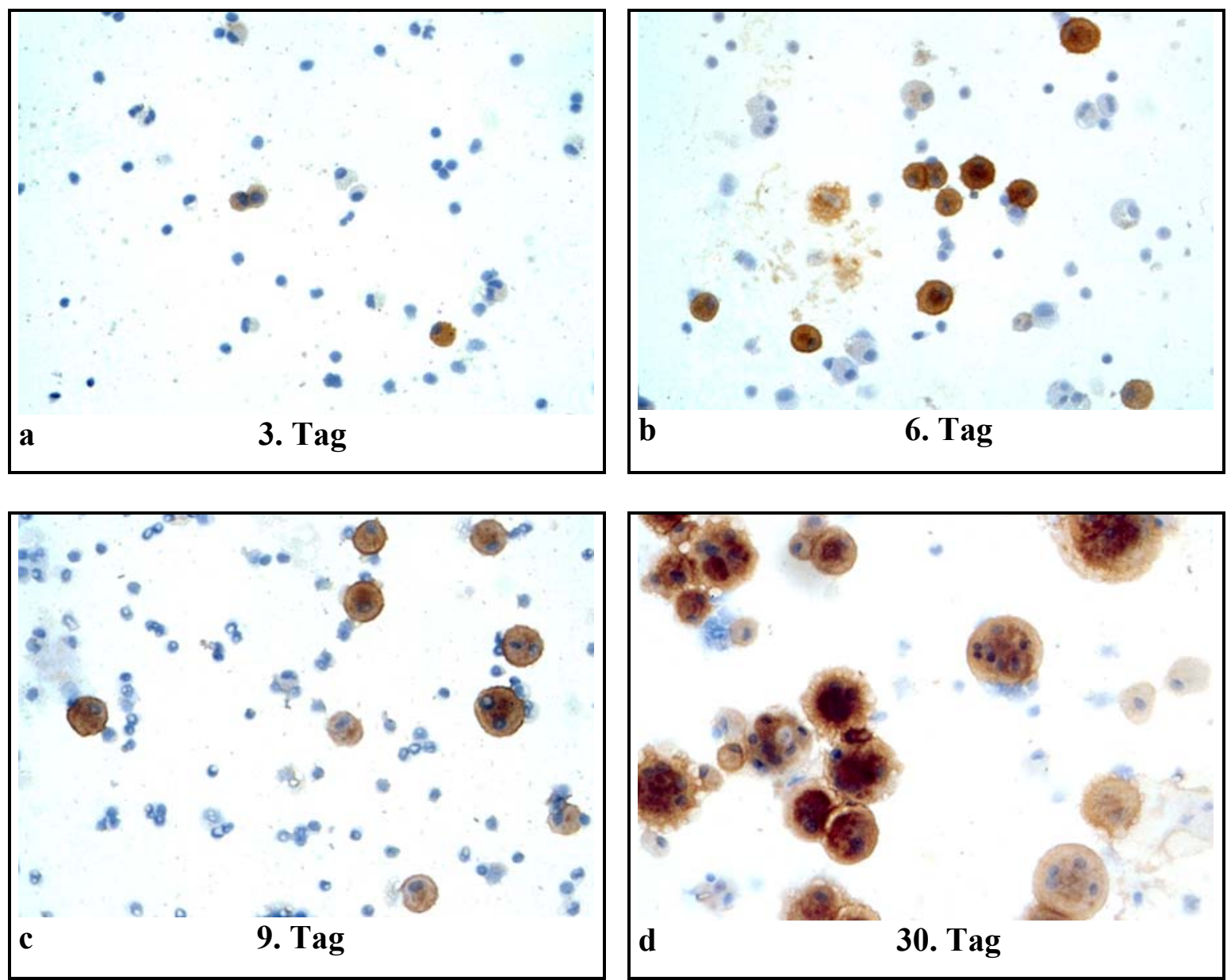

Abbildungen 7 a - d: Lichtmikroskopische Aufnahmen von Zytospinpräparaten mit VNR-positiv gefärbten Zellen am 3., 6., 9. und 30. Tag der Osteoklastendifferenzierung (x100)

\subsubsection{Nachweis des Kathepsin $K$}

Die Degradation des organischen Knochenanteils erfolgt unter Einfluss von MatrixMetalloproteinasen (MMP) und Zysteinproteasen, zu denen die Kathepsine K, B und L gehören. Kathepsin $\mathrm{K}$ ist unter streng regulierten Bedingungen das Schlüsselenzym im Knochenabbau beim physiologischen Knochenstoffwechsel. Die Expression und Aktivität von Kathepsin L, wurde erst bei stimulierter Knochenresorption gesteigert, wie die Experimente von FURUYAMA et al., 2000, zeigten. Hingegen konnte die Synthese und Sekretion von Kathepsin B in diesen Versuchen nicht beeinflusst werden.

Die Kathepsine gelangen nach Untersuchungen von BLAIR et al., 1988, möglicherweise über einen Mannose-6-phoshat-Rezeptor (M6PR), der an der „ruffled 
border" von Osteoklasten exprimiert wird, in den Extrazellulärraum. Kathepsin K baut Kollagen Typ I ab und zeigt sowohl bei saurem $\mathrm{pH}$ als auch unter neutralen Bedingungen Aktivität.

Im Gegensatz zu den vorab beschriebenen Osteoklastenmarkern wurde Kathepsin K erst ab dem 9. Tag auf den Vorläuferzellen exprimiert, wie der immunzytochemische Nachweis mit einem polyklonalen Antikörper gegen Kathepsin K an Zytospinpräparaten zeigte (Abbildung $8 \mathrm{a}-\mathrm{d}$ ). Die Zellkerne wurden mit Hämatoxylin gegengefärbt. Am 3. und 6. Tag waren alle Zellen Kathepsin K-negativ. Erst am 9. Tag zeigten $40 \%$ der Zellen einen positiv Farbniederschlag. Die Anteil der Kathepsin Kpositiven Zellen stieg bis zum 30. Tag bis auf $70 \%$. Darunter waren sowohl mono- als auch multinukleäre Zellen.
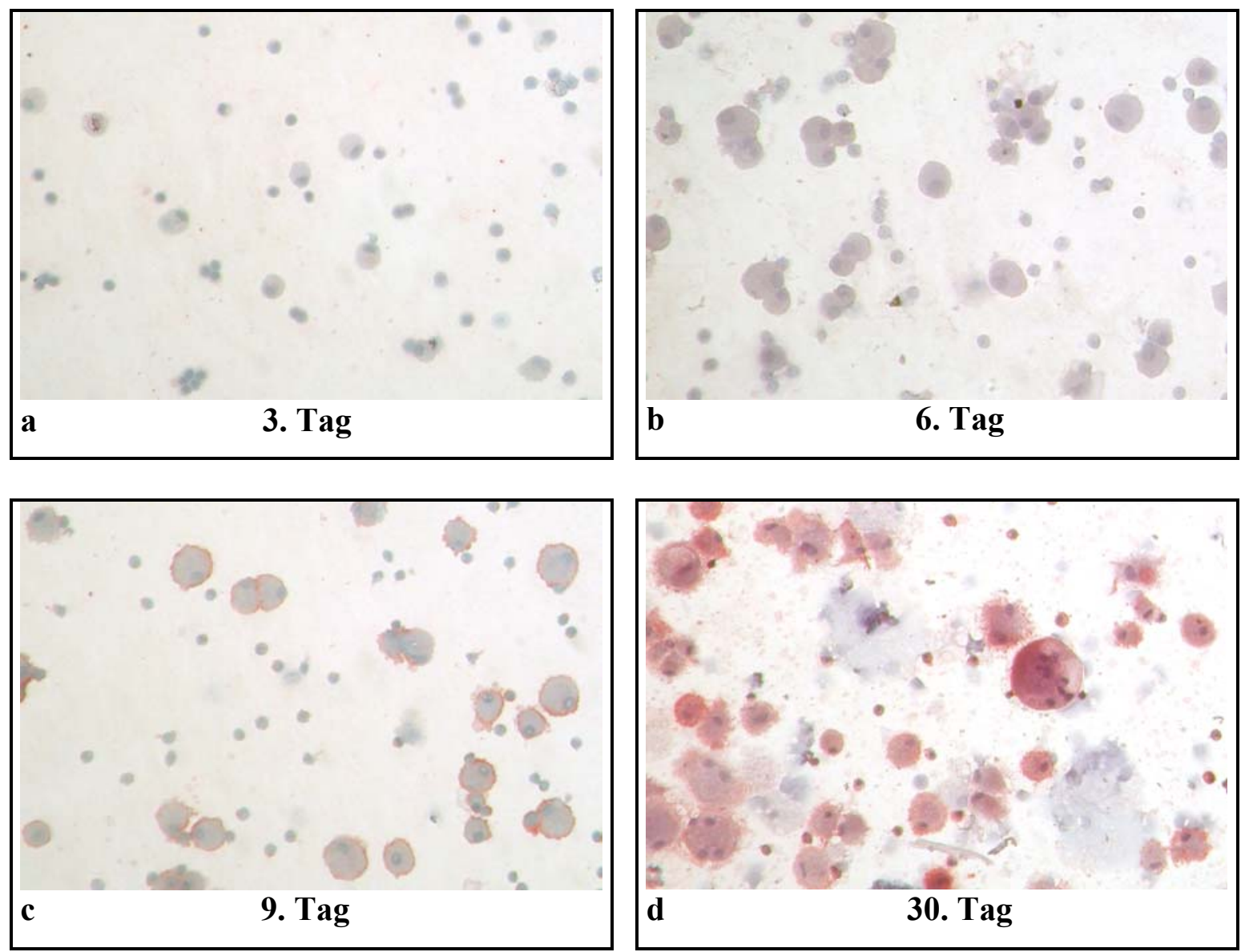

Abbildungen 8 a - d: Lichtmikroskopische Aufnahmen von Zytospinpräparaten mit Kathepsin K-positiv gefärbten Zellen am 3., 6., 9. und 30. Tag der Osteoklastendifferenzierung (x100) 


\subsubsection{Nachweis von Osteoklastenmarkern mitttels RT-PCR}

Eine spezielle Variante der PCR-Technik, die RT-PCR, ermöglicht es, die Aktivität bestimmter Gene auf der Ebene der messanger-RNA zu bestimmen. Dabei wird zuerst die aus den Zellen gewonnene mRNA mit dem Enzym reverse Transkriptase in DNA umgeschrieben. In einem zweiten Schritt werden dann definierte DNA-Bereiche der Zielgene amplifiziert.

In dieser Arbeit wurde mit der RT-PCR die mRNA Expression der TRAP, des RANK, des VNR, des CTR und des Kathepsin $\mathrm{K}$ in humanen Osteoklasten nachgewiesen. Für die TRAP, den RANK, den VNR und das Kathepsin K erfolgte der Nachweis zusätzlich zytochemisch (s. 3.2.1) bzw. immunzytochemisch (s. 3.2.2). Hierbei wurde der CTR nicht berücksichtigt, da der Nachweis bislang nur mit radioaktiv markierten Lachscalcitonin möglich ist.

Der CTR wird, innerhalb der Gruppe myeloischer Zellen, nur von Osteoklasten und deren Vorläuferzellen exprimiert (LEE et al, 1995). Außerhalb dieser Gruppe wurde CTR Expression u.a. in Zellen gefunden, die zum zentralen Nervensystem und zum Thymus gehören, in renalen Epithelzellen und auch in Krebszelllinien, wobei Funktion des Rezeptors häufig nicht geklärt ist (GOLDRING et al., 1996). Über die Bindung des Peptidhormons Calcitonin an den CTR der Osteoklasten wird die Knochenresorption inhibiert. Wie bereits für die anderen Osteoklastenmarker unter 3.2 erläutert, ist auch der CTR kein Osteoklasten-spezifischer Faktor. Über den Nachweis des CTR können Osteoklasten von aktivierten, TRAP und VNR positiven Makrophagen abgegrenzt werden (QUINN et al., 1999).

Die Isolation der Gesamt-RNA erfolgte aus Osteoklasten nach 14tägiger Differenzierung. Nach reverser Transkription wurden die gesuchten cDNA-Bereiche mittels PCR unter Standardbedingungen amplifiziert. Die Primer zum Nachweis des CTR (KULIWABA et al., 2000), des RANK (ATKINS et al., 2000), des Kathepsin K (INAOKA et al., 1995)) und der TRAP (ATKINS et al., 2000) wurden Literaturangaben entnommen. Die Konstruktion der VNR-Primer erfolgte anhand der bekannten Gensequenz. Als Positivkontrolle wurde E-Actin Primer verwendet. Die verwendeten Primer, deren Position in der Gensequenz, die Amplifikatgröße sowie die jeweilige Anlagerungstemperatur $\mathrm{T}_{\mathrm{m}}$ sind in Tabelle 5 aufgelistet: 
Tabelle 5: Oligonukleotide zur Osteoklastencharakterisierung

\begin{tabular}{|c|c|c|c|}
\hline Bezeichnung & Primersequenz & $\begin{array}{l}\text { Größe des } \\
\text { Amplifikats }\end{array}$ & $\mathbf{T}_{\mathbf{m}}$ \\
\hline TRAP & $\begin{array}{l}\text { fw: } 5^{\prime}-\text { ctg get gat ggt gec acc cct }-3^{\prime} \\
\text { rv }: 5^{\prime}-\text { ctc tca ggc tgc tgg ctg agg }-3^{\prime}\end{array}$ & $469 \mathrm{bp}$ & $58^{\circ} \mathrm{C}$ \\
\hline CTR & $\begin{array}{l}\text { fw: } 5^{\prime}-\text { gca atg ctt tca ctc ctg aga aa }-3^{\prime} \\
\text { rv : } 5^{\prime}-\text { agt gca tca cgt aat cat ata }-3^{\prime}\end{array}$ & $782 \mathrm{bp}$ & $58^{\circ} \mathrm{C}$ \\
\hline Kathepsin K & $\begin{array}{c}\text { fw: } 5^{\prime}-\text { ggc caa ctc aag aag aaa ac }-3^{\prime} \\
\text { rv : } 5^{\prime}-\text { gtg ctt gtt tcc ctt ctg g }-3^{\prime}\end{array}$ & $450 \mathrm{bp}$ & $58^{\circ} \mathrm{C}$ \\
\hline RANK & $\begin{array}{l}\text { fw: } 5^{\prime}-\text { cct acg cac aag gcg aag atg }-3^{\prime} \\
\text { rv }: 5^{\prime}-\text { cgt aga cca cga tga tgt } \operatorname{cgc} c-3^{\prime}\end{array}$ & $704 \mathrm{bp}$ & $60^{\circ} \mathrm{C}$ \\
\hline VNR & $\begin{array}{l}\text { fw: } 5^{\prime}-\text { tca cca act cca cat tgg } t t-3^{\prime} \\
\text { rv: } 5^{\prime}-\text { cca ttt tca tga ggt tga agc }-3,\end{array}$ & $213 \mathrm{bp}$ & $55^{\circ} \mathrm{C}$ \\
\hline E-Actin & $\begin{array}{c}\text { fw: } 5^{\prime}-\text { gtg ggg cgc agg cac ca }-3^{\prime} \\
\text { rv: } 5^{\prime}-\text { ctc ctt att gtc acg cac gat ttc }-3\end{array}$ & $370 \mathrm{bp}$ & $60^{\circ} \mathrm{C}$ \\
\hline
\end{tabular}

Die oben aufgeführten Oligonukleotid-Paare ergaben bei Amplifikation mit der Osteoklasten cDNA Fragmente, die mit der erwarteten Größe übereinstimmten. Die E-Actin Kontrolle war positiv.

Die Analyse der Reaktionsprodukte auf einem Agarosegel mit EthidiumbromidFärbung ist in Abbildung $9 \mathrm{a}-\mathrm{c}$ dargestellt. 


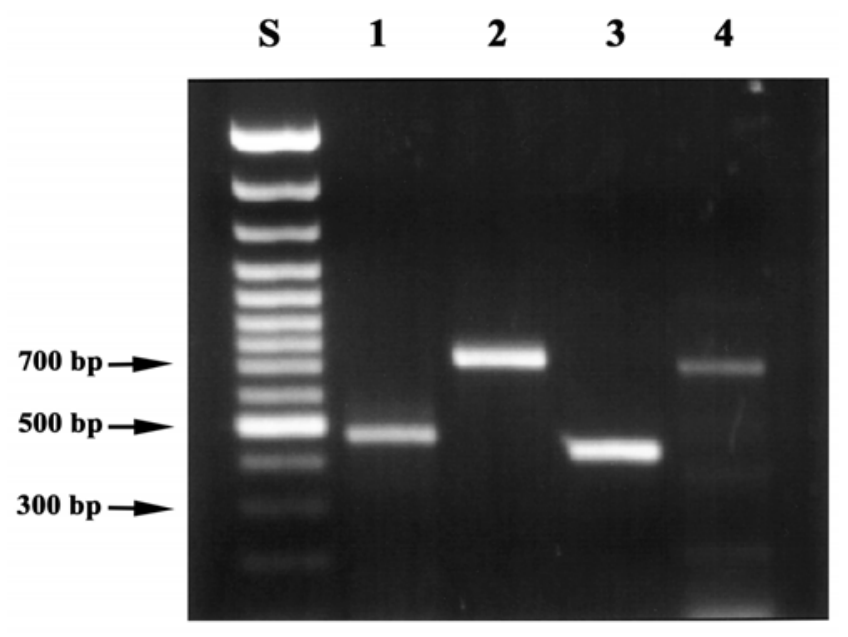

$\mathbf{a}$

Abbildungen 9 a: Analyse des RT-PCR-Ansatzes mit Produkten aus Osteoklasten RNA und spezifischen Primern für

$\begin{array}{lll} & \text { Spur 1: TRAP, } & 469 \mathrm{bp} \\ & \text { Spur 2: CTR, } & 782 \mathrm{bp} \\ & \text { Spur 3: Kathepsin K, } & 450 \mathrm{bp} \\ & \text { Spur 4: RANK, } & 704 \mathrm{bp} \\ \text { 9 b: } & \text { Spur 1: VNR, } & 213 \mathrm{bp}\end{array}$

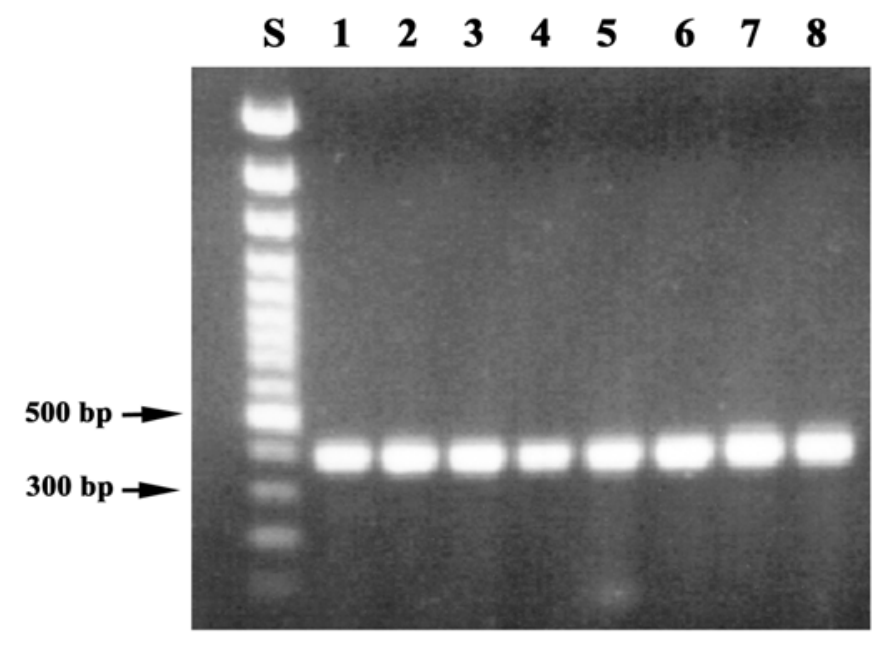

Abbildung 9 c: Analyse des RT-PCR-Ansatzes mit E-Actin-Primern und Spur 1 bis 6: Produkte aus 6 x RA synovialen Fibroblasten RNA Spur 7 und 8: Produkte aus 2 x Osteoklasten RNA

Das PCR-Fragment aus der Reaktion mit Primerpaar VNR wurde aus dem Agarosegel extrahiert (s. 2.7.5), um eine Sequenzierung durchführen $\mathrm{zu}$ lassen, da diese Primersequenzen nicht Literaturangaben entnommen wurden. 


\subsubsection{Analyse der Sequenzdaten}

Das VNR-Reaktionsprodukt (s. 3.2.3) wurde von der Fa. SEQLAB, Göttingen, sequenziert, um das Fragment hinsichtlich der Basenabfolge mit der veröffentlichten Sequenz des VNR-Gens (Zugangsnummer: NM 002210) zu vergleichen. Bei einer Leseweite von 180 bp wurde eine Übereinstimmung der Sequenzdaten des Amplifikats mit der veröffentlichten VNR-Sequenz von $100 \%$ erzielt. Die Sequenzanalyse erfolgte mit dem Computerprogramm NCBI Blast 2 Sequences.

\subsubsection{Bildung von F-Actin-Ringen}

Actinfilamente treten in allen Zellen auf und spielen u.a. bei Bewegungsvorgängen und bei der Zellteilung eine wichtige Rolle. Außerdem haben sie in den Mikrovilli eine Funktion als Stützelemente des Zytoskeletts. Actinfilamente sind dynamische Strukturen, die laufend umorganisiert werden. Sie liegen unter der Zelloberfläche, sind in der Zellmembran verankert und zeigen eine strangartig strukturelle Anordnung.

Bei Adhäsion auf Plastik, Glas oder Dentin bilden Osteoklasten eine ringartige Struktur aus F-Actinfilamenten, die auf eine Polarisation der Zelle hindeuten (NAKAMURA et al., 1995). Es wird vermutet, dass sich dieses kontinuierliche Band aus F-Actinfilamenten um einen Substratbereich ausbildet (TOSHIKATA et al., 2001), in dem später eine Resorptionslakune entsteht.

Durch Bindung eines fluoreszierenden Farbstoffes, einem Rhodamin-konjugierten Phalloidin, kann das F-Actin sichtbar gemacht werden und imponiert bei Osteoklasten als sogenannter F-Actinring. Abbildung 10 zeigt rot gefärbte F-Actinringe von Osteoklasten, die über 4 Wochen in Plastikschalen herandifferenziert wurden. Die Ausbildung der Ringe wurde von LADER et al., 2000, als ein weiteres Merkmal zur Charakterisierung von Osteoklasten gewertet. Im Vergleich hierzu demonstriert Abbildung 11 die strangartige Actinfilamentverteilung an einem Fibroblasten unter gleichen Färbebedingungen. 


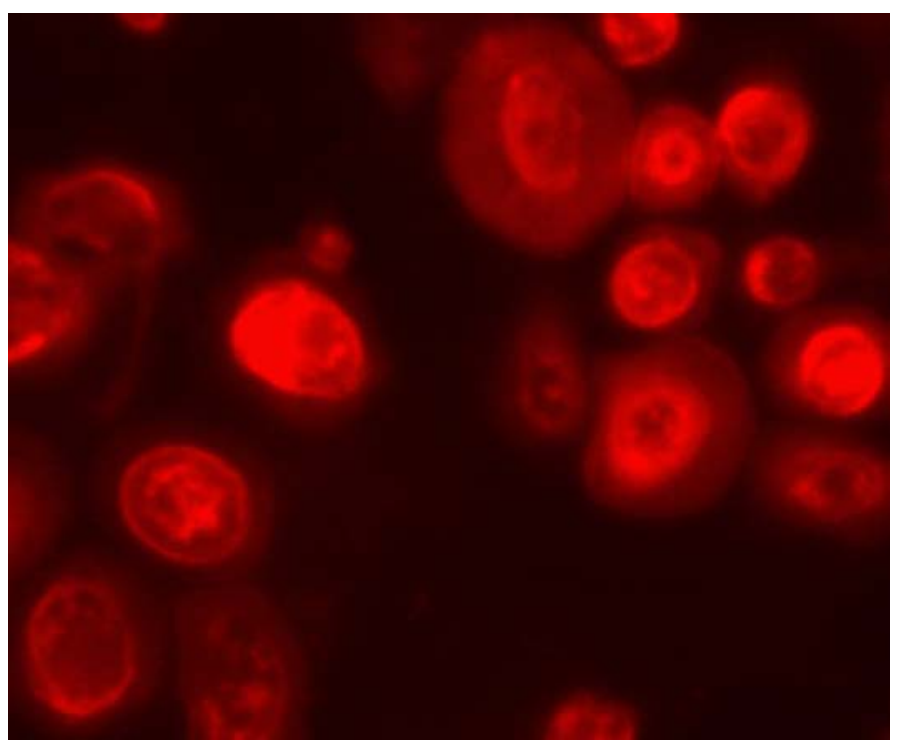

Abbildung 10: Fluoreszenz-Aufnahme des ringförmig angeordneten F-Actins in Osteoklasten, gefärbt mit Rhodamin-konjugierten Phalloidin (x 300)

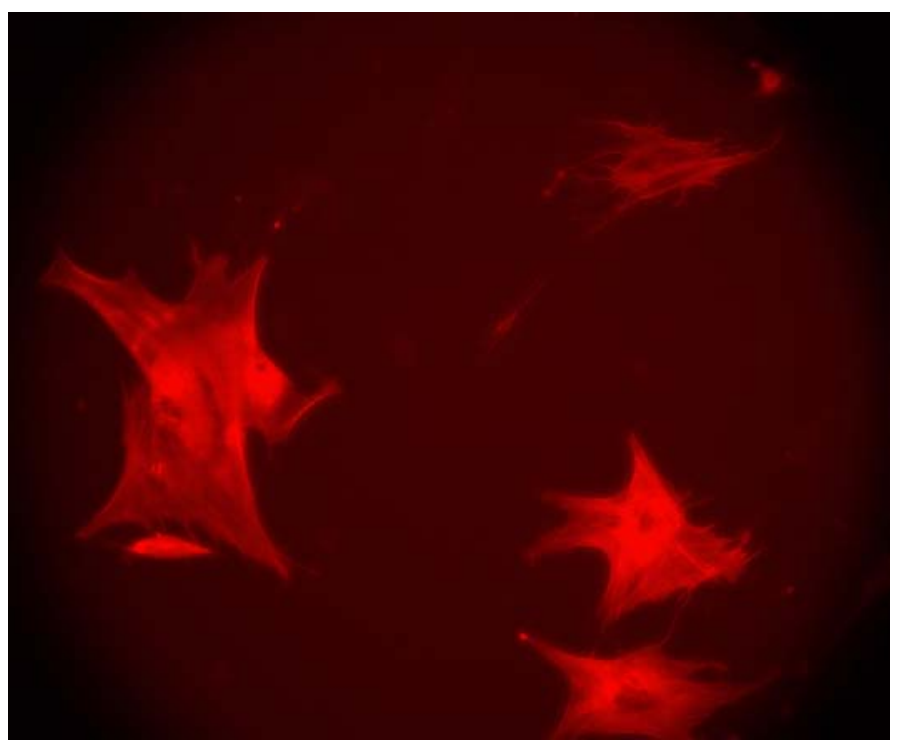

Abbildung 11: Fluoreszenz-Aufnahme des strangartig angeordneten F-Actins RA synovialer Fibroblasten, gefärbt mit Rhodamin-konjugierten Phalloidin (x 300) 


\subsection{Rasterelektronenmikroskopische Darstellung von Osteoklasten auf Dentin}

Die rasterelektronenmikroskopische Darstellung von Osteoklasten diente der Identifikation der Zellen und dem Nachweis ihrer resorptiven Aktivität. Hierzu wurde die Morphologie der Osteoklasten untersucht sowie Ausbreitungs- und Adhäsionsvorgänge der Zellen dargestellt. Eine Möglichkeit zum Aktivitätsnachweis ist die Beurteilung von Howship'schen Lakunen in einem in vitro System. Die Aushöhlung von Dentinoberflächen ist dabei ein Maß für die Aktivität der Zellen und kann rasterelektronenmikroskopisch gut beurteilt werden (BOYDE et al., 1984). Die Darstellung der bislang nicht im REM untersuchten, frühen Stadien der osteoklastären Resorption war für die vergleichenden Untersuchungen mit den aktivierten Fibroblasten notwendig.

\subsubsection{Etablierung des Dentin-Resorptionsassays}

Mit dem Dentin-Resorptionsassay wurde die funktionelle Aktiviät der herandifferenzierten Osteoklasten (s. 3.1) untersucht. Hierbei wurden die Zellen auf ein bestimmtes Substrat gesetzt und die resorptive Fähigkeit anhand der sich bildenden Lakunen nachgewiesen. In Vorversuchen wurden verschiedene Osteoklastenkulturen und unterschiedliche Dentinvarianten eingesetzt, um eine befriedigende Dichte morphologisch vitaler Zellen auf dem Substrat zu erhalten.

\subsubsection{Auswahl der Matrix für den Resorptionsassay}

Als Knochenersatz wurde in dem Zellkultursystem Dentin eingesetzt. Dentin eignet sich besser als Knochen für den Resorptionsassay, da Dentin eine relativ homogene Struktur aufweist (BOYDE et al., 1984). Außerdem ist bei der Verwendung von Knochen ist nicht auszuschließen, dass dieser bereits durch Osteoklasten verändert wurde. Für die hier verwendeten Bereiche des Dentins sind Abbauprozesse durch Osteoklasten nicht zu vermuten. Zu Beginn wurden Wildschweinhauer als Substrat getestet, die sich aber aufgrund ausgeprägter Zahnsteinablagerungen als völlig ungeeignet herausstellten. Die Oberfläche war durch diese Rückstände so uneben, dass Resorptionslakunen im Dentin kaum darstellbar waren. 
Als weiterer Knochenersatz wurden humane Weisheitszähne verwendet, die Patienten des Klinikums Göttingen entnommen wurden. Die Zähne wurden gleich nach der Entnahme in $\mathrm{H}_{2} \mathrm{O}_{\text {bidest }}$ gelegt und anschließend in $300-400 \mu \mathrm{m}$ dicke Scheiben geschnitten. Der Einsatz von humanen Weisheitszähnen war auch problematisch, da die Zähne nach dem Zusägen erhebliche Rückstände von Sägemehl aufwiesen. Mit einer Ultraschallreinigung konnten die Sägemehlspänne entfernt werden. Diese Behandlung wurde in den nachfolgenden Versuchen immer vorgeschaltet. Das gravierendste Problem bei der Verwendung des humanen Dentins stellte die bakterielle Kontamination der Zahnoberfläche dar. Hierdurch kam es regelmäßig zu bakterieller Überwucherung des Resorptionsassays. Nach Vorbehandlung der Zähne durch Desinfektion und Inkubation in einer hochkonzentrierten Antibiotikalösung, traten keine Kontaminationsprobleme mehr auf, aber die resorptive Aktivität der Zellen wurde durch diese Sterilisationsmethode negativ beeinflusst. Die Zellen adhärierten zwar gut auf dem Substrat, aber es wurden nur wenige resorptive Veränderungen im Dentin gefunden. Eine Dampfsterilisation mit Erhitzung der Zahnstücke auf $121{ }^{\circ} \mathrm{C}$ anstelle der Inkubation in einer hochkonzentrierten Antibiotikalösung wurde nicht angewandt, um die Struktur des Substrats nicht zu verändern.

Am besten eignete sich letztlich das Dentin eines Pottwals für den Resorptionsassay. Der Pottwalzahn, der uns freundlicherweise von Prof. Willmann, Abt. Zoologie und Anthropologie, Universität Göttingen, zur Verfügung gestellt wurde, hatte eine Länge von ca. $30 \mathrm{~cm}$. Um das Dentin in dem Zellkultursystem einsetzen zu können, wurde der Zahn mit einer diamantierten Säge quer durchgeschnitten und von einem Endstück $300-400 \mu \mathrm{m}$ dicke Scheiben abgesägt. In der Abbildung 12 a ist das Endstück des Pottwalzahns zu sehen, von dem die Scheiben abgeschnitten wurden. Im Querschnitt ist der Aufbau des Zahns dargestellt (Abbildung 12 b). Den äußeren Rand bildet das Elfenbein. Der innen gelegene Dentinzahn enthält den Zahnkeim sowie rudimentäre Kernzähne. Qualitative Elementanalysen ergaben, dass der anorganische Anteil des Zahns nur aus Kalziumphosphat und Schwefel besteht, die einzelnen Zahnregionen aber unterschiedliche Mengen dieser Elemente aufweisen (BEHRMANN, 2001). Die anorganische Phase des Dentinzahns eines Pottwals enthält nach diesen Analysen hauptsächlich Kalziumphosphat und nur wenig Schwefel. 

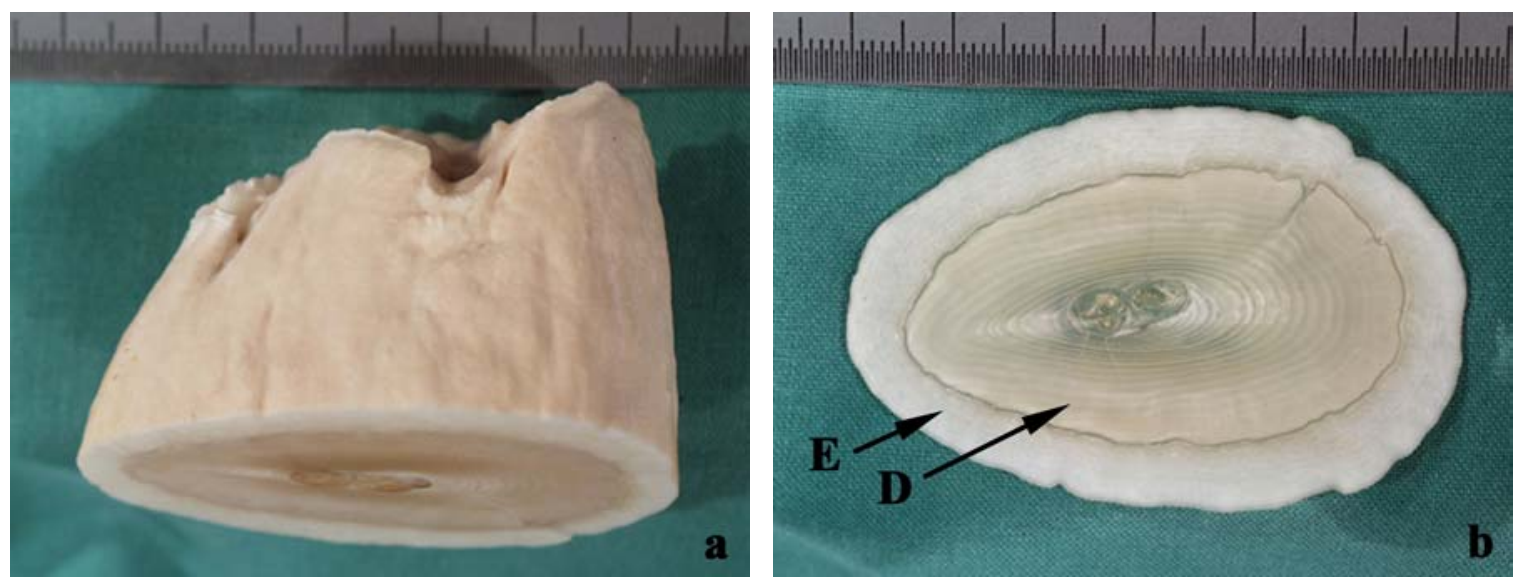

Abbildungen 12 a: Endstück eines Pottwalzahns

12 b: Dentinscheibe, äußerer Rand aus Elfenbein (E), der innere Bereich ist der Dentinzahn (D)

Um einen Einfluss der unterschiedlichen Zusammensetzung der Zahnregionen auf die Matrix-degradierenden Zellaktivitäten zu vermeiden, wurde in dem Resorptionsassay nur der Dentinzahn eingesetzt. Zur Entfernung der durch das Sägen entstandenen Riefen und zur Erzeugung einer möglichst glatten Oberfläche, wurden die Scheiben vorab mit einer Diamantpulverpaste und einem Hochgeschwindigkeitspoliergerät mit Filzaufsatz poliert. Anschließend wurden die Scheiben in $0,4 \times$ x 0,4 cm große Stücke gebrochen. Um die Rückstände des Poliermittels zu entfernen wurden die Dentinscheiben einer Ultraschallreinigung unterzogen und anschließend in den Zellkulturen eingesetzt. Abbildung 12 c zeigt die glatte Oberfläche der polierten Dentinstücke. Die Reste des durch das Sägen entstandenen Furchen sind nach der Politur nur noch als parallel verlaufende Linien mit einem Abstand von 1 - $2 \mu \mathrm{m}$ zu erkennen. Die in den Versuchen verwendeten Zellen adhärierten gut auf dem Dentin und waren resorptiv aktiv. Die rasterelektronenmikroskopische Untersuchungen ergaben, dass auch Veränderungen von einer Größe um $1 \mu \mathrm{m}$ im Pottwaldentin gut darstellbar waren. 


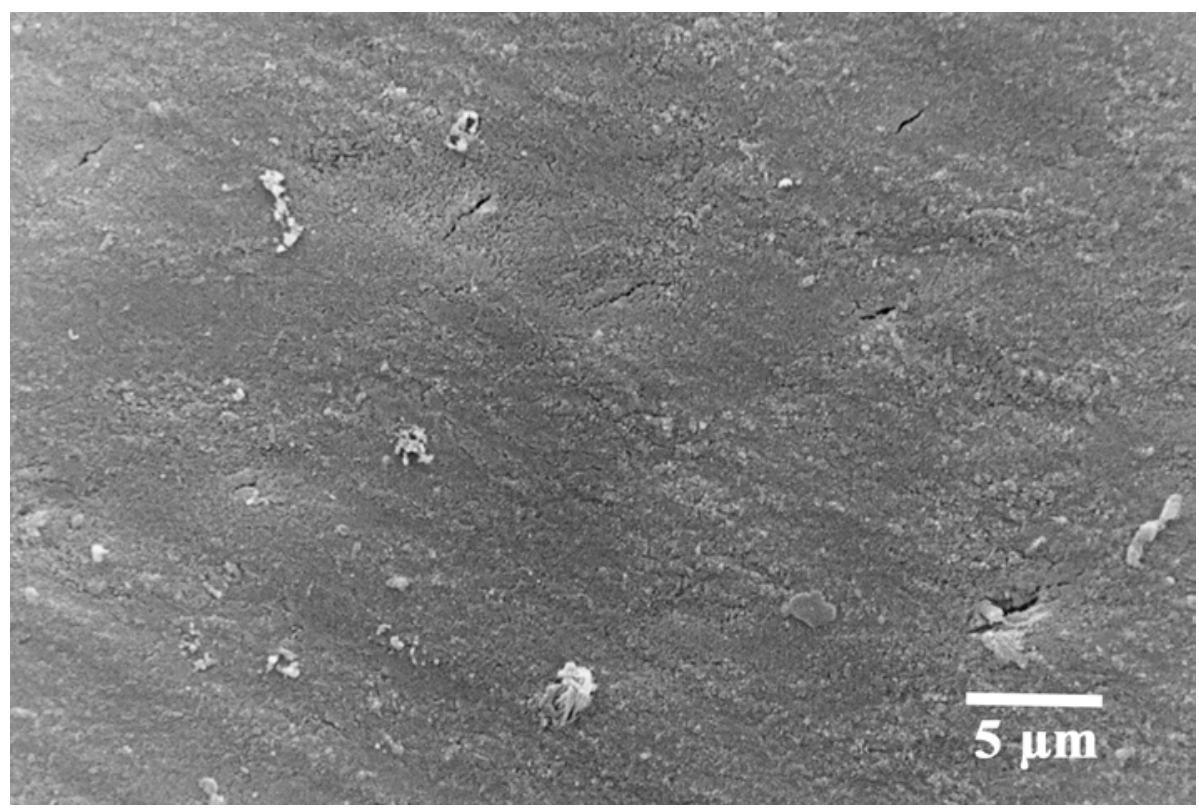

Abbildung 12 c: Dentinoberfläche, REM-Aufnahme

\subsubsection{Osteoklastenkulturen im Dentin-Resorptionsassay}

In den ersten Versuchen wurden Osteoklastenkulturen verwendet, die noch mit synovialen Fibroblasten koinkubiert wurden. Die Zellen wurden nach 4-wöchiger Differenzierungsdauer auf das Knochenersatzmaterial gesetzt. Aufgrund der unter 3.1.2 dargelegten hohen Proliferationsrate der Fibroblasten, konnte nur eine begrenzte Anzahl an Osteoklasten im Rahmen der Mischkultur in dem Resorptionsassay eingesetzt werden. Die Zellen adhärierten zwar gut auf dem Substrat, aber die zu geringe Zelldichte der Osteoklasten führte mutmaßlich dazu, dass diese Zellen keine Resorptionslakunen bildeten (AMLING et al., 2001).

Mit dem Einsatz des Differenzierungsfaktors RANKL in den Zellkulturen konnte auf eine Koinkubation mit synovialen Fibroblasten verzichtet werden (s. 3.1.2). Lichtmikroskopisch waren bereits nach 2-wöchiger Differenzierungsdauer viele multinukleäre Zellen $\mathrm{zu}$ sehen, die nach Anreicherung (s. 2.3.6) auf das Knochenersatzmaterial gesetzt wurden. Zur Ermittlung der Inkubationzeit auf dem Substrat, wurden die Zellen für unterschiedlich lange Perioden in dem Resorptionsassay kultiviert. Die optimale Inkubationsdauer zur Bildung typischer Resorptionslakunen betrug 2 Wochen. Frühe Stadien der Resorption waren bereits nach 3 Tagen Inkubation auf dem Dentin zu erkennen (s. 3.3.6). 


\subsubsection{Oberflächenmorphologie der Osteoklasten}

Bei der Betrachtung der rasterelektronenmikroskopischen Aufnahmen der Osteoklastenkulturen, die auf Pottwaldentin inkubiert wurden, sind zwei verschiedene Zelltypen zu erkennen (Abbildung 13). Zum einen gibt es rosettenförmige Zellen (Pfeil 1) mit einem Durchmesser von $10-20 \mu \mathrm{m}$, die teilweise schmale Zellausläufer (Pfeil 2) mit einer Länge von bis zu $50 \mu \mathrm{m}$ aufweisen. Vergleiche mit anderen REM Aufnahmen lassen vermuten, dass es sich bei diesen Zellen um dendritische Zellen handelt, die von der Monozytenreihe abstammen.

Des weiteren sind flache bis gewölbte, rundliche Zellen (Pfeile 3 u. 4) von 30 bis über $100 \mu \mathrm{m}$ Durchmesser zu erkennen, die aufgrund der Größe und der Bildung von Resorptionslakunen (Pfeil 5) als Osteoklasten identifiziert wurden. Die Zellen weichen zum Teil vom der rundlichen Form ab und zeigen lappenförmige Ausläufer (Pfeil 6) mit oder auch ohne breiten Steg (Pfeil 7). Die Oberseite dieser Zellen ist selten ganz glatt, wie es bei den ganz flach ausgestreckten Osteoklasten vorkommt. Meist weist die Oberseite eine zentrale Kuppel (Pfeil 4) mit vielen kleine Fortsätze und Lamellen.

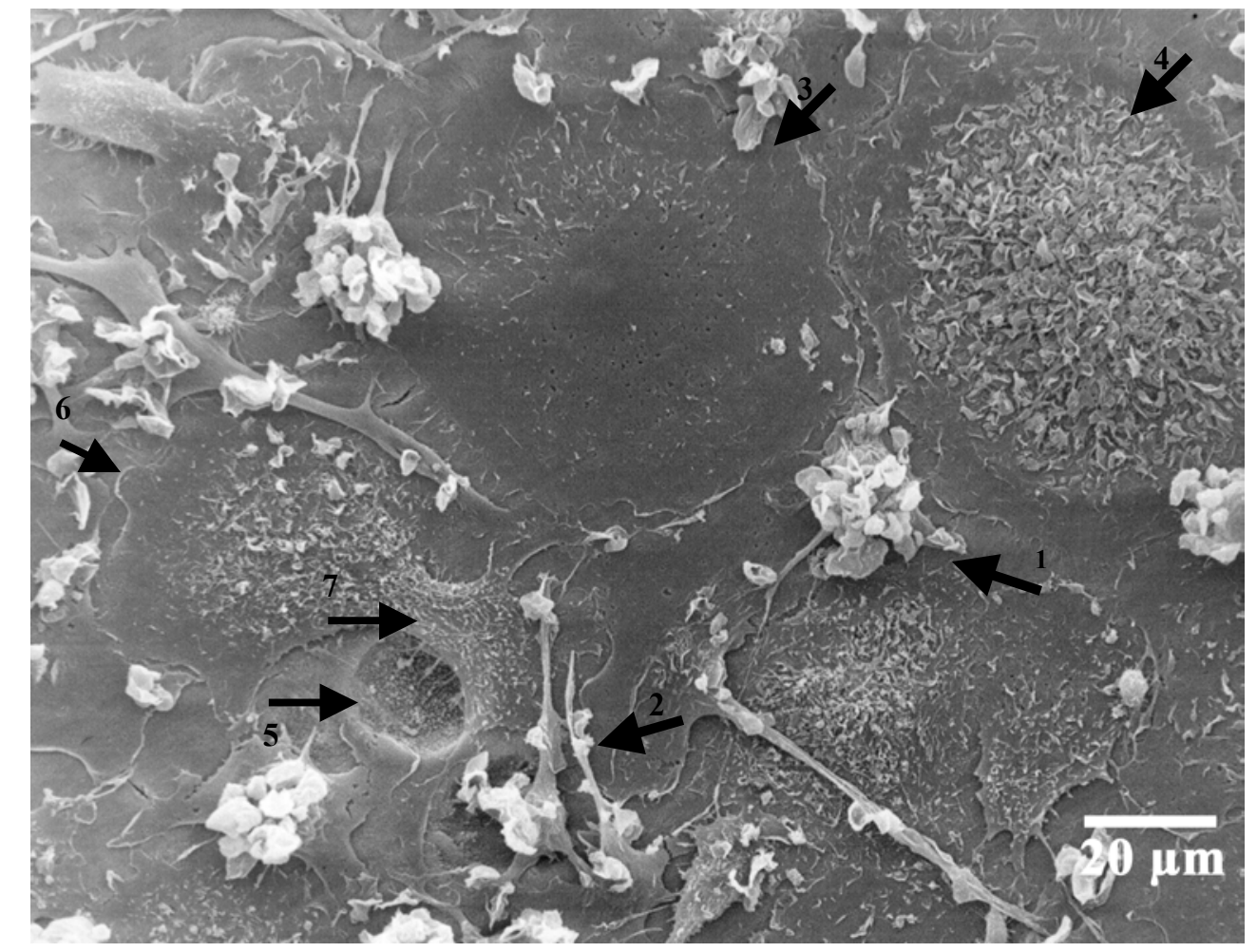

Abbildung 13: Humane Osteoklasten nach 14tägiger Inkubation auf Pottwaldentin, REM-Aufnahme 
Die Detailaufnahme in Abbildung 14 zeigt eine große Anzahl von Mikrovilli an der Membranoberseite des Osteoklasten, die der Oberflächenvergrößerung dienen.

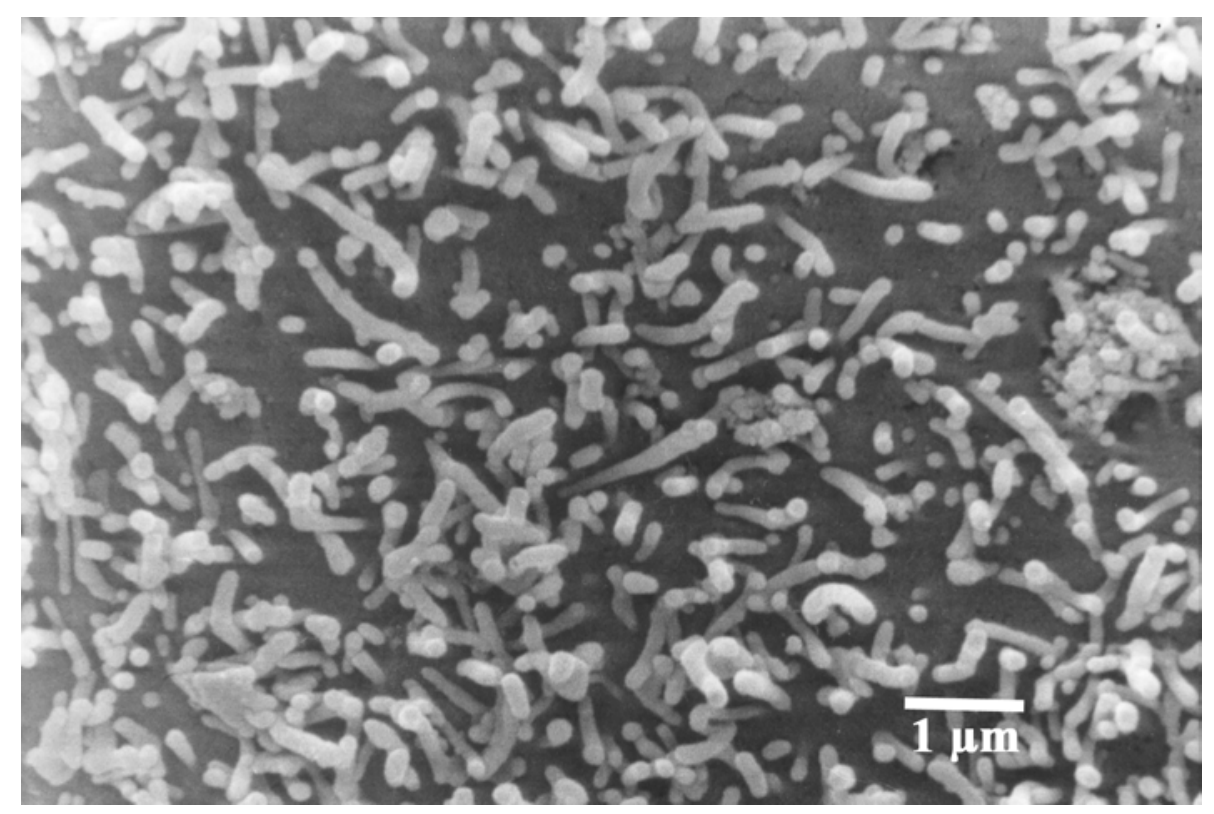

Abbildung 14: Mikrovilli auf der Membranoberseite eines Osteoklasten, REM-Aufnahme

\subsubsection{Darstellung der Ausbreitung von Osteoklasten auf einer Oberfläche}

Um den Adhäsions- und Ausbreitungsvorgang der Osteoklasten auf einer Oberfläche zu demonstrieren, wurden die über 14 Tage herandifferenzierten Zellen nach Ablösen aus der Kulturschale in Nährmedium aufgenommen. Die Zellsuspension wurde auf Glasplättchen gegeben, die mit Poly-L-Lysine beschichtet waren. Die Beschichtung ist notwendig, damit die Zellen auf den Plättchen für die folgenden rasterelektronenmikroskopischen Behandlungsschritte sicher anhaften. Anschließend wurden die Zellen auf den Plättchen für 5, 10, 15 und 30 min sowie $1 \mathrm{~h}$ und $2 \mathrm{~h}$ unter Kulturbedingungen inkubiert, nach Ablauf der jeweiligen Inkubationsdauer sofort fixiert und für die rasterelektronenmikroskopische Untersuchung aufgearbeitet.

Abbildung 15 a zeigt eine Zelle nach 5minütiger Inkubation auf dem Poly-L-LysinePlättchen. Es ist eine kugelförmige Zelle von ca. $15 \mu \mathrm{m}$ Durchmesser mit vielen lamellenartigen und haarförmigen Strukturen auf der Oberfläche zu erkennen. Da die Zellen im Lichtmikroskop vor dem Ablösen aus den Kulturschalen eine flache bis 
gewölbte Form zeigten und die meisten Zellen nach 5 min Inkubation kugelförmig aussahen, ist anzunehmen, dass sich die Zellen während des Ablösevorgangs abrunden. Nach 10minütiger Inkubation war bereits die beginnende Ausbreitung der Zellen zu sehen (Abbildung 15 b). In diesem Stadium ist die Kugelform der Zellen noch erhalten, aber es ist ein 5-10 $\mu \mathrm{m}$ breiter, flach auf dem Plättchen ausgebreiteter Saum (Pfeil 1) um die Zelle herum zu erkennen, der lamellenartige Auffaltungen trägt. Die Kugelform der Zelle wirkt nach 15minütiger Inkubation abgeflacht und es bilden sich von dem Saum aus eine große Anzahl fadenförmiger Ausläufer (Pfeil 2), mit einer Länge von bis zu $8 \mu \mathrm{m}$ (Abbildung 15 c). Nach CHAMBERS et al., 1984 handelt es sich bei derartigen Ausläufern um Filopodien. Nach 30 min Inkubation hat sich die Kugelform aufgelöst (Abbildung 15 d). Die Zelle wirkt in der Mitte aufgewölbt und trägt dort die größte Anzahl an Lamellen und Membranfaltungen. Vom Saum aus werden zahlreiche, nun breitere Ausläufer mit fadenförmigen Enden (Pfeil 3) und einer Gesamtlänge von bis zu $20 \mu \mathrm{m}$ nach allen Seiten ausgestreckt. Nach $1 \mathrm{~h}$ ist eine flächenförmige Zelle mit einem Durchmesser von $60 \mu \mathrm{m}$ zu erkennen, die eine Aufwölbung mit vielen lamellenartigen und haarförmigen Strukturen (Pfeil 4) von $15 \mu \mathrm{m}$ Durchmesser trägt (Abbildung $15 \mathrm{e}$ ). Die Aufwölbung nimmt im weiteren zeitlichen Verlauf ab und es ist nach $2 \mathrm{~h}$ Inkubation nur noch eine zentrale Anhäufung von Lamellen und Membranfaltungen auf einer sonst glatten und flachen Zelle von $80 \mu \mathrm{m}$ Durchmesser zu erkennen (Abbildung 15 f). Der linke Rand der Zelle weist fadenförmige Filopodien (Pfeil 5) auf, während am rechten Rand lappenförmige Ausstülpungen (Pfeil 6) zu erkennen sind, bei denen es sich um Pseudopodien handeln könnte (CHAMBERS et al., 1984). Die Ausbildung derartiger Strukturen ist auch in der Abbildung 16 a (Pfeil 1: Filopodien, Pfeil 2: Pseudopodien) gut zu erkennen, in der ein Osteoklast auf Pottwaldentin dargestellt ist. Der oben aufgezeigten Vorgänge demonstrieren, dass sich die, nach dem Ablösen vom Untergrund, abgekugelte Zelle unter vorübergehender Bildung von Ausläufern auf einer Oberfläche innerhalb von $2 \mathrm{~h}$ flächig ausbreitet. 

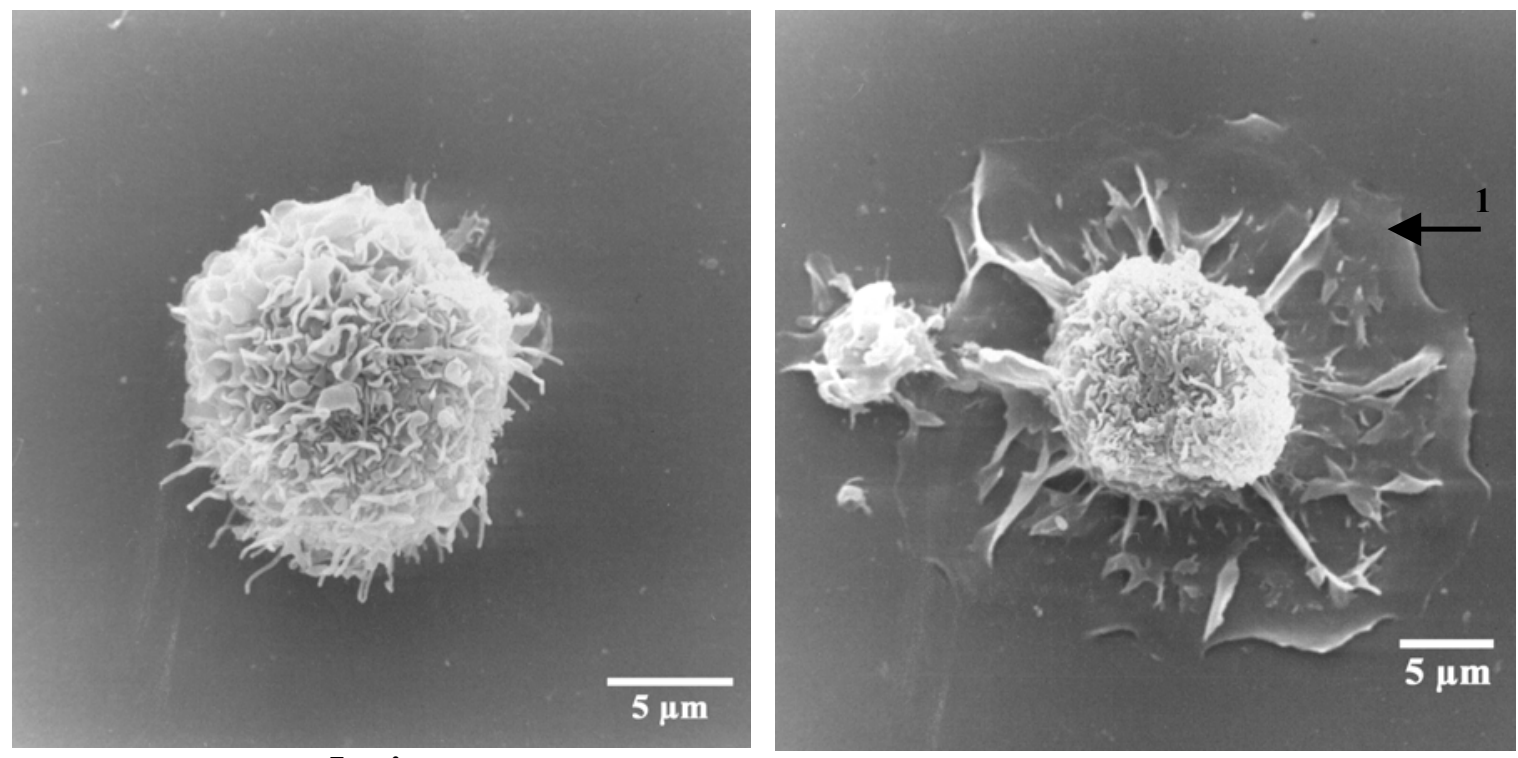

a

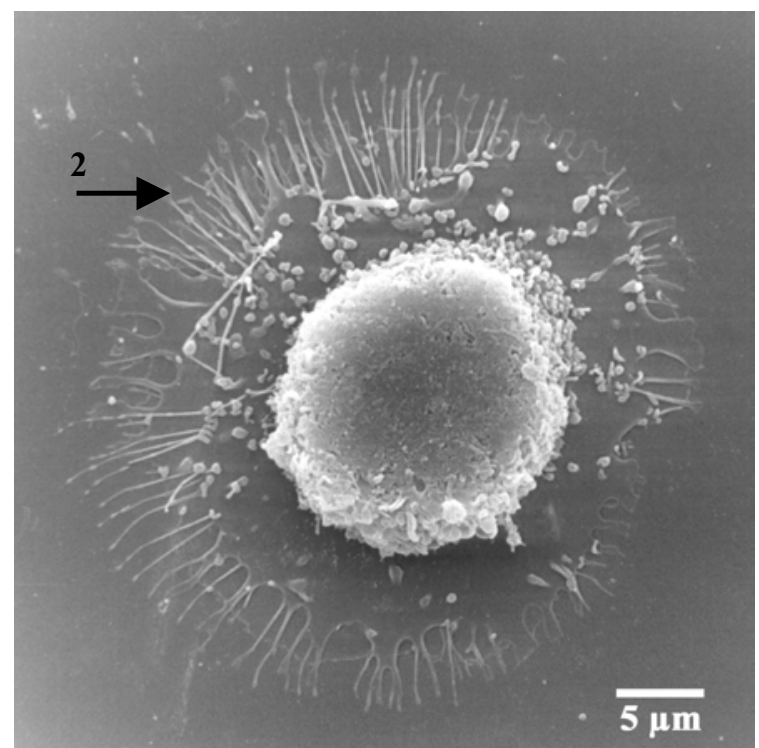

c

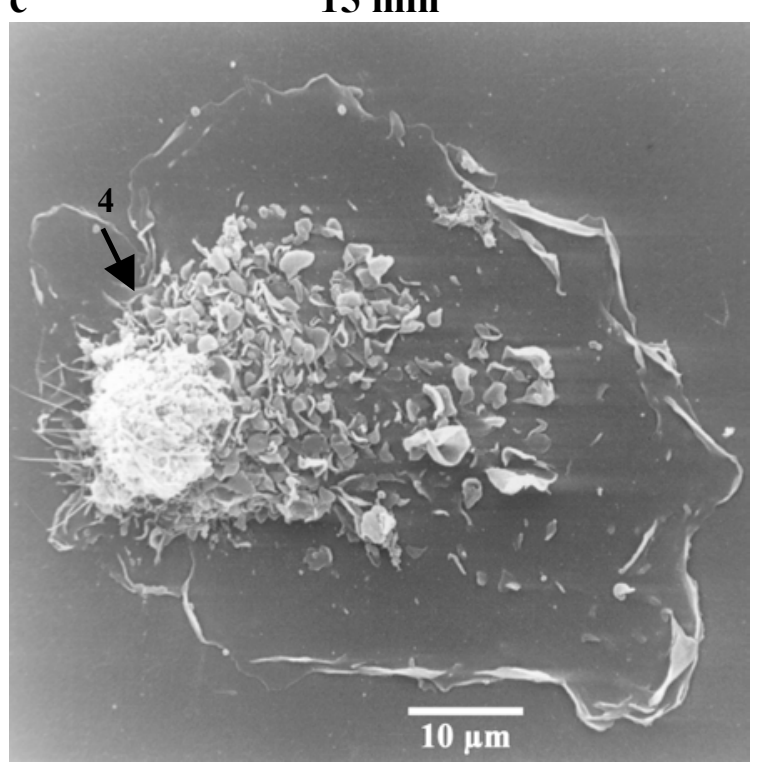

$1 \mathrm{~h}$ b

10 min

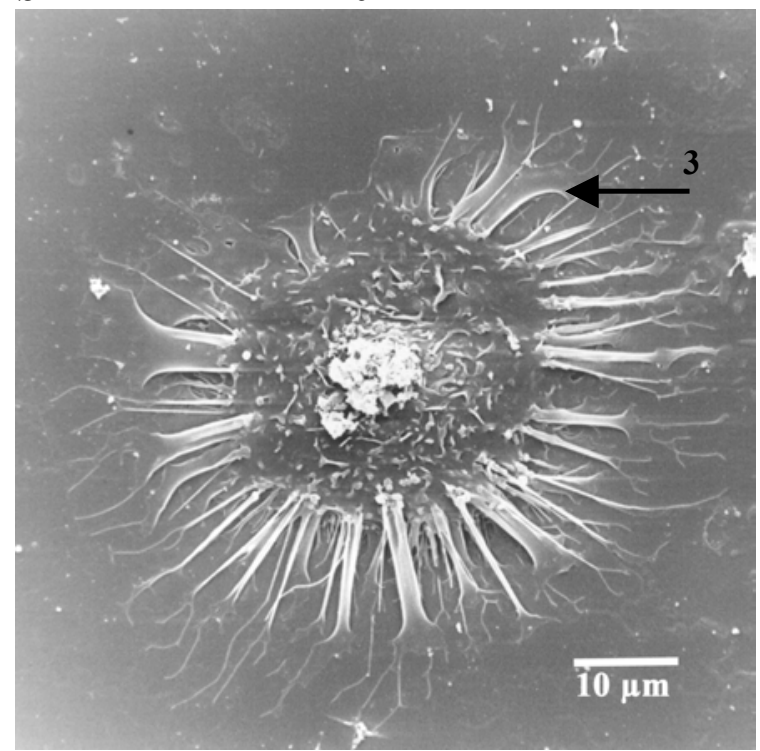

d

30 min

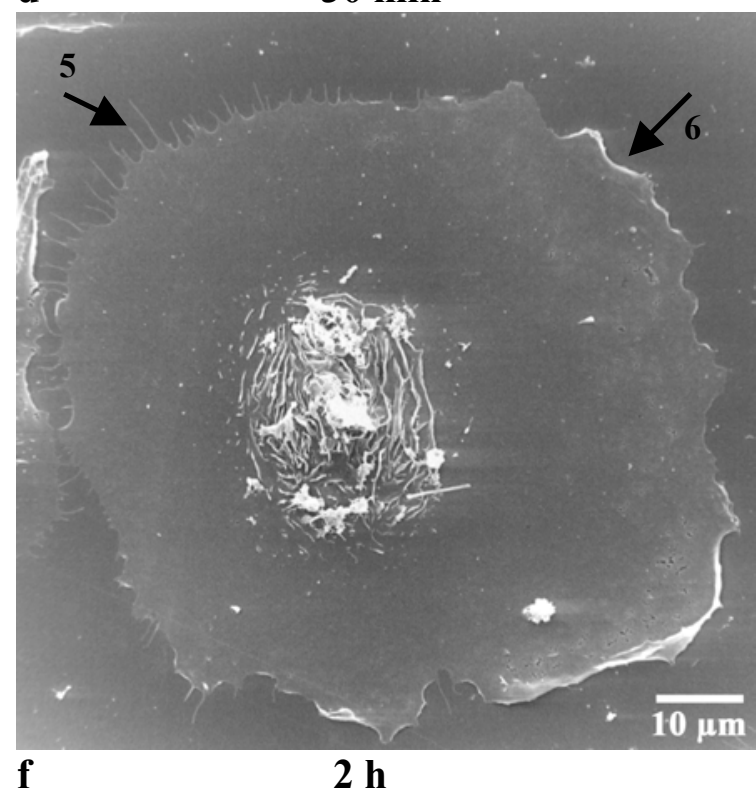

Abbildungen 15 a - f: Osteoklasten auf Poly-L-Lysin-Plättchen, REM-Aufnahme 


\subsubsection{Oberflächenmorphologie der Resorptionslakunen}

Die durch Inkubation mit Osteoklasten entstandenen resorptiven Veränderungen im Dentin waren bei einigen Proben bereits mit Zellen auf der Oberfläche zu erkennen. Abbildung 16 a zeigt einen Osteoklasten (Pfeil 3), nach zweiwöchiger Inkubation auf dem ottwaldentin, in unmittelbarer Nähe von Resorptionslakunen (Pfeile 4 bis 6). Die Aufnahme demonstriert deutlich die Größenverhältnisse des Osteoklasten mit einem Durchmesser von ca. $80 \mu \mathrm{m}$ zu den Lakunen mit ungefähr $20 \mu \mathrm{m}$ Durchmesser.

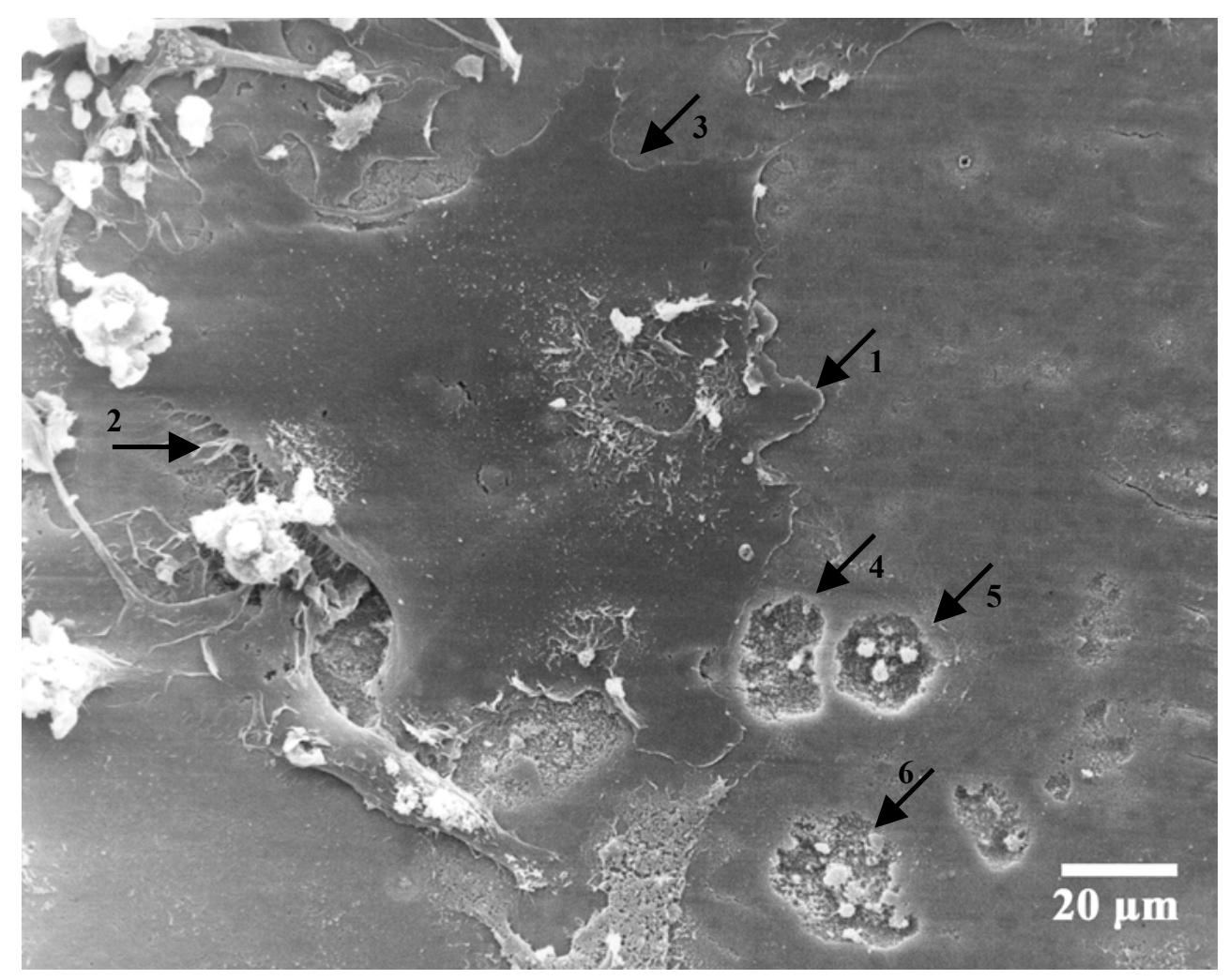

Abbildung 16 a: Osteoklast auf Pottwaldentin mit Resorptionslakunen (Pfeil 1: Filopdien, Pfeil 2: Pseudopodien), REM-Aufnahme

Nach Entfernen der Zellen von der Oberfläche (s. 2.15) sind die Veränderungen jedoch am besten darstellbar. Nach 2 bis 4 Wochen Inkubation der Zellen auf dem Pottwaldentin, anschließendem Ablösen der Zellen und erneuter Bedampfung der Dentinplättchen für die REM, sind typische Resorptionslakunen erkennbar (Abbildung 16 b). Die Aushöhlungen haben einen Durchmesser von 5 bis $50 \mu \mathrm{m}$. Es handelt sich zum einen um rundliche, klar abgrenzbare Löcher (Pfeil 1) und zum anderen um komplexe, wolkenartige Gruben (Pfeil 2), bei denen die Vertiefungen 
durch, tiefer als die Oberfläche gelegene Stege (Pfeil 3) getrennt sind. Außerdem sind flache, großflächigere Lakunen (Pfeil 4) zu erkennen, die ohne klar abgrenzbaren Rand in die nicht resorbierte Matrix übergehen. In den Lakunen sind zahlreiche helle Vorwölbungen (Pfeil 5) von ca. $2 \mu \mathrm{m}$ Durchmesser zu sehen.

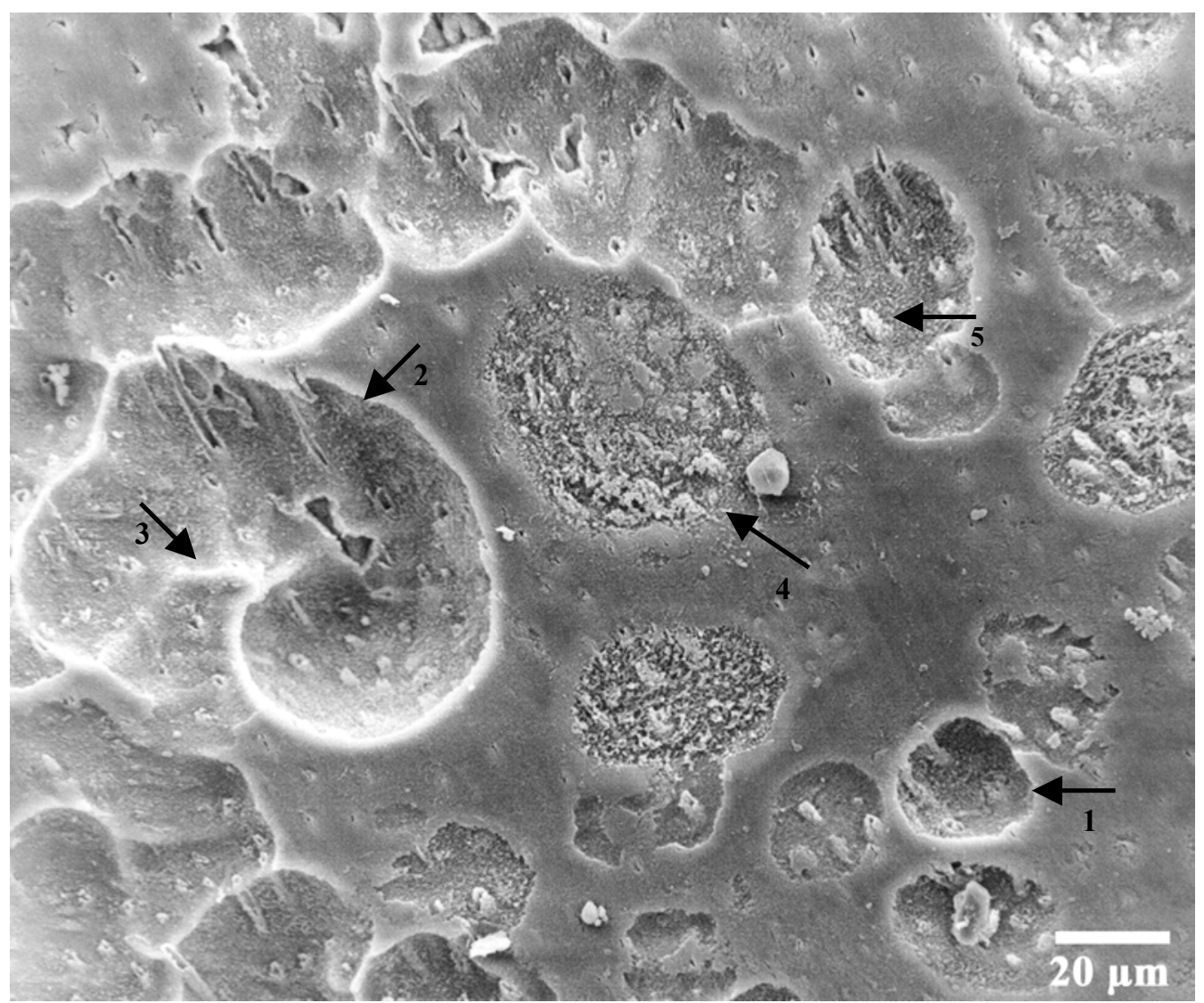

Abbildung 16 b: Resorptionslakunen im Pottwaldentin nach 14tägiger Inkubation von Osteoklasten auf dem Substrat, Zellen abgelöst, REM-Aufnahme

In der Vergrößerung ist erkennbar (Abbildung $16 \mathrm{c}$ ), dass diese Vorwölbungen stiftförmig hervorragen und ein zentrales Loch aufweisen (Pfeil). Es handelt sich mutmaßlich um Dentinkanälchen, die von peritubulären Dentin ummantelt sind. Diese verdickte bzw. verhärtete Struktur konnte scheinbar von den Osteoklasten nicht oder aber nur langsamer abgebaut werden, so dass die Zellen nach Resorption des angrenzenden Substrats bereits weiter wandern und die Vorwölbungen stehen bleiben. 


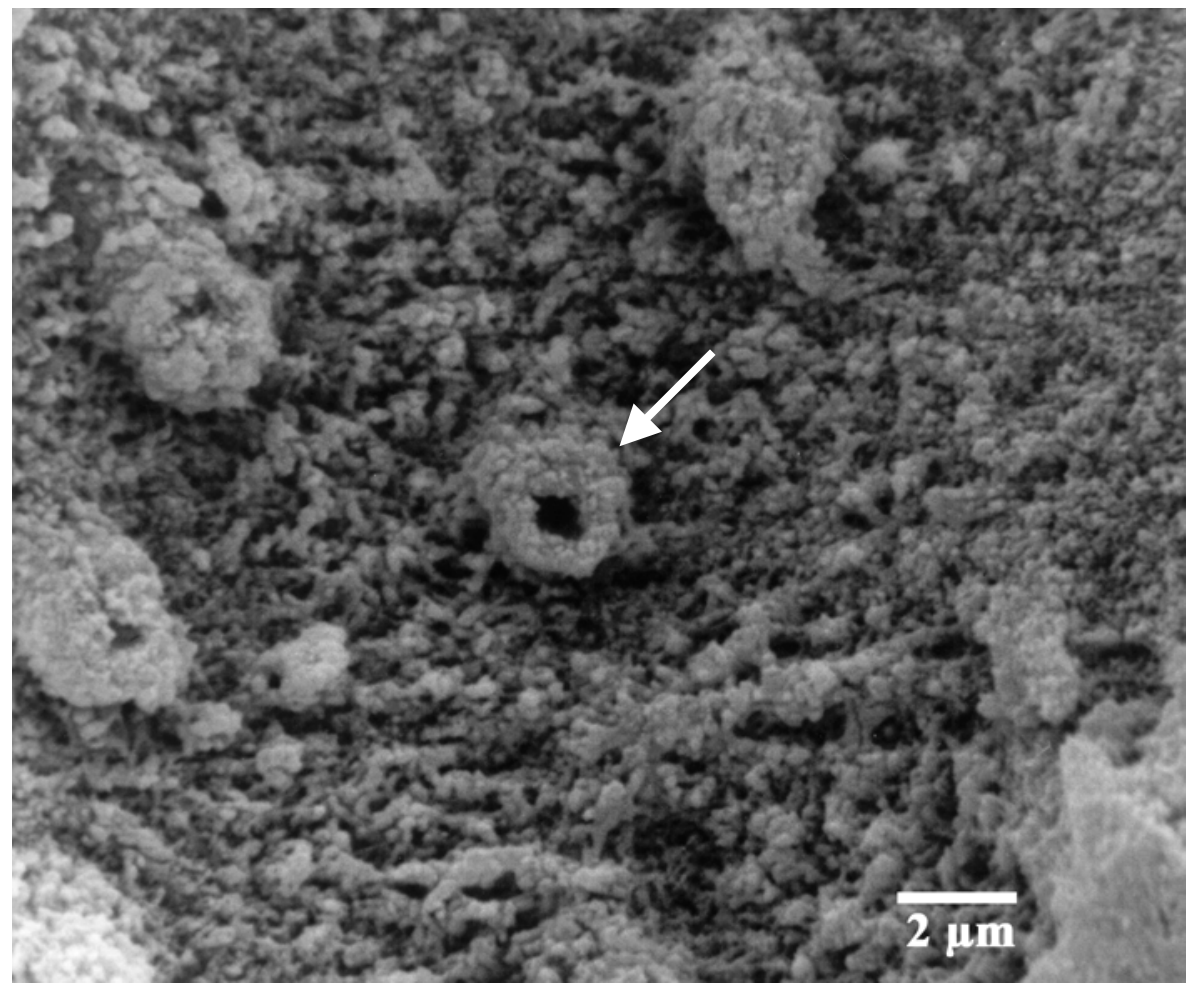

Abbildung 16 c: stiftförmige Vorwölbungen mit zentralem Loch innerhalb von Resorptionslakunen, Ausschnitt aus einer Lakune, REM-Aufnahme

\subsubsection{Darstellung früher Stadien der osteoklastären Dentinresorption}

Da die Entwicklung der Resorptionslakunen bisher nicht dargestellt wurde, sollten die verschiedenen Resorptionsstadien der Osteoklasten analysiert werden und im weiteren dem Vergleich mit aktivierten Fibroblasten dienen. Zur Untersuchung der frühen Stadien des Substratabbaus, wurden die über 14 Tage herandifferenzierten Osteoklasten für 3 bis 7 Tage auf Pottwaldentin inkubiert, anschließend fixiert und für die REM aufgearbeitet. In Abbildung 17 sind, nach Entfernung der Osteoklasten, frühe resorptive Veränderungen zu erkennen. Es sind kleine, gut abgrenzbare, runde Vertiefungen mit einer angerauten Oberfläche (s. Pfeile). Der Durchmesser dieser Veränderungen ist sehr einheitlich und beträgt $2-5 \mu \mathrm{m}$. Bei den kleinsten - möglicherweise auch frühsten Veränderungen wurde anscheinend häufig erst ein Graben gebildet, während die Oberfläche in der Mitte noch nicht angegriffen war. Diese Beobachtung wurde auch bei 
dem Resorptionsprozess auf den Calciumphosphatplättchen gemacht (s. 3.4). Scheinbar wird die frühen Veränderungen im Dentin im Laufe des Resorptionsprozesses weiter ausgehöhlt. Außerdem wurde vermutet, dass ein Osteoklast für mehrere der frühen Resorptionslakunen verantwortlich ist, da der Abstand dieser Vertiefungen sehr viel geringer ist als der Durchmesser eines Osteoklasten.

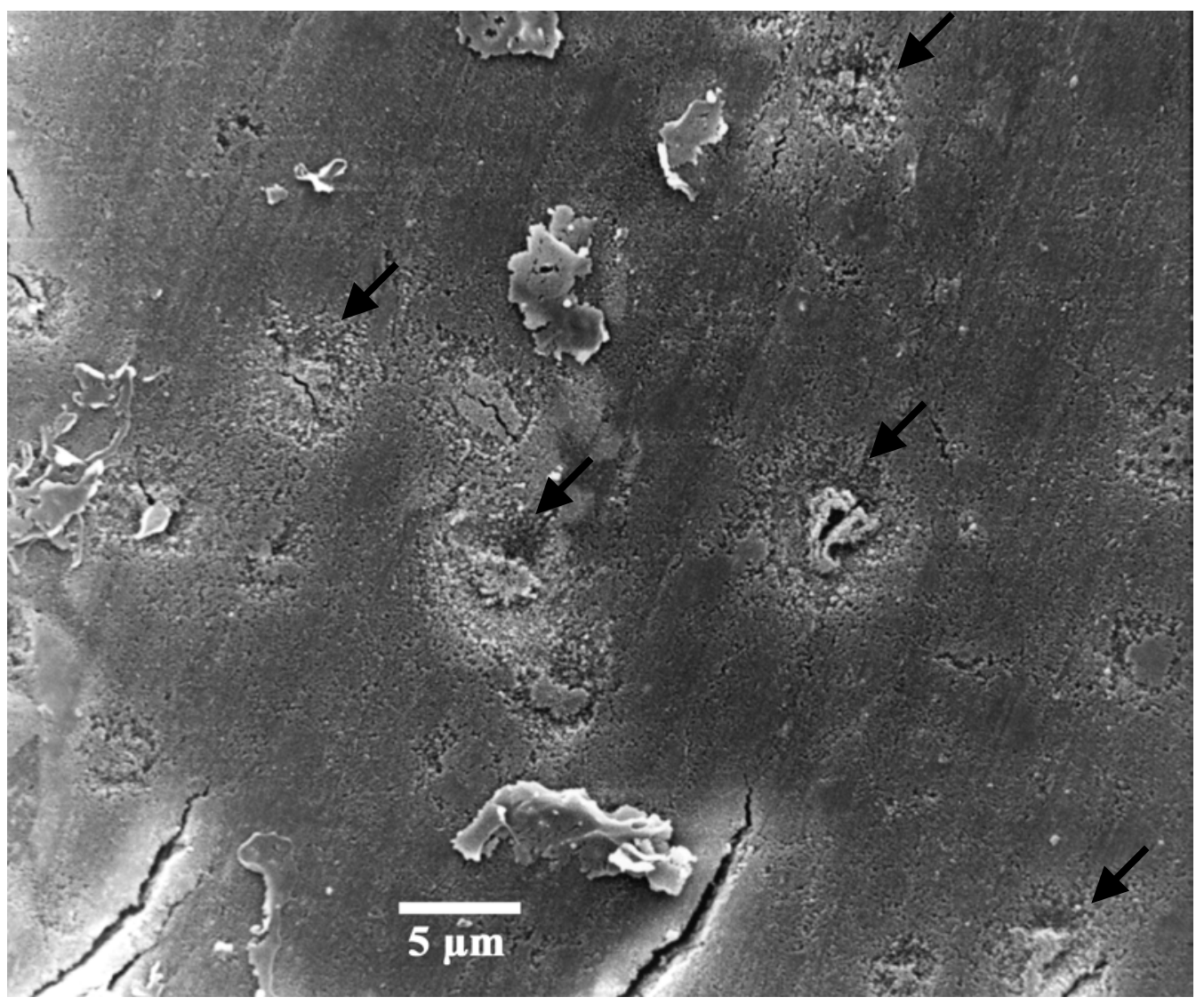

Abbildung 17: resorptive Veränderungen im Pottwaldentin nach 4tägiger Inkubation der Osteoklasten auf dem Substrat, Zellen abgelöst, REM-Aufnahme 


\subsubsection{Untersuchung spenderabhängiger Unterschiede bei Osteoklasten auf Pottwaldentin}

Die bereits bei der Anzahl der ausdifferenzierten Osteoklasten festgestellten spenderabhängigen Unterschiede (s. 3.1.1) zeigten sich auch bei dem Vergleich dieser Zellen im Resorptionsassay. Die aus Vorläuferzellen von zwei männlichen (SP1/SP2) und zwei weiblichen (SP3/SP4) Spendern herandifferenzierten Zellen wurden für vier Wochen auf Pottwaldentin inkubiert. Anschließend wurden die Dentinstücke mit den Zellen fixiert und für die REM aufgearbeitet.

Der Vergleich der rasterelektronenmikroskop untersuchten Proben ergab Unterschiede in der zahlenmäßigen Zusammensetzung der Zelltypen bei den verschiedenen SpenderInnen. Bei SP1 sind einige riesige Osteoklasten (Pfeil 1) mit einem Durchmesser von bis zu $200 \mu \mathrm{m}$ sowie viele rosettenartige (Pfeil 2) und einige schmale, langgestreckte Zellen zu sehen (Abbildung 18 a). Die Zellen von Spender SP2 zeigen hauptsächlich rosettenartige (Pfeil 3) bzw. langgestreckte (Pfeil 4) Formen (Abbildung 18 b). Osteoklasten sind nur vereinzelt zu finden. SP3 enthält vermehrt Osteoklasten (Pfeil 5) mit einem Durchmesser von $100 \mu \mathrm{m}$ und nur wenige rosettenförmige Zellen (Abbildung $18 \mathrm{c}$ ). Bei SP4 in Abbildung $18 \mathrm{~d}$ wiederum sind neben Osteoklasten (Pfeil 6) auch viele rosettenförmige Zellen (Pfeil 7) zu erkennen.

Um das Ergebnis der Abbauvorgänge besser demonstrieren zu können, wurden die Zellen teilweise von den Dentinplättchen entfernt (s. 2.15). Das Dentinplättchen, dass mit den Zellen der Spenderin SP3 inkubiert wurde, zeigt die meisten resorptiven Veränderungen (Abbildung 19 c). Die Oberfläche weist viele wolkenartige Lakunen (Pfeil 4) auf, die sehr dicht liegen und teilweise in einander übergehen. Auf dem Dentinplättchen, auf dem die Zellen von Spender SP1 saßen, sind vermehrt rundliche, klar abgrenzbare Löcher (Pfeil 1) zu sehen, aber auch einige wolkenartige Lakunen (Abbildung 19 a). Die Aushöhlungen auf dem Dentinplättchen, das mit den Zellen von Spenderin SP4 inkubiert wurde (Abbildung 19 d), sind flacher und nicht so klar abgrenzbar wie bei Spender SP1 (Pfeil 5). Die Durchmusterung der Dentinplättchen ergab, dass sowohl das Dentin von SP1 als auch das von SP4 sehr viel weniger Resorptionslakunen aufwies, als das Dentin von SP3. Nur auf dem Dentinplättchen mit den Zellen von SP2 traten kaum erkennbare, resorptive Veränderungen (Pfeil 2 u. 3) auf (Abbildung 19 b). 
Abb. 18 a:

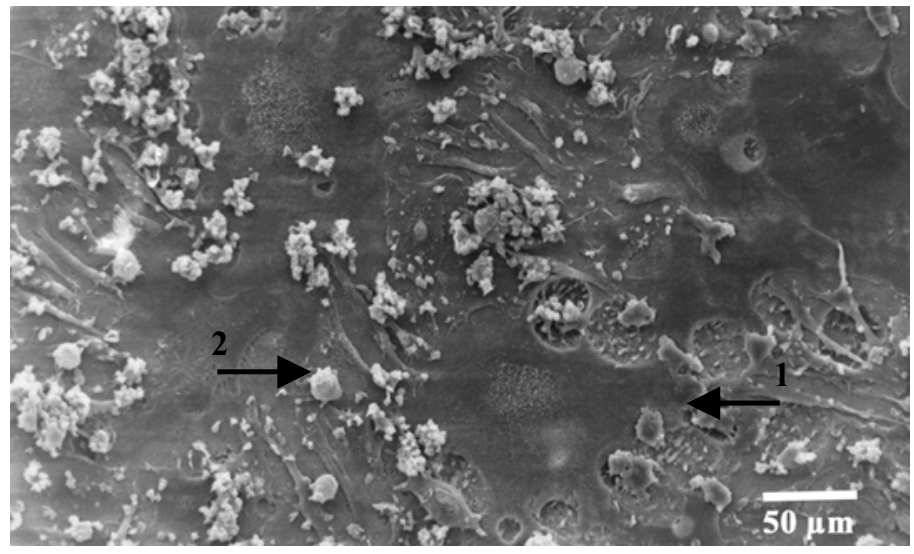

Abb. 18 b:

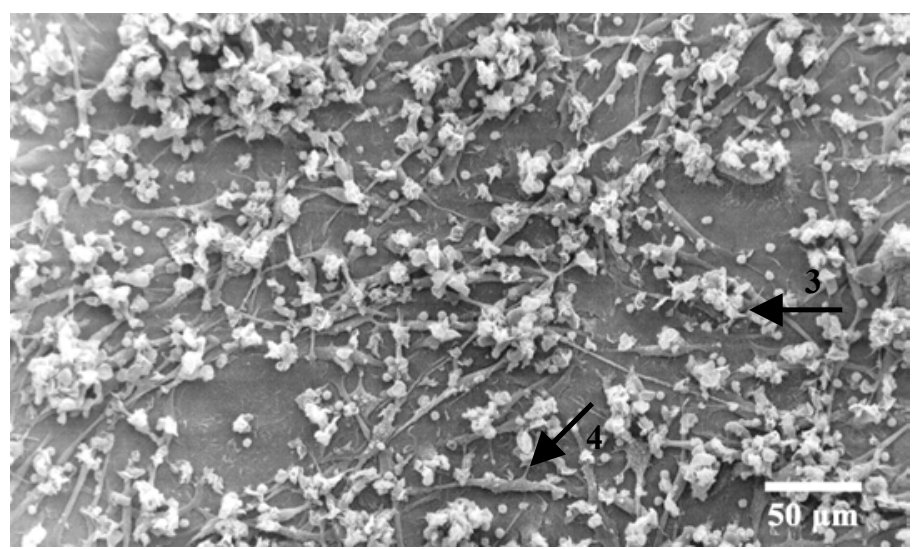

Abb. 18 c:

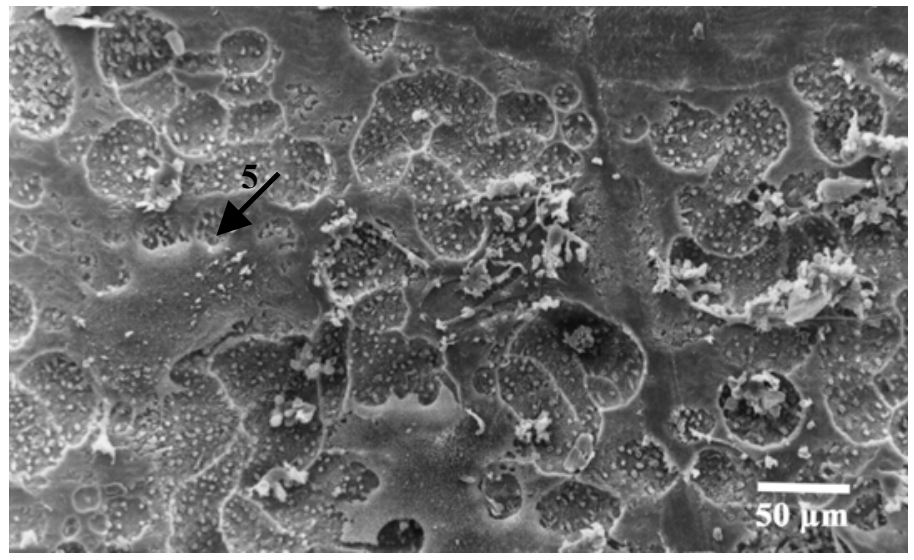

Abb. 18 d:

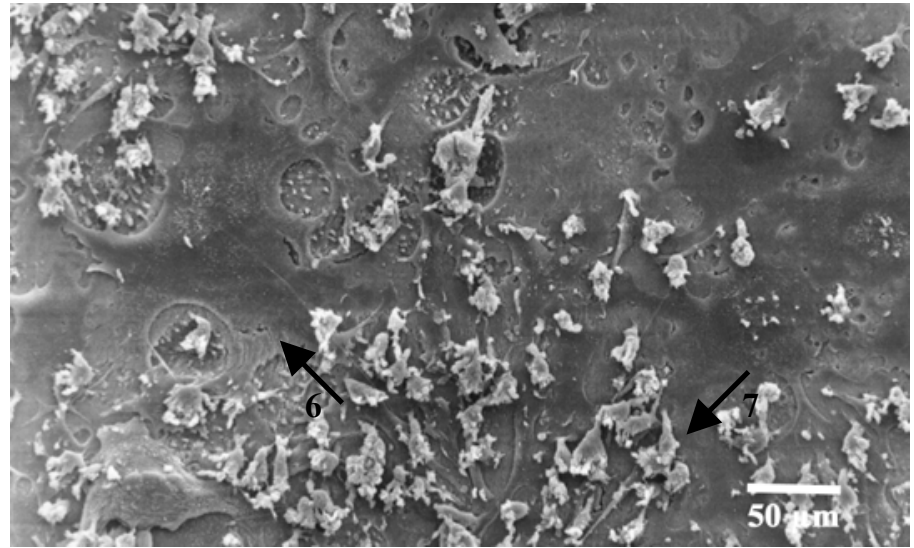

Abbildungen 18 a - d: Osteoklasten verschiedener SpenderInnen auf Pottwaldentin, REM-Aufnahme 
Abb. 19 a:

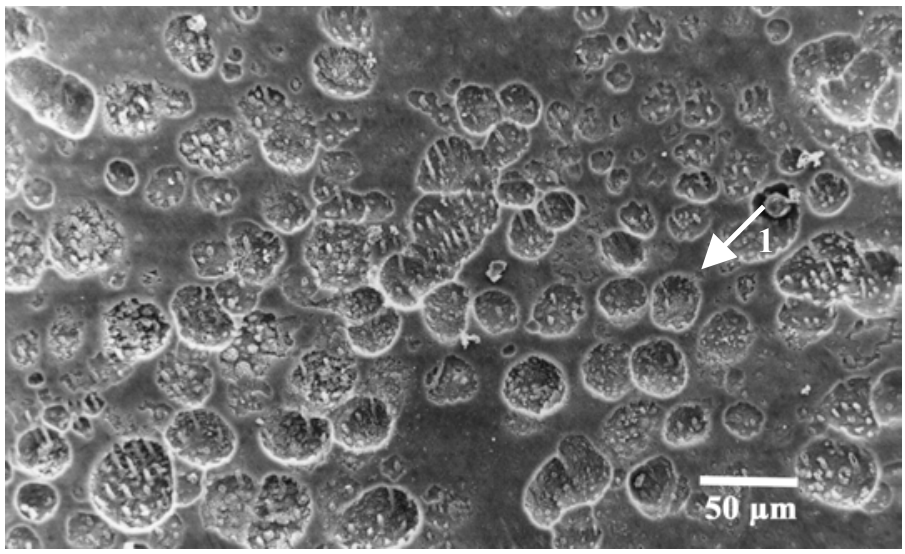

Abb. 19 b:

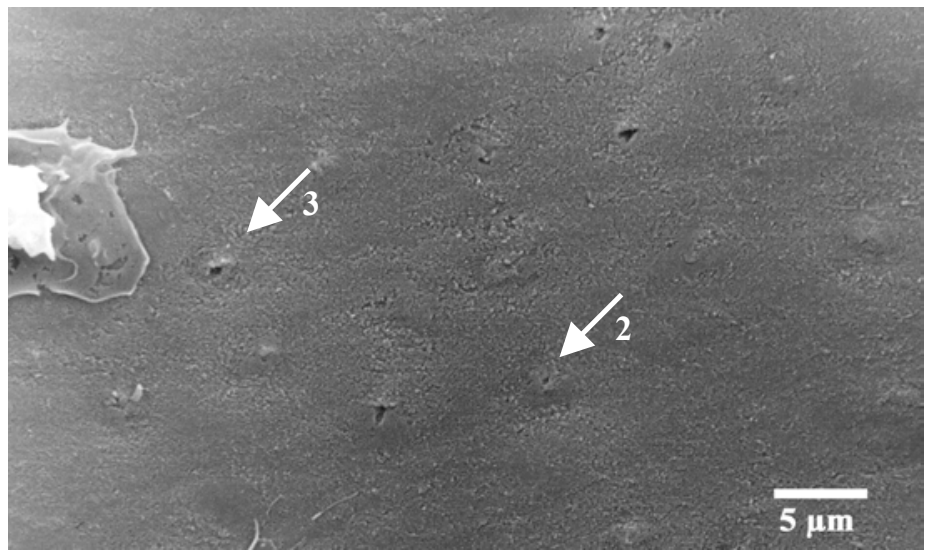

Abb. 19 c:

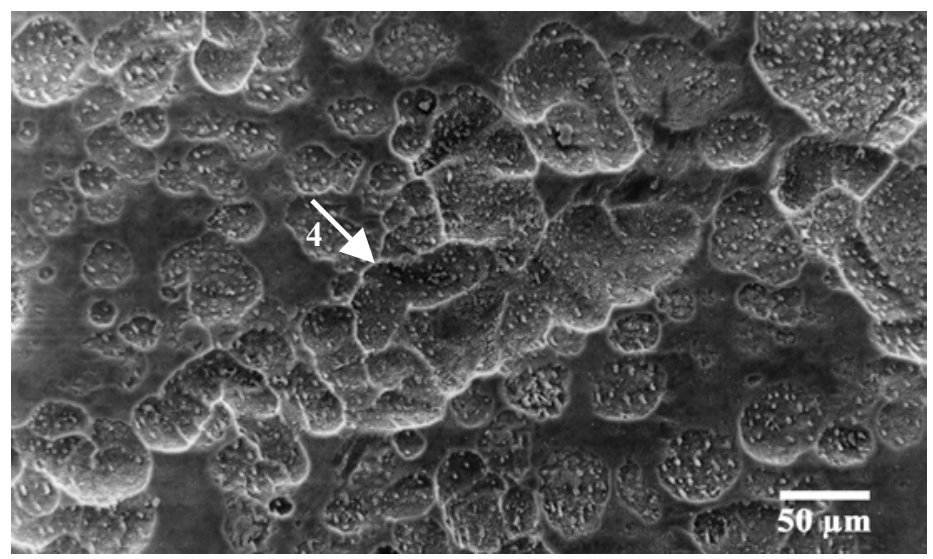

Abb. 19 d:

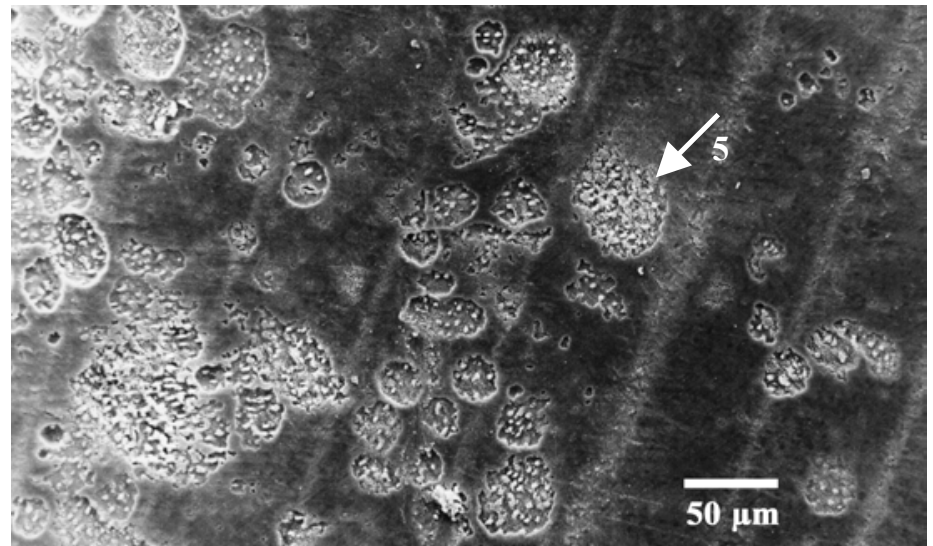

Abbildungen 19 a - d: Resorptionslakunen im Pottwaldentin nach Inkubation mit Osteoklasten verschiedener SpenderInnen, Zellen entfernt, REM-Aufnahme 


\subsubsection{Darstellung der Substratseite des Osteoklasten}

Es wird angenommen, dass Osteoklasten an der, dem Substrat zugewandten Seite, einen abgeschlossenen extrazellulären Raum, die sogenannte „sealing zone“, erzeugen, in dem der $\mathrm{pH}$ durch Protonen abgesenkt und damit das Calciumphosphat des Knochens in Lösung gebracht wird. Die $\mathrm{H}^{+}$-Ionen werden dabei über eine zellmembrangebundene ATPase abhängige Protonenpumpe in den Extrazellularraum abgegeben. Die Protonenpumpen sind Bestandteile des funktionellen Organs der Osteoklasten, der sogenannten ruffled border, an dem die Resorptionsprozesse erfolgen. Transmissionselektronenmikroskopische Aufnahmen zeigen die ruffled border im Querschnitt als unregelmäßige, vielfach verzweigte Membranfaltungen (LOMAGA et al., 1999). Die demineralisierte Knochenmatrix wird im weiteren unter Wirkung von extrazellulär sezernierten Proteasen und intrazellulär, lysosomal gelegenen Proteasen degradiert. Resorbierte Stoffe werden an der „ruffled border“ in sekundäre Lysosomen aufgenommen und können später wieder abgegeben werden.

Rasterelektronenmikroskopische Untersuchungen sollten zeigen, wie die Substratseite der in vitro herandifferenzierten Osteoklasten in der Aufsicht morphologisch gestaltet ist und wieviel Raum die „ruffled border“ auf der Substratseite des Osteoklasten einnimmt. Diese Fragen können mit der transmissionselektronenmikroskopischen Technik, die häufig zur Darstellung der „ruffled border“ angewandt wurde, nicht geklärt werden.

Zur Darstellung der Substratseite wurden Osteoklasten über 3 Wochen auf Pottwaldentin inkubiert und deren resorptive Aktivität anhand der Bildung von Resorptionslakunen im Rasterelektronenmikroskop gezeigt. Anschließend wurden die Zellen mit der Tape-Methode (s. 2.15) vorsichtig von dem Dentin abgehoben. Die auf dem Tape haftenden Zellen wurden mit der Unterseite nach oben bedampft und im Rasterelektronenmikroskop betrachtet. Abbildung 20 zeigt die Substratseite eines Osteoklasten. Es sind glatte und gefaltete Membranbereiche zu erkennen. Der Bereich mit den vielen unregelmäßigen und verzweigten Membranfaltungen (s. Pfeil) nimmt ungefähr ein Drittel der gesamten Unterseite des Osteoklasten ein. Vergleiche mit den transmissionsmikroskopischen Aufnahmen der Querschnitte (LOMAGA et al., 1999) lassen darauf schließen, dass dieser Bereich die „ruffled border“ des Osteoklasten darstellt. Der Raum, den dieser spezialisierte Membranbereich einnimmt, entspricht der Größe der Resorptionslakunen. Es ist vorstellbar, dass der gefaltete Membranbereich in 
die Resorptionslakune hineinragt, während der glatte Bereich flach dem Substrat anliegt.

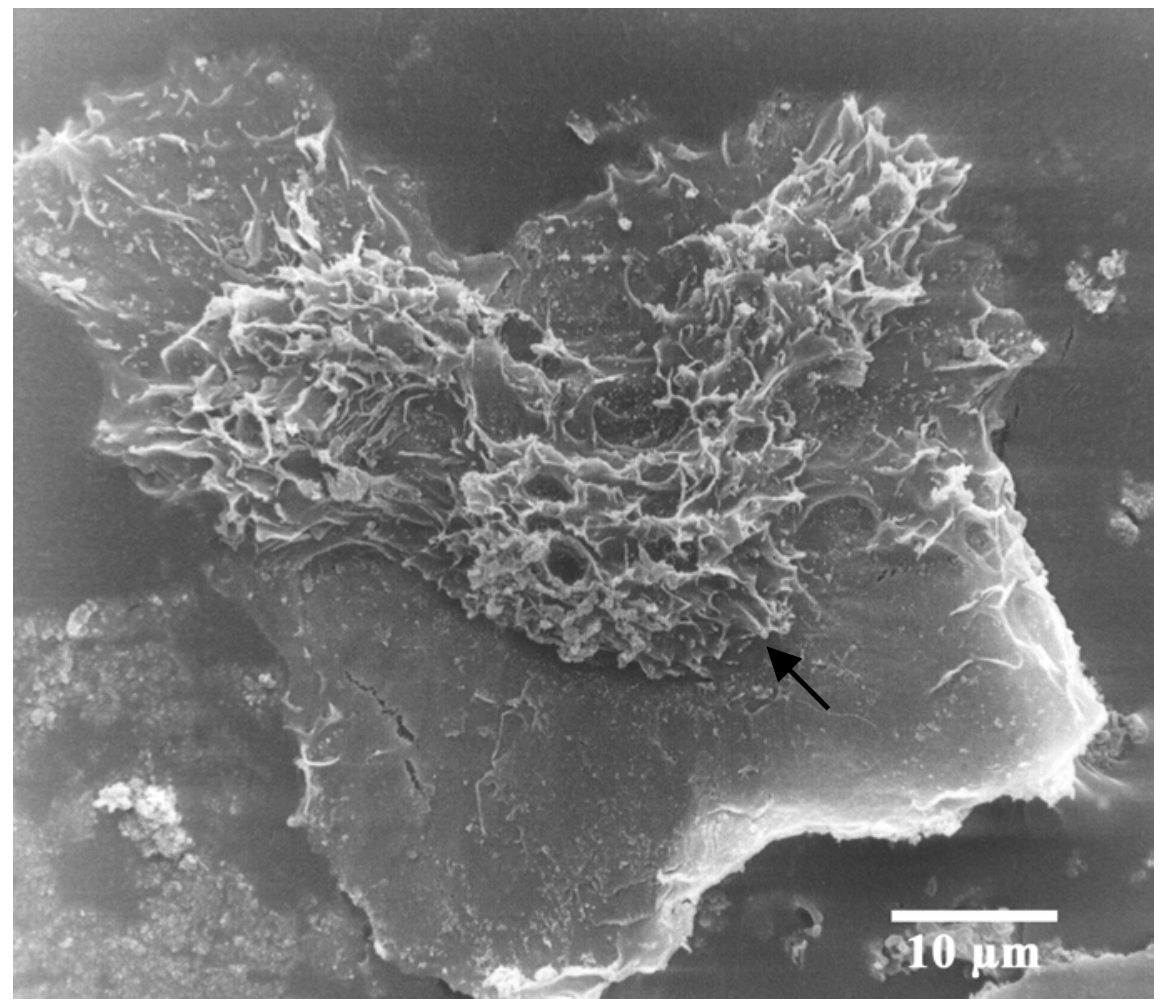

Abbildung 20: Substratseite eines Osteoklasten mit glatten und gefalteten Membranbereichen, REM-Aufnahme

Die Substratseiten der Osteoklasten waren morphologisch unterschiedlich aufgebaut. Einige Membranen waren glatt und ohne Faltungen (Abbildung $21 \mathrm{a}$ ), andere bildeten nur wenige große Falten aus und wiesen viele kleinste faden- und läppchenförmige Ausstülpungen auf (Abbildung 21 b). Wiederum andere Bereiche der Substratseite zeigen vielfach verzweigte Faltungen in der Membran (Abbildung 21 c). Möglicherweise handelt sich um verschiedene Aktivitätsformen der ruffled border. Auffällig war, dass sowohl auf der glatten Membranunterseite als auch auf der Membran mit den wenigen, großen Falten sowie der Substratseite mit den vielen, verzweigten Faltungen Löcher mit einem Durchmesser von $2-5 \mu \mathrm{m}$ zu finden waren (s. Pfeile in Abbildungen 21 a - c). Diese Löcher erinnern an zelluläre Vesikel, die sich zum Extrazellularraum hin öffnen. Die Anzahl dieser Löcher war von Zelle zu Zelle unterschiedlich. Auf der Oberseite der Osteoklasten wurden derartige Löcher nicht gefunden. 
Abb. 21 a

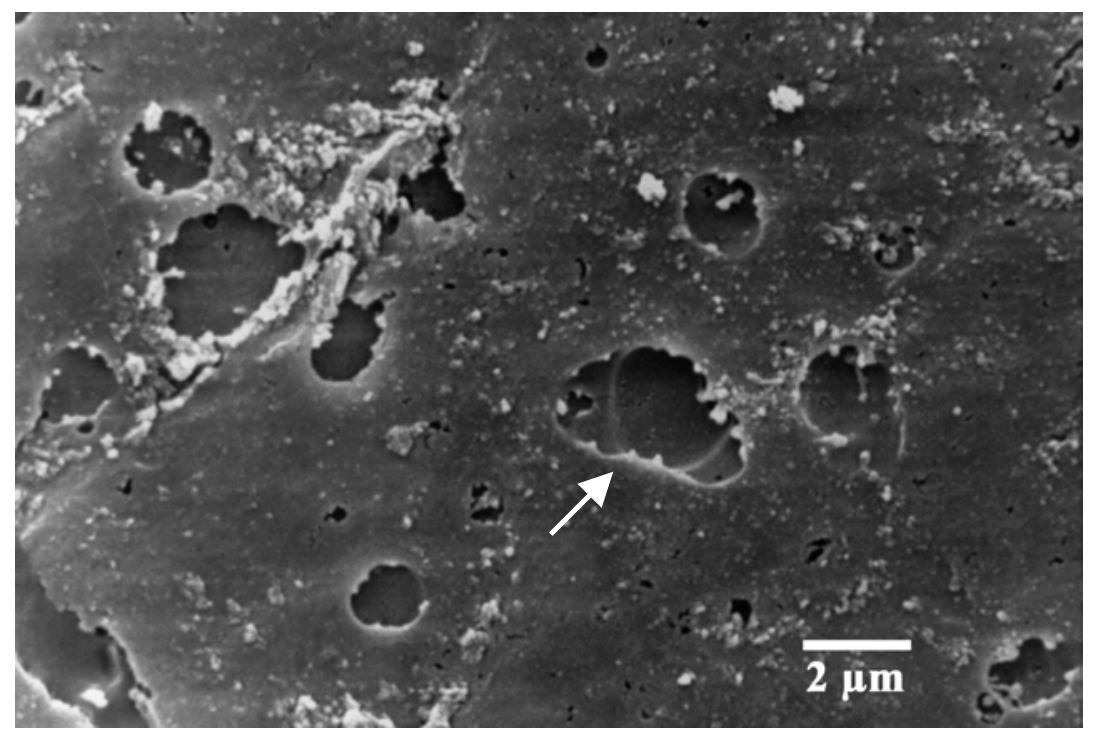

Abb. 21 b

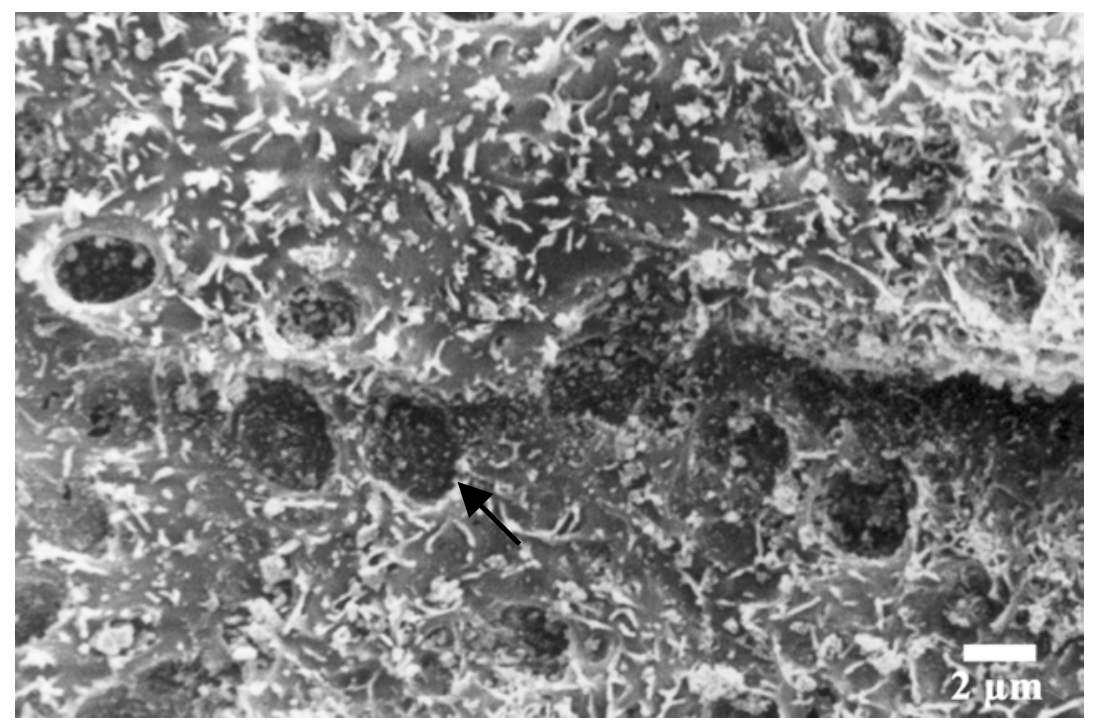

Abb. 21 c

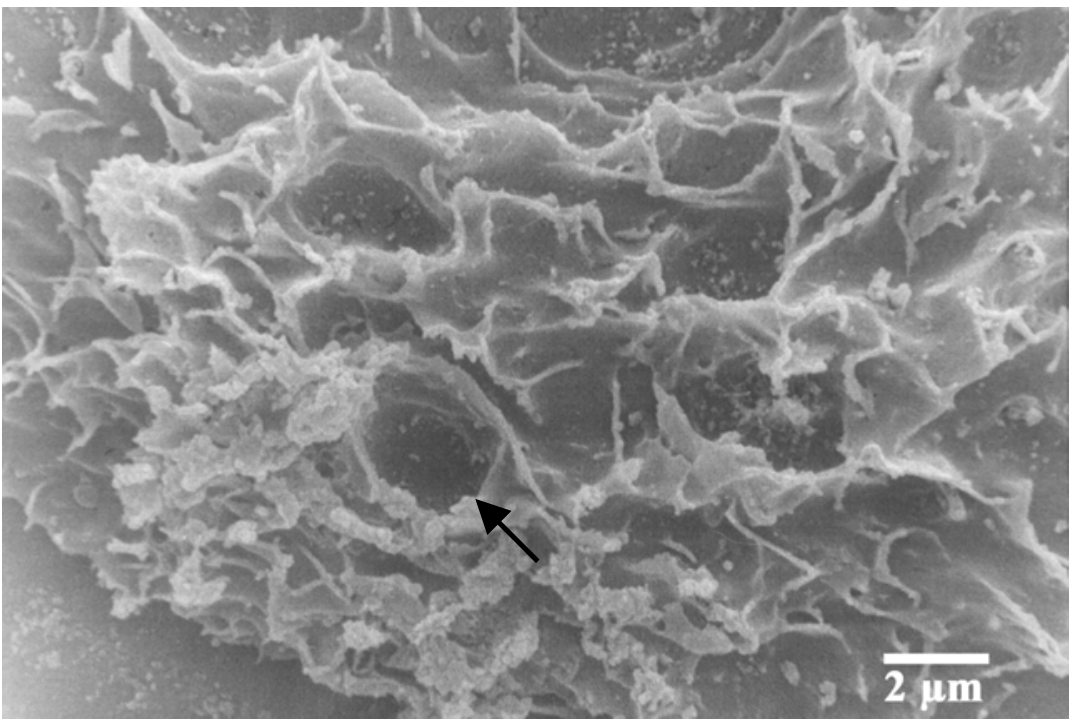

Abbildungen 21 a -c: unterschiedlich gestaltete Membranbereiche der Substratseite von Osteoklasten, REM-Aufnahme 
Eine Detailaufnahme (Abbildung 22) der ruffled border zeigt die stark verzweigte Membran mit den verschmolzenen Vesikeln, in denen Substratpartikel zu erkennen sind (s. Pfeil). Möglicherweise handelt es sich um aufgelöste Stoffe, die in die Zelle aufgenommen werden sollen.

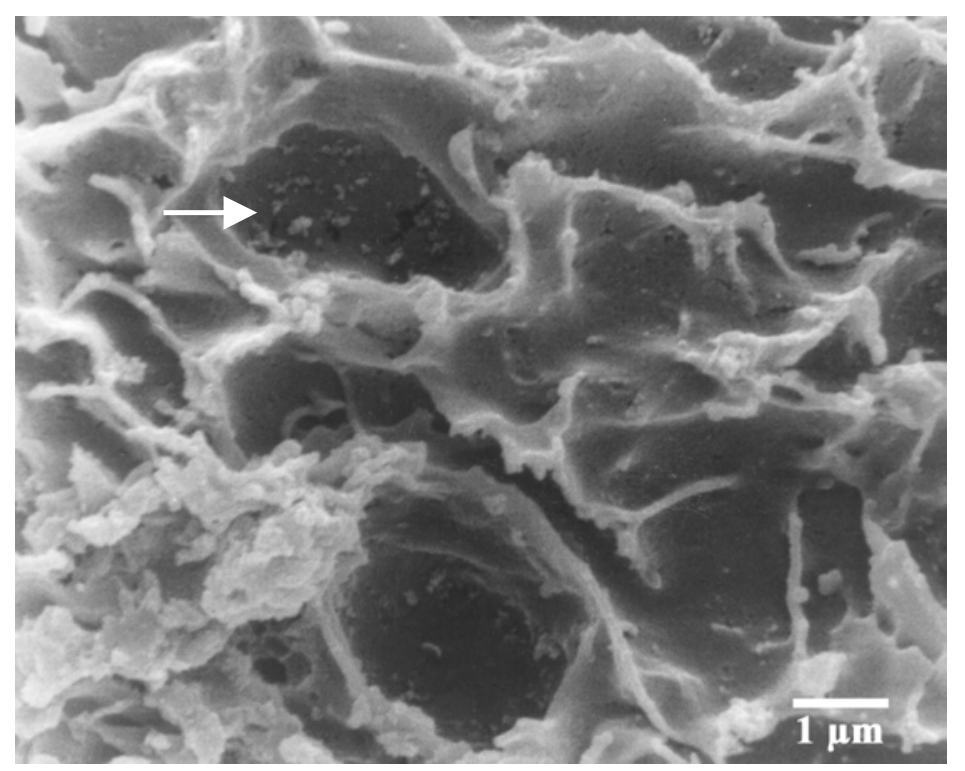

Abbildung 22: Membran-verschmolzene Vesikel mit Substratpartikeln an der Substratseite eines Osteoklasten, REM-Aufnahme

In einem anderen Bereich der ruffled border wurden knopfförmige, auf einem Stiel sitzende Strukturen gefunden (Abbildung 23), die in Hinblick auf Größe und Gestalt Gebilden ähneln, die für Endozytose-Vorgänge verantwortlich sind.

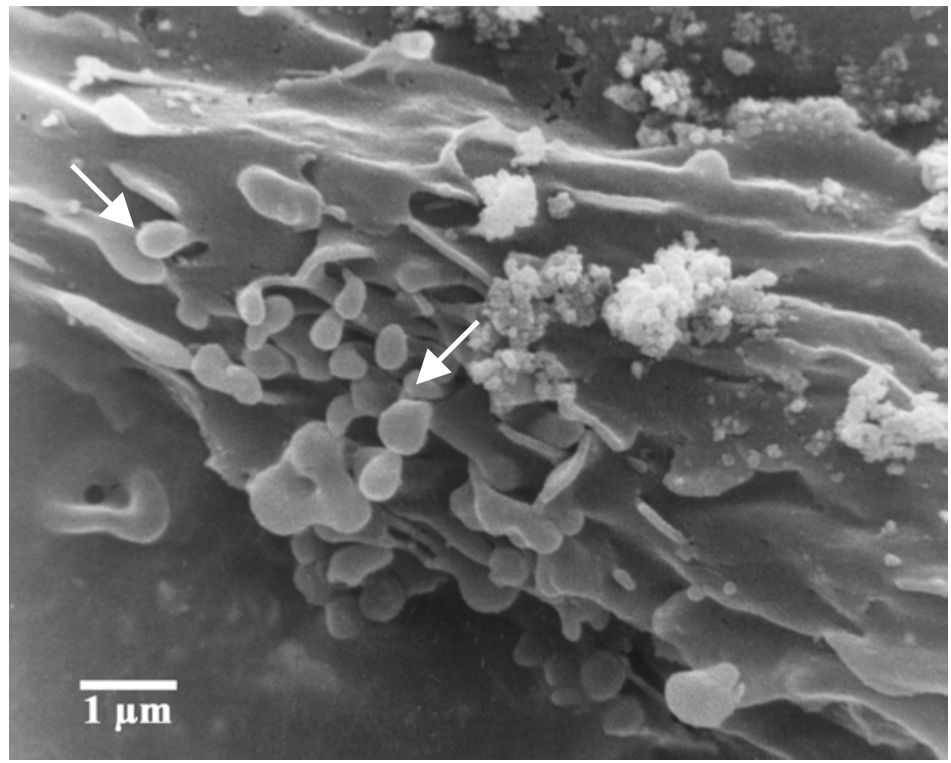

Abbildung 23: Strukturen im gefalteten Membranbereich der Substratseite eines Osteoklasten, REM-Aufnahme 


\subsection{Osteoklasten auf Calciumphosphat-Plättchen}

Um Unterschiede in der resorptiven Aktivität von Osteoklasten bezüglich verschiedener SpenderInnen sowie unterschiedlicher Inkubationszeiten demonstrieren $\mathrm{zu}$ können, wurden die aus peripheren Blut gewonnenen Zellen der SpenderInnen Sp1 bis Sp4 auf Calciumphosphat-(CP-) Plättchen herandifferenziert (s. 2.3.10). Die gesamte Inkubationsdauer betrug 30 Tage. Die Zellen wurden dann nach den Angaben des Herstellers von den Plättchen entfernt. Abbildungen 24 a $-\mathrm{d}$ zeigen die lichtmikroskopischen Aufnahmen dieser Plättchen im Vergleich.
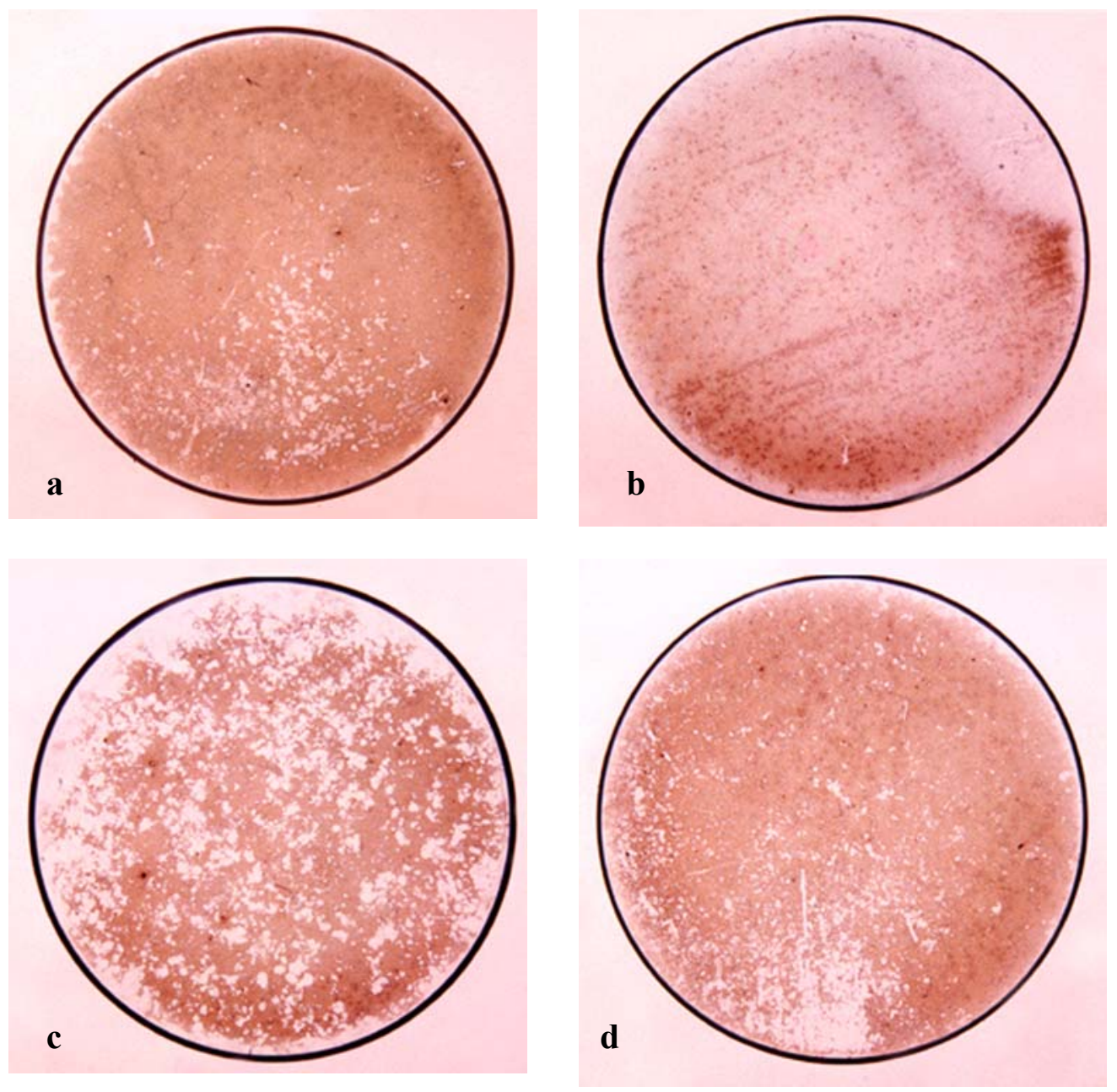

Abbildungen 24 a-d: Lichtmikroskopische Aufnahmen der CP-Plättchen nach Inkubation mit Osteoklasten verschiedener SpenderInnen; (x 5) 
Die rundlichen Aufhellungen in dem bräunlichen Beschichtung stellen die resorbierten Bereiche dar. Am deutlichsten sind die Unterschiede bei Betrachtung von Abbildungen $24 \mathrm{~b}$ und c. Abbildung 24 b zeigt das CP-Plättchen, auf dem Zellen von Sp2 inkubiert wurden und Abbildung 24 c, das CP-Plättchen von Sp3. Die CP-Plättchen von Sp1 (Abb. 24 a) und Sp4 (Abb. 24 d) liegen hinsichtlich der resorbierten Beschichtung zwischen Sp2 und Sp3.

Eine Vergrößerung (Abbildung 25) der CP-Plättchen demonstriert Morphologie der Resorptionslakunen (s. 3.3.4) und zeigt die wiederholt auftretende „Grabenbildung“ der Lakune mit einem Substratrest in der Mitte (s. Pfeil).

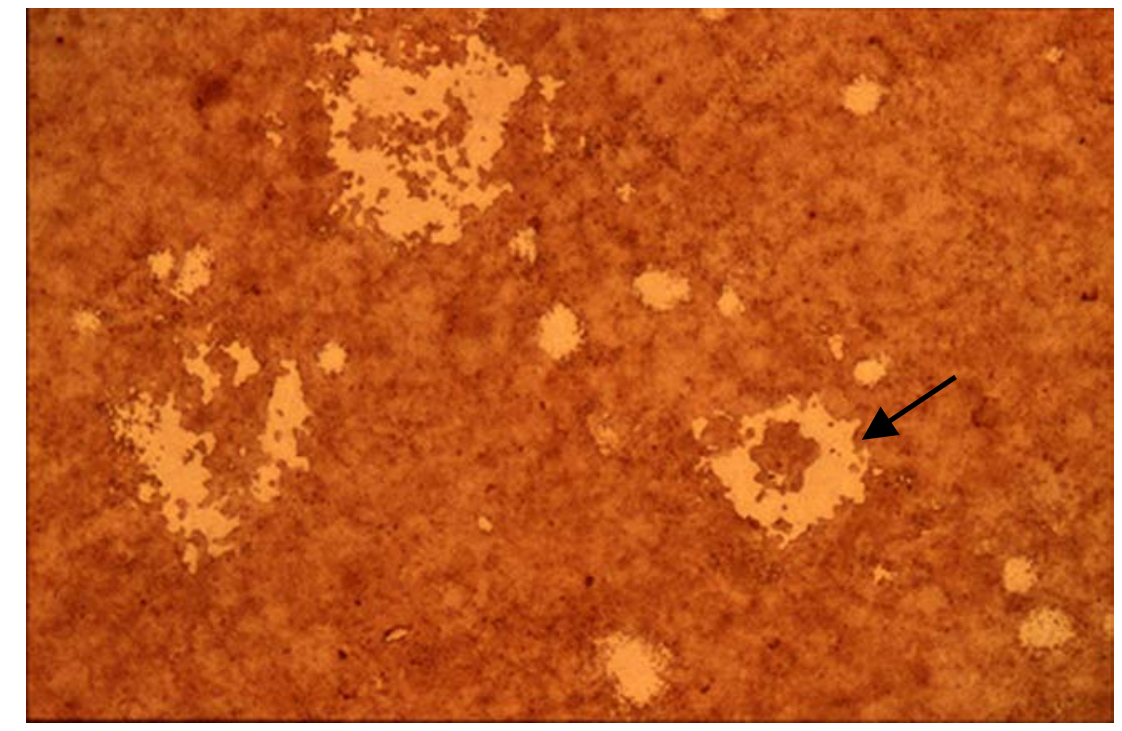

Abbildung 25: Lichtmikroskopische Aufnahme der Resorptionslakunen in der Beschichtung der CP-Plättchen, (x 800)

Eine quantitative Analyse der Plättchen erfolgte mittels stereometrischen Verfahren. Wie bereits lichtmikroskopisch zu erkennen ist, war die Calciumphosphatresorption auf dem Plättchen der Spenderin Sp3 am höchsten: 45 \% der Beschichtung wurde abgebaut. Bei Spenderin Sp4 wurden hingegen nur 24 \% resorbiert, bei Spender Sp1 waren es 15 $\%$ und bei Sp2 fehlten nur $4 \%$ der Beschichtung. 


\subsection{Untersuchungen zur Beteiligung von aktivierten Fibroblasten an}

\section{Knochen-Resorptionsprozessen}

\section{$\underline{\text { 3.5.1 Auswahl des Zellmaterials }}$}

Bislang galten Osteoklasten neben Odontoklasten als die einzigen Zellen, die zur Resorption von Knochensubstanzen befähigt sind. Odontoklasten resorbieren vorzugsweise Dentin und Zement, können aber auch Knochen angreifen.

Klinische Studien im Rahmen der Osteoporose-Forschung haben Zweifel daran aufkommen lassen, ob Osteoklasten allein an der Bildung von Knochenerosionen verantwortlich sind, da trotz Hemmung der resorptiven Aktivität der Osteoklasten durch Bisphosphonate und Calcitonin die gesteigerte Knochendegradation nicht aufgehalten wurde (SILEGHEM et al., 1992; EGGELMEIJER et al., 1996).

Möglicherweise sind aktivierte Fibroblasten, wie im folgenden erläutert, maßgeblich an Resorptionsprozessen bei Erkrankungen beteiligt, bei denen es zur Knochendestruktion durch hyperplastisches Gewebe kommt.

\subsubsection{Synoviale Fibroblasten von Patienten mit rheumatoider Arthritis}

Die rheumatoide Arthritis manifestiert sich vor allem als chronische Entzündung der Gelenkinnenhäute (Synovium). Sie kann durch Erosionen von Gelenkknorpel und -knochen bis $\mathrm{zu}$ einer vollständigen Gelenkzerstörung führen. Den RA synovialen Fibroblasten wird eine Schlüsselrolle bei der Knorpeldestruktion zugeschrieben. In einem Modellsystem konnte gezeigt werden, das synoviale Fibroblasten von Patienten mit rheumatoider Arthritis (RA synoviale Fibroblasten) in Abwesenheit von anderen Zellen in der Lage sind, Knorpel zu zerstören (MÜLLER-LADNER et al., 1996). Der Gelenkknorpel wird durch bestimmte Proteasen zerstört, die vor allem von den aktivierten synovialen Fibroblasten abgegeben werden (PAP et al., 2000). Zu den Matrix-degradierenden Proteasen gehören die Matrix-Metalloproteinasen (MMPs) wie Kollagenasen, Gelatinasen sowie die Kathepsine. An den Stellen, an der die Knorpelzerstörung bis an die Knochengrenze reicht, kommt es zur Knochendestruktion. In diesen Bereichen wurden nicht nur Osteoklasten, sondern auch Fibroblasten gefunden, die Kathepsin K mRNA exprimieren (HUMMEL et al., 1998). Das Kathepsin K Protein wurde später durch HOU et al., 2001, in RA synovialen Fibroblasten 
nachgewiesen. Bislang wurde Kathepsin $\mathrm{K}$ hauptsächlich im Zusammenhang mit Osteoklasten beschrieben. Des Weiteren haben OTSU et al., 2000, eine Osteoklastenähnliche v-ATPase in aktivierten RA synovialen Fibroblasten gefunden.

In den Abbbildungen 26 a - d sind histologische Schnitte von Gewebeproben aus dem Bereich des Synoviums mit angrenzendem Knochen eines an rheumatoider Arthritis erkrankten Patienten zu sehen. Osteoklasten wurden mittels TRAP-Färbung sichtbar gemacht. Die Pfeile in Abbildung 26 a zeigen auf violett-bräunlich gefärbte, zum Teil mehrkernige Zellen, die als Osteoklasten identifiziert wurden. In Abbildung 26 b sind von Osteoblasten gebildete Knochenbälkchen dargestellt. Abbildungen $26 \mathrm{c}$ und $\mathrm{d}$ demonstrieren das Auftreten verschiedener Zellarten im Bereich von Knochenerosionen. Die roten Pfeile zeigen auf Osteoklasten, während die schwarze Pfeile mononukleäre Zellen markieren, die im Bereich von Knochenerosionen vorkommen und keine TRAP-positive Färbung aufweisen.
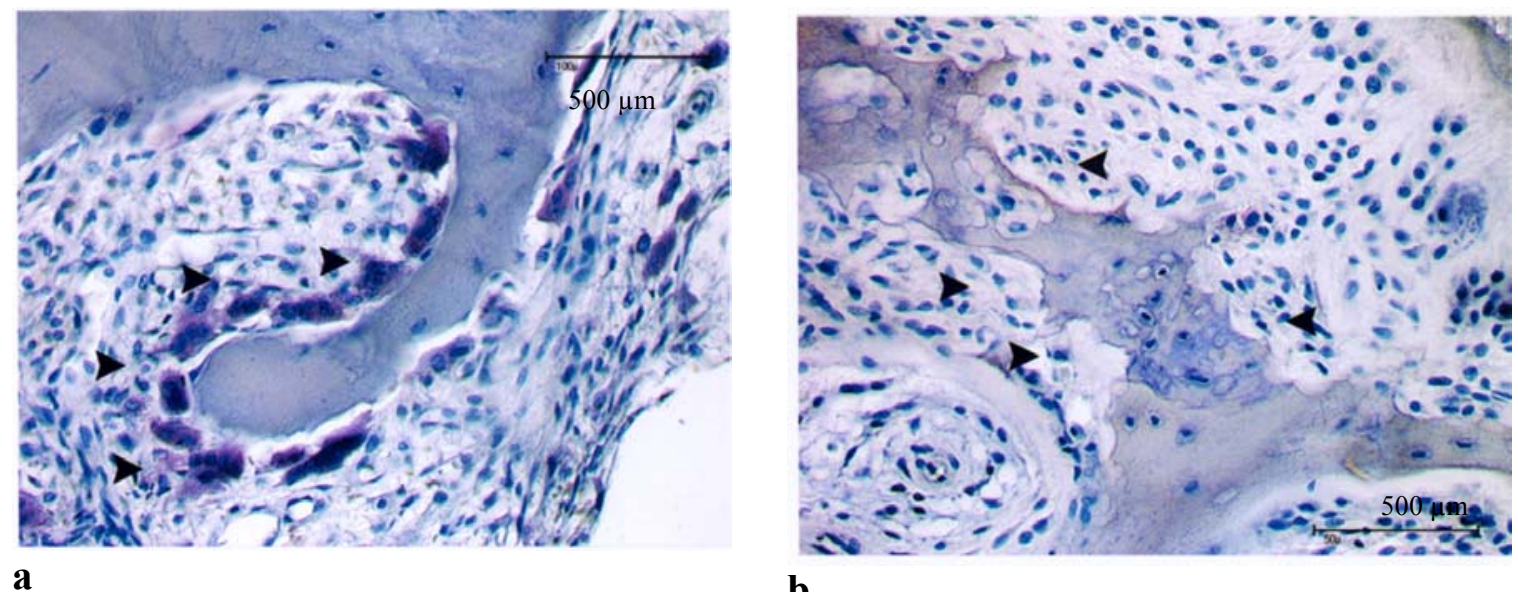

$\mathbf{a}$

b

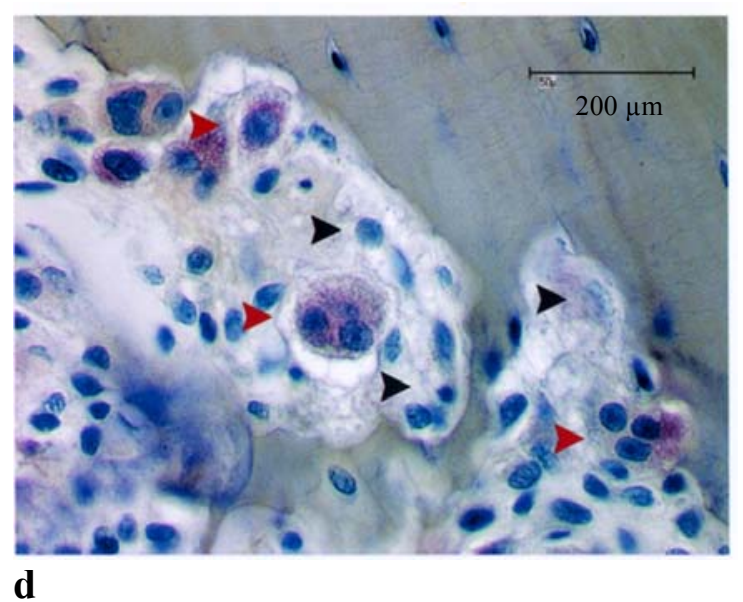

Abbildungen 26 a - d: Lichtmikroskopische Aufnahmen histologischer Schnitte von Gewebeproben (RA Patienten), TRAP- u. Hämatoxylin-Färbung 
Aufgrund der dargelegten Hinweise wurden Fibroblasten, die aus Synovialgewebe oder synovialer Flüssigkeit von Patienten mit rheumatoider Arthritis isoliert wurden, in dem unter 3.3.1 etablierten Resorptionsassay eingesetzt und bezüglich ihrer Fähigkeit untersucht, knochenähnliches Hartgewebe abzubauen. Außerdem wurden RA synoviale Fibroblasten verwendet, die freundlicherweise von Prof. S. Gay, University Hospital Zurich, Switzerland, zur Verfügung gestellt wurden.

\subsubsection{Humane Fibroblasten aus einer Membran im Bereich einer Prothesenlockerung}

Weitere, in dem Kultursystem eingesetzte, aktivierte Fibroblasten stammen aus einer Membran, die sich an der Knochenoberfläche bei einer aseptischer Prothesenlockerung gebildet hat. Untersuchungen von GOLDRING et al., 1983, haben gezeigt, dass diese Membran Ähnlichkeiten mit dem hyperplastischen Synovium bei der rheumatoiden Arthritis aufweist. Auch die aus dieser Membran isolierten Prothesenlockerungs(PL) Fibroblasten zeigen Übereinstimmungen mit den synovialen Fibroblasten (RA Patienten), u.a. hinsichtlich der Produktion matrixabbauender Proteasen (MMP's sowie Kathepsine) und der Expression einer v-ATPase (PAP et al., 1999). Im Gegensatz zu den RA Fibroblasten, die sich bei einer Erkrankung aus der dünnen Synovialmembran entwickeln, stammen die PL Fibroblasten mutmaßlich direkt von mesenchymalen Vorläuferzellen des Knochenmarks ab. Die PL Fibroblasten wurden freundlicherweise von Dr. T. Pap, Abt. Experimentelle Rheumatologie, Universität Magdeburg, zur Verfügung gestellt und dort mittels FACS-Analyse charakterisiert. 99 \% der Zellen waren mit den Fibroblastenmarkern Prolyl-4-Hydroxylase positiv gefärbt. Die FACS-Färbung mit dem Makrophagenmarker CD68 war in allen Kulturen negativ $(<0,1 \%)$.

\subsubsection{Prothesenlockerungs-Fibroblasten aus einem ICSS Wistar Rattenmodell}

Um PL Fibroblasten hinsichtlich ihrer Fähigkeit zur Hartgeweberesorption in einem frühen Stadium der Membranbildung bei einer Prothesenlockerung zu untersuchen, wurden Zellen aus einem ICSS Wistar Rattenmodell in dem Resorptionsassay eingesetzt. An der Universität Magdeburg, Abt. Experimentelle Rheumatologie, wurden ausgewachsenen männlichen Wistar Ratten Tibia Gelenkprothesen in das linke Knie 
implantiert. Die Tiere wurden anschließend in ein Laufrad gesetzt und durch intrakraniale Eigenstimulation (intracranial self stimulation = ICSS) zum vermehrten Laufen angeregt. Mit dieser Methode konnte die normale Laufaktivität 100fach gesteigert werden (PAP, G. et al., 2001) und führte zur Bildung einer Membran zwischen der Knochenoberfläche und der Prothese, die der unter 3.4.1.2 beschriebenen Membran aus dem Bereich der humanen Prothesenlockerung sehr ähnlich war. Der Unterschied bestand in dem frühen Bildungsstadium der Ratten-Membran. Nach 12 Wochen konnte eine Prothesenlockerung festgestellt werden. $\mathrm{Zu}$ diesen Zeitpunkt wurde die Membran, die sich an der Knochenoberfläche gebildet hatte, aus der Ratte entnommen. Nach Isolierung der Zellen aus dem Gewebe und Kultivierung über 4 Passagen, wurden die Ratten PL Fibroblasten wie unter 3.5.1.2 beschrieben mittels FACS-Analyse charakterisiert. Über $99 \%$ der Zellen waren hinsichtlich der Fibroblastenmarker positiv gefärbt, aber negativ bezüglich des Antikörpers gegen CD68. Auch die PL Fibroblasten aus dem Rattenmodell wurden für den Einsatz im Resorptionsassay von der Abt. Experimentelle Rheumatologie der Universität Magdeburg zur Verfügung.

\subsubsection{Charakterisierung RA synovialer Fibroblasten}

Vor dem Einsatz im Dentin-Resorptionsassay wurden die RA synovialen Fibroblastenkulturen mittels FACS-Analyse und RT-PCR charakterisiert. Die Expression des Kathepsin K, einer der wichtigsten Zystein-Proteasen bei der Knochendegradation, wurde zusätzlich auf Proteinebene mittels Western-Blot nachgewiesen.

\subsubsection{FACS-Analyse}

RA synoviale Fibroblastenkulturen der 5. Passage wurden in der Durchflusszytometrie mit dem Fibroblasten-Antikörper D-7FIB charakterisiert. Die Untersuchung der Zellkulturen mit forward und sideward scatter ergab eine homogene Population, die für die weitere Analyse eingegrenzt wurde (Abbildung 27 a). Die grüne Kurve in Abbildung 27 b zeigt die indirekte Färbung mit dem Fibroblastenmarker. Die rote Kurve stellt die negative Isotypenkontrolle dar. Als Negativkontrolle für Verunreinigungen der Kulturen mit Leukozyten wurde ein monoklonaler Antikörper gegen CD45 verwendet. In Abbildung $27 \mathrm{c}$ ist die direkte Färbung mit dem CD45 
Antikörper zu erkennen. Die Isotypenkontrolle ist in Abbildung $27 \mathrm{~d}$ dargestellt. Es wurden keine CD45 positiven Zellen in den Kulturen gefunden.
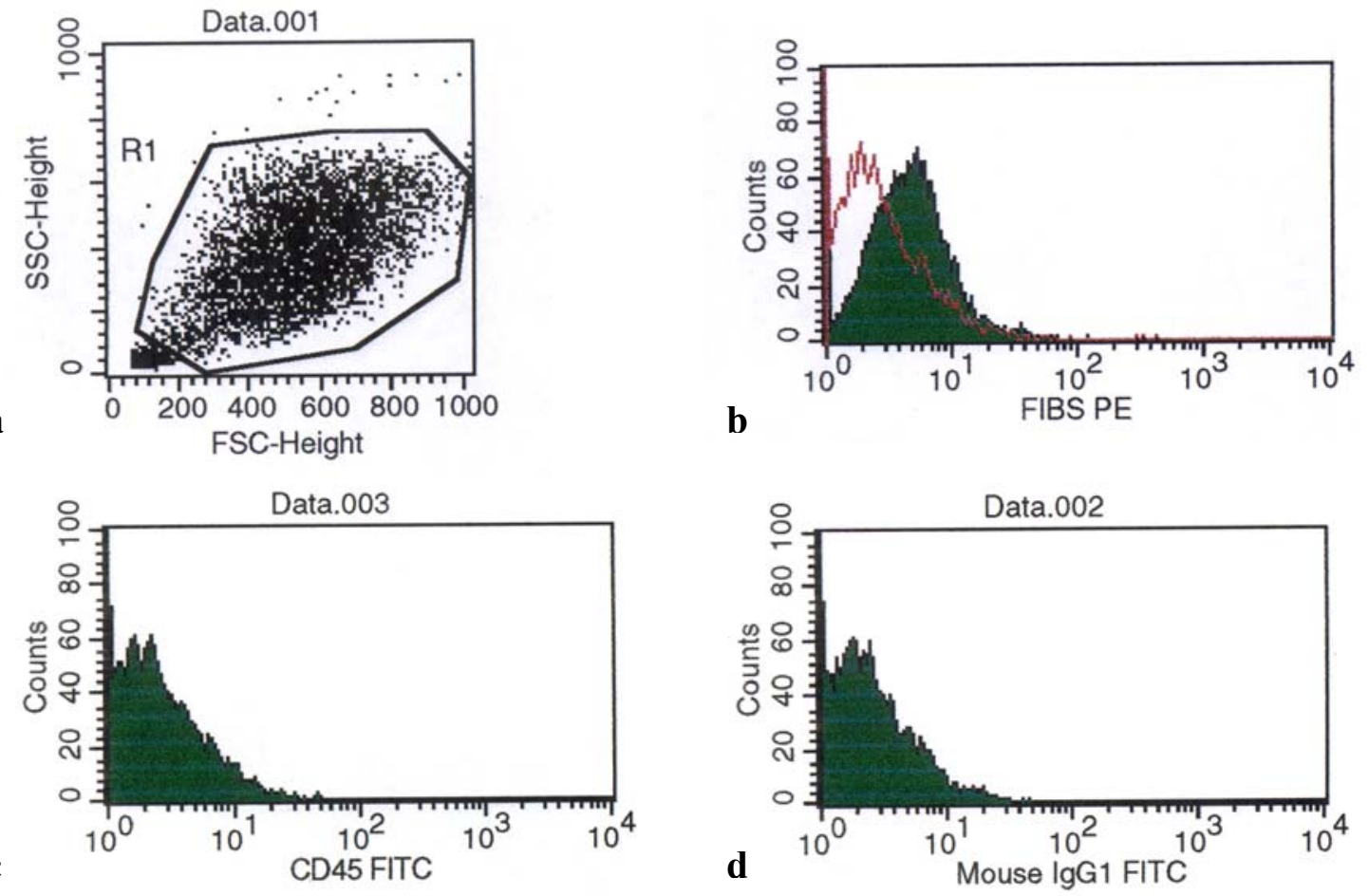

Abbildungen 27 a - d: FACS-Analyse RA synovialer Fibroblasten

\subsubsection{RT-PCR mit Osteoklastenmarkern}

Die Analyse der RA synovialen Fibroblasten mittels RT-PCR mit den Osteoklastenmarkern RANK und CTR sollte den Nachweis erbringen, dass sich keine Osteoklasten oder Osteoklasten-Vorläuferzellen in den Kulturen befinden. Die verwendeten Primersequenzen sind unter 3.2.3 aufgeführt. Für die RA synovialen Fibroblastenkulturen konnten nach Amplifikation über 35 Zyklen keine Signale bezüglich der Osteoklastenmarker CTR und RANK gefunden werden (Abbildung 28 a und $b$ ). Hingegen zeigten sich für die als Positivkontrolle mitgeführten Osteoklasten cDNA Fragmente, die mit der erwarteten Größe übereinstimmten. Die E-Actin-Kontrolle war für alle RA Fibroblasten bei 25 Zyklen Amplifikation positiv (s. Abbildung $9 \mathrm{c}$ ). 


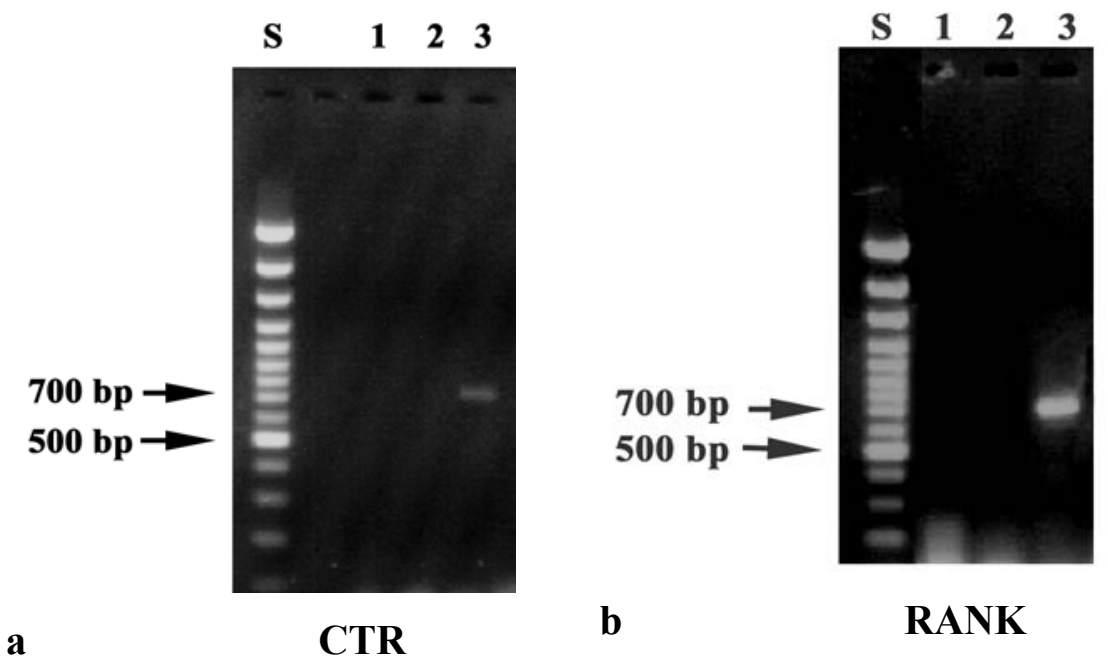

Abbildungen 29 a + b: Analyse der RT-PCR mit spezifischen Primern für

a) CTR (782 bp) und b) RANK (704 bp)

Spur 1 u. 2: keine Produkte aus RA synovialer Fibroblasten RNA Spur 3: Produkte aus Osteoklasten RNA als Positivkontrolle

Für die RT-PCR mit Kathepsin K wurden positive Signale mit den RA synovialen Fibroblasten erzielt (Abbildung 28 c). HUMMEL et al, 1998, wiesen Kathepsin K mRNA in RA Fibroblasten nach, die im Bereich von Knochenerosionen und adhärierenden Synovium gefunden wurden.

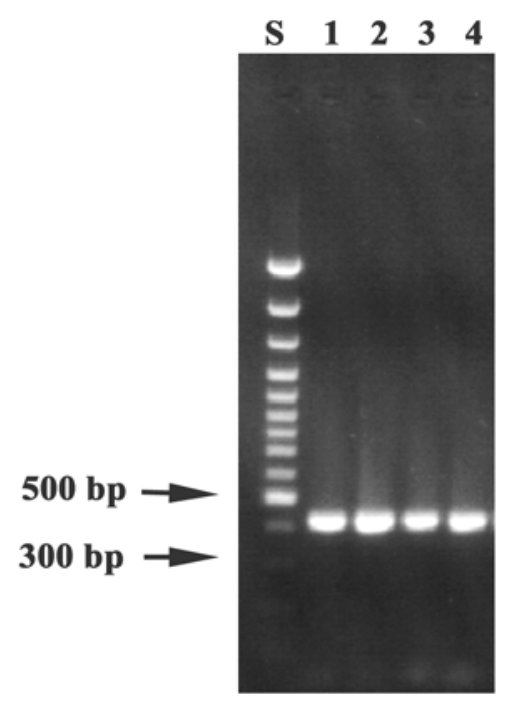

Abbildung 29 c: RT-PCR-Analyse mit spezifischen Primern für Kathepsin K (450 bp) Spur 1 - 3: Produkte aus RA synovialer Fibroblasten RNA Spur 4: Produkt aus Osteoklasten RNA als Positivkontrolle 
Da die Osteoklastenmarker TRAP und VNR bei Fibroblasten aus der embryonalen Lunge bzw. aus der Gingiva (s. 3.2.) gefunden wurden, sind diese Faktoren nicht zur Fibroblasten-Charakterisierung herangezogen worden.

\subsubsection{Nachweis von Kathepsin K im Western Blot}

Um zu zeigen, dass die für den Knochenabbau wichtige Zysteinprotease Kathepsin K auch auf Proteinebene in RA synovialen Fibroblasten exprimiert wird, wurde eine Western Blot Analyse durchgeführt. Parallel hierzu wurde der Nachweis dieser Protease für Osteoklastenkulturen geführt. Als Positivkontrolle diente rekombinantes Kathepsin K. Die aus den RA synovialen Fibroblasten- und Osteoklastenkulturen gewonnenen Proteine (s. 2.8) wurden aufkonzentriert (s. 2.10), in einer SDS-PAGE aufgetrennt (s. 2.11) und auf eine PVDF-Membran auftragen. Um die Übertragung der Proteine auf die Membran zu überprüfen, wurden die Proteine mit Ponceau S Rot gefärbt. Nach Entfärbung erfolgte die Detektion mit einem Primärantikörper gegen Kathepsin K. Bei der anschließende Exposition auf dem Röntgenfilm konnten bei den ersten Experimenten keine positiven Signale gefunden werden. Erst nachdem auf die Färbung mit Ponceau S Rot verzichtet wurde, zeigte sich für das rekombinante Kathepsin K eine deutliche Markierung auf Höhe des SDS-Standards für die Carboanhydrase bei $31 \mathrm{kDa}$. Auch in den Laufspuren der Proteine RA synovialer Fibroblasten und der Osteoklastenproteine wurden nun Banden detektiert, die der berechneten molekularen Masse von $31 \mathrm{kDa}$ des Kathepsin K entsprachen (Abbildung 30).

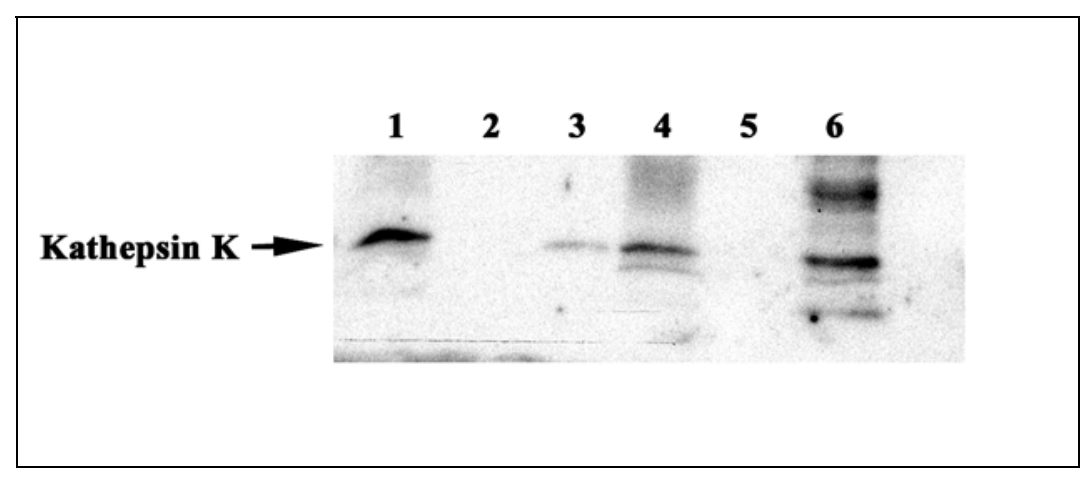

Abbildung 30: Western-Blot mit Antikörper gegen Kathepsin K,

Spur 1: Osteoklastenproteine

Spur 3: rekombinantes Kathepsin K

Spur 4 und 6: Proteine RA synovialer Fibroblasten 


\subsection{Rasterelektronenmikroskopische Darstellung aktivierter}

\section{Fibroblasten auf Dentin}

Um die Fähigkeit von aktivierten Fibroblasten zur Resorption von knochenähnlichen Substanzen in vitro zu untersuchen, wurden 6 Kulturen mit RA synovialen Fibroblasten sowie 4 humane PL Fibroblastenkulturen als auch 1 Kultur mit PL Fibroblasten aus der Ratte für 4 und 6 Wochen auf Pottwaldentin inkubiert. Die Kulturen wurden vor dem Einsatz im Resorptionsassay mindestens fünfmal passagiert. Lichtmikroskopische Kontrollen zeigten, dass die Zellen gut auf den Dentinplättchen adhärierten und während der gesamten Inkubationsdauer vital waren. Anschließend wurden die Dentinstücke fixiert und für die REM aufgearbeitet.

\subsubsection{Oberflächenmorphologie der Fibroblastenkulturen}

Die rasterelektronenmikroskopischen Aufnahmen bestätigten die bereits im Lichtmikroskop erkennbare Vitalität und gute Adhäsion der eingesetzten Fibroblastenkulturen auf dem Pottwaldentin. Die Zellen hatten das Dentinstück nach Ablauf der Inkubationsdauer vollständig bewachsen. Die RA synovialen Fibroblasten (Abbildung 31 a) und die humanen PL Fibroblasten (Abbildung 31 b) sahen morphologisch gleich aus. Die Zellen sind durchschnittlich $60 \mu \mathrm{m}$ lang x $20 \mu \mathrm{m}$ breit und haben eine meist glatte Membranoberseite. RA synoviale Fibroblasten und humane PL Fibroblasten zeigen eine bipolare Ausrichtung, während die PL Fibroblasten aus dem Rattenmodell auch flächig ausgebreitete, rundliche Formen annehmen (Abbildung $31 \mathrm{c}$ ). In allen Kulturen wurden nur fibroblastenartige Zellen gefunden.

Eine Detailaufnahme (Abbildung 31 d) zeigt einen kleinen Bereich des Dentins, der nicht mit Zellen besetzt ist. Auf der, von Zellrändern RA synovialer Fibroblasten begrenzte, Substratfläche ist eine, von den Zellen abgegebene, netzartige Substanz zu erkennen ist (s. Pfeil). Eine derartige Benetzung der Oberfläche wurde bei keiner der Osteoklastenkulturen, die auf Dentin inkubiert wurden, gefunden. 
Abb. 31 a

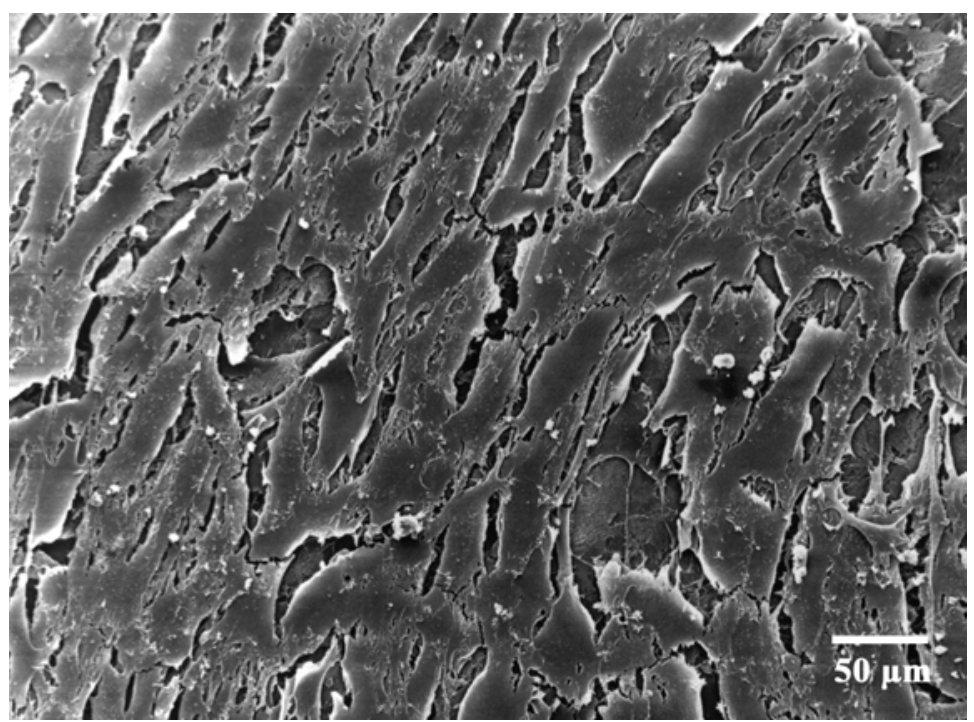

Abb. 31 b

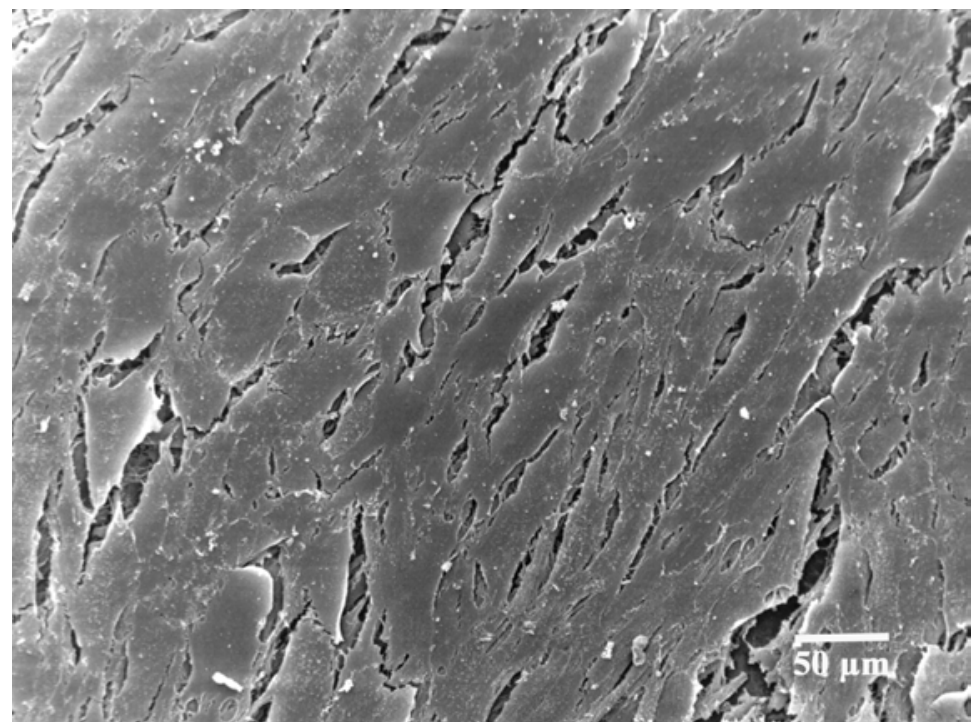

Abb. 31 c

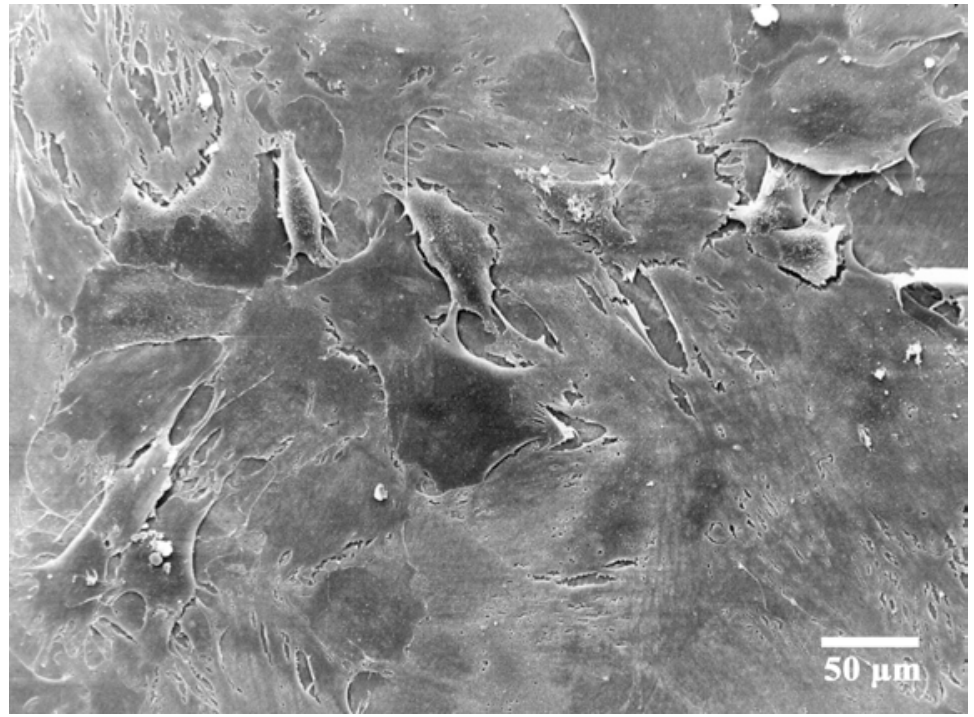

Abbildungen 31 a - c: RA synoviale Fibroblasten (a) und humane PL Fibroblasten (b) u. PL Fibroblasten aus dem Rattenmodell (c) auf Pottwaldentin nach 4-wöchiger Inkubation, REM-Aufnahme 


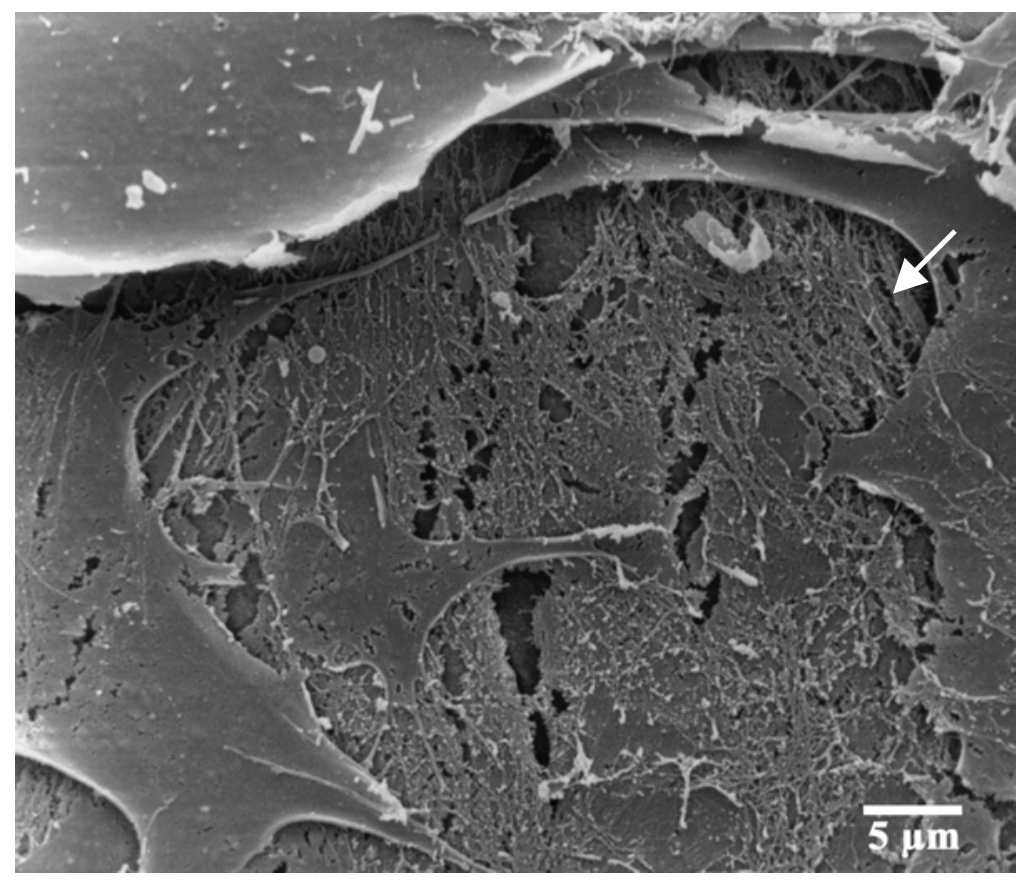

Abbildung 31 d: Netzartige Substanz zwischen den Zellrändern RA synovialer Fibroblasten auf Pottwaldentin, 4-wöchige Inkubation, REM-Aufnahme

\section{$\underline{\text { 3.6.2 Resorptive Veränderungen im Pottwaldentin durch aktivierte Fibroblasten }}$}

Nach 4- bzw. 6-wöchiger Inkubation der RA synovialen Fibroblasten- und PL Fibroblastenkulturen auf Dentin und anschließender Darstellung im Rasterelektronenmikroskop, wurden die Zellen mit der Tape-Methode (s. 2.15) vom Substrat entfernt. Nach erneuter Bedampfung der Präparate, wurden die Substratoberflächen im REM untersucht. Bei 5 der 6 Kulturen mit RA synovialen Fibroblasten wurden resorptive Veränderungen im Dentin gefunden, die an die frühen Resorptionsstadien der Osteoklasten erinnerten (Abbildung 32 a). Es sind kleine, runde Vertiefungen mit rauher Oberfläche, die einem Durchmesser von $2-5 \mu \mathrm{m}$ aufweisen (s. Pfeile). Auch bei den PL Fibroblasten aus dem Rattenmodell und bei 2 der 4 humanen PL Fibroblastenkulturen wurden derartige Veränderungen im Dentin gefunden (Abbildungen $32 \mathrm{~b}$ und c). Die Durchmusterung der Dentinpräparate ergab, dass keine tiefen Resorptionslakunen, wie bei den Osteoklastenkulturen, gebildet wurden. Außerdem wurde deutlich, dass meist in einem Bereich gehäuft Veränderungen auftraten. Mehrere dieser Anhäufungen waren auf einem Präparat verteilt. Andere Bereiche der Dentinoberfläche blieben hingegen unverändert. 
Abb. 32 a

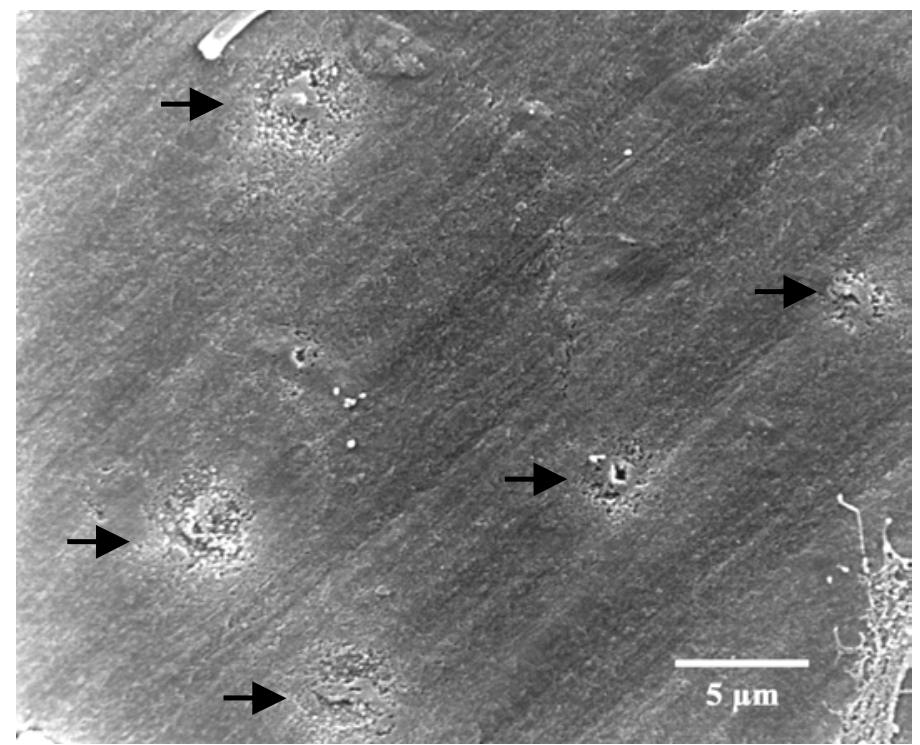

Abb. 32 b

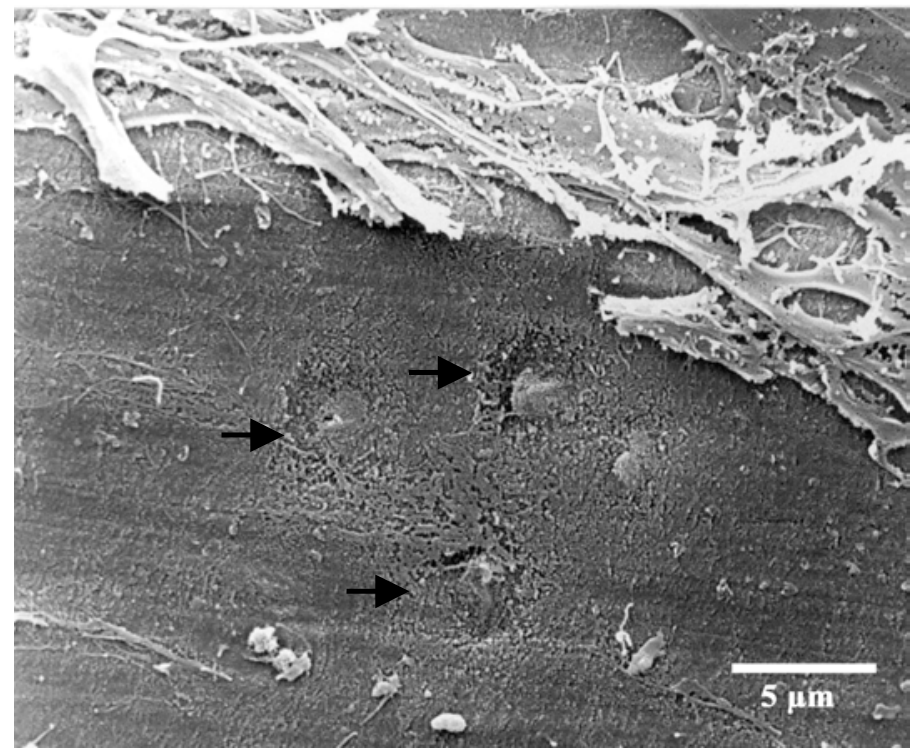

Abb.32 c

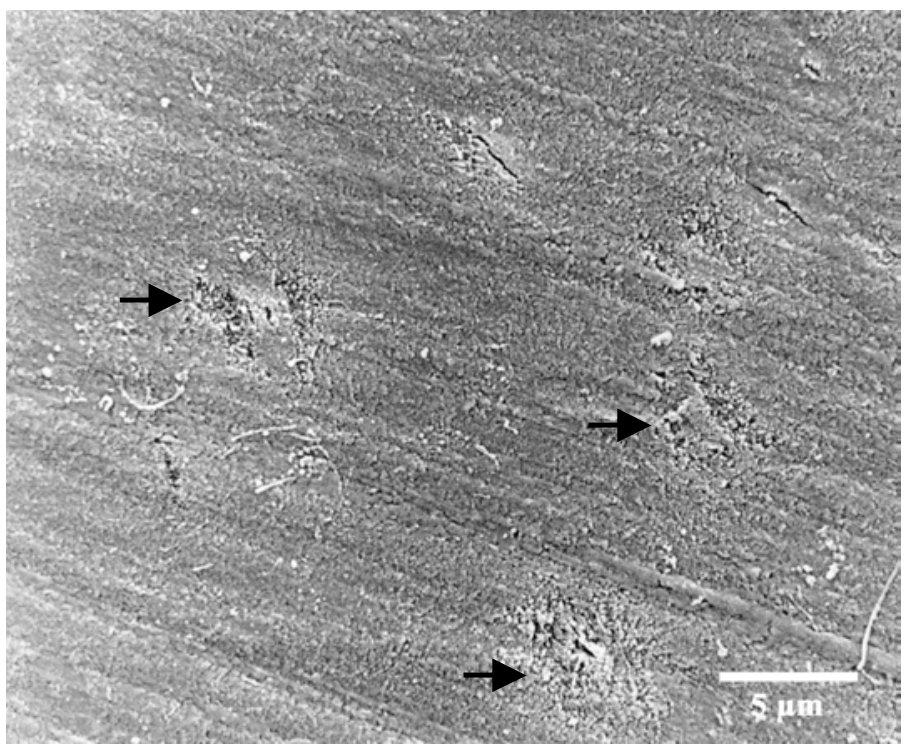

Abbildungen 32 a - c: rundliche Vertiefungen im Pottwaldentin nach 6-wöchiger Inkubation mit Fibroblasten, Zellen abgelöst, REM-Aufnahme 
Abbildung 33 zeigt eine Übersicht über die als Resorptionszonen bezeichneten Vertiefungen, die sich als punktförmige Aufhellungen darstellen. Bei Inkubationszeiten unter 4 Wochen waren bei allen Kulturen keine Veränderungen an der Substratoberfläche erkennbar.

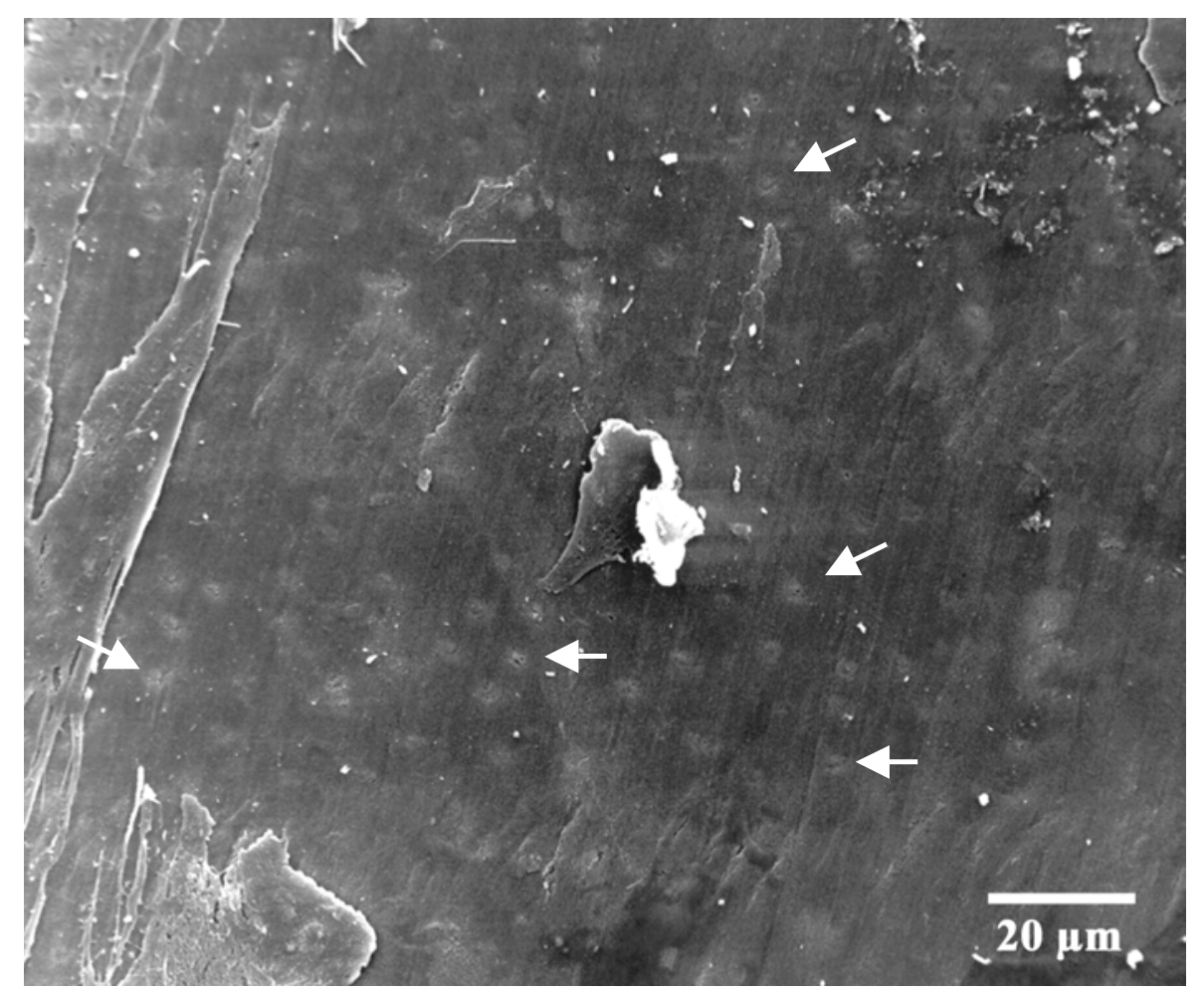

Abbildung 33: Resorptionszonen im Pottwaldentin nach 6wöchiger Inkubation mit RA synovialen Fibroblasten, Zellen abgelöst, REM- Aufnahme (Pfeile zeigen nur einige der vielen Vertiefungen an)

\subsubsection{Hemmung RA synovialer Fibroblasten im Dentin-Resorptionsassay}

Zur Analyse der matrixdegradierenden Fähigkeiten aktivierter Fibroblasten, wurde den Kulturen mit RA synovialen Fibroblasten während der 6 Wochen Inkubationszeit auf dem Dentin alle 3 Tage Bafilomycin $A_{1}$ zugesetzt. Bafilomycin $A_{1}$ interagiert mit der vATPase (BOWMANN et al., 1988) und führt bei Osteoklasten zu einer Hemmung der resorptiven Aktiviät.

Die Zugabe von $10^{-6} \mathrm{M}$ Bafilomycin $\mathrm{A}_{1}$ war für die Zellen letal. Bei Konzentrationen von $10^{-7}$ und $10^{-8} \mathrm{M}$ hingegen, waren die RA synovialen Fibroblasten über 6 Wochen vital. Nach Ablösen der Zellen und Durchmusterung der Dentinoberfläche im REM 
konnten keine resorptiven Veränderungen gefunden werden (Abbildung 34 a). Bei der mitgeführten Kontrolle ohne Bafilomycin $A_{1}$ konnten nach Entfernung der Zellen Resorptionszonen im Dentin dargestellt werden (Abbildung 34 b).

Abb. 34 a

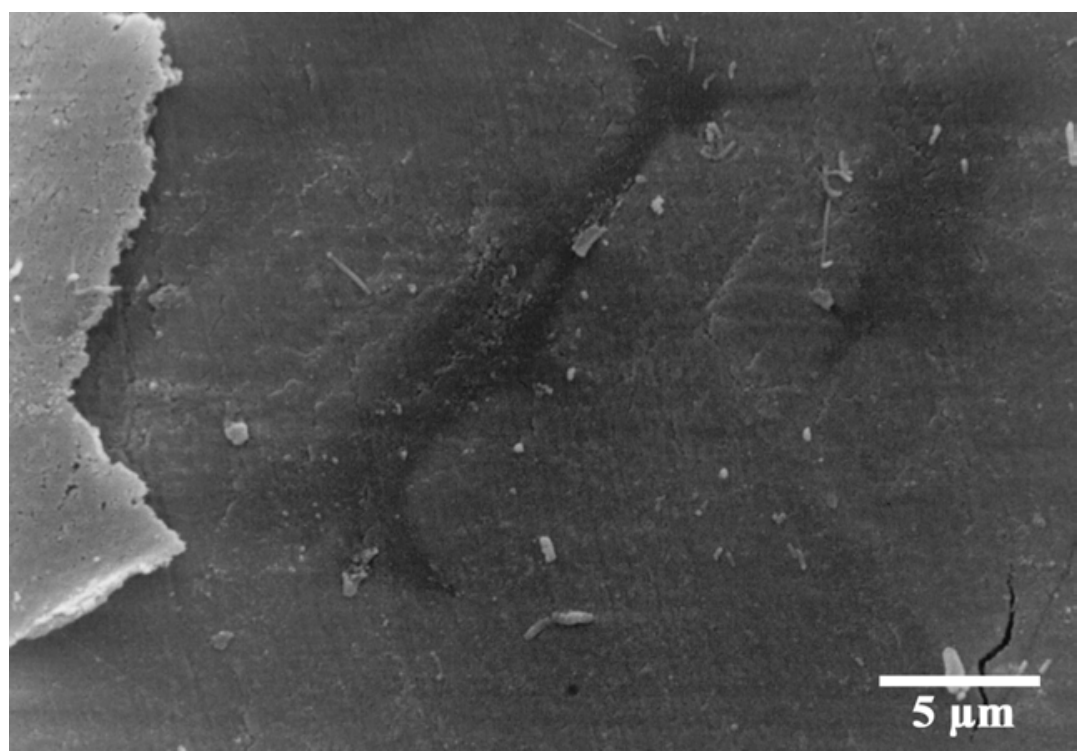

Abb. 34 b

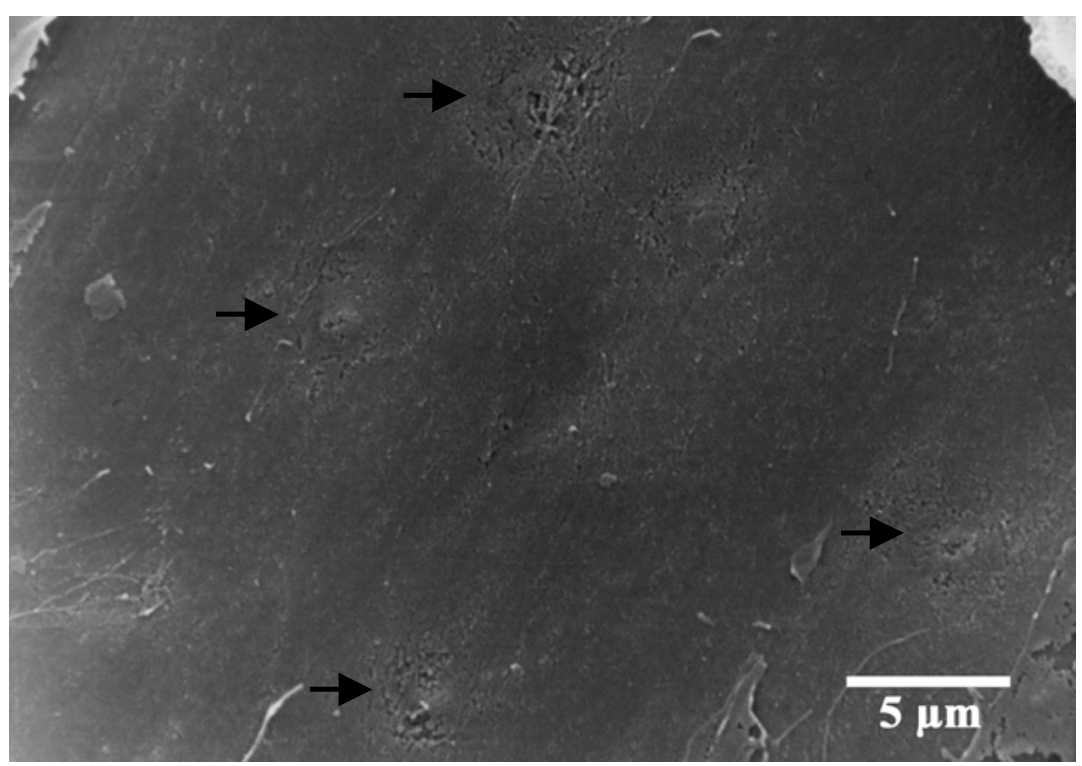

Abbildungen 34 a + b: Oberfläche des Pottwaldentins nach 6-wöchiger Inkubation mit RA synovialen Fibroblasten

a) mit $10^{-7} \mathrm{M}$ Bafilomycin $\mathrm{A}_{1}$ als Kulturzusatz

b) ohne Bafilomycin $\mathrm{A}_{1}$,

Zellen abgelöst, REM-Aufnahme 


\subsubsection{Stimulierung RA synovialer Fibroblasten im Dentin-Resorptionsassay}

Für Stimulierungsversuche wurden den RA synovialen Fibroblasten im Resorptionsassay für 6 Wochen $10 \mathrm{ng} / \mathrm{ml}$ TNF-D zugesetzt. Es konnten für alle 6 Zellkulturen resorptive Veränderungen im Dentin festgestellt werden, einschließlich der Kultur mit negativen Ergebnis ohne Stimulation. Es wurden auch hier keine tiefen Resorptionslakunen, wie sie bei den Osteoklastenkulturen entstehen, gefunden.

\subsubsection{Darstellung der Substratseite RA synovialer Fibroblasten}

Zur Untersuchung der Substratseite RA synovialer Fibroblasten wurden Zellen verwendet, deren resorptive Aktivität bereits anhand rasterelektronen-mikroskopischer Aufnahmen der Veränderungen im Dentin demonstriert worden ist (s. 3.4.3.2). Die mittels Tape-Methode (s. 2.15) abgehobenen Zellen wurden mit der Unterseite nach oben auf Objektträgern befestigt und bedampft. Die rasterelektronenmikroskopische Aufnahme (Abbildung 35 a) zeigt den Ausschnitt einer Zellunterseite. Die Membran der Fibroblastenunterseite ist im wesentlichen glatt, während die Osteoklastenunterseite auch verzweigte, unregelmäßige Membranfaltungen aufweist (vergleiche Abbildungen $21 \mathrm{a}-\mathrm{c}$ ).

An einigen Membranbereichen wurden leichte Vertiefungen von 2-4 $\mu \mathrm{m}$ Durchmesser festgestellt (Abbildung 35 a). Außerdem waren Vesikel-ähnliche Strukturen, wie sie an der Substratseite der Osteoklasten gezeigt wurden (vergleiche Abbildung 21 a), auch an der Fibroblastenunterseite zu finden (Abbildung 35 b). Diese rundlichen Löcher hatten einen Durchmesser von 2 - $5 \mu \mathrm{m}$ (s. Pfeil). Im Vergleich zu den Osteoklasten, waren die Anzahl der Vesikel bei den RA synovialen Fibroblasten geringer. Die zum Vergleich kontrollierte Oberseite der Zellen wies derartige Strukturen nicht auf. 
Abb. 34 a

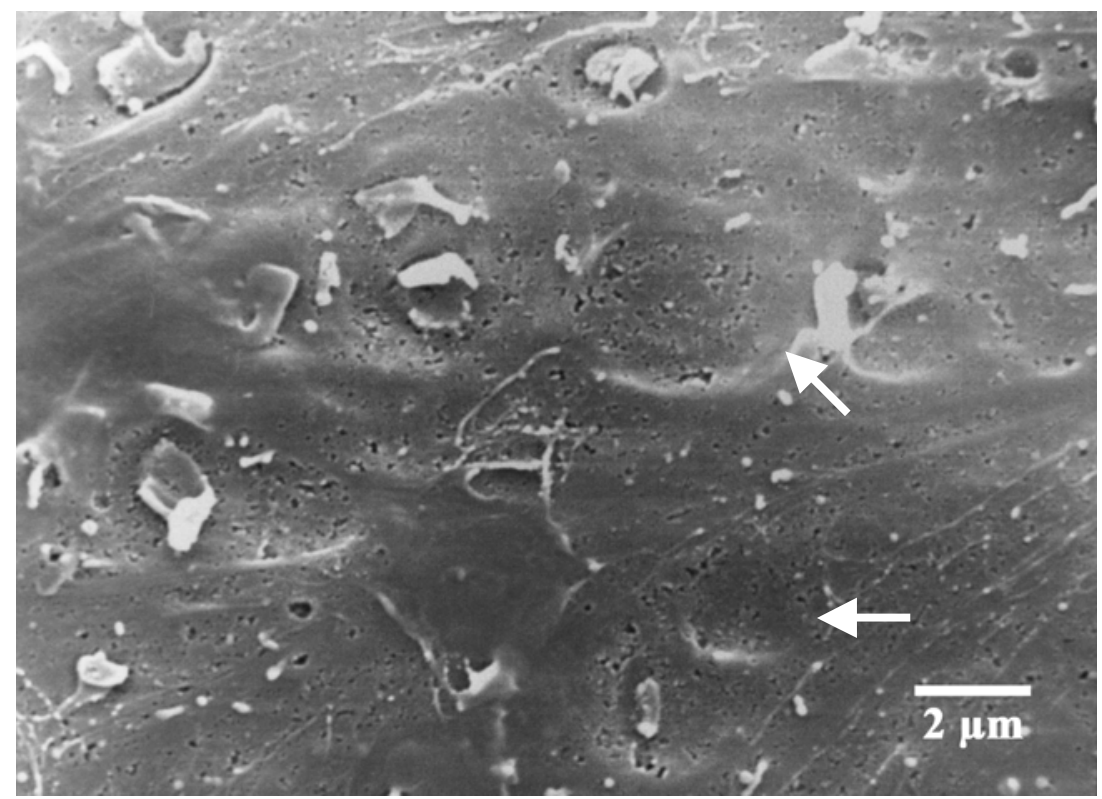

Abb. 34 b

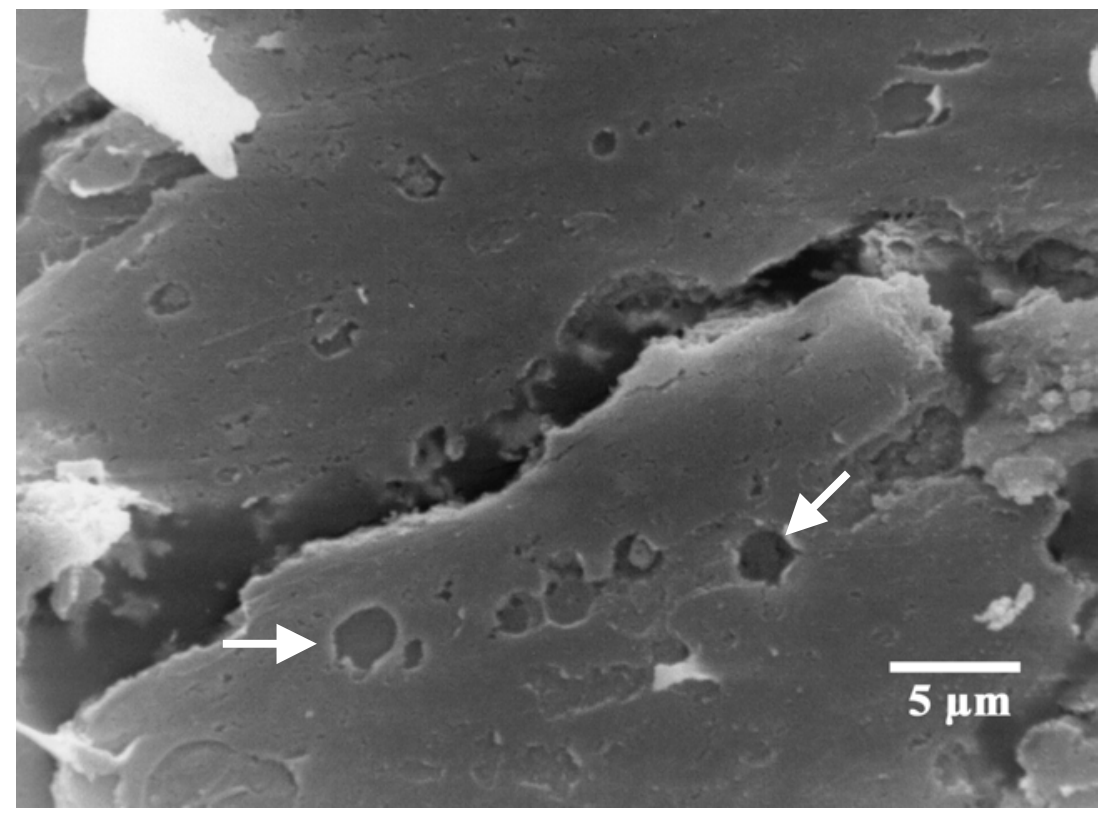

Abbildungen 34 a + b: Substratseite RA synovialer Fibroblasten mit Vesikel-ähnlichen Strukturen, REM-Aufnahme 


\section{Diskussion}

Unter physiologischen Bedingungen wird Knochen im Rahmen der Calciumhomöostase, des Wachstums sowie mechanischer Beanspruchung ständigen Umbauprozessen unterworfen. Für den stetigen Auf- und Abbau des Knochens, auch „remodelling“ genannt, sind Osteoklasten und Osteoblasten verantwortlich. Die Remodellierung erfolgt nach dem Prinzip der primären Lakunenbildung durch resorbierende Osteoklasten und nachfolgender Knochenbildung durch Osteoblasten.

Bei bestimmten Krankheitszuständen gerät der dynamische Umbauprozess durch gesteigerte Knochenresorption oder verminderte Knochenneubildung aus dem Gleichgewicht. Diese Situation führt in der Bilanz zu einem Knochenverlust. Von besonderem Interesse für die vorliegende Arbeit ist die gesteigerte Knochenresorption bei der rheumatoiden Arthritis. Diese chronisch entzündliche Gelenkserkrankung führt im Verlauf charakteristischerweise zu einer Zerstörung des Knorpels und des Knochens der betroffenen Gelenke, die klinisch als Gelenkfehlstellung und Versteifung imponiert. Pathophysiologisch entwickelt sich aus der normalerweise ein- bis zweilagigen Synovialmembran unter der Wirkung proinflammatorischer Zytokine ein tumorartiges Gewebe, der sogenannte Pannus, der Knorpel und Knochen invadiert und destruiert. Knochendestruktion durch ein fibroproliferatives Gewebe ist ein Phänomen, das auch bei der aseptischen Prothesenlockerung auftritt. Durch biomechanische, tribologische oder oberflächenstrukturelle Einflüsse bildet sich zwischen Prothese und Knochenoberfläche eine bindegewebige Membran, die Ähnlichkeiten mit dem entzündlich proliferierenden Synovium der rheumatoiden Arthritis aufweist. An der hyperplastischen Grenzmembran kommt es zu einer gesteigerten Knochenresorption, die nach Jahren eine Prothesenlockerung zur Folge haben kann.

Nach TEITELBAUM, 2000, ist Knochenresorption an spezifische Funktionen von Osteoklasten oder Osteoklasten-ähnliche Zellen der Monozyten-/Makrophagenlinie gebunden. Nur für diese Zellen ist bisher die Fähigkeit der Knochendemineralisation durch Ansäuerung des extrazellulären Milieus beschrieben (AMLING et al., 1997). Studien der letzten Jahre haben Hinweise darauf gegeben, dass neben den Osteoklasten auch aktivierte synoviale Fibroblasten an der rheumatischen Knochendestruktion beteiligt sind (HUMMEL et al., 1998). 
Bei histologischen Untersuchungen von rheumatischen Gelenken wurden in den Destruktionszonen der betroffenen Knochen neben Osteoklasten und deren Vorläuferzellen auch Fibroblasten gefunden. Die synovialen Fibroblasten von Patienten mit rheumatoider Arthritis (RA synoviale Fibroblasten) sind als sehr stoffwechselaktive Zellen beschrieben, die in der Lage sind über die Produktion matrixdegradierender Proteasen Knorpelmatrix abzubauen. Ähnliche Merkmale weisen Fibroblasten auf, die aus der Grenzmembran bei der aseptischen Prothesenlockerung isoliert werden, sogenannte Prothesenlockerungs- (PL-) Fibroblasten.

Im Rahmen dieser Arbeit wurde die direkte Beteiligung der RA synovialen Fibroblasten sowie humaner PL-Fibroblasten und PL-Fibroblasten aus einem Rattenmodell an Knochenresorptionsvorgängen untersucht. Die Analyse der Abbauprozesse erfolgte in einem in vitro System, in dem die resorptiven Fähigkeiten der Zellen durch Bildung von Aushöhlungen in knochenähnlicher Matrix demonstriert werden können. Zur Etablierung des in vitro Systems wurden humane Osteoklasten verwendet und in verschiedenen Stadien der Resorption definiert, um eine Grundlage für Vergleiche mit Fibroblasten zu schaffen.

Zunächst wurden die humanen Osteoklasten aus peripheren Blutmonozyten herandifferenziert und mittels (immun-) zytochemischer Nachweisverfahren sowie RTPCR charakterisiert. Anschließend wurden die Osteoklasten in dem in vitro System morphologisch und funktionell bei dem Prozess der Matrixresorption untersucht. Die Ultramorphologie der Osteoklasten ist bislang nur teilweise erfasst. Es gibt transmissionselektronenmikroskopische Aufnahmen, die resorbierende Osteoklasten im Querschnitt zeigen. Diese weisen auf der Substratseite eine vielfach gefaltete Membran auf, die als „ruffled border“ bezeichnet wird (LOMEGA et al., 1999). Die zum Beginn dieser Arbeit bekannten rasterelektronenmikroskopischen Aufnahmen geben Osteoklasten lediglich in der Aufsicht wieder.

Zur Aufklärung der morphologischen Struktur und für Vergleiche mit den Fibroblasten wurden in dieser Arbeit rasterelektronenmikroskopische Untersuchungen von der Oberseite als auch von der Substratseite der Osteoklasten durchgeführt. Um die verschiedenen Stadien der Resorptionsprozesse $\mathrm{zu}$ untersuchen, wurden die Osteoklasten für verschiedene Zeitspannen auf der knochenähnlichen Matrix inkubiert und abschließend für die REM aufgearbeitet. Außerdem wurden Osteoklasten, deren 
Vorläuferzellen von verschiedenen SpenderInnen stammten, bezüglich ihrer Gestalt und ihrer resorptiven Fähigkeiten vergleichend untersucht.

Die RA synovialen Fibroblasten wurden aus synovialer Flüssigkeit und Synovialgewebe isoliert und mittels FACS Analyse, RT-PCR und Western Blot charakterisiert. Humane PL-Fibroblasten und PL-Fibroblasten aus einem Rattenmodell wurden freundlicherweise von Dr. T. Pap, Abt. Experimentelle Rheumatologie am Zentrum Innere Medizin der Universität Magdeburg zur Verfügung gestellt. Die Analyse von resorptiven Fähigkeiten erfolgte durch Inkubation dieser Zellen auf knochenähnlicher Matrix in dem in vitro System und anschließender Aufarbeitung der Proben für REM.

\subsection{Differenzierung von Osteoklasten}

Osteoklasten stammen von der Monozyten/Makrophagenlinie ab (UDAGAWA et al., 1990) und sind terminal differenzierte Zellen. Die Isolierung dieser Zellen direkt aus dem Knochen oder dem Knochenmark gestaltet sich schwierig und wenig effektiv, da sie beim Erwachsenen nur eine kleine Population darstellen, weniger als $1 \%$ der Knochenoberfläche bedecken und fest auf der Matrix haften. Die Entwicklung von Methoden der in vitro Differenzierung von Osteoklasten in Kokulturen von Knochenmarkzellen und Osteoblasten in den letzten zwanzig Jahren (BURGER et al., 1982, UDAGAWA et al., 1990, TAKAHASHI et al., 1994) haben neben der zytologischen auch eine funktionelle Analyse dieser Zellen ermöglicht und die Vorstellungen über die Resorptionsprozesse wesentlich erweitert. TAKAYANAGI et al. zeigte 1997, dass Osteoklasten-ähnliche Zellen auch in Kokulturen von peripheren Blutmonozyten mit rheumatoiden synovialen Fibroblasten unter Zugabe von M-CSF und 1,25-Dihydroxyvitamin $\mathrm{D}_{3}$ gebildet werden können. Diese Zusatzstoffe galten bis dahin als essentielle und direkte Faktoren für Differenzierung und Wachstum der Osteoklasten.

Zusammen mit anderen Zytokinen fördert M-CSF die Proliferation und Differenzierung von hämatopoietischen Stammzellen zu Makrophagen. M-CSF-Knockoutmäuse zeigen eine Verminderung der Makrophagenzahl, besitzen keine Osteoklasten und entwickeln eine Osteopetrose (WIKTOR-JEDRZEJCZAK et al., 1990). Bei der Osteopetrose, auch Marmorknochenkrankheit genannt, ist der Knochenabbau bei erhaltener Knochenbildung eingeschränkt. Die Folgen sind keulenförmig aufgetriebene 
Knochenenden, die Verödung des Markraums und marmorartig verdichtete Knochen. M-CSF wird von Osteoblasten und stromalen Zellen produziert. Die Stimulierung der Osteoklastendifferenzierung erfolgt direkt über Bindung von M-CSF an seinen Rezeptor auf den Vorläuferzellen. Für diesen Rezeptor kodiert das Protoonkogen $c$-fms. c-fms wird sowohl von Vorläuferzellen als auch von terminal differenzierten Osteoklasten exprimiert (TANAKA et al., 1993) und führt nach Aktivierung zu einer Motilitätssteigerung und zum Schutz vor Apoptose (FULLER et al., 1993). Außerdem zeigten ARAI et al., 1999, dass M-CSF an der Induktion des RANK (Receptor Activator of Nuclear Factor NB (NF-kB)) auf Osteoklastenvorläuferzellen beteiligt ist.

Ein direkter Einfluss auf Osteoklastenvorläuferzellen scheint nach neuen Untersuchungen für 1,25-Dihydroxyvitamin $\mathrm{D}_{3}$ jedoch nicht $\mathrm{zu}$ bestehen. Es wird angenommen, dass 1,25-Dihydroxyvitamin $\mathrm{D}_{3}$ die RANKL (Receptor Activator of Nuclear Factor NB (NF-kB) Ligand)-Expression in Osteoblasten und/oder stromalen Zellen induziert und somit die Osteoklastendifferenzierung und die Fusion von mononukleären Vorläuferzellen indirekt über RANKL stimuliert wird (KITAZAWA et al., 1999, ROODMAN, 1999). Reife Osteoklasten exprimieren Vitamin D Rezeptoren, aber es ist nicht bekannt, ob 1,25-Dihydroxyvitamin $\mathrm{D}_{3}$ die Zellen direkt beeinflusst (MENAA et al., 1997). Eine Wirkung von 1,25-Dihydroxyvitamin $\mathrm{D}_{3}$ auf den Knochenabbau ist jedoch nachgewiesen. Unter dem stimulierenden Einfluss des Parathormons erhöht 1,25-Dihydroxyvitamin $\mathrm{D}_{3}$ die osteoklastäre Knochenresorption (ROODMAN, 1999). Die Behandlung mit 1,25-Dihydroxyvitamin $\mathrm{D}_{3}$ führte bei Mäusen zu einer Hyperkalzämie (ABE et al., 1989).

Der 1998 erstmals beschriebene Differenzierungsfaktor RANKL und sein membranständiger Rezeptor RANK sind Mitglieder der TNF-(Tumor Necrosis Factor) Familie (LACEY et al., 1998) bzw. der TNF-Rezeptor-Superfamilie (ANDERSON et al., 1997). Die Bindung von RANKL an seinen Rezeptor führt über Interaktionen mit TRAF (TNF-Receptor assoziated Factor) 1, 2, 3, 5 und 6 zur Differenzierung und Aktivierung der Osteoklasten, wobei TRAF6 scheinbar zur Aktivierung des Transkripionsfaktors NFNB führt. Die TRAF's sind Signaltransduktionsmoleküle, die als Adapter zwischen dem zellmembranständigen RANK und NFNB bzw. JNK (c-Jun N-terminal Kinase) vermitteln. Nach LI et al., 2000, entwickeln RANK-Knockoutmäuse ebenso wie M-CSF-Knockoutmäuse aufgrund fehlender Osteoklasten eine schwere Osteopetrose. 
Nach heutigem Wissensstand sind unter physiologischen Bedingungen RANKL (KONG et al., 1999) und M-CSF (YOSHIDA et al., 1990) essentiell für die Osteoklastenentwicklung. Bei Erkrankungen mit gesteigerter Knochenresorption wie beispielsweise der rheumatoiden Arthritis und Osteoporose sind zusätzlich möglicherweise auch andere Faktoren beteiligt (SUDA et al., 2001). So spielt z.B. TNF-D, in Anwesenheit von M-CSF, anscheinend über Bindung an die beiden Oberflächenrezeptoren TNFR (TNF Receptor Type)-1und -2 unter Signaltransduktion über TRAF 2 für die Osteoklastendifferenzierung eine wichtige Rolle. IL-1 scheint in ähnlicher Weise wie RANKL über Interaktion mit TRAF6 und NFNB die Osteoklastenaktivierung zu induzieren (KOBAYASHI et al., 2000). SUDA et al., 2001, zeigten, dass Osteoklasten in vitro unter der alleinigen Wirkung von TNF-D und IL-1 herandifferenziert und aktiviert werden konnten. Diese beiden Faktoren, die unter pathologischen Bedingungen eine wichtige Rolle spielen, stellten in der Studie einen Ersatz für RANKL im gesamten osteoklastären Resorptionsprozess dar.

Als mit den Experimenten zu dieser Arbeit begonnen wurde, war die wichtige Funktion des RANKL bei der Osteoklastendifferenzierung gerade bekannt geworden. Als rekombinantes Protein war RANKL zu diesem Zeitpunkt aber noch nicht kommerziell erhältlich. Die Differenzierung von humanen Osteoklasten wurde daher zunächst nach der Methode von TAKAYANAGI et al., 1997, versucht. Hiernach wurden periphere Blutzellen in Kokultur mit synovialen Fibroblasten unter Zugabe von 2 ng/ml M-CSF und $10^{-7} \mathrm{M}$ 1,25-Dihydroxyvitamin $\mathrm{D}_{3}$ über 4 Wochen kultiviert. Aus Gründen der unterschiedlichen Proliferationsrate wurde außerdem ein zahlenmäßiges Verhältnis von 10:1 zwischen der Monozyten/Lymphozyten-Fraktion und den synovialen Fibroblasten beachtet. Auf diese Weise wurden multinukleäre Zellen herandifferenziert, die Charakteristika von Osteoklasten aufwiesen. Aufgrund der hohen Proliferationsrate nahm unter diesen Bedingungen der relative Anteil an RA synovialen Fibroblasten in den Kulturen sehr schnell zu und die Ausbeute an Osteoklasten in diesen Vorversuchen war nur gering.

Zur Optimierung der Differenzierungsbedingungen wurden in Vorversuchen unterschiedliche Anreicherungsmethoden der Monozyten aus peripherem Blut verwendet. Von der über Ficoll-Separation aus peripheren Blutzellen isolierten Monozyten/Lymphozyten-Fraktion wurden die Monozyten mittels sogenannter Plastikadhäsion sowie alternativ durch Negativselektion unter Verwendung von 
„Dynabeads“ angereichert. Parallel dazu wurde die Monozyten/Lymphozyten-Fraktion unverändert in den Zellkulturen eingesetzt. Die Differenzierung der Zellen erfolgte über einen Zeitraum von 4 Wochen. Nach Ablauf der Inkubationszeit wurden schwach adhärierende Zellen, durch Inkubation der Zellkulturen in einer Pronase E/EDTA -Lösung von den fest adhärierenden Osteoklasten abgetrennt. Beide Anreicherungsmethoden stellten einen höheren Aufwand bei der Durchführung der Experimente dar und erbrachten dennoch keine Vorteile gegenüber dem unveränderten Einsatz der Monozyten/Lymphozyten-Fraktion. Hingegen wurde sogar festgestellt, dass sich die Kultivierung der nicht weiter angereicherten Monozyten zusammen mit den Lymphozyten positiv auf die Osteoklastenausbeute auswirkte, was möglicherweise auf die Expression von membrangebundenen RANKL durch T-Lymphozyten zurückzuführen ist. Nach WONG et al., 1997, und ANDERSON et al., 1997, produzieren T-Lymphozyten RANKL.

Die Vorversuche zur Etablierung einer effizienten Differenzierungsmethode waren aufgrund der Kultivierungsdauer von 4 Wochen und der mehrfach durchgeführten Experimente zur Ermittlung vergleichbarer Zellzahlen sehr zeitaufwendig. Nachdem RANKL als rekombinantes Protein kommerziell erhältlich war, konnten die Differenzierungsbedingungen wesentlich vereinfacht werden. Monozyten/Lymphozyten wurden ohne Anwendung weiterer Anreicherungsmethoden und ohne Zugabe von mesenchymalen Zellen mit $50 \mathrm{ng} / \mathrm{ml}$ RANKL und $25 \mathrm{ng} / \mathrm{ml} \mathrm{M-CSF} \mathrm{(LADER} \mathrm{et} \mathrm{al.,}$ 2000) inkubiert. Nach dieser Differenzierungsmethode konnte in einem kürzeren Zeitraum ein höherer Osteoklastenanteil erzielt werden.

Die Methodik bot weiterhin die Möglichkeit, Osteoklasten- und Fibroblastenkulturen in dem folgenden Dentin-Resorptionsassay gegenüberzustellen. Da Osteoklasten nun ohne Koinkubation mit mesenchymalen Zellen herandifferenziert wurden, konnten die Veränderungen im Dentin nur auf die Aktivität der Osteoklasten zurückgeführt werden. Damit war ein direkter Vergleich mit den Dentinveränderungen, die durch Fibroblastenkulturen hervorgerufen wurden, möglich.

\subsection{Charakterisierung von Osteoklasten}

Osteoklasten werden als knochenresorbierende vielkernige Zellen beschrieben, die von hämatopoietischen Vorläuferzellen abstammen (ASH et al., 1980, KURIHARA et al., 1989) und durch Fusion mononukleärer Zellen entstehen (ROODMAN et al., 1987). 
Die Reifung der mononukleärer Zellen steht am Anfang der Entwicklung zum Osteoklasten. Die sich anschließende Fusion der einkernigen Zellen zu vielkernigen Osteoklasten wird nach ROODMAN, 1999, indirekt von 1,25-Dihydroxyvitamin $\mathrm{D}_{3}$ und dem Parathormon beeinflusst. Reife Osteoklasten sind lichtmikroskopisch als große, vielkernige Zellen zu erkennen.

Zur Charakterisierung der Osteoklasten wird die Morphologie, der Nachweis bestimmter Proteine und die Knochenresorption herangezogen. Morphologisches Merkmal des reifen Osteoklasten ist neben der Größe von 30 bis über $100 \mu \mathrm{m}$ Durchmesser nach BARON et al., 1986, die Vielkernigkeit. Als Osteoklastenmarker gelten die TRAP, der VNR, der CTR, das Kathepsin K und der RANK. Diese Marker sind jedoch nicht spezifisch.

Eines der Enzyme, die im Laufe der Osteoklastendifferenzierung sehr früh exprimiert werden, ist die TRAP (ROODMAN, 1999). Dieses Enzym wird in Osteoklasten vermehrt produziert und wurde in Lysosomen, dem Golgi-Apparat sowie im Bereich der „ruffled border“ nachgewiesen (ANDERSSON et al., 1991). Die TRAP ist an physiologischen Knochenumbauprozessen und an der Regulation der Calciumhomöostase beteiligt. Der RANK wird nach einer Studie von SHALHOUB et al., 2000, bereits auf peripheren, Blutmonozyten - ohne vorherige Stimulation mit Zytokinen - exprimiert. Über die Bindung von RANKL dient dieser Rezeptor der Transduktion von Signalen, die die Osteoklastendifferenzierung induzieren. Nach Untersuchungen von LADER et al., 2000, sind VNR-positive Zellen am 3. bis 4. Tag der Osteoklastendifferenzierung zu finden. Über den VNR werden Adhäsionsprozesse der Zelle sowie Umstrukturierung des Zytoskeletts gesteuert. Kathepsin K gehört zu den Enzymen, die erst später in der Entwicklung zum reifen Osteoklasten gebildet werden. Bei Knochenabbauprozessen ist Kathepsin $\mathrm{K}$ eines der wichtigsten Matrixdegradierenden Enzyme. Der CTR wird erst am Ende des osteoklastären Differenzierungsprozesses gebildet. Über Bindung von Calcitonin an den CTR kann die Resorptionsaktivität reifer Osteoklasten inhibiert werden.

Erst der Nachweis aller Faktoren, kombiniert mit der Demonstration der knochenresorptiven Fähigkeiten, erlaubt eine eindeutige Identifizierung von reifen und funktionsfähigen Osteoklasten.

Die funktionelle Bedeutung der Vielkernigkeit ist noch unklar. Anhand der Untersuchungen von CONNOR et al., 1995 wurden Resorptionsprozesse durch 
mononukleäre Osteoklasten im humanen Osteophyten nachgewiesen, die Osteoarthritis-Patienten im Rahmen einer Arthroplastik entfernt wurden. Diese einkernigen Zellen exprimierten die TRAP, waren aber negativ bezüglich der nicht spezifischen D-Naphthyl Acetat Esterase (NSE). In den Resorptionslakunen wurden neben diesen Osteoklasten auch mononukleäre Zellen gefunden, die NSE-positiv und TRAP-negativ waren, sowie Zellen, die für beide Enzyme negativ und positiv waren. Nach Interpretation des Autors entwickeln sich aus NSE-positiven und TRAP-negativen mononukleären Zellen NSE- und TRAP-positive Zellen, die sich weiter zu TRAPpositiven und NSE-negativen mononukleären Zellen differenzieren, aus denen dann im weiteren Verlauf multinukleäre Zellen entstehen, die TRAP-positiv sind. Somit findet mutmaßlich im Laufe der Entwicklung eine Umschaltung von einer NSE-positiven auf eine TRAP-positive mononukleäre Zelle statt, die erst dann resorptiv aktiv ist. Unterstützt wird diese These durch den Nachweis steigender Osteopontin mRNA Expression in der oben genannten Reihenfolge der Zellen, wobei NSE-positive/TRAPnegative Zellen keine Osteopontin mRNA exprimierten und multinukleäre TRAPpositive Zellen die höchste Expression zeigten (CONNOR et al., 1995). Das Protein Osteopontin wurde in hohen Konzentrationen in Osteoklasten (DODDS et al., 1994b) sowie in Osteoblasten und Osteozyten (WEINREB et al., 1990) nachgewiesen. Nach CHELLAIAH und HRUSKA, 1996, bindet Osteopontin an den VNR im Bereich der osteoklastären Podosomen und stimuliert Zytoskelettumstrukturierungen sowie die Knochenresorption.

Studien von HATTERSLEY und CHAMBERS, 1989, ergaben, dass die Fähigkeit zur Knochenresorption der Osteoklasten mit der Expression des CTR korreliert, aber nicht die Vielkernigkeit mit der Knochenresorption. Außerdem wurden bei in vivo Untersuchungen von DOMON et al., 1991, in Mäusen mononukleäre Osteoklasten gefunden, die Knochensubstanz resorbierten.

In der vorliegenden Arbeit wurden bei der Charakterisierung von Osteoklasten mittels (immun-) zytochemischer Nachweisfahren neben multinukleären Zellen auch stets mononukleäre Zellen gefunden, die Marker reifer Osteoklasten aufwiesen. Die o.g. Untersuchungen von CONNOR et al., 1995, lassen vermuten, dass es sich bei diesen Zellen um funktionsfähige mononukleäre Osteoklasten handelt. 
Der Nachweis der Osteoklastenmarker wurde in den Experimenten zu dieser Arbeit für die TRAP zytochemisch mit einem kommerziellen Testsystem und für Kathepsin K, VNR und RANK immunzytochemisch mit spezifischen Antikörpern durchgeführt. Eine RT-PCR wurde zusätzlich zu den oben genannten Markern auch für CTR etabliert. Die (immun-) zytochemischen Nachweise erfolgten anhand von Zytospinpräparaten, die am 3., 6., 9. und 30. Tag der Osteoklastenreifung angefertigt wurden.

Den Literaturangaben entsprechend (ROODMAN, 1999) konnte die TRAP an den Zytospinpräparaten bereits am 3. Tag auf $30 \%$ der Zellen nachgewiesen werden. Der Anteil der TRAP positiven Zellen stieg im Laufe der Inkubationszeit bis auf $70 \%$ am 30. Tag an.

Die Experimente ergaben weiterhin, dass RANK bereits am 3. Tag der Inkubationszeit von $35 \%$ der Zellen exprimiert wurde und somit zu den frühen Markern in der Entwicklung zum Osteoklasten gehört. Am 30. Tag betrug der Anteil RANK-positiver Zellen $70 \%$.

Am 3. Tag der Inkubationszeit waren $5 \%$ der Zellen VNR-positiv. Bis zum 30. Tag stieg der Anteil der VNR-positiven Zellen auf $70 \%$.

Die Kathepsin K Expression wurde erst später während der Osteoklastendifferenzierung, am 9. Tag der Inkubationszeit, auf den Zytospinpräparaten nachgewiesen. Bis zum 30. Tag erhöhte sich der Anteil auf $70 \%$ positiver Zellen.

Anhand des Tages, an dem die Vorläuferzellen bezüglich des jeweiligen Osteoklastenmarkers positiv gefärbt waren und anhand des Anteils positiv gefärbter Zellen lässt sich folgende Reihenfolge aufstellen:

\section{Tag: RANK, TRAP, VNR - 9. Tag: Kathepsin K}

Die Auflistung gibt den zeitlichen Ablauf der Proteinexpression während der Osteoklastendifferenzierung in den Experimenten dieser Arbeit wieder.

Mit der RT-PCR wurde die mRNA Expression des CTR, der TRAP, des RANK, des VNR und des Kathepsin $\mathrm{K}$ in Zellen nach 14tägiger Differenzierung zu reifen Osteoklasten analysiert. Es wurden für alle Osteoklastenmarker positive Signale erhalten. Mit dem Nachweis des CTR wurde gezeigt, dass sich in den Kulturen auch reife Osteoklasten befanden. 
Die Darstellung der Osteoklastenmarker zu verschiedenen Zeitpunkten während der Differenzierung lieferte am Rande der eigentlichen Untersuchungen einen Einblick in den zeitlichen Ablauf der Proteinexpression auf Vorläuferzellen. Die Expression der TRAP, des VNR und des RANK konnten bereits am 3. Tag der Differenzierung auf den Zellen nachgewiesen werden. Studien von SHALHOUB et al., 2000, erbrachten den Nachweis, dass RANK bereits auf den mononukleären peripheren Blutzellen exprimiert wird. Scheinbar erhöhte sich der Anteil der RANK-positiven Zellen durch das Absterben anderer Zellen, da die Kulturbedingungen für die Differenzierung von Osteoklasten optimiert waren. Die Expression des VNR begann, den Literaturangaben von LADER et al., 2000, entsprechend am 3. Tag der Differenzierung. Daher waren am 3. Tag nur wenige Zellen VNR-positiv gefärbt, deren Anteil am 6. Tag bereits auf das 4 fache gestiegen war und im Laufe der Entwicklung weiter zu nahm. Kathepsin K hat als Matrix-degradierendes Enzym eine Funktion während der Knochenresorption und wurde daher vermutlich erst später, von den Osteoklasten exprimiert. Zwischen dem 7. und 9. Tag der Osteoklastendifferenzierung wurde in den Experimenten zu dieser Arbeit die Kathepsin K Expression induziert.

Die Charakterisierung der Zellen ergab, dass in den Resorptionsversuchen Kulturen eingesetzt wurden, die neben reifen multinukleären Osteoklasten auch OsteoklastenVorläuferzellen in verschiedenen Stadien der Differenzierung enthielten. Da nach 14tägiger Differenzierung Kathepsin K bereits auf den Zellen exprimiert war, wurde der Zeitraum von 14 Tagen im folgenden als Differenzierungsdauer für die Osteoklasten gewählt. Anschließend wurden die Osteoklasten zum Nachweis ihrer Funktionalität auf eine knochenähnliche Matrix umgesetzt.

\section{$\underline{4.3 \text { Osteoklasten im Dentin-Resorptionsassay }}$}

Mit humanen Osteoklasten wurde ein Dentin-Resorptionsassay in Anlehnung an Literaturbeschreibungen etabliert (BOYDE et al., 1984, SCHWARTZ et al., 2000). Zunächst wurde die Morphologie der Osteoklasten im REM mit Beschreibungen aus der Literatur verglichen. Die funktionelle Aktivität der Osteoklasten wurde anhand der Bildung von Resorptionslakunen dargestellt. In gleicher Weise wurden später RA synoviale Fibroblasten und PL Fibroblasten in dem Dentin-Resorptionsassay untersucht. 
Zur Etablierung eines solchen in vitro Systems, wurden über 14 Tage herandifferenzierte Osteoklasten auf Pottwaldentin inkubiert. Das Dentin des Pottwal weist große Ähnlichkeiten mit dem Knochen auf (BOYDE et al., 1984). Um die Morphologie der Osteoklasten in verschiedenen Phasen der Adhäsion auf einer Oberfläche zu erfassen, wurden die Zellen über bestimmte Zeitspannen inkubiert und anschließend rasterelektronenmikroskopisch untersucht. Eine morphologische Besonderheit der Osteoklasten ist die ringförmige Struktur aus F-Actin, die von Osteoklasten bei der Adhäsion auf einer Oberfläche durch Umstrukturierung des Zytoskeletts ausgebildet wird. Dieser sogenannte F-Actinring spielt als „sealing zone“ im Resorptionsprozess eine wichtige Rolle (s.u.) und wurde durch Kopplung eines Farbstoffes im Fluoreszenzmikroskop dargestellt.

Im REM erfolgte die funktionelle Analyse der Osteoklasten während des Resorptionsprozesses. Das als Substrat im Resorptionsassay eingesetzte Pottwaldentin wurde nach Ablauf der Inkubationszeit und dem Ablösen der Zellen hinsichtlich der Bildung von Resorptionslakunen untersucht. Durch Inkubation der Osteoklasten auf dem Pottwaldentin für unterschiedliche Zeitspannen wurden die verschiedenen Stadien der Resorption erfasst. Zur Analyse der Kontaktzone, an der die Resorptionsprozesse ablaufen, wurde u.a. auch die Substratseite des Osteoklasten rasterelektronenmikroskopisch dargestellt.

\subsubsection{Oberflächenmorphologie der Osteoklasten}

Im REM weisen Osteoklasten eine charakteristische Morphologie mit einem Zelldurchmesser von 30 bis über $100 \mu \mathrm{m}$ auf. Die Vielkernigkeit ist rasterelektronenmikroskopisch nicht darstellbar.

Nach 14-tägiger Inkubation auf Pottwaldentin stellen sich einige Osteoklasten flach auf der Oberfläche ausgebreitet dar, meistens ist der Zellkörper jedoch in einem Bereich nach oben gewölbt (s. Abbildung 13). Diese zentrale Kuppel weist häufig eine Vielzahl feiner Mikrovilli auf, die auch über die gesamte Oberseite einer Zelle verteilt sein können (s. Abbildung 14). Mikrovilli dienen als schlauchförmige Zellfortsätze der Oberflächenvergrößerung und fördern darüber den Stoffaustausch zwischen Zelle und dem umgebenden Medium. Die meisten Osteoklasten bilden am Zellrand lappenartige Ausstülpungen, sogenannte Pseudopodien, sowie feine, fadenartige Strukturen, die Filopodien, von unregelmäßiger Länge und Durchmesser aus (s. Abbildung 16 a). Diese 
Strukturen dienen der Fortbewegung der Zellen. Die Morphologie der Osteoklasten in dieser Arbeit entspricht den Beschreibungen und Aufnahmen von CHAMBERS et al., 1984, deren Studie Osteoklasten während des Resorptionsprozesses im REM darstellt.

\subsubsection{Der osteoklastäre Resorptionszyklus}

Die Ereignisse, die auf zellulärer Ebene bei der Knochenresorption ablaufen, werden von VÄÄNÄNEN et al., 1996, als sogenannter Resorptionszyklus beschrieben: der Zellwanderung folgt das Anhaften an den Knochen, die Polarisation der Zelle und die Bildung von neuen Membrandomänen. Es schließt sich die Auflösung des Hydroxyapatits und der Abbau der organischen Matrix an, gefolgt von der Entfernung der Abbauprodukten aus den Resorptionslakunen. Abschließend gehen die Osteoklasten in ein vorübergehendes nicht-resorbierendes Stadium oder in die Apoptose über.

\subsubsection{Wanderung der Osteoklasten}

Nach CHAMBERS et al., 1984, wandern Osteoklasten mittels sich aus- und rückbildender, formveränderlicher Pseudopodien und Filopodien auf dem Substrat. Pseudopodien sind dynamische actinreiche Ausstülpungen der Zelloberfläche, die zusammen mit Cytoplasmaströmungen eine amöboide Fortbewegung ermöglichen. Die Zellfortbewegung mittels feiner Filopodien, wie sie z.B. bei Fibroblasten vorkommt, beruht hingegen vermutlich auf der lokalen Polymerisation von Actin an den Stelle des Filopodienwachstums (THERIOT and MITCHISON, 1991) und dem aktiven Vorwärtsschieben bereits gebildeter Filamente (CRAMER and MITCHISON, 1993). Rasterelektronenmikroskopische Aufnahmen von CHAMBERS et al.,1984, zeigen die Morphologie von Osteoklasten, die aus einem Kaninchen isoliert wurden, während der Fortbewegung auf einem Knochenstück und dem Resorptionsprozess. Hierbei sind polarisierte Zellen mit breiten Pseudopodien an einem Pol und Filopodien an dem anderen Pol zu erkennen, die eine Wanderung in Richtung der breiten Pseudopodien vermuten lassen. Neben diesen Zellen sind Osteoklasten dargestellt, die nur feine Filopodien ausbilden und scheinbar nicht in Bewegung sind, sowie Zellen, die nur mit Pseudopodien ausgestattet sind.

Diese drei Ausbildungsformen wurden bei den rasterelektronenmikroskopischen Untersuchungen der Osteoklasten in den Experimenten zu dieser Arbeit ebenfalls 
gefunden. Besonders deutlich ist die unterschiedliche Gestalt der Osteoklasten in den Aufnahmen, die Zellen bei der Ausbreitung auf einer Oberfläche (s. 3.3.3) darstellen. Die nach Ablösen von der Plastikschale abgekugelten Osteoklasten breiten sich innerhalb von $2 \mathrm{~h}$ auf einer Oberfläche aus. Während der Ausbreitung bilden die Zellen zum Teil fadenförmige Ausläufer aus (s. Abbildung $15 \mathrm{c}$ ), die den als Filopodien bezeichneten Strukturen entsprechen. Abbildung 15 f zeigt die Strukturen einer polarisierten Zelle, mit Pseudopodien an einem Pol der Zelle und feinen Filopodien auf der gegenüberliegenden Seite. Eine Polarisierung der Zelle wurde auch bei Osteoklasten gefunden, die auf Pottwaldentin inkubiert wurden. In Abbildung 16 a ist ein Osteoklast in unmittelbarer Nähe von Resorptionslakunen mit ausgebreiteten Pseudopodien und feinen Filopodien am linken Zellrand dargestellt. Diese Strukturen dienen möglicherweise der Fortbewegung in Richtung oberen, rechten Bildrand.

\subsubsection{Adhäsion auf einer Oberfläche}

Die Möglichkeit zur Adhäsion auf einer Oberfläche ist bereits während der Entwicklung zum Osteoklasten notwendig. MIYAMOTO et al., 2000, zeigten, dass sich Vorläuferzellen in einem Kultursystem unter Bedingungen, die eine Adhäsion auf einem Untergrund verhinderten, nicht $\mathrm{zu}$ reifen, multinukleären Osteoklasten entwickeln konnten.

Bei dem Prozess der Adhäsion an die Knochenmatrix und der Resorption spielen Integrine eine wichtige Rolle (RODAN et al., 1997). Neben diesen Funktionen sind sie an der Zellmobilität sowie an der Signalübertragung von außen in die Zelle und von intrazellulär nach extrazellulär beteiligt. Integrine sind Zell-Matrix-Rezeptoren, die als Heterodimere aus einer D- und einer E-Untereinheit bestehen.

Die an der Zellaußenseite gelegene Domäne der Integrine bindet an einen Proteinbestandteil der extrazellulären Matrix. Dabei erkennen die meisten Integrine Liganden mit einer Argenin-Glycin-Asparagin Aminosäuresequenz, sogenannte RGD-haltige Proteine, wie beispielsweise Kollagen, Fibronectin und Laminin. Ein Ligand kann meist eine Verbindung mit mehreren Integrinen eingehen. Die intrazelluläre Domäne der Integrine ist über einen Komplex aus Anheftungsproteinen, darunter Vinculin, Talin und D- Actinin, mit Bündeln von Actin-Filamenten des Zytoskeletts verbunden. Als Transmembranverbindungsglieder vermitteln Integrine 
somit Wechselwirkungen in beiden Richtungen zwischen extrazellulärer Matrix und dem Actin des Zytoskeletts Die Adhäsionsfähigkeit der Integrine kann von der Zelle über Änderung der Matrix-Bindungsstellen dieser Proteine oder ihre Anheftung an Actin-Filamente geändert werden (HYNES, 1987).

In Osteoklasten wurden vier verschiedene Integrine beschrieben: $D_{v} E_{3}, D_{v} E_{5}, D_{2} E_{1}$ und $\mathrm{D}_{\mathrm{v}} \mathrm{E}_{1}$ (NESBITT et al., 1993). Ein Integrin, das auch als Osteoklastenmarker eingesetzt wird, ist der Vitronectinrezeptor (VNR) $D_{v} E_{3}$, der in der Plasmamembran und zahlreichen intrazellulären Vakuolen gefunden wurde. Durch RGD-haltige Proteine wie Echistatin und Kistrin kann die Knochenresorption durch Osteoklasten über die Bindung an $D_{v} E_{3}$ Rezeptor sowohl in vitro als auch in vivo inhibiert werden (HORTON et al., 1997, FISHER et al., 1993). CHELLAIAH et al., 1996 zeigten, dass die Bindung von Osteopontin an den $D_{v} E_{3}$ Rezeptor die Umorganisation des Zytoskeletts und die Stimulierung der Knochenresorption bewirkt. Die genaue Funktion des $D_{v} E_{3}$ Rezeptors bei der Knochenresorption ist noch nicht bekannt. Möglicherweise vermittelt der $D_{v} E_{3}$ Rezeptor das Anheften einer von den Zellen gebildeten Kontaktzone mit dichter Struktur, der sogenannten „sealing zone“, an das Substrat (HOLT et MARCHALL, 1998). Bisher konnte der $D_{v} E_{3}$ Rezeptor jedoch noch nicht in der „sealing zone“ nachgewiesen werden (LAKKAKORPI et al., 1991). Einige Autoren postulieren daher, dass spezifische Moleküle, möglicherweise Cadherine, für die Zell-Matrix-Kontakte an der ,sealing zone“ des resorbierenden Osteoklasten verantwortlich sind (ILVESARO et al., 1998, VÄÄNÄNEN et al., 2000).

Die Bildung der „sealing zone“ während der Polarisierung der Osteoklasten beruht auf einer Umstrukturierung des Zytoskeletts. Das Zytoskelett besteht aus einem komplexen Geflecht von Proteinfilamenten, hauptsächlich Actin-Filamenten, Mikrotubuli und Intermediärfilamenten. Diese hoch dynamische Struktur wird ständig neu organisiert, wenn die Zelle auf ihre Umgebung reagiert. Das Zytoskelett erstreckt sich über das gesamte Zytoplasma und ermöglicht der Zelle verschiedene Formen anzunehmen. Bei dem Wechsel von einem nicht-resorbierenden in ein resorbierendes Stadium, werden das über spezifische Zytoskelettstrukturen, den Podosomen, verteilte F-Actin und Vinculin umorganisiert. Podosomen werden als Anheftungsstellen nur vorübergehend ausgebildet und bestehen aus einem F-Actin Kern, der von Actin-bindenden Proteinen Vinculin, Talin und D-Actinin umgeben ist. Beim Übergang in das resorptive Stadium dissoziieren Vinculin und F-Actin voneinander und das F-Actin bildet eine dichte, 
ringförmige Struktur, die die künftigen Resorptionszonen umgibt (VÄÄNÄNEN and HORTON, 1995).

Nach NAKAMURA et al., 1995, bilden Osteoklasten die ringförmigen F-Actinstrukturen, sogenannte F-Actinringe, aus, wenn sie unter adhärenten Bedingungen auf Plastik, Glas oder Dentin kultiviert werden. Neben der Matrix können auch Wachstumsfaktoren den Umbau des Zytoskeletts in einer Zelle stark beeinflussen. Osteoklasten, die aus jungen Ratten isoliert und unter Zugabe von M-CSF kultiviert wurden, bildeten F-Actinringe aus, während bei den Osteoklasten, die ohne M-CSF kultiviert wurden, das F-Actin vermehrt im Bereich der Nukleoli und in den Podosomen angeordnet wurde (AMANO et al., 1998).

Zum Nachweis der charakteristischen ringförmigen F-Actin-Struktur wurde in den Experimenten zu dieser Arbeit das F-Actin der Osteoklasten nach der Methode von AMANO et al., 1998, mit einem fluoreszierenden Farbstoff, einem Rhodaminkonjugierten Phalloidin, markiert. Das Pilzgift Phalloidin aus Amanita phalloides bindet selektiv an F-Actin, das durch Kopplung an das fluoreszierende Rhodamin darstellbar wird. Im Fluoreszenzmikroskop konnten die rot fluoreszierenden ringförmigen FActinstrukturen sichtbar gemacht werden. Das zum Vergleich markierte F-Actin eines RA synovialen Fibroblasten liegt hingegen im netzartigen Verbund über die ganze Zelloberfläche verteilt vor.

$\mathrm{Ob}$ die Ausbildung dieser Ringstruktur bei Osteoklasten zur Bildung einer nach außen abgeschlossenen Kontaktzone, der ,sealing zone“, zwischen Osteoklasten und Knochenmatrix führt, in dem die Resorptionsprozesse ablaufen, ist noch nicht geklärt. Möglicherweise dienen die ringförmige Struktur sowie die dort exprimierten Integrine, die extrazelluläre Signale aufnehmen und in die Zelle weiterleiten, der Erkennung der Matrix und induziert darüber den Resorptionsprozess (STENBECK and HORTON, 2000).

\subsubsection{Osteoklasten in der matrixdegradierenden Phase}

Die Darstellung der osteoklastären Resorptionsmuster in dem in vitro System dienten als Grundlage der zu untersuchenden fibroblastären Resorption.

Die Resorption des Knochens oder auch des Dentins umfasst Vorgänge der Demineralisierung und der enzymatischen Matrixdegradation. Osteoklasten verfügen im 
Bereich des resorptiven Organs, der sogenannten „ruffled border“, über vakuoläre ATPase-abhängige Protonenpumpen, mit denen sie den $\mathrm{pH}$ im extrazellulären Bereich der Kontaktzone zum Knochen bis auf ungefähr 4 absenken und matrixgebundenes Calciumphosphat in Lösung bringen. Diese Protonenpumpe ist physiologisch und strukturell identisch mit der $\mathrm{H}^{+}$-ATPase in der Niere (BLAIR et al., 1989). Die Elektronenneutralität wird durch $\mathrm{Cl}^{-}$-Kanäle, die eng an die $\mathrm{H}^{+}$-ATPasen gekoppelt sind, hergestellt (SCHLESINGER et al., 1993). Durch energieunabhängige $\mathrm{Cl}^{-} / \mathrm{HCO}_{3}$-Austauscher außerhalb der resorptiven Kontaktbereichs wird der intrazelluläre pH aufrechterhalten (TETI et al., 1989). Die demineralisierte Knochenmatrix wird dann unter Wirkung von extrazellulär sezernierten sowie lysosomalen Proteasen abgebaut. Osteoklasten produzieren Matrixmetalloproteinasen 9, die zusammen mit Kollagenasen die Kollagenmatrix degradieren (ROODMAN, 1999). Eines der wichtigsten Matrix-degradierenden Enzyme der Osteoklasten ist die lysosomale Zysteinproteinase Kathepsin K, die Kollagen I - den Hauptbestandteil der organischen Knochenmatrix - abbaut. Nach STENBECK und HORTON, 2000, ist die Kathepsin K Expression im Kontaktbereich von Zelle und Knochen, speziell auch am Rand von Resorptionslakunen, erhöht. Die Autoren vermuten anhand der Topologie, das Kathepsin $\mathrm{K}$ an der Bewegungsfront der Zelle lokalisiert ist und das in diesem Bereich auch die aktiven Resorptionsprozesse stattfinden.

Im Weiteren werden Knochenabbauprodukte mittels Endozytose im Bereich der „ruffled border“ von Osteoklasten aufgenommen und nach weiterer Degradation an der substratabgewandten Membran freigesetzt (NESBITT et HORTON, 1997).

Das Ergebnis dieser Resorptionsprozesse wird anhand der gebildeten Aushöhlungen im Knochen bzw. in der knochenähnlichen Matrix deutlich. Die Wahl des Substrats fiel nach einigen Vorversuchen auf Pottwaldentin, dass in seiner Zusammensetzung dem Knochen sehr ähnlich ist und sich aufgrund seiner homogenen Struktur für den Resorptionsassay eignet (BOYDE et al., 1985). Im Gegensatz zu den in der Literatur beschriebenen Methoden, nach denen die Osteoklastendifferenzierung auf dem Substrat erfolgte, wurden in dieser Arbeit Osteoklasten im Vorfeld über 14 Tage herandifferenziert und erst dann auf das Pottwaldentin umgesetzt. Damit waren bereits zu Beginn der Inkubation funktionsfähige Osteoklasten auf dem Dentin, was mutmaßlich zur besseren Erfassung der verschiedenen Stadien der Knochenresorption beitrug. Zum Teil wurden die Zellen von dem Dentin entfernt, um die Resorptionslakunen besser darstellen zu können. Abbildung 13 zeigt eine Aushöhlung 
in unmittelbarer Nähe eines Osteoklasten, dessen Filopodien in die Lakune hineingreifen. Die Variabilität der Resorptionslakunen in Gestalt und Größe ist in Abbildung 16 b dargestellt. Die Veränderungen im Dentin haben einen Durchmesser von 5 bis $50 \mu \mathrm{m}$ und sind damit in den meisten Fällen kleiner als die Osteoklasten. Es sind drei Grundformen erkennbar.

Es gibt fast kreisförmige, relativ tiefe Aushöhlungen mit einem kleinen Durchmesser, sowie flachere Einbuchtungen mit etwas größerer Ausdehnung und komplexe Lakunen mit unregelmäßigerem, manchmal wolkenartigem Umriss. Die kreisförmigen, tiefen Lakunen weisen meist einen klar definierten Rand auf, während die flacheren Aushöhlungen eher ohne Kantenbildung in die nicht angegriffene Matrix überzugehen scheinen. CHAMBERS et al., 1984, unterscheiden ebenfalls drei Grundformen und sehen einen möglichen Zusammenhang mit unterschiedlich ablaufenden Resorptionsvorgängen. Die kreisrunden, tiefen Veränderungen entstehen demzufolge durch wechselnde Perioden von Resorption, bei der die Zelle auf einer Stelle bleibt, und Wanderung des Osteoklasten, während die flacheren Einbuchtungen sowie die komplexen Lakunen bei einer kontinuierlichen Resorption während der Wanderung des Osteoklasten gebildet werden.

In den Lakunen sind zahlreiche stiftartige Vorwölbungen mit einem Durchmesser von ca. $2 \mu \mathrm{m}$ zu erkennen, die ein zentrales Loch aufweisen. Bei den Vorwölbungen handelt es sich am ehesten um freigelegte Dentinkanälchen, die eine Ummantelung aus peritubulären Dentin tragen. Diese verhärtete Struktur kann von den Osteoklasten möglicherweise nur langsamer oder gar nicht abgebaut werden.

Zur Darstellung früher Resorptionsstadien wurden Osteoklasten für unterschiedliche Zeitspannen auf dem Pottwaldentin inkubiert. Nach 3 Tagen Inkubation wurden bereits erste Oberflächenveränderungen im Sinne beginnender Resorption gefunden. Es sind kleine, runde gut abgrenzbare Areale mit deutlich angerauter Oberfläche und einem Durchmesser von ungefähr $5 \mu \mathrm{m}$. Die Vertiefungen finden sich zum Teil in Abständen von weniger als $10 \mu \mathrm{m}$ zueinander, also deutlich weniger als der Durchmesser eines Osteoklasten. Somit können die Vertiefungen simultan oder jeweils nach kurzen Wanderungsstrecken der Osteoklasten entstanden sein. 


\subsubsection{Rasterelektronenmikroskopische Darstellung der Substratseite der} $\underline{\text { Osteoklasten }}$

Zur Analyse der Kontaktzone, an der die Resorptionsprozesse ablaufen, wurde die Substratseite des Osteoklasten im REM dargestellt und später mit der Substratseite von RA synovialen Fibroblasten verglichen. An der Substratseite bilden Osteoklasten einen Bürstensaum, die sogenannte ,ruffled border“, aus. Diese Struktur repräsentiert das resorptive Organ der Zelle und wird nur ausgebildet, wenn der Osteoklast auf einem Substrat haftet. An der „ruffled border“ fusionieren lysosomale Vesikel mit der Plasmamembran und setzen lysosomale Proteasen und $\mathrm{HCl}$ in die Lakunen frei.

Die rasterelektronenmikroskopische Darstellung der Substratseite eines Osteoklasten zeigt zwei verschiedene Membranbereiche. Zweidrittel der Membranoberfläche an der Substratseite sind vorwiegend glatt. In dem anderen Bereich sind viele Membranfaltungen zu erkennen, die denen der „,ruffled border“ ähneln.

Außerdem wurden Membranstrukturen, die Ähnlichkeiten mit Membranverschmolzenen Vesikeln aufweisen, an der Substratseite der Osteoklasten gefunden. Die Anzahl dieser sich zum Extrazellularraum öffnenden Vesikel variiert stark von Zelle zu Zelle und ist möglicherweise Ausdruck unterschiedlicher Aktivitätsstadien. Die Vergrößerung eines mit der Membran fusionierenden Vesikels lässt im Innern Substratpartikel erkennen und stellt vielleicht den Endozytosevorgang dar.

Der Membranbereich um die Vesikel ist sehr unterschiedlich gestaltet: es sind sowohl weitgehend glatte Membranoberflächen zu finden, als auch Membranen mit vielen haarförmigen Ausstülpungen sowie wenigen großen Falten und vielfach verzweigte Membranen. Möglicherweise handelt es sich bei diesen unterschiedlichen Membranbereichen um sich ständig verändernde Strukturen während der Resorption.

In Membranbereichen, die möglicherweise die ,ruffled border“ darstellen, wurden stiftförmige Strukturen mit einem knopfartigen Abschluss gefunden. Diese Strukturen ähneln in Hinblick auf Größe und Gestalt Gebilden auf der Eizelle und sind möglicherweise an Stoffaustauschprozessen beteiligt (Dr. Schwartz, Abt. Anatomie, Universität Göttingen, persönliche Mitteilung). 


\subsection{Spenderabhängige Unterschiede im Ausmaß der}

\section{Knochenresorption}

Monozyten als Osteoklastenvorläuferzellen wurden in dieser Arbeit aus peripheren Blutzellen gesunder, erwachsener SpenderInnen gewonnen. Anfangs wurden die Vorläuferzellen aus Buffy Coat-Präparaten isoliert, die von der Blutbank des Göttinger Klinikums zur Verfügung gestellt wurden.

Bereits bei der Differenzierung von Vorläuferzellen zu Osteoklasten als auch bei der Charakterisierung der Zellen und später bei der Untersuchung der resorptiven Aktivität wurden deutliche spenderabhängige Unterschiede festgestellt. Bei der lichtmikroskopischen Kontrolle der Zellkulturen während der Differenzierung wurde beobachtet, dass die von verschiedenen SpenderInnen abstammenden Kulturen hinsichtlich des Anteils an mononukleären und multinukleären Zellen unterschiedlich zusammengesetzt waren.

Zur systematischen Untersuchung dieser Unterschiede wurden Osteoklasten und deren Vorläuferzellen von vier bekannten EinzelspenderInnen wiederholt verglichen. Der Anteil der Zellen, die nach definierter Differenzierungszeit für den Osteoklastenmarker TRAP positiv gefärbt waren, lag für Spender Sp2 bei $40 \%$ und Spenderin Sp4 bei 20 \%, während bei Spender Sp1 60 \% und bei Spenderin Sp3 80 \% der Zellen TRAPpositiv waren. Die Kultur Sp3 mit dem höchsten Anteil an TRAP-positiven Zellen zeigte auch die höchste resorptiven Aktivität auf dem Pottwaldentin. Die Zellen wurden außerdem auf Calziumphosphat-beschichteten (CP-) Plättchen inkubiert.

Zur Auswertung der CP-Plättchen wurden die Zellen von der Oberfläche entfernt. Die Feststellung der resorptiven Aktivität der Zellen erfolgte anhand der stereometrischen Bestimmung des Anteils an resorbierter Beschichtung. Bei Sp3 wurden $45 \%$ des Calciumphosphates abgebaut, bei Sp4 fehlten $24 \%$ der Beschichtung und bei Sp1 wurden $15 \%$ resorbiert. Für Sp2 konnte nur $4 \%$ resorbierte Beschichtung festgestellt werden.

Diese Ergebnisse korrelieren mit der resorptiven Aktivität, die die Zellen der vier SpenderInnen auf Pottwaldentin zeigten. Bei der Durchmusterung der Dentinstücke nach Entfernung der Zellen konnten für Sp3 die meisten Resorptionslakunen festgestellt werden, während für Sp1 und Sp4 um die Hälfte weniger Lakunen beobachtet wurden. Bei Sp2 wurden nur leichte resorptive Veränderungen im Dentin festgestellt. Auf den Dentinplättchen der SpenderInnen $\mathrm{Sp} 1, \mathrm{Sp} 3$ und $\mathrm{Sp} 4$ sind die beschriebenen drei 
Grundformen der Resorptionslakunen im unterschiedlichen Maß vertreten. Während bei den Resorptionslakunen von Sp3 alle drei Grundformen $\mathrm{zu}$ finden waren, enthielt das Dentinstück von Sp1 hauptsächlich tiefe, klar abgrenzte Lakunen mit kleinem Durchmesser. Bei Sp4 waren vermehrt flache Einbuchtungen von größerer Oberfläche vertreten.

Bei der lichtmikroskopischen Kontrolle der Zellkulturen wurde ein im Vergleich hoher Anteil mononukleärer Zellen in einer Osteoklastenkultur (Sp3) festgestellt, die die höchste resorptive Aktivität auf Pottwaldentin zeigte (s. 3.3 .5 und 3.4). Für die Spenderin Sp3 mit der höchsten resorptiven Aktivität der Osteoklasten und für den Spender Sp2 mit wenig resorptiven Veränderungen fanden sich im Differenzialblutbild zum Zeitpunkt der Blutspende gleiche Monozytenzahlen für die Osteoklastendifferenzierung.

In den Experimenten zu dieser Arbeit waren die spenderabhängigen Unterschiede reproduzierbar. In der Literatur ist dieses interessante Phänomen bisher nicht beschrieben. Auch ist nach dem derzeitigen Kenntnisstand keine plausible Erklärung zu finden. Über die klinische Relevanz dieser Unterschiede für Erkrankungen des Knochens kann nur spekuliert werden. Möglicherweise hat die Feststellung unterschiedlicher knochenresorptiver Aktivitäten eine klinische Bedeutung in der Risikoabschätzung für die Entwicklung einer Osteoporose.

\subsection{Untersuchung von RA synovialen Fibroblasten und Prothesen- lockerungsfibroblasten im Dentin-Resorptionsassy}

Es gibt Hinweise, die eine direkte Beteiligung von aktivierten Fibroblasten an der Destruktion extrazellulärer Matrix bei verschiedenen Erkrankungen vermuten lassen. Sowohl die rheumatoide Arthritis als auch die aseptische Prothesenlockerung ist durch das Auftreten von aktivierten Fibroblasten gekennzeichnet.

Bisher wird die Knochendestruktion bei der rheumatoiden Arthritis auf eine vermehrte Rekrutierung von Osteoklastenvorläuferzellen und eine erhöhte Aktivität von reifen Osteoklasten zurückgeführt. Wenig ist jedoch über die Mechanismen bekannt, die zu den Knochenerosionen durch das Pannusgewebe führen. Der Pannus enthält einen hohen Anteil an Fibroblasten mit einem aktivierten Phänotyp. In neueren Studien wurde gezeigt, dass diese RA synovialen Fibroblasten mehrere Eigenschaften aufweisen, die auch bei der Knochenresorption durch Osteoklasten eine Rolle spielen. Demnach 
exprimieren RA synoviale Fibroblasten eine membrangebundene vakuoläre $\mathrm{H}^{+}$-ATPase (OTSU et al., 2000) und produzieren außerdem Matrix-Metalloproteinasen und Kathepsin K (HUMMEL et al., 1998, HOU et al., 2001), eine der wichtigsten Proteasen im osteoklastären Knochenabbau. Diese Eigenschaften weisen auch sogenannte Prothesenlockerungsfibroblasten auf. Dabei handelt es sich um Fibroblasten, die aus der Grenzmembran zwischen Knochen und Hüftgelenksendoprothesen isoliert wurden und denen eine maßgebliche Rolle (PAP, T., et al., 1999, OTSU et al., 2000) bei der aseptischen Prothesenlockerung zugeschrieben wird.

In dem Dentin-Resorptionsassay wurden sowohl RA synoviale Fibroblasten als auch humane PL Fibroblasten und PL Fibroblasten aus einem Rattenmodell eingesetzt.

In dem von PAP, G., et al., 2001, etablierten ICSS Wistar-Ratten-Modell können die Mechanismen der Prothesenlockerung untersucht werden. Dabei sind bereits frühe Stadien der Grenzmembranbildung erfassbar. Humane PL Fibroblasten können hingegen nur im Rahmen von Revisionseingriffen bei einer fortgeschrittenen Prothesenlockerung gewonnen werden. In dem Modellsystem wurden, nach Implantation einer tibialen Hemiarthroplastik in ein Knie, die Ratten mittels intrakranialer Eigenstimulation (SCHWARZBERG et al., 1989) zum ultraphysiologischen Laufen in einem Laufrad angeregt. Dadurch wurde die normale Laufaktivität um das 100fache gesteigert und führte zur Bildung einer Grenzmembran an der Prothesenoberfläche. Nach zwölf Wochen erfolgte die Entnahme des periprosthetischen Membrangewebes. Die isolierten PL Fibroblasten wurden anschließend im Dentin-Resorptionsassay untersucht.

\subsubsection{Charakterisierung der Fibroblastenkulturen}

Es wurden für die Resorptionsexperimente Fibroblastenkulturen der 5. bis 8. Passage verwendet. Die Kultivierung erfolgte ohne Zusätze wie M-CSF oder RANKL. Kontaminationen der Fibroblastenkulturen mit Osteoklasten waren bereits aufgrund der Kulturbedingungen auszuschließen, da Osteoklasten im Gegensatz zu Fibroblasten nicht proliferieren und zur Differenzierung spezielle Kulturbedingungen benötigen.

Die PL Fibroblastenkulturen wurden in der Abt. für Experimentelle Rheumatologie am Zentrum Innere Medizin der Universität Magdeburg charakterisiert und Kontaminationen der Kulturen mit anderen Zellen ausgeschlossen. 
Die RA synovialen Fibroblasten wurden mittels FACS-Analyse positiv auf einen Fibroblastenmarker und negativ auf den pan-Leukozytenmarker CD45 getestet. CD45 wird von Osteoklasten und deren Vorläuferzellen sowie Monozyten exprimiert. Kontaminationen von RA synovialen Fibroblastenkulturen mit Osteoklasten und Osteoklastenvorläuferzellen wurden mit einer RT-PCR für die Osteoklastenmarker RANK und CTR ausgeschlossen. Hingegen konnten bei der RT-PCR für die mRNA Expression von Kathepsin K positive Signale erhalten werden. Außerdem wurde im Western-Blot Kathepsin K Protein in RA synovialen Fibroblasten sowie in Osteoklasten nachgewiesen.

\subsubsection{Oberflächenmorphologie der Fibroblasten auf Dentin}

RA synoviale Fibroblasten und PL Fibroblasten waren im Dentin-Resorptionsassay rasterelektronenmikroskopisch bezüglich ihrer Morphologie homogen. Es konnten keine osteoklastenartigen Zellen gefunden werden. Die PL Fibroblasten aus der Ratte zeigten hingegen keine einheitliche bipolare Orientierung. Diese Kulturen enthielten sowohl längliche als auch flächig ausgebreitete Zellen.

Die rasterelektronenmikroskopische Untersuchung ergab, dass die Fibroblasten unter günstigen Kulturbedingungen inkubiert wurden: die Zellen adhärierten auf der Dentinoberfläche, bildeten mehrere Zelllagen aus und sezernierten eine extrazelluläre Matrix. Eine solche Matrix dient dem Zusammenhalt der Zellen und beeinflusst ihre Entwicklung und Polarität. Sie enthält faserbildende Proteine wie Kollagene zur Strukturbildung und Fibronektin zur Adhäsion. Außerdem waren am Zellrand Filopodien zu erkennen, die den Zellen als Strukturen zur Adhäsion und Fortbewegung dienen. Bei der Fortbewegung eines Fibroblasten, gleiten Filopodien sowie dünne, flächige Fortsätze, sogenannte Lamellopodien, die nicht an der Kulturschale festhaften, über die Oberfläche der Zelle. Diese Fortbewegungsart wird auch als Kräuselung beschrieben (SMALL, J. V., 1989). 
$\underline{\text { 4.5.3 Bildung resorptiver Veränderungen durch aktivierte Fibroblasten im Dentin- }}$ Resorptionsassay

In dem Resorptionsassay wurden sechs verschiedene RA synoviale Fibroblastenkulturen, vier humane PL Fibroblastenkulturen und eine Kultur mit PL Fibroblasten aus dem Rattenmodell getestet. In Übereinstimmung mit Untersuchungen von TAKAYANAGI et al., 1997, bei denen RA synoviale Fibroblasten als Negativkontrolle im Resorptionsassay eingesetzt wurden, waren innerhalb von vier Wochen keine Veränderungen im Dentin zu finden.

Erst nach Inkubationszeiten von vier bis sechs Wochen auf dem Substrat wurden bei der Mehrzahl (5/6) der RA synovialen Fibroblastenkulturen, bei der Hälfte der (2/4) humanen PL Fibroblastenkulturen sowie bei der Kultur mit PL Fibroblasten aus dem Rattenmodell viele kleine Oberflächenveränderungen im Dentin gefunden, die im Vergleich $\mathrm{zu}$ den frühen Veränderungen durch Osteoklasten als Resorptionszonen interpretiert wurden. Zwischen den verschiedenen Fibroblastenkulturen konnten keine Unterschiede in der Gestalt und Größe dieser Vertiefungen festgestellt werden. Der Abstand der Resorptionszonen von unter $10 \mu \mathrm{m}$ lässt vermuten, dass ein Fibroblast - mit Durchschnittsmassen von $20 \mu \mathrm{m}$ Breite und $60 \mu \mathrm{m}$ Länge - mehrere dieser Veränderungen erzeugt, wie es auch bei Osteoklasten beobachtet wurde.

Die in den Experimenten eingesetzten humanen PL Fibroblasten stammten aus späten Stadien der Prothesenlockerung, in denen möglicherweise der Resorptionsprozess bereits abgeschlossen war. Mit dem Einsatz der PL Fibroblasten aus dem ICSS-WistarRatten Modell wurde auch für die Zellen aus frühen Stadien der Membranbildung die Fähigkeit zur Bildung resorptiver Veränderungen im Dentin demonstriert.

Bei Stimulierungsversuchen mit dem proinflammatorischen Zytokin TNF-D wurden auch für die primär nicht resorbierenden Fibroblastenkulturen die typischen Oberflächenveränderungen gefunden. Diese Experimente lassen vermuten, dass TNF-D die Matrixdegradation durch RA synoviale Fibroblasten erhöht, möglicherweise über Aktivierung der membranständigen Protonenpumpe und gesteigerter Produktion von proteolytischen Enzymen. Tiefe Lakunen von größerem Ausmaß, wie sie in den späteren osteoklastären Resorptionsstadien vorkommen, konnten auch nach Stimulation nicht gefunden werden.

Die Bildung von Resorptionszonen durch RA synoviale Fibroblasten konnte durch Bafilomycin $A_{1}$ gehemmt werden. Bafilomycin $A_{1}$ interagiert mit der $17 \mathrm{kD}$ 
Untereinheit der vakuolären $\mathrm{H}^{+}$-ATPase. Ein direkter zytotoxischer Effekt des Bafilomycin $A_{1}$ in den verwendeten Konzentrationen auf die Fibroblasten konnte durch morphologische Untersuchungen mittels REM nicht gesehen werden. Die Hemmung der resorptiven Aktivität durch spezifische Blockierung der vakuolären $\mathrm{H}^{+}$-ATPase unterstützt die Vermutung, dass RA synoviale Fibroblasten und PL Fibroblasten eine osteoklastenähnliche $\mathrm{H}^{+}$-ATPase an der Substratseite exprimieren. Nanomolare Konzentrationen an Bafilomycin $\mathrm{A}_{1}$ hemmen spezifisch die in vitro Knochenresorption durch Blockierung der vakuolären $\mathrm{H}^{+}$-ATPase in Osteoklasten (SUNDQUIST et al., 1990). $\mathrm{H}^{+}$-ATPasen spielen ebenfalls eine wichtige Rolle beim Protonentransport in den renalen Tubuluszellen und in Zellen des Innenohrs (KARET et al., 1999).

Bei der Untersuchung der Substratseiten der RA synovialen Fibroblasten und der Osteoklasten wurden weitere Gemeinsamkeiten gefunden. Beide Zellen wiesen eine Polarisation der Zellmembran mit Ausbildung von vesikelähnlichen Strukturen auschließlich auf der Substratseite auf. Diese Strukturen waren jedoch bei Osteoklasten wesentlich zahlreicher zu finden. Dieser Unterschied mag z.T. die höhere resorptive Aktivität der Osteoklasten erklären. Zusätzlich wiesen Osteoklasten rasterelektronenmikroskopisch gefaltete und stark verzweigte Membranbereiche auf, die mutmaßlich der „ruffled border“ entsprechen. Diese ist allerdings bisher nur transmissionselektronenmikroskopisch dargestellt worden.

Das geringere Ausmaß der durch Fibroblasten gebildeten Resorptionszonen ist möglicherweise in einer verminderten $\mathrm{H}^{+}$-ATPase-Aktivität oder in einer niedrigeren Anzahl vorhandener Protonenpumpen begründet. Nach OTSU et al., 2000, ist die Expression der osteoklastenähnlichen vakuolären $\mathrm{H}^{+}$-ATPase in RA synovialen Fibroblasten und PL Fibroblasten zwar erhöht, sie erreicht möglicherweise aber nicht das Ausmaß, um zur Bildung tiefer Resorptionslaunen beizutragen. Vielleicht handelt es sich bei der nachgewiesenen Isoform der osteoklastären vakuolären $\mathrm{H}^{+}$-ATPase auch um ein weniger aktives Enzym.

Alternativ kann vermutet werden, dass Osteoklasten neben der Expression der entsprechenden Proteasen und Protonenpumpen andere wichtige Eigenschaften aufweisen, die ihre hohe Resorptionsaktivität im Vergleich zu Firboblasten erklärt. In Frage kommen besondere Adhäsionsmechanismen. Osteoklasten bilden bei der Adhäsion auf einer Oberfläche eine F-Actin-haltige Ringstruktur, die „sealing zone“, aus. Ob die Funktion der ,sealing zone“ in der Erkennung der Matrix oder auch in der Bildung eines abgeschlossenen, extrazellulären Bereiches liegt, ist noch unbekannt. Die 
in dieser Arbeit eingesetzten aktivierten Fibroblasten bilden bei der Oberflächenadhäsion eine derartige Struktur nicht aus.

Es besteht die Möglichkeit, dass auch die unterschiedlichen Fortbewegungsarten bei dem Resorptionsprozess eine Rolle spielen. Nach CHAMBERS et al., 1984, entstehen verschiedene Lakunenformen durch Osteoklasten scheinbar zum einen durch wechselnde Phasen der Wanderung der Zellen und des Verbleibens an einem Ort zur Matrixdegradation, zum anderen durch eine kontinuierliche Resorption während der Wanderung. Besteht ein Zusammenhang zwischen Fortbwegung und Gestalt der Lakunen, ist es möglich, dass die unterschiedliche Motilität von Osteoklasten und Fibroblasten einen Einfluss auf die Bildung von resorptiven Veränderungen nimmt. Während sich Osteoklasten unter Ausbildung von Pseudopodien und Filopodien amöboid fortbewegen, wird für Fibroblasten eine Fortbewegung mittels Lamellipodien und Filopodien durch lokale Actin-Polymerisation an Orten des Filopodienwachstums und aktives Vorwärtsschieben der Filamente beschrieben.

In der vorliegenden Arbeit konnte gezeigt werden, das aktivierte synoviale Fibroblasten und Fibroblasten aus Prothesenlockerungsgewebe in der Lage sind, eine knochenähnliche Matrix zu resorbieren. Dieses Ergebnis ist von weitreichender klinischer Bedeutung, da die bisherige Entwicklung spezifischer Therapieansätze für pathologische Knochenresorption ausschließlich auf Osteoklasten abzielen. Selbst bei einer deutlich niedrigeren resorptiven Aktivität, wie sie auch in unseren Untersuchungen zum Ausdruck kommt, kann die Wirkung der Fibroblasten angesichts ihrer sehr großen Zahl im Pannusgewebe und in der Prothesenlockerungsmembran und der jahrelangen Krankheitsentwicklung dennoch beträchtlich sein. In weiteren Studien wären die Regulationsmechanismen der fibroblastären Knochenresorption zu untersuchen. 


\section{Zusammenfassung}

Neuere Untersuchungen zur Pathophysiologie der Knochenresorption bei der rheumatoiden Arthritis und der sogenannten aseptischen Prothesenlockerung ergaben Hinweise auf eine direkte Beteiligung von aktivierten Fibroblasten. Bisher war ausschließlich Osteoklasten die Fähigkeit zur Knochenresorption zugeschrieben worden. In der vorliegenden Arbeit wurden Fibroblasten aus der synovialen Membran von Patienten mit rheumatoider Arthritis (RA synoviale Fibroblasten) und aus Prothesenlockerungsgewebe (PL Fibroblasten) sowie humane Osteoklasten in einem in vitro Resorptionsassay eingesetzt und die resorptive Aktivität verglichen.

1. Zunächst wurden in dem in vitro Resorptionsassay verschiedene Stadien der osteoklastären Matrixresorption dargestellt. Dazu wurden aus peripheren mononukleären Blutzellen gesunder, erwachsener SpenderInnen in vitro unter Zusatz von Wachstumsfaktoren Osteoklasten herandifferenziert. Die Charakterisierung der Osteoklasten erfolgte durch (immun-) zytochemische Nachweisverfahren und mittels RT-PCR. Die Osteoklastenkulturen wurden auf Pottwaldentin inkubiert, das eine dem Knochen vergleichbare Matrix aufweist. Unterschiedliche Inkubationszeiten ergaben in der REM unterschiedlich ausgeprägte resorptive Läsionen, von der leichten Oberflächenveränderung bis hin $\mathrm{zu}$ tiefen Resorptionslakunen. Zur quantitativen Analyse resorptiver Aktivitäten verschiedener Zellkulturen, wurden Osteoklasten außerdem auf Calciumphosphat-Plättchen inkubiert.

2. Vergleichend wurden im Dentin-Resorptionsassay RA synoviale Fibroblasten eingesetzt, die mittels Durchflusszytometrie und RT-PCR charakterisiert wurden. Es wurden weiterhin humane PL Fibroblasten und PL Fibroblasten aus einem Rattenmodell eingesetzt, das Untersuchungen zur pathophysiologischen Mechanismen in der frühen Phase der Erkrankung erlaubt. Nach vier- bis sechswöchiger Inkubation der RA synovialen Fibroblasten und PL Fibroblasten wurden rasterelektronenmikroskopisch kleine resorptive Veränderungen im Pottwaldentin festgestellt. Diese Vertiefungen zeigten große Ähnlichkeiten mit den durch Osteoklasten erzeugten Aushöhlungen in den Anfangsstadien des Resorptionsprozesses nach dreitägiger Inkubation. 
3. Auch nach Stimulation mit dem proinflammatorischen Zytokin TNF-D konnten für RA synoviale Fibroblasten und humane PL Fibroblasten keine tiefen Resorptionslakunen wie für Osteoklasten gefunden werden.

Bekanntermaßen hemmt Bafilomycin $\mathrm{A}_{1}$ über Inhibition der vakuolären $\mathrm{H}^{+}$-ATPase die osteoklastäre Knochenresorption. In dieser Arbeit wurde auch die Bildung resorptiver Veränderungen durch RA synoviale Fibroblasten mit Bafilomycin $\mathrm{A}_{1}$ gehemmt.

4. Fluoreszenzmikroskopisch konnten in adhärierenden Osteoklasten die sog. F-Actinringe dargestellt werden, die Zytoskelettveränderungen im Kontakt- bzw. Resorptionsbereich entsprechen. RA synoviale Fibroblasten hingegen wiesen keine F-Actinringe auf. REM Untersuchungen der Zellmembranen zeigten auf der Substratseite der RA synovialen Fibroblasten Membranveränderungen, die als Exooder Endozytoseversikel interpretiert wurden. Ähnliche Membranstrukturen wurden in deutlich größerer Dichte an der osteoklastären Substratseite gefunden. Zusätzlich konnte in Osteoklasten rasterelektronenmikroskopisch die sogenannte „ruffled border“ dargestellt werden.

5. In dieser Arbeit wurde mittels eines in vitro Assays erstmals gezeigt, dass neben Osteoklasten auch Zellen mesenchymalen Ursprungs zur Resorption einer knochenähnlichen Matrix befähigt sind. Die Resorption durch aktivierte Fibroblasten weist einige Merkmale der Resorption durch Osteoklasten auf. Sie ist aber deutlich geringer ausgeprägt. Angesichts ihres hohen Anteils im RA Synovium sowie im PL Gewebe und des langsamen Krankheitsverlaufs, spielen aktivierte Fibroblasten möglicherweise eine wichtige Rolle bei der Knochendestruktion, die bei der Entwicklung neuer Therapiestrategien berücksichtigt werden sollten. 


\section{Literaturverzeichnis}

Albrektsson,T., Jakobsson, M., Turesson, I. (1985). Bone remodelling at implant sites after irradiation injury. Methodological approaches to study the effects of Co60 administered in a single dose of 15 Gy. Swed Dent J Suppl. 28:193-203.

Amano, H., Yamada, S., Felix, R. (1998). Colony-stimulating factor-1 stimulates the fusion process in osteoclasts. J Bone Miner Res 13: 846-853.

Amling, M. \& Delling, G. (1997). Differenzierung und Funktion des Osteoklasten neue Ergebnisse und Modellvorstellungen. Osteologie 6: 5-14.

Amling, M., Schillung, A. F., Rueger, J. M. (2001). Zell-Zell-Kontakt ist essentiell für Differenzierung und Funktion humaner Osteoklasten in vitro. Osteologie 2001, Band 10 Suppl. 1: S89

Anderson D. M., Maraskovsky E., Billingsley W. L., Dougall W. C., Tometsko M. E., Roux E. R., Teepe M. C., DuBose R. F., Cosman D., Galibert L. (1997). A homologue of the TNF receptor and its ligand enhance T-cell growth and dendritic-cell function. Nature 390: 175-179.

Andersson, G., Ek-Rylander, B., Minkin, C. (1991). Acid phosphatases. In Rifkin B., Gay, C. V. eds. The biology and physiology of hte osteoclast. Boca Raton, FL, CRC Press 55

Ash, P., Loutit, J. F., Townsend K. M. (1980). Osteoclasts derived from haematopoietic stem cells. Nature 283: 669-70.

Athanasou, N. A. (1996). Cellular biology of bone-resorbing cells. J Bone Joint Surg Am 78: 1096-112.

Atkins, G. J., Haynes, D. R., Graves, S. E., Evdokiou, A., Hay, S., Bouralexis, S., Findlay, D. M. (2000). Expression of osteoclast differentiation signals by stromal elements of giant cell tumors. J Bone Miner Res 15: 640-9.

Baron, R., Neff, L., Van, P. T., Nefussi, J. R., Vignery, A. (1986). Kinetic and cytochemical indentification of osteoclasts precursors and their differentiation into multinucleated osteoclasts. Am J Path 121: 363.

Behrmann, G. (2001). Lebensraum Meer; Nachtrag 1 zur Anatomie des Zahnwalkopfes. Nordseemuseum u. Centre for Marine Research and Investigations on Cetacea, Bremerhaven Heft 23

Bertolini, D. R., Nedwin, G. E. (1986). Stimulation of bone resorption and inhibition of bone formation in vitro by human tumour necrosis fachtors. Nature 319: 516-518.

Blair H. C., Teitelbaum S. L., Schimke P. A., Konsek J. D., Koziol C. M., Schlesinger, P. H. (1988). Receptor-mediated uptake of mannose-6-phosphate bearing glykoprotein by isolated chicken osteoclasts. J Cell Physiol 137: 476-482. 
Blair, H. C., Teitelbaum, S., Ghiselli, R., Gluck, S. (1989). Osteoclastic bone resorption by a polarized vacuolar proton pump. Science 245: 855-57.

Bowmann, E. J., Siebers, A., Altendorf, K. (1988). Bafilomycins: a class of inhibitors of membrane ATPases from microorganisms, animal cells, and plant cells. Proc Natl Acad Sci USA 85: 7972-76.

Boyde, A. \& Lester, K. S. (1967). Electron microscopy of resorbing surfaces of dental hard tissues. Z Zellfrosch 83: 538-548.

Boyde, A., Ali, N. N., Jones, S. J. (1984). Resorption of dentine by isolated osteoclasts in vitro. Br Dent J 156: 216-20.

Bromley, M. \& Woolley D. E. (1984). Chondroclasts and osteoclasts at subchondral sites of erosion in the rheumatoid joint. Arthritis Rheum 27: 968-75.

Bull, H., Choy, B., Manyonda, I., Brown, C. A., Wadron, E. E., Holmes, S. D., Booth, J. M., Nelson, P. N. (1999). Reactivity and assay restriction profiles of monoclonal and polyclonal antibodies to acid phosphatases: a preliminary study. Immunol Letters 70: 143-149.

Burger EH, Van der Meer, J. W. M., van de Gevel, J. S., Gribnau, J. C., Thesingh, C. W., van Furth, R. (1982). In vitro formation of osteoclasts from long-term cultures of bone marrow mononuklear phagocytes. J Exp Med 156: 1604.

Burkhardt, R. (1992). Der Osteoblast-Schlüssel zum Verständnis des Skelettorgans. Osteologie 1: 139-170.

Chambers, T. J., Revell, P. A., Fuller, K., Athanasou, N. A. (1984). Resorption of bone by isolated rabbit osteoclasts. J Cell Sci 66: 383-99.

Chellaiah, M. \& Hruska, K.A. (1996). Osteopontin stimulates gelsolin associated phosphoinositide levels and PtdIns 3-hydroxyl kinase. Mol Biol Cell 7: 743-53.

Chellaiah, M., Kizer, N., Silva, M., Alvarez, U., Kwiatkowski, D., Hruska, K. A. (2000). Gelsolin Deficiency blocks podosome assembly and produces increased bone mass and strength. J Cell Biol 148: 665-78.

Chomczynski, P. \& Sacchi, N. (1987). Single-step method of RNA isolation by acid guanidinium thiocyanate-phenol-chloroform extraction. Anal Biochem 162:156-9.

Connor, J. R., Dodds, R. A., James, I. E., Gowen, M. (1995). Human osteoclast and giant cell differentiation: the apparent switch from nonspecific esterase to tartrate resistant acid phosphatase activity coincides with the in situ expression of osteopontin mRNA. J Histochem Cytochem 43: 1193-201.

Cramer, L. \& Mitchison, J. T. (1993). Moving and stationary actin filaments are involved in spreading of postmitotic PtK2 cells. J Cell Biol 122:833-43.

Darling, J. M., Goldring SR, Harada, Y., Handel, M. L., Glowacki, J., Gravallese, E. M. (1997). Multinucleated cells in pigmented villonodular synovitis and 
giant cell tumor of tendon sheath express features of osteoclasts. Am J Pathol 150: 1383-93.

Darnay B. G., Haridas V., Ni J., Moore P. A., Aggarwal, B. B. (1998). Charakterization of the intracellular domain of receptor activator of NF-NB (RANK). Interaction with tumor necrosis factor receptor-associated factors and activation of NFNB and c-Jun N-terminal kinase. J Biol Chem 273: 20551-55.

Dodds, R. A., Connor, J. R. James, I. E., Gowen, M. (1994b). Osteopontin as a marker of human osteoclast differentiation. J Bone Miner Res 9: S368.

Domon, T. \& Wakita, M. (1991). The three-dimensional structure of the clear zone of a cultured osteoclast. J Electron Microsc 40:34-40.

Dougall, W. C., Glaccum, M., Charrier, K., Rohrbach, K., Brasel, K., De Smedt, T., Daro, E., Smith, J., Tometsko, M. E., Maliszewski, C. R., Armstrong, A., Shen, V., Bain, S., Cosman, D., Anderson, D., Morrissey, P.J., Peschon, J. J., Schuh, J. (1999). RANK is essential for osteoclast and lymph node development. Genes Dev 13: 2412-24.

Duong, L. T., Lakakorpi, P. T., Nakamura, I., Machwate, M., Nagy, R. M., Rodan, G. A. (1998). PYK2 in osteoclasts is an adhesion kinase, localized in the sealing zone, activated by ligation of alpha(v)beta3 integrin, and phosphorylated by src kinase. J Clin Invest 102:881-92.

Eggelmeijer, F., Papapoulos, S. E., van Paassen, H. C. (1996). Increased bone mass with pamidronate treatment in rheumatoid arthritis, Results of a three-year randomized, double-blind trial. Arthritis Rheum 39: 396-402.

Fassbender, HG (1983). Histomorphologic basis of articular cartilage destruction in rheumatoid arthritis. Coll Relat Res 3:141-155.

Fisher, J. E., Caufield, M. P., Sato, M., Quartuccio, H. A., Gould, R. J., Garsky, V. M., Rodan, G. A., Rosenblatt, M. (1993). Inhibition of osteoclastic bone resorption in vivo by echistatin, an arginylglycyl-aspartyl (RGD)-containing protein. Endocrinology 132: $1411-1413$.

Fornasier, V. L. \& Cameron, H. U. (1976). The femoral stem/cement interface in total hip replacement. Clin Orthop 116: 248-252.

Franz, J. K., Pap T., Hummel, K. M., Nawrath, M., Aicher, W. K., Shigeyama, Y., Muller-Ladner, U., Gay, R. E., Gay, S. (2000). Expression of sentrin, a novel antiapoptotic molecule, at sites of synovial invasion in rheumatoid arthritis. Arthritis Rheum 43: 599-607.

Fuller, K., Owens, J. M., Jagger, C. J., Wilson, A., Moss, R., Chambers, T. J. (1993). Macrophage colony-stimulating factor stimulates survival and chemotactic behavior in isolated osteoclasts. J Exp Med 178: 1733.

Furuyama, N. \& Fujisawa, Y. (2000). Distinct roles of cathepsin K and cathepsin L in osteoclastic bone resorption. Endocrine Res 26: 189-204. 
Gay, S., R. E. Gay, Koopmann, W. J. (1993). Molecular and cellular mechanisms of joint destruction in rheumatoid arthritis: two cellular mechanisms explain joint destruction. Ann Rheum Dis 52: S39-S47.

Goldring, S. R., Schiller, M. D., Roelke, M., Rourke, C. M., O’Neill, D. A., Harris, W. H. (1983). The synovial-like membrane at the bone-cement interface in loose total hip replacements an its proposed role in bone lysis. J Bone J Surg 65: 575-584.

Goldring, S. R. (1996). The structure and molecular biology of the calcitonin receptor. In: Bilezikian, J. P. et al.; Principles of bone biology. San Diego, CA: Academic: 461470.

Gravallese, E. M., Harada, Y., Wang, J. T., Gorn, A. H., Thornhill, T. S., Goldring, S. R. (1998). Identification of cell types responsible for bone resorption in rheumatoid arthritis and juvenile rheumatoid arthritis. Am J Path 152: 943-951.

Gravallese, E. M. \& Goldring, S. R. (2000). Cellular mechanisms and the role of cytokines in bone erosions in rheumatoid arthritis. Arthritis Rheum 43: 2143-51.

Hattersley, G. \& Chambers, T. J. (1989). Calcitonin receptors as markers for osteoclastic differentiation: correlation between generation of bone-resorptive cells and cells that express calcitonin receptors in mouse bone marrow cultures. Endocrinology 125: 1606.

Heilmann, K., Diezel, P. B., Rossner, J. A., Brinkmann, K. A. (1975). Morphological studiesin tissues surrounding alloarthroplastic joints. Virchows Arch Path Anat 366: 93106.

Hemmerlein, B., Markus, A., Wehner, M., Kugler, A., Zschunke, F., Radzum, H. J. (2000). Expression of acute and late-stage inflammatory antigens, c-fms, CSF-1, and human monocytic serine esterase 1 , in tumor-associated macrophages of renal cell carcinomas. Cancer Immunol Immunother 49: 485-92.

Hersmann, G. H., Kriegsmann, J., Simon, J., Huttich, C., Brauer, R. (1998). Expression of cell adhesion molecules and cytokines in murine antigen- induced arthritis. Cell Adhes Commun 6: 69-82.

Heynes, R. O. (1987). Integrins: a family of cell surface receptors. Cell 48: 549-554.

Horton, M. A., Lewis, D., McNultuy, K., Pringle, J. A. S., Chambers, T. J. (1985). Monoclonal antibodies to osteoclastomas (giant cell bone tumors): definition of osteoclast-spezific cellular antigens. Cancer research 45: 5663-69.

Horton M. A. (1997). The alpha $\mathrm{v}$ beta 3 integrin vitronectin receptor. Int J Biochem Cell Biol 29: 721-5.

Hou, W. S., Li, Z., Gordon, R. E. (2001). Cathepsin K is a critical protease in synovial fibroblast-mediated collagen degradation. Am J Pathol 159: 2167-77. 
Hummel, K. M., Petrow, P. K., Franz, J. K., Muller-Ladner, U., Aicher, W. K., Gay, R. E., Bromme, D., Gay, S. (1998). Cysteine proteinase cathepsin K mRNA is expressed in synovium of patients with rheumatoid arthritis and is detected at sites of synovial bone destruction. J Rheumatol 25: 1887-94.

Inaoka, T., Bilbe, G., Ishibashi, O., Tezuka, K., Kumegawa, M., Kokubo, T. (1995). Molecular cloning of human cDNA for cathepsin K: novel cysteine proteinase predominatly expressed in bone. Biochem Biophys Res Comm 206: 89-96.

Inoue, M., Yoshida, H., Akisaka, T. (1999). Visualization of acidic compartments in cultured osteoclasts by use of an acidotrophic amine as a marker for low $\mathrm{pH}$. Cell Tissue Res 298: 527-37.

Ilvesaro, J. M., Lakkakorpi, P. T., Väänänen, H. K. (1998). Inhibition of bone resorption in vitro by a peptide containing the cadherin cell adhesion recognition sequence HAV is due to prevention of sealing zone formation. Exp Cell Res 242: 75-83.

Itoh, K., Udagawa, N., Matsuzaki, K., Takami, M., Amano, H., Shinki, T., Ueno, Y., Takahashi, N., Suda, T. (2000). Importance of membrane- or matrixassociated forms of M-CSF and RANKL/ODF in osteoclastogenesis supported by SaOS-4/3 cells expressing recombinant PTH/PTHrP receptors. J Bone Miner Res 15: 1766-75.

Jimi, E., Akiyama, S., D., Tsurukai, T., Okahashi, N., Kobayashi, K., Udagawa, N., Nishihara, T. Takahashi, N., Suda, T. (1999). Osteoclast differentiation factor acts as a multifunctional regulator in murine osteoclast differentiation and function. J Immunol 163:434-42.

Karet, F. E., Finberg, K. E., Nelson, R. D., Nayir, A., Mocan, H., Sanjad, S. A., Rodriguez-Soriano, J., Santos, F., Cremers, C. W., Di Pietro, A., Hoffbrand, B. I., Winiarski, J., Bakkaloglu, A., Ozen, S., Dusunsel, R., Goodyer, P., Hulton, S. A., Wu, D. K., Skvorak, A. B., Morton, C. C., Cunningham, M. J., Jha, V., Lifton, R. P. (1999). Mutations in the gene encoding B1 subunit of $\mathrm{H}^{+}$-ATPase cause renal tubular acidosis with sensorineural deafness. Nat Genet 21: 84-90.

Kawaguchi, N. \& Noda, M. (2000). Mitf is expressed in osteoclast progenitors in vitro. Exp Cell Res 260: 284-91.

Kitazawa, R., Kitazawa, S., Yoon, S., Kasuga, M., Maeda, S. (1999). In situ demonstration of parathyroid hormone-related protein mRNA in sclerosing hepatic carcinoma. Virchows Arch 35:137-42.

Kobayashi, K, Takahashi, N., Jimi, E., Udagawa, N., Takami, M., Kotake, S., Nakagawa, N., Kinosaki, M., Yamaguchi, K., Shima, N., Yasuda, H., Morinaga, T., Higashio, K., Martin, T. J., Suda, T. (2000). Tumor necrosis factor D stimulates osteoclast differentiation independent of the ODF/RANK signaling system. J Exp Med 191: $275-85$.

Kong, Y. Y., Feige, U., Sarosi, I., Bolon, B., Tafuri, A., Morony, S., Capparelli, C., Li, J., Elliott, R., McCabe, S., Wong, T., Campagnuolo, G., Moran, E., Bogoch, E., R., Van, G., Nguyen, L. T., Ohashi, P. S., Lacey, D. L., Fish, E., Boyle, 
W. J., Penninger, J. M. (1999). Activated $T$ cells regulate bone loss and joint destruction in adjuvant arthritis through osteoprotegerin ligand. Nature 402: 304-9.

Kong, Y. Y., Boyle, W. J., Penninger, J. M. (1999). Osteoprotegerin ligand: a common link between osteoclastogenesis, lymph node formation and lymphocyte development. Immunol Cell Biol 77: 188-93.

Kong, Y. Y., Yoshida, H., Sarosi, I. Tan, H. L., Timms, E., Capparelli, C., Morony, S., Oliveira-dos-Santos, A. J., Van, G., Itie, A., Khoo, W., Wakeham, A., Dunstan, C. R., Lacey, D. L., Mak, T. W., Boyle, W. J., Penninger, J. M. (1999). OPGL is a key regulator of osteoclastogenesis, lymphocyte development and lymphnode organogenesis. Nature 397: 315-23.

Kreyszer, G. M., A. H. Heer, Gay, S. (1994). Cytokines and oncogenes in cellular interactions of rheumatoid arthritis. Stem Cells 12: 75-80.

Kriegsmann, J., G. M. Keyszer, Geiler, T., Brauer, R., Gay, R. E., Gay, S. (1995). Expression of vascular cell adhesion molecule-1 mRNA and protein in rheumatoid arthritis synovium demonstrated bei in situ hybridization and immunohistochemistry. Lab Invest 72: 209-213.

Kukita, T. \& Roodman, G. D. (1989). Development of a monoclonal antibody to osteoclasts formed in vitro which recognizes mononuclear osteoclast precursors in the marrow. Endocrinology 125: 630-7.

Kuliwaba, J. S., Findlay D., M., Atkins, G. J., Forwood, M. R., Fazzalari, N. L. (2000). Enhanced expression of osteocalcin mRNA in human osteoarthritic trabecular bone of the proximal femur is associated with decreased expression of interleukin- 6 and interleukin-11 mRNA. J Bone Miner Res 15: 332-41.

Kurihara, N., Suda, T., Miura, Y., Nakauchi, H., Kodama, H., Hiura, K., Hakeda, Y., Kumegawa, M. (1989). Generation of osteoclasts from isolated hematopoitic progenitor cells. Blood 74: 1295.

Kurihara, N., Chenu, C., Miller, M., Civin, C., Roodman, G. D. (1990). Identification of committed mononuclear precursors for osteoclast-like cells formed in long term human marrow cultures. Endocrinology 126: 2733-41.

Kurihara, N., Gluck, S., Roodman, G. D. (1990). Sequential expression of phenotype markers for osteoclasts during differentiation of precursors for multinucleated cells formed in long- term human marrow cultures. Endocrinology 127: 3215-21.

Kurihara, N., Tatsumi, J., Arai, F., Iwama, A., Suda, T. (1998). Macrophagestimulating protein (MSP) and its receptor, RON, stimulate human osteoclast activity but not proliferation: effect of MSP distinct from that of hepatocyte growth factor. Exp Hematol 26: 1080-5.

Lacey, D. L., Timms, E., Tan, H. L., Kelley, M. J., Dunstan, C. R., Burgess, T., Elliott, R., Colombero, A., Elliott, G., Scully, S., Hsu, H., Sullivan, J., Hawkins, N., Davy, E., Capparelli, C., Eli, A., Qian, Y. X., Kaufman, S., Sarosi, I., Shalhoub, V., 
Senaldi, G., Guo, J., Delaney, J., Boyle, W. J. (1998). Osteoprotegerin ligand is a cytokine that regulates osteoclast differentiation and activation. Cell 93: 165-76.

Lader, C. S., Scopes, J., Horton, M. A., Flanagan, A. M. (2001). Generation of human osteoclasts in stromal cell-free and stromal cell- rich cultures: differences in osteoclast CD11c/CD18 integrin expression. Br J Haematol 112: 430-7.

Lafyatis, R., Remmers, E. F., Roberts, A. B., Yocum, D. E., Sporn, M. B., Wilder, R. L. (1989). Anchorage-independent growth of synoviocytes from arthritic and normal joints. Stimulation by exogenous platelet-derived growth factor and inhibition by transforming growth factor-beta and retinoids. J Clin Invest 83: 1267-76.

Lakkakorpi, P. T. \& Väänänen, H. K. (1991). Kinetics of the osteoclast cytoskeleton during the resorption cycle in vitro. J Bone Miner Res 6: 817-826.

Lau, K. H., Thomas, A. B., Yoo, A., Nguyen, T. S., Wergedal, J. E. (1992). Conversion of skeletal tartrate-sensitive acid phosphatases into tartrate-resistant isoenzymes in vitro. Int J Biochem 24: 1815-24.

Lee, S. K., Goldring, S. R., Lorenzo, J. A. (1995). Expression of calcitonin receptor in bone marrow cell cultures and in bone: a specific marker of the differentiated osteoclast that is regulated bei calcitonin. Endocrinology 136: 4572-81.

Lee, S. K., Lorenzo, J. A. (1999). Parathyroid hormone stimulates TRANCE and inhibits osteoprotegerin messenger ribonucleic acid expression in murine bone marrow cultures: correlation with osteoclast-like cell formation. Endocrinology 140: 3552-61.

Li, J., Sarosi, I., Yan, X.-Q., Morony, S., Capparelli, C., Tan. H.-L. McCabe, S., Elliott., R., Scully, S., Van, G., Kaufmann, S., Juan, S.-C., Sun, Y., Tarpley, J., Martin, L., Christensen, K., McCabe, J., Kostenuik, P., Hsu, H., Fletcher, F., Dunstan, C. R., Lacey, D. L., Boyle, W. J. (2000). RANK is the intrinsic hematopoitic cell surface receptor that controls osteoclastogenesis and regulation of bone mass an calcium metabolism. PNAS 97: 1566-71.

Lomega, N. I. A., Yeh, W. C., Sarosi, I., Duncan, G. S., Furlonger, C., Ho, A., Morony, S., Capparelli, C., Van, G., Kaufman, S., van der Heiden, A., Itie, A., Wakeham, A., Khoo, W., Sasaki, T., Cao, Z., Penninger, J. M., Paige, C. J., Lacey, D. L., Dunstan, C. R., Boyle, W. J., Goeddel, D. V., Mak, T., W. (1999). TRAF6 defiency results in osteopetrosis and defective interleukin-1, CD40, and LPS signaling. Genes Dev 13: 1015-24.

MacDonald, B. R., Takahashi, N., McManus, L. M., Holahan, J., Mundy, G. R., Roodman, G. D. (1987). Formation of multinucleated cells that respond to osteotropic hormones in long term human bone marrow cultures. Endocrinology 120: 2326-33.

Manolagas, S. C. (1995). Role of cytokines in bone resorption. Bone 17(2 Suppl): 63S$67 \mathrm{~S}$.

Marie, J., Wakkach, A., Coudray, A., Chastre, E., Berrih-Aknin, S., Gespach, C. (1999). Functional expression of receptors for calcitonin gene-related peptide, 
calcitonin, and vasoactive intestinal peptide in the human thymus and thymomas from myasthenia gravis patients. J Immunol 162: 2103-12.

Matayoshi, A., Brown, C., DiPersio, J. F., Haug, J., Abu-Amer, Y., Liapis, H., Kuestner, R., Pacifici, R. (1996). Human blood-mobilized hematopoietic precursors differentiate into osteoclasts in the absence of stromal cells. Proc Natl Acad Sci U S A 93: $10785-90$.

Matsunaga, T., Inoue, H., Kojo, T., Hatano, K., Tsujisawa, T., Uchiyama, C., Uchida, Y. (1999). Increase in the potential of osteoblasts to support bone resorption by osteoclasts in vitro in response to roughness of bone surface. Calcif Tissue Int 65: 4548.

Matsuzaki, K., Udagawa, N., Takahashi, N., Yamaguchi, K., Yasuda, H., Shima, N., Morinaga, T., Toyama, Y., Yabe, Y., Higashio, K., Suda, T.et al. (1998). Osteoclast differentiation factor (ODF) induces osteoclast-like cell formation in human peripheral blood mononuclear cell cultures. Biochem Biophys Res Commun 246: 199204.

Mbalaviele, G., Jaiswal, N., Meng, A., Cheng, L., Van Den Bos, C., Thiede, M. (1999). Human mesenchymal stem cells promote human osteoclast differentiation from CD34+ bone marrow hematopoietic progenitors. Endocrinology 140: 3736-43.

McHugh, K.P., Hodivala-Dilke, K., Zheng, M. H., Namba, N., Lam, J., Novack, D., Feng, X., Ross, F. P., Heynes, R. O., Teitelbaum, S., L. (2000). Mice lacking beta3 integrins are osteosclerotic because of dysfunctional osteoclasts. J Clin Invest 105: 433.

Menaa, C. \& Roodman, GD (1997). Increased sensitivity to $1,25-(\mathrm{OH})_{2} \mathrm{D}_{3}$ of osteoclast precursors in Paget's disease is not due to differences in expression levels of the 1,25- $\mathrm{D}_{3}$ receptor. J Bone Miner Res 12: S330.

Miyamoto, T., Arai, F., Ohneda, O., Takagi, K., Anderson, D. M., Suda, T. (2000). An adherent condition is required for formation of multinuclear osteoclasts in the presence of macrophage colony-stimulating factor and receptor activator of nuclear factor NB ligand. Blood 96: 4335-4343.

Müller-Ladner, U., Kriegsmann, J., Franklin, B. N., Matsumoto, S., Geiler, T., Gay, R. E. and Gay, S. (1996). Synovial fibroblasts of patients with rheumatoid arthritis attach to and invade normal human cartilage when engrafted into SCID mice. Am J Pathol 149: 1607-15.

Nagai, M., S. Kyakumoto, S., Sato, N. (2000). Cancer cells responsible for humoral hypercalcemia express mRNA encoding a secreted form of ODF/TRANCE that induces osteoclast formation. Biochem Biophys Res Commun 269: 532-6.

Nakamura, I., Takahashi, N. Sasaki, T., Tanaka, S., Udagawa, N., Murakami, H., Kimura, K., Kabuyama, Y., Kurokawa, T., Suda, T., (1995). Whortmannin, a specific inhibitor of phosphatidylinositol-3-kinase, blocks osteoclastic bone resorptio. FEBS Lett 361: 79-84. 
Neale, S. D., Fujikawa, Y., Sabokbar, A., Gundle, R., Murray, D. W., Graves, S. E., Howie, D. W., Athanasou, N. A. (2000). Human bone-derived cells support formation of human osteoclasts from arthroplasty-derived cells in vitro. J Bone Joint Surg $\mathrm{Br} \mathbf{8 2}$ : 892-900.

Nesbitt, S. A. \& Horton, M. A. (1997). Trafficking of matrix collagens through boneresorbing osteoclasts. Science 276: 266-9.

Nicholson, G. C., Moseley, J. M., Sexton, P. M., Mendelsohn, F. A., Martin, T. J. (1986). Abundant calcitonin receptors in isolated rat osteoclasts. Biochemical and autoradiographic characterization. J Clin Invest 78: 355-60.

O'Brien, E. A., Williams, J. H., Marshall, M. J. (2001). Osteoprotegerin is produced when prostaglandin synthesis is inhibited causing osteoclasts to detach from the surface of mouse parietal bone and attach to the endocranial membrane. Bone 28: 208-14.

Otsu, S., Pap, T., Shigeyama, Y. (2000). Identification of a novel splice variant of an osteoclast-like v-ATPase Beta-1 subunit in activated fibroblasts. Arthritis Rheum 2000: S591.

Pandey, R., Quinn, J., Joyner, C., Murray, D. W., Triffitt, J. T., Athanasou, N. A. (1996). Arthroplasty implant biomaterial particle associated macrophages differentiate into lacunar bone resorbing cells. Ann Rheum Dis 55: 388-95.

Pap, G., Machner, A., Rinnert, T., Hörler, D., Gay, R. E., Schwarzberg, H., Neumann, W., Michel, B. A., Gay, S., Pap, T. (2001). Development and characteristics of a synovial-like interface membrane arround cement tibial hemiarthroplastics in a novel rat model of aseptic prothesis loosing. Arthritis Rheum 44: 956-63.

Pap, T., Pap, G., Hummel, K. M., Franz, J., Jeisy, E., Saunsbury, I., Gay, R. E., Billingham, M., Neumann, W., Gay, S. (1999). Membrane-type-1 matrix metalloproteinase is abundantly expressed in fibroblasts and osteoclasts at the boneimplant interface of aseptic loosened joint arthroplasties in situ. J Rheumatol 26: 166169.

Pap, T., Shigeyama, Y., Kuchen, S., Fernihough, J. K., Simmen, B., Gay, R. E., Billingham, M., Gay, S. (2000). Differential expression pattern of membrane-type matrix metalloproteinases in rheumatoid arthritis. Arthritis Rheum 43: 1226-32.

Petrow, P. K., Hummel, K. M., Schedel, J., Franz, J. K., Klein, C. L., Müller-Ladner, U., Kriegsmann, J., Chang, P. L., Prince, C. W., Gay, R. E., Gay, S. (2000). Expression of osteopontin messenger RNA and protein in rheumatoid arthritis: effects of osteopontin on the release of collagenase 1 from articular chondrocytes and synovial fibroblasts. Arthritis Rheum 43: 1597-605.

Quinn, J. M., Elliott, J., Gillespie, M. T., Martin, T. J. (1998). A combination of osteoclast differentiation factor and macrophage- colony stimulating factor is sufficient for both human and mouse osteoclast formation in vitro. Endocrinology 139: 4424-7. 
Quinn, J. M., Morfis, M., Lam, M. H., Elliott, J., Kartsogiannis, V., Williams, E. D., Gillespie, M. T., Martin, T. J., Sexton, P. M.et al. (1999). Calcitonin receptor antibodies in the identification of osteoclasts. Bone 25: 1-8.

Quinn, J. M., Horwood, N. J., Elliott, J., Gillespie, M. T., Martin, T. J.et al. (2000). Fibroblastic stromal cells express receptor activator of NF-kappa B ligand and support osteoclast differentiation [In Process Citation]. J Bone Miner Res 15: 1459-66.

Rodan, S. B. \& Rodan, G. A. (1997). Integrin function in osteoclasts. J Endocrinol 154: 47-56.

Rodan, G. A., \& J. Martin, J. (2000). Therapeutic approaches to bone diseases. Science 28: $1508-14$.

Roodman, G. D. (1999). Cell biology of the osteoclast. Exp Hematol 27: 1229-41.

Saftig, P., Hunziker, E., Wehmeyer, O., Jones, S., Boyde, A., Rommerskirch, W., Moritz, J. D., Schu, P., von Figura, K. (1998). Impaired osteoclastic bone resorption leads to osteopetrosis in cathepsin-K-deficient mice. Proc Natl Acad Sci U S A 95: 13453-8.

Saftig, P., Hunziker, E., Everts, V., Jones, S., Boyde, A., Wehmeyer, O., Suter, A., von Figura, K. (2000). Functions of cathepsin $K$ in bone resorption. Lessons from cathepsin K deficient mice. Adv Exp Med Biol 477: 293-303.

Scharla, S. (2001). Bisphosphonate in der Osteoporosetherapie. Osteologie forum 2001 7: 44-47.

Schlesinger, P. H. \& Blair, H. C. (1989). Characterization of the osteoclast ruffled border chloride channel and its role in bone resorption. J Biol Chem25;272: 18636-43.

Schwarzberg, H., Roth, N., Sturmer, I. (1989). Increased locomotor activity of rats by self-stimulation in a running wheel. Physiol Behav 46: 767-9.

Schwartz, Z., Lohmann, C. H., Wieland, M., Cochran, D. L., Dean, D. D., Textor, M., Bonewald, L. F., Boyan, B. D. (2000). Osteoblast proliferation and differentiation on dentin slices are modulated by pretreatment of the surface with tetracycline or osteoclasts. J Periodontol 7: 586-97.

Shalhoub, V., Elliott, G., Chiu, L., Manoukian, R., Kelley, M., Hawkins, N., Davy, E., Shimamoto, G., Beck, J., Kaufman, S. A., Van, G., Scully, S., Qi, M., Grisanti, M., Dunstan, C., Boyle, W. J., Lacey, D. L. (2000). Characterization of osteoclast precursors in human blood. Br J Haematol 111: 501-12.

Saunders, P. T. K., Renegar, R. H., Raub, T. J., Baumbach, G. A., Atkinson, P. H., Bazer, F. W., Roberts, R. M. (1985). The carbohydrate structure of porcine uteroferrin and the role of the high mannose chains in promoting uptake by the reticuloendothelial cells of the fetal liver. J Biol Chem 260: 3658-3663. 
Shigeyama, Y., Pap, T., Kunzler, P., Simmen, B. R., Gay, R. E., Gay, S.et al. (2000). Expression of osteoclast differentiation factor in rheumatoid arthritis [In Process Citation]. Arthritis Rheum 43: 2523-30.

Sileghem, A., Geusens, P., Dequeker, J. (1992). Intranasal calcitonin for the prevention of bone erosion and bone loss in rheumatoid arthritis. Ann Rheum Dis 51: 761-4.

Singer, I. I., Scott, S., Kawka, D. W., Kazazis, D. M., Gailit, J., Ruoslahti, E. (1988). Cell surface distribution of fibronectin and vitronectinreceptors depends on substrate composition and extracellular matrix accumulation. J Cell Biol 106: 2171-82.

Small, J. V. (1989). Microfilament-based motility in non-muscle cells. Curr Opin Cell Biol 1: 75-9.

Stenbeck, G. \& Horton, M. A. (2000). A new specialized cell-matrix interaction in actively resorbing osteoclasts. J Cell Sci 113: 1577-87.

Suda, T., K. Kobayashi, Jimi, E., Udagawa, N., Takahashi, N. (2001). The molecular basis of osteoclast differentiation and activation. Novatis Foundation Symposium 232: 235-250.

Sundquist, K., Lakkakorpi, P. T., Wallmark, B., Väänänen, H. K. (1990). Inibition of osteoclast proton transport by bafilomycin $\mathrm{A}_{1}$ abolishes bone resorption. Biochem Biophys Res Commun 168: 309-313.

Takahashi, N., Kukita, T., MacDonald, B. R., Bird, A., Mundy, G. R., McManus, L. M., Miller, M., Boyde, A., Jones, S. J., Roodman, G. D. (1989). Osteoclast-like cells form in long-term human bone marrow but not in peripheral blood cultures. J Clin Invest 83: 543-50.

Takahashi, S., Reddy, S. V., Chirgwin, J. M., Devlin, R., Haipek, C., Anderson, J., Roodman, G. D. (1994). Cloning and identification of Annexin II as an autocrine /paracrine factor that increases osteoclast formation and bone resorption. J Biol Chem 269: $286-96$.

Takayanagi, H., Oda, H., Yamamoto, S., Kawaguchi, H., Tanaka, S., Nishikawa, T., Koshihara, Y. (1997). A new mechanism of bone destruction in rheumatoid arthritis: synovial fibroblasts induce osteoclastogenesis. Biochem Biophys Res Commun 240: 279-86.

Tanaka, S., Takahashi, N., Udagawa, N., Tamura, T., Akatsu, T., Stanley, E. R., Kurokawa, T., Suda, T. (1993). Macrophage colony-stimulating factor is indispensiable for both proliferation and differentiation of osteoclasts progenitors. J Clin Invest 91: 257-63.

Teitelbaum, S. (2000). Bone resorption by osteoclasts. Science 289: 1504-08.

Teti, A., Blair, H. C., Schlesinger, P., Grano, M., Zambonin-Zallone, A., Kahn, A. J., Teitelbaum, S. L., Hruska, K. A. (1989). Extracellular protons acidify osteoclasts, 
reduce cytosolic calcium, and promote expression of cell-matrix attachment structures. $\mathrm{J}$ Clin Invest 84:773-80.

Tezuka, K., Sato, T., Kamioka, H., Nijweide, P. J., Tanaka, K., Matsuo, T., Ohta, M., Kurihara, N., Hakeda, Y., Kumegawa, M. (1992). Identification of osteopontin in isolated rabbit osteoclasts. Biochem Biophys Res Commun 186: 911-7.

Thavarajah, M., Evans, D. B., Kanis, J. A. (1991). 1,25(OH)2D3 induces differentiation of osteoclast-like cells from human bone marrow cultures. Biochem Biophys Res Commun 176: 1189-95.

Theriot, J. A. \& Mitchison, T. J. (1991). Actin microfilament dynamics in locomoting cells. Nature 352:126-31.

Thoshitaka, A. \& Yoshida, H. (2001). Organisation of cytoskeletal F-Actin, G-Actin, and Gelsolin in the adhesion structures in cultured osteoclast. 16: 1248.

Tondravi, M. M., McKercher, S. R., Anderson, K., Erdmann, J. M., Ouiroz, M., Maki, R., Teitelbaum, S. L. (1997). Osteopetrosis in mice lacking haematopoietic transcription factor PU.1. Nature 386: 81.

Trabandt, A., Gay, R. E., Gay, S. (1992). Oncogene activation in rheumatoid synovium. APMIS 100: 861-875.

Tsukii, K., Shima, N., Mochizuki, S., Yamaguchi, K., Kinosaki, M., Yano, K., Shibata, O., Udagawa, N., Yasuda, H., Suda, T., Higashio, K. (1998). Osteoclast differentiation factor mediates an essential signal for bone resorption induced by 1 alpha,25-dihydroxyvitamin D3, prostaglandin E2, or parathyroid hormone in the microenvironment of bone. Biochem Biophys Res Commun 246: 337-41.

Udagawa, N., Takahashi, N., Akatsu, T., Tanaka, H., Sasaki, T., Nishihara, T., Koga, T., Martin, T. J., Suda, T. (1990). Differentiating into osteoclasts under a suitable micoroenvironment prepared by bone marrow-derived cells. Proc Natl Acad Sci USA 87: 7260-64.

Väänänen, H. K. \& Horton, M. (1995). The osteoclast clear zone is a specialized cellextracellular matrix adhesion structure. J Cell Sci 108: 2729-32.

Väänänen H. K. (1996). Osteoclast function: Biology and mechanisms In principles of bone biology (ed. J. P. Bilezikian et al.), pp. 103-113. San Diego : Academic Press.

Väänänen, H. K., Zhao, H., Mulari, M., Halleen, J. M. (2000). The cell biology of osteoclast function. J Cell Sci 113: 377-81.

Weitzmann, M. N., Cenci, S., Rifas, L., Haug, J., Dipersio, J., Pacifici, R. (2001). T cell activation induces human osteoclast formation via receptor activator of nuclear factor kappaB ligand-dependent and -independent mechanisms. J Bone Miner Res 16: 328-37. 
Wezeman, F. H., Kuettner, K. E., Horton, J. E. (1979). Morphology of osteoclasts in resorbing fetal rat bone explants: effects of PTH and AIF in vitro. Anat Rec 194: 31123.

Wiktor-Jedrzejczak, W., Bartocci, A., Ferrante, A. W. Jr, Ahmed-Ansari, A., Sell, K. W., Pollard, J. W., Stanley, E. R. (1990). Total absence of colony-stimulating factor 1 in the macrophage-deficient osteopetrotic (op/op) mouse. Proc Natl Acad Sci USA 87: 4828-4832.

Wilkinson, L. S., Edwards J. C. D., Poston, R. N., Haskard, D. O. (1993). Expression of vascular cell adhesion molecule-1 in normal and inflamed synovium. Lab Invest 68: 682-688.

Wirz, J. \& Jäger, K. (1999). Modern alternatives to amalgam: cementable restorations and inlays. Quintessence Int 30:551-6.

Wong, B. R., Josien, R., Lee, S. Y., Sauter, B., Li, H. L., Steinman, R. M., Choi, Y. (1997). TRANCE (tumor necrosis factor (TNF)-related activation-induced cytokine), a new TNF family member predominantly expressed in T cells, is a dendritic dell-specific survival factor. J Exp Med 186: 2075-80.

Xu, J. W., Konttinen, Y. T., Waris, V., Patiala, H., Sorsa, T., Santavirta, S. (1997). Macrophage-colony stimulating factor (M-CSF) is increased in the synovial-like membrane of the periprosthetic tissues in the aseptic loosing of total hip replacement (THR). Clin Rheumatol 16: 243-248.

Xue, C., Takahashi, M., Hasunuma, T., Aono, H., Yamamoto, K., Yoshino, S., Sumida, T., Nishioka, K. (1997). Charakterization of fibroblast-like cells in pannus lesions of patients with rheumatoid arthritis sharing properties of fibroblasts and chondrozytes. Ann Rheum Dis 56: 262-67.

Yasuda, H., Shima, N., Nakagawa, N. (1998). Osteoclast differentiation factor is a ligand for osteoprotegerin/osteoclastogenesis-inhibitory factor and is identical to TRANCE/RANKL. Proc Natl Acad Sci USA 95: 3597.

Yoshida, H., Hayashi, S., Kunisada, T., Ogawa, M., Nishikawa, S., Okamura, H., Sudo, T., Shultz, L. D., Nishikawa, S. (1990). The murine mutation osteopetrosis is in the coding region of the macrophage colony stimulating factor gene. Nature 345: $442-$ 44 .

Zaidi, M., Bax, B. E., Shankar, V. S., Moonga, B. S., Simon, B., Alam, A. S., Gaines Das, R. E., Pazianas, M., Huang, C. L. (1994). Dimensional analysis of osteoclastic bone resorption and the measurement of biologically active calcitonin. Exp Physiol 79: 387-99.

Zimmermann, U., Fluehmann, B., Born, W., Fischer, J. A., Muff, R. (1997). Coexistence of novel amylin-binding sites with calcitonin receptors in human breast carcinoma MCF-7 cells. J Endocrinol 155: 423-31. 